UNIVERSIDADE DE BRASÍLIA

FACULDADE DE TECNOLOGIA

DEPARTAMENTO DE ENGENHARIA CIVIL E AMBIENTAL

\title{
ESTUDO EXPERIMENTAL E DE MODELAGEM MATEMÁTICA DO ESCOAMENTO SUBTERRÂNEO EM UMA VERTENTE DE ZONA RIPÁRIA NO BIOMA CERRADO
}

ANDRÉIA DE ALMEIDA

\author{
ORIENTADOR: SÉRGIO KOIDE \\ COORIENTADOR: CARLOS T. C. NASCIMENTO
}

DISSERTAÇÃO DE MESTRADO EM TECNOLOGIA AMBIENTAL E RECURSOS HÍDRICOS

PUBLICAÇÃO: PTARH.DM - 186/16

BRASÍLIA/DF: AGOSTO - 2016 
UNIVERSIDADE DE BRASÍLIA

FACULDADE DE TECNOLOGIA DEPARTAMENTO DE ENGENHARIA CIVIL

ESTUDO EXPERIMENTAL E DE MODELAGEM MATEMÁTICA DO ESCOAMENTO SUBTERRÂNEO EM UMA VERTENTE DE ZONA RIPÁRIA NO BIOMA CERRADO

ANDRÉIA DE ALMEIDA

DISSERTAÇÃO SUBMETIDA AO DEPARTAMENTO DE ENGENHARIA CIVIL E AMBIENTAL DA FACULDADE DE TECNOLOGIA DA UNIVERSIDADE DE BRASÍLIA COMO PARTE DOS REQUISITOS NECESSÁRIOS PARA A OBTENÇÃO DO GRAU DE MESTRE EM TECNOLOGIA AMBIENTAL E RECURSOS HÍDRICOS.

APROVADA POR:

Prof. Sérgio Koide, PhD (ENC-UnB)

(Orientador)

Prof. Dirceu Silveira Reis Junior, PhD (ENC-UnB)

(Examinador Interno)

Prof. Luiz Rafael Palmier, PhD (UFMG)

(Examinador Externo)

BRASÍLIA/DF, AGOSTO DE 2016. 


\section{FICHA CATALOGRÁFICA}

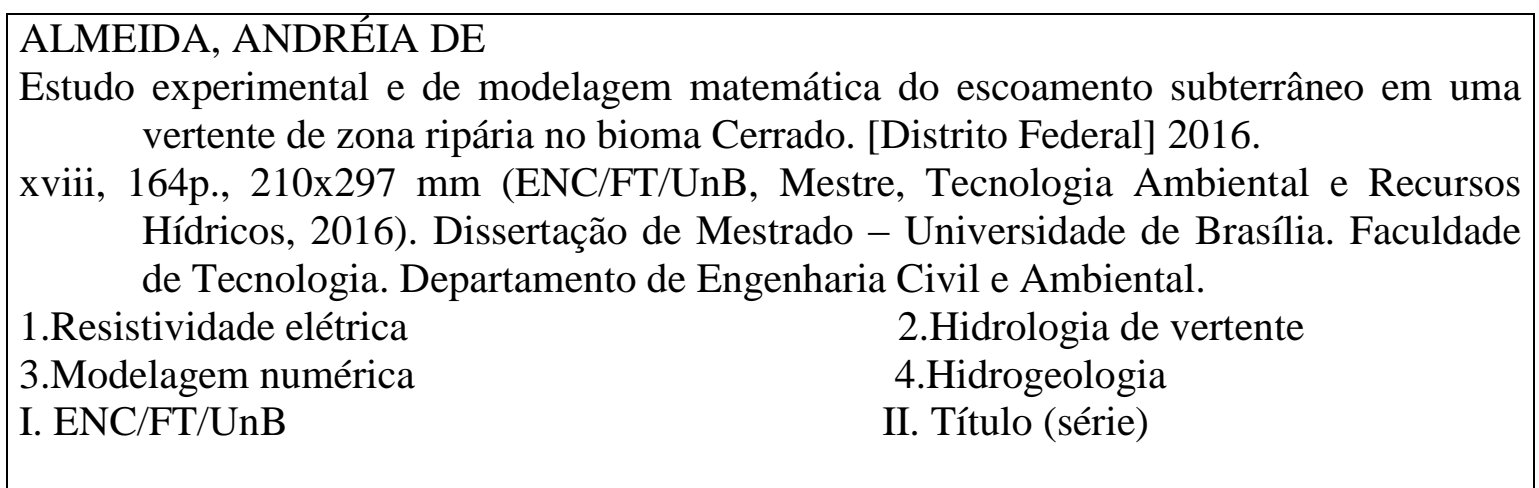

\section{REFERÊNCIA BIBLIOGRÁFICA}

ALMEIDA, A. (2016). Estudo experimental e de modelagem matemática do escoamento subterrâneo em uma vertente de zona ripária no bioma Cerrado. Dissertação de Mestrado em Tecnologia Ambiental e Recursos Hídricos, Publicação PTARH.DM - 186/2016, Departamento de Engenharia Civil e Ambiental, Universidade de Brasília, Brasília, DF, $164 p$.

\section{CESSÃO DE DIREITOS}

AUTOR: Andréia de Almeida.

TÍTULO: Estudo experimental e de modelagem matemática do escoamento subterrâneo em uma vertente de zona ripária no bioma Cerrado.

GRAU: Mestre

ANO: 2016

É concedida à Universidade de Brasília permissão para reproduzir cópias desta dissertação de mestrado e para emprestar ou vender tais cópias somente para propósitos acadêmicos e científicos. $\mathrm{O}$ autor reserva outros direitos de publicação e nenhuma parte desta dissertação de mestrado pode ser reproduzida sem autorização por escrito do autor.

Andréia de Almeida

Avenida Deodato Louly $n^{\circ} 29$, Planaltina

CEP: 73.320-130, Brasília - DF, Brasil 


\section{AGRADECIMENTOS}

Agradeço em primeiro lugar a Deus, por guiar meus passos em todos os instantes. Aos meus pais, Sofia e Jânio, pelas lições transmitidas com afeto e ternura. À minha irmã e meu sobrinho, Angélica e Pedro, pelo carinho e acolhimento. Ao meu companheiro, Tiago Borges Kisaka, por todo o amor e compreensão, somados ao incentivo constante nos momentos mais difíceis. E aos demais familiares, também responsáveis pela realização deste trabalho.

À Samara dos Anjos, por sua amizade de longos anos. Aos amigos do PTARH/UnB, em especial Anne Relvas, Daniel Valência, Gilliard Souza, Nielde Prado, Patrícia Cruvinel, Paulo Bueno e Thallyta Rosário, pelos momentos e experiências vivenciados com alegria. À Bruno Távora, pelo apoio, especialmente nas atividades em campo. À Carolina Neves e Sara Ferrigo, pelo tempo dedicado ao esclarecimento de dúvidas diversas.

À professora Elaine Nolasco, por fornecer a carta de recomendação para o processo seletivo do curso de mestrado. Ao professor Carlos Tadeu Carvalho do Nascimento, por acreditar no meu trabalho e contribuir diretamente para sua elaboração. Ao professor Sérgio Koide, não apenas pela orientação e garantia de estrutura necessária à realização deste projeto, mas também por sua paciência, seus conselhos e palavras de motivação. Aos demais professores do PTARH/UnB, pelos ensinamentos repassados ao longo do mestrado. E a todos os funcionários do $P T A R H / U n B$, em especial a Irioman Júnior, pela colaboração e cordialidade.

À Fazenda Água Limpa $(F A L)$, na pessoa do professor José Mauro da Silva Diogo, pela autorização para desenvolvimento da fase experimental deste estudo. Aos funcionários da $F A L / U n B$, que auxiliaram nos trabalhos em campo. Ao professor Cícero da Silva, por permitir acesso à série histórica de dados hidroclimatológicos da área em estudo. Aos laboratórios de Geotecnia e de Análise de Águas ( $L A A)$ da Universidade de Brasília, sob responsabilidade dos professores Luís Fernando e Cristina Brandão, respectivamente, por cederem estrutura para as análises de umidade do solo. Ao Laboratório de Geociências/UnB, por fornecer o equipamento necessário para levantamento de dados geofísicos. Ao pesquisador Jorge Enoch, pelo empréstimo dos tubos de acesso e do leitor de umidade do solo. 
À $D H I-W A S Y$, por disponibilizar uma licença de uso do programa FEFLOW.

Ao Conselho Nacional de Desenvolvimento Científico e Tecnológico $(C N P q)$ e à Coordenação de Aperfeiçoamento de Pessoal de Nível Superior (CAPES), pelas bolsas de estudos. À Fundação de Amparo à Pesquisa do Distrito Federal (FAPDF), pelo suporte financeiro para aquisição dos materiais necessários à instalação do experimento em campo.

Agradeço ainda àqueles que, por ventura, não tenham sido mencionados e que também contribuíram de maneira direta ou indireta para concretização desta dissertação.

Muito obrigada! 


\section{RESUMO}

Zonas ripárias possuem papel essencial de conectividade hidrológica entre a vertente e os corpos hídricos, ressaltando a importância da compreensão dos processos hidrológicos que nelas se estabelecem. Diante disso, este trabalho consiste na aquisição de dados geofísicos para caracterização indireta do comportamento da água no solo e a resolução de um modelo numérico bidimensional vertical voltado à simulação do fluxo de água em ambiente de zona ripária. A bacia do córrego Capetinga, localizada na porção sul do Distrito Federal, foi utilizada como área experimental para coleta de dados geofísicos e monitoramento da umidade do solo no período de agosto de 2015 a fevereiro de 2016. Os levantamentos geofísicos foram realizados pelo método elétrico de corrente contínua, com técnica de caminhamento elétrico e arranjo de Wenner, considerando a variação espacial num trecho de $200 \mathrm{~m}$ de vertente, totalizando seis linhas de monitoramento (cinco paralelas e uma horizontal ao córrego Capetinga). A equação diferencial que rege o fluxo de água em superfícies de saturação variável foi solucionada por aproximação numérica pelo método de elementos finitos. $\mathrm{O}$ imageamento elétrico possibilitou acompanhar a variação espacial e temporal nos valores de resistividade elétrica do solo, como um indicativo do comportamento da água, especialmente no que diz respeito à identificação da zona saturada na vertente. Desse modo, as informações geofísicas permitiram a caracterização das condições iniciais e a verificação dos resultados de carga hidráulica simulados. Com relação à umidade do solo, os métodos gravimétrico, sonda TDR e de blocos de gesso foram aplicados com o intuito de instrumentalizar a obtenção de dados diretos e indiretos e ampliar a escala temporal e espacial de monitoramento do teor de água na zona não saturada. O modelo numérico, por sua vez, apresentou convergência para condutividade hidráulica equivalente a 0,04 m/dia. Nesse caso, os valores de escoamento de base simulados resultaram em ordem de grandeza equivalente àqueles decorrentes do filtro automático de Arnold e Allen (1999). De modo geral, este trabalho contribuiu para a análise do comportamento da água no solo, sendo um passo inicial para compreensão da complexidade dos processos hidrológicos estabelecidos em ambientes de vertente. 


\section{ABSTRACT}

Riparian zones have essential role of hydrological connectivity between the hillslope and the streams, emphasizing the importance of understanding the hydrological processes that are established in them. Therefore, this paper presents the development of an experimental design with the acquisition of geophysical data for the indirect characterization of soil water behavior as well as from the resolution of a two-dimensional vertical numerical model focused on the simulation of water flow in the soil environment riparian zone. The watershed of the Capetinga stream, located in the southern part of the Federal District, was used as an experimental area with collection of geophysical data and monitoring of soil moisture during the period from August 2015 to February 2016. Geophysical surveys were conducted through electrical method of direct current resistivity technique and Wenner arrangement, considering the spatial variation in 200 meters of hillslope, totaling six lines monitoring (five parallel and one orthogonal to the Capetinga stream). Differential equation that governs the flow of water in the saturation of surfaces was solved by numerical approximation by finite element method. The electrical resistivity traversing possible to monitor the spatial and temporal variations in the values of electrical resistivity soil, as an indication of the behavior of water, especially identifying the saturated zone along the hillslope. Thus, the information obtained from the geophysical surveys allowed the characterization of the initial conditions and verification of the results of head hydraulic resulting from the simulation of water flow in the model domain. Regarding the soil moisture, the application of gravimetric methods, TDR probe and gypsum blocks was carried out in order to instrumentalize obtaining direct and indirect data and expand the temporal and spatial scale of the water content monitoring in the unsaturated zone. The numerical model, in turn, results had converged by adopting hydraulic conductivity equal to $0.04 \mathrm{~m} / \mathrm{d}$. In this case, the simulators base flow values presented order of magnitude equivalent to those resulting from recursive filter Arnold and Allen (1999). Overall, this work contributed to the water of behavior analysis on soil hillslope, being an initial step in understanding the complexity of hydrological processes established in this environment that is a unit of essential landscape at the watershed scale. 


\section{SUMÁRIO}

1 - INTRODUÇÃO ...............................................................................................................................

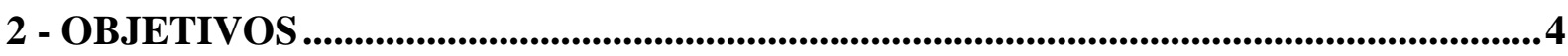

2.1 - GERAL ........................................................................................................................................

2.2 - ESPECÍ́fICOS ……................................................................................................4

3 - FUNDAMENTOS TEÓRICOS E REVISÃO DA LITERATURA ...................................5

3.1 - PROCESSOS HIDROLÓGICOS EM ZONAS RIPÁRIAS.......................................5

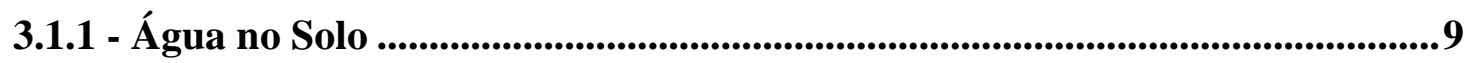

3.1.1.1 - Potencial e Conteúdo de Água no Solo ............................................................ 10

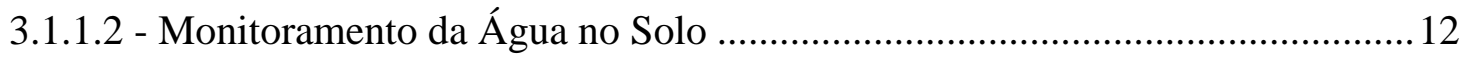

3.1.2 - Fluxo de Água no Solo............................................................................................19

3.1.3 - Relação entre Águas Superficiais e Subterrâneas ............................................22

3.1.3.1 - Determinação do Escoamento de Base.............................................................24

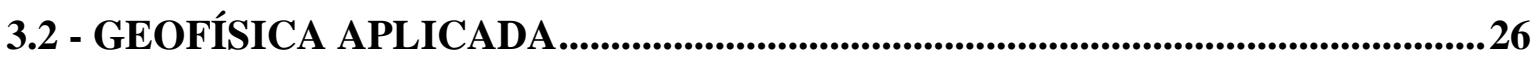

3.2.1 - Método Elétrico de Corrente Contínua ..............................................................26

3.2.1.1 - Princípios Básicos Relacionados ao Método Elétrico de Corrente Contínua

3.2.1.2 - Procedimento para Aquisição de Dados Geofísicos......................................... 32

3.2.1.3 - Teoria Básica para Inversão de Dados Geoelétricos .........................................36

3.3 - MODELAGEM MATEMÁTICA DE PROCESSOS HIDROLÓGICOS ............37

3.3.1 - Modelagem Matemática por Métodos Numéricos.............................................37

3.3.1.1 - Etapas de Modelagem Numérica.......................................................................39

3.3.2 - Modelagem Numérica pelo Método de Elementos Finitos ...............................44

3.3.2.1 - Aplicação do Método de Elementos Finitos..........................................................46

3.3.2.2 - Confiabilidade dos Resultados Obtidos por Aproximação Numérica.............51

3.3.2.3 - Pacote Computacional FEFLOW ................................................................. 52

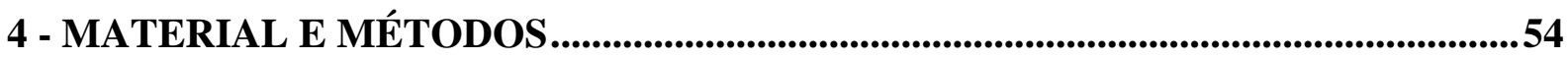

4.1 - ÁREA DE ESTUDO ...................................................................................54

4.1.1 - Desenho Experimental ................................................................................................56

4.1.2 - Aspectos Fisiográficos ......................................................................................57

4.1.2.1 - Características Climáticas ...........................................................................57 
4.1.2.2 - Conformação Topográfica e Aspectos de Uso e Cobertura do Solo ...............58

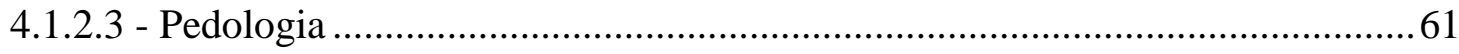

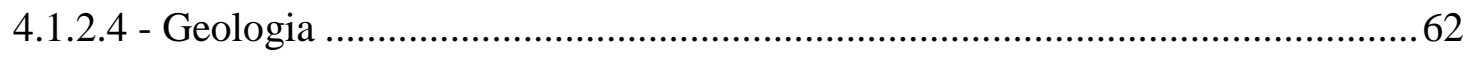

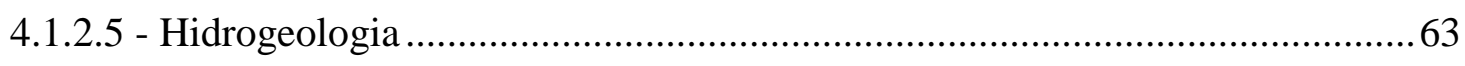

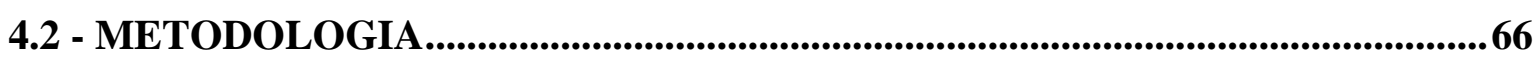

4.2.1 - Imageamento Elétrico do Solo...............................................................67

4.2.1.1 - Instalação do Experimento e Aquisição de Dados ...........................................67

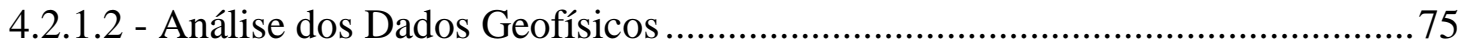

4.2.2 - Monitoramento da Água na Zona Não Saturada .............................................79

4.2.2.1 - Determinação da Umidade Gravimétrica ....................................................81

4.2.2.2 - Monitoramento da Umidade pelo Método de Reflectometria no Domínio

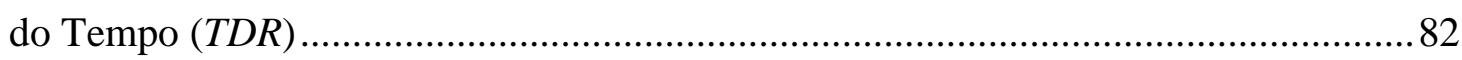

4.2.2.3 - Determinação do Potencial de Água do Solo com Blocos de Resistência

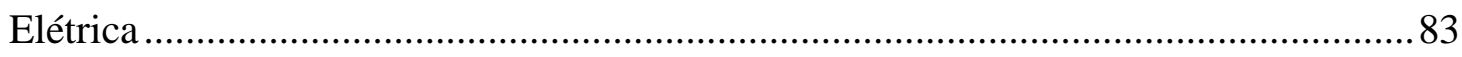

4.2.3 - Simulação Hidrológica da Carga Hidráulica................................................84

4.2.3.1 - Elaboração do Modelo Conceitual e Matemático ............................................. 84

4.2.3.2 - Aplicação do Modelo Numérico de Elementos Finitos................................... 86

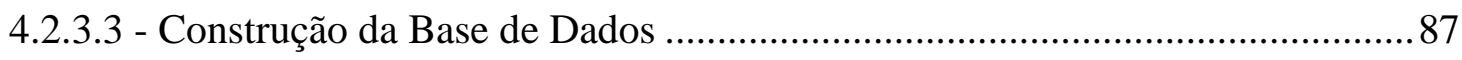

4.2.4 - Representação Esquemática da Metodologia ...............................................91

5 - RESULTADOS E DISCUSSÃO _............................................................................93

5.1 - CARACTERIZAÇÃO GEOELÉTRICA NA VERTENTE DO CÓRREGO

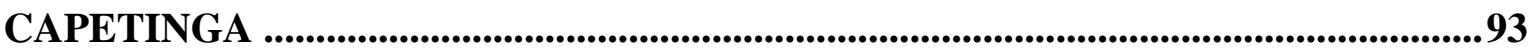

5.1.1 - Imageamento Elétrico do Solo.................................................................................93

5.1.2 - Mapeamento dos Valores de Resistividade Elétrica do Solo ......................103

5.1.3 - Variação Temporal dos Valores de Resistividade Elétrica..........................110

5.2 - COMPORTAMENTO DA ÁGUA NA ZONA NÃO SATURADA ......................119

5.2.1 - Monitoramento da Umidade Gravimétrica .............................................119

5.2.2 - Umidade Volumétrica com Aplicação do Método TDR ..............................122

5.2.3 - Blocos de Resistência Elétrica .................................................................126

5.3 - MODELAGEM NUMÉRICA DO FLUXO DE ÁGUA SUBTERRÂNEA NA

VERTENTE DO CÓRREGO CAPETINGA..................................................................128

5.3.1 - Balanço Hídrico e Dados de Entrada do Modelo Numérico.........................128 
5.3.2 - Modelo Numérico Estacionário: Condições Iniciais de Carga Hidráulica 131

5.3.3 - Modelo Numérico Transiente .132

6 - CONCLUSÃO E CONSIDERAÇÕES FINAIS 139

REFERÊNCIAS BIBLIOGRÁFICAS ................................................................................142

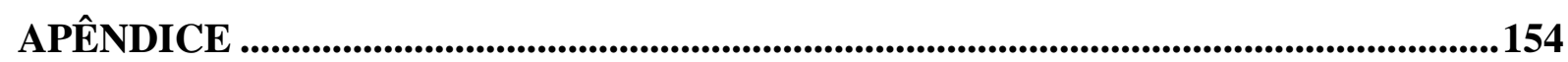

APÊNDICE A - ANÁLISE DESCRITIVA DOS VALORES DE RESISTIVIDADE CALCULADOS A PARTIR DO PROCESSO DE INVERSÃO .............................155

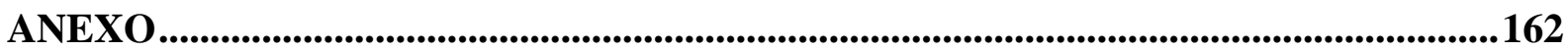

ANEXO A - CURVA DE CALIBRAÇÃO DOS BLOCOS DE GESSO ....................163 


\section{LISTA DE TABELAS}

Tabela 3.1 - Variações do arranjo de Wenner.................................................................. 34

Tabela 3.2 - Análise comparativa entre os arranjos de Wenner e Schlumberger. .............. 34

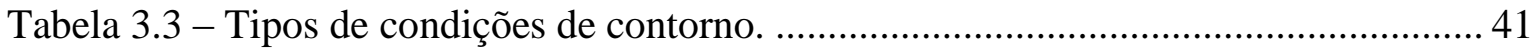

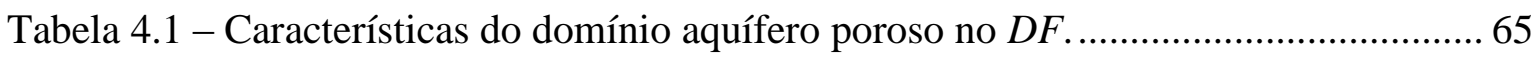

Tabela 4.2 - Características do domínio aquífero fraturado no $D F$. .................................. 65

Tabela 4.3 - Data de aquisição dos dados em campo. ..................................................... 75

Tabela 4.4 - Detalhes a respeito dos métodos aplicados................................................ 80

Tabela 4.5 - Data de coleta das amostras de solo e de medição da umidade em campo. ... 80

Tabela 4.6 - Propriedades hidráulicas adotadas no modelo.............................................. 86

Tabela 5.1 - Umidade gravimétrica $(\mathrm{g} / \mathrm{g})$ determinada para os pontos $U A, U C$ e $U E$. Na semana 1 (19/08/2015) não foram obtidos dados de umidade gravimétrica. ........ 120

Tabela 5.2 - Valores de umidade volumétrica $\left(\mathrm{m}^{3} / \mathrm{m}^{3}\right)$ e tensão da água no solo $(\mathrm{mV})$... 123

Tabela 5.3 - Resistência elétrica dos blocos de gesso $(\Omega)$ e umidade disponível (\%)...... 126

Tabela 5.4 - Balanço hídrico para estimativa da recarga na área de estudo. .................... 129

Tabela 5.5 - Comparação entre os resultados do escoamento de base.............................. 136 


\section{LISTA DE FIGURAS}

Figura 3.1 - Representação esquemática dos processos hidrológicos em escala de vertente. Adaptado de Cederstrom (1964).

Figura 3.2 - Representação das zonas de aeração e saturação do subsolo. Fonte: Karmann (2008)

Figura 3.3 - Método Elétrico de Corrente Contínua no contexto dos métodos geofísicos de prospecção. Fonte: Telford et al. (1990).

Figura 3.4 - Arranjos tipicamente utilizados para aquisição de dados geofísicos, com disposição dos eletrodos de corrente $(A$ e $B)$ e de potencial $(M$ e $N)$. a) Arranjo de Schlumberger, com distância $a$ fixa e $L$ crescente. b) Arranjo de Wenner, com distância $a$ constante. Adaptado de Braga (2007).

Figura 3.5 - Etapas para desenvolvimento do modelo. Modificado de Bear e Cheng (2010).

Figura 3.6 - Exemplo de domínio $(D)$ bidimensional horizontal com contorno $(I)$ discretizado por diferenças finitas e por elementos finitos. Fonte: Diersch (2014). 45

Figura 4.1 - Localização da área de estudo. b) Bacia hidrográfica do córrego Capetinga no DF. c) Bacia do córrego Capetinga em escala de 1:45000, com exutório na Estação Fluviométrica $F A L-U n B$. d) Visualização detalhada da vertente em estudo, com escala de 1:5000. O Córrego Capetinga foi representado pelo traçado branco para contraste.

Figura 4.2 - a) Estações Pluviométrica e b) Fluviométrica automáticas FAL-UnB (Código: 60478482). Fonte: Távora (2016).

Figura 4.3 - a) Delimitação do desenho experimental (retângulo em negrito) e do perfil selecionado para modelagem numérica (tracejado cinza). b) Ilustração esquemática do desenho experimental adotado nos levantamentos geofísicos. c) Vista bidimensional do perfil utilizado na modelagem numérica, com informação de altitude $(m)$ no eixo $y$ e extensão longitudinal do perfil no eixo $x$. O destaque referese ao posicionamento da linha $F$ de monitoramento geofísico. 56

Figura 4.4 - Comportamento médio mensal dos valores de temperatura $\left({ }^{\circ} \mathrm{C}\right)$ e precipitação ( $\mathrm{mm}$ ) entre os anos de 1965 e 2015. Fonte: INMET (2016) 57

Figura 4.5 - Conformação topográfica da bacia do Capetinga. 58

Figura 4.6 - Classes de declividade (\%) na área de estudo. 59 
Figura 4.7 - Uso e cobertura do solo na bacia do córrego Capetinga. O traçado do córrego não foi inserido nesse mapa, ao contrário dos demais, para facilitar a visualização da cobertura do solo

Figura 4.8 - Composição da vegetação ripária predominante na área em estudo.

Figura 4.9 - Vegetação identificada na vertente em estudo. a) Formação florestal "Cerradão". b) Formações savânica e campestre, denominadas conjuntamente de "Cerrado". 61

Figura 4.10 - Mapa pedológico 62

Figura 4.11 - Mapa geológico. 63

Figura 4.12 - Domínios aquíferos poroso e fraturado do Distrito Federal. Adaptado de Lousada e Campos (2005).

Figura 4.13 - Mapa hidrogeológico da área de estudo, com espacialização dos domínios aquíferos poroso e fraturado. 66

Figura 4.14 - Ilustração esquemática do desenho experimental, sendo seis linhas de monitoramento com $200 \mathrm{~m}$ cada. As letras de " $A$ " a " $E$ " designam as seções paralelas ao córrego, com eletrodos espaçados $10 \mathrm{~m}$ entre si. A letra " $F$ " denomina a seção transversal ao córrego, com eletrodos distribuídos a cada $5 \mathrm{~m}$. 68

Figura 4.15 - a) Placa de conexão posicionada no ponto central de cada linha. Os parafusos fixados nas tábuas foram identificados com numeração sequencial indicativa da posição dos fios a eles associados. b) Caixas plásticas contendo a placa de conexão dos elétrodos. Neste caso, é observada a interceptação entre as linhas $C$ (caixa menor, abaixo), paralela ao córrego; e $F$ (caixa maior, acima), transversal ao córrego.

Figura 4.16 - a) Visualização de um trecho da linha $A$, com a vegetação circundante. b) Disposição da linha $B$. 71

Figura 4.17 - a) Interceptação das linhas $C$ (paralela ao córrego Capetinga) e $F$ (ortogonal ao córrego Capetinga). b) Visualização da linha $D$.

Figura 4.18 - a) Linha $E$, com ênfase para a placa de conexão. b) Aquisição dos dados em campo, com destaque para o resistivímetro Geopulse interligado à placa de conexão dos eletrodos. .73

Figura 4.19 - Representação esquemática da aquisição de dados nas seções $A, B, C, D$ e $E$, com espaçamento de $10 \mathrm{~m}$ entre os eletrodos a partir do nível 1, totalizando 76 pontos de medição em cada seção. 
Figura 4.20 - Representação esquemática da aquisição de dados na seção $F$, com espaçamento de $5 \mathrm{~m}$ entre os eletrodos para o nível 1, totalizando 168 pontos de medição em cada seção.

Figura 4.21 - Representação esquemática da metodologia adotada para caracterização geoelétrica da vertente.

Figura 4.22 - Monitoramento da umidade do solo. $U A, U C$ e $U E$ - pontos de coleta de amostras de solo para determinação da umidade gravimétrica. $U A$ a $U E-$ determinação da umidade por $T D R$ e blocos de resistência elétrica. $P E$ - poço de monitoramento no domínio aquífero poroso.

Figura 4.23 - Poço de observação dotado de linígrafo para monitoramento do nível da água no domínio aquífero poroso, instalado próximo à seção geofísica $E$ (ao fundo)..... 81

Figura 4.24 - a) Tubo de fibra de vidro instalado em campo para acesso da sonda TDR. b)

Procedimento para aquisição dos dados.

Figura 4.25 - a) Recipiente para armazenamento dos fios conectados aos blocos. b) Equipamento utilizado para leitura dos blocos de gesso. 84

Figura 4.26 - Modelo conceitual da vertente em estudo, com indicação das direções $x$ (coordenada longitudinal) e $y$ (altitude, indicada pela letra $z$ ), condições de contorno de fluxo nulo (divisor topográfico e camada impermeável, e o canal do córrego Capetinga. 85

Figura 4.27 - Perfil bidimensional utilizado na modelagem numérica. A área destacada corresponde à seção $F$ de monitoramento geofísico. 88

Figura 5.1 - Imageamento elétrico bidimensional das linhas " $A$ ” a " $E$ ”. 97

Figura 5.2 - Gráficos box plot da variação nos valores de resistividade para as linhas " $A$ ", “ $B$ ", "C", " $D$ "e " $E$ ” em função das profundidades investigadas.

Figura 5.3 - Variação vertical dos valores de resistividade na seção " $F$ ”, desde a estrada (fração a esquerda, com maior elevação) até a proximidade do córrego Capetinga. 101

Figura 5.4 - Variação dos valores de resistividade para a linha “ $F$ ” em gráfico box plot 101 Figura 5.5 - Mapas de resistividade calculada ( $\Omega . \mathrm{m})$. As siglas P5, P10, P15,5, P21,5, P28 e P35,5 indicam as profundidades investigadas. As linhas tracejadas e em negrito indicam a posição das seções geolétricas ao longo da vertente do córrego Capetinga, no sentido da Seção $A$ (primeira à esquerda) à $E$ (primeira à direita). 109

Figura 5.6 - Variação espacial e temporal da resistividade modelada ( $2 . m)$ para cada profundidade de investigação nas seções " $A$ ” a " $E$ ”. 110 
Figura 5.7 - Variação temporal dos valores de resistividade nas seções " $A$ " a " $E$ ". 114

Figura 5.8 - Precipitação diária (mm/d) ao longo do período de estudo (agosto de 2015 a fevereiro de 2016), com indicação da data de ocorrência dos levantamentos geofísicos.

Figura 5.9 - Teste de hipótese de Mann-Whitney aplicado para as seções de $A$ a $E$ considerando a diferença em função variação temporal para cada seção. 116

Figura 5.10 - Teste de hipótese de Mann-Whitney aplicado para as profundidades de 5 a $35 \mathrm{~m}$ considerando a diferença em função variação temporal em cada seção. 117

Figura 5.11 - Variação temporal dos valores de resistividade elétrica na seção $F$. 118

Figura 5.12 - Umidade gravimétrica nos $U A, U C$ e $U E$ nas profundidades de 0,0 a 1,0 m.

Figura 5.13 - Amostras de solo coletadas nos pontos $U A, U C$ e $U E$ (da esquerda para a direita), dispostas de modo que a primeira linhas (de cima para baixo) representa a porção de solo superficial, enquanto que a última é formada pelas amostras de solo a $1 \mathrm{~m}$ de profundidade.

Figura 5.14 - Correlação obtida entre dados de umidade gravimétrica (g/g) e volumétrica $\left(\mathrm{m}^{3} / \mathrm{m}^{3}\right)$ nos pontos $U A, U C$ e $U E$.

Figura 5.15 - Resultado da calibração da sonda TDR por comparação com dados de umidade gravimétrica.

Figura 5.16 - Potencial da água do solo $(m)$ nas profundidades de $0,5,1,0$ e 1,5m.

Figura 5.17 - Determinação do escoamento de base da vertente do córrego Capetinga, no período de 05 de fevereiro de 2000 a 04 de fevereiro de 2016, com filtro automático proposto por Arnold e Allen (1999), sendo o parâmetro de ajuste $\beta=0,994$.

Figura 5.18 - Condições iniciais de carga hidráulica para a vertente do córrego Capetinga. A região em destaque refere-se à área da seção geoelétrica $F$. 131

Figura 5.19 - Simulação em regime transiente ao longo de 12.783 dias. A região em destaque refere-se à área da seção geoelétrica $F$.

Figura 5.20 - Distribuição da carga hidráulica em 19 de agosto de 2015. A região em destaque refere-se à área da seção geoelétrica $F$. 134

Figura 5.21 - Distribuição da carga hidráulica em 04 de fevereiro de 2016. A região em destaque refere-se à área da seção geoelétrica $F$.

Figura 5.22 - Comparação entre os resultados do levantamento geofísico e da modelagem numérica. 135 
Figura 5.23 - Comparação entre os valores de escoamento de base obtidos a partir da simulação matemática e do filtro automático desenvolvido por Arnold e Allen (1999) 138 


\section{LISTA DE SÍMBOLOS}

$A$ - Área $\left[L^{2}\right]$

$A$ - Eletrodo de corrente

$A$ - Matriz de sensibilidade

$A$ - Subsistema do domínio aquífero fraturado Paranoá

$a$ - Espaçamento entre os eletrodos $[L]$

AB/TR - Forward Adams Bashforth/Backward Trapezoid

ADASA - Agência Reguladora de Águas e Saneamento do Distrito Federal ANA - Agência Nacional de Águas

$A P A$ - Área de Proteção Ambiental

ARIE - Área de relevante interesse ecológico

$B$ - Eletrodo de corrente

$b$ - espessura da camada saturada $[L]$

BDMEP - Banco de Dados Meteorológicos para Ensino e Pesquisa

$B F I_{\max }$ - Parâmetro de calibração do filtro matemático de Eckhardt (2005) [adimensional]

$b_{t}$ - Escoamento de base $\left[L^{3} T^{-1}\right]$

$c$ - velocidade da luz $\left[L T^{l}\right]$

$C d$ - Cambissolo húmico

$C E$ - Caminhamento elétrico

CNRH - Conselho Nacional de Recursos Hídricos

CODEPLAN - Companhia de Planejamento do Distrito Federal

Cwa-Clima tropical de altitude

$D$ - Domínio

$D F$ - Distrito Federal

DFM - Difference finite model (Modelo de diferenças finitas)

Embrapa - Empresa Brasileira de Pesquisa Agropecuária

EPA - Environmental Protection Agency (Agência de Proteção Ambiental dos Estados Unidos)

ERT - Electrical resistivity traversing (travessia por resistividade elétrica)

ERT - Eletrical Resistivity Tomography (tomografia por resistividade elétrica)

ETo - Evapotranspiração de referência $\left[L^{3} T^{-1}\right]$

ETr - Evapotranspiração real $\left[L^{3} T^{1}\right]$ 
$f$ - Função conhecida

$F$ e $F / Q / M$ - Subsistemas do domínio aquífero fraturado Canastra

$F A L$ - Fazenda Água Limpa

FE/BE - Forward Euler/Backward Euler

FEFLOW - Finite Element Subsurface Flow and Transport Simulation System (Sistema de simulação de fluxo e transporte subsuperficial por elementos finitos)

FEM - Finite element model (Modelo de elementos finitos)

$h$ - Carga hidráulica $[L]$

$h_{h}$ - Potencial hidrostático $[L]$

$h_{g}$ - Potencial gravitacional $[L]$

$h_{m}-$ Potencial matricial $[L]$

$h_{O}$ - Potencial osmótico $[L]$

$h_{T}$ - Potencial total da água do solo $[L]$

$H i$ - Solo hidromórfico

$I$ - Intensidade da corrente elétrica $[A]$

$I B G E$ - Instituto Brasileiro de Geografia e Estatística

In - Interceptação $\left[L^{3} T^{-1}\right]$

INMET - Instituto Nacional de Meteorologia

$J$ - Densidade de corrente $\left[A L^{-1}\right]$

$K$ - Condutividade hidráulica $\left[L T^{-1}\right]$

$K$ - Fator geométrico que depende da disposição dos eletrodos $A B M N$ na superfície do terreno

$K_{x x}, K_{y y}$ e $K_{z z}-$ Tensores de condutividade hidráulica nas direções x, y e z $\left[L T^{l}\right]$

$K c$ - Coeficiente da vegetação ou cultura [adimensional]

$K p$ - Coeficiente do tanque [adimensional]

$K s$ - Coeficiente dependente da umidade do solo [adimensional]

$K s$ - Condutividade hidráulica saturada $\left[L T^{-1}\right]$

$L$ - Comprimento $[L]$

$L$ - Operador diferencial

$L V$ - Latossolo Vermelho

$L V A$ - Latossolo vermelho-amarelo

$M$ - massa [M]

$M$ - Eletrodo de potencial 
$M s$ - Massa seca $[M]$

$M u$ - Massa úmida $[M]$

$m$ - Parâmetro das equações de Mualem (1976) e van Genuchten (1980) [adimensional]

$M D E$ - Modelo digital de elevação

MNPpq3 - Unidade metarritmito arenoso

MNPpr4 - Unidade Ardórsia

$N$ - Matriz de funções de interpolação.

$N$ - Eletrodo de potencial

$n$ - Parâmetro do tipo de solo para equação de van Genuchten (1980) [adimensional]

$n$-Coeficiente empírico da Lei de Archie [adimensional]

$n_{x}$ e $n_{y}$ - Cossenos diretores da normal externa ao contorno

$P$ - Vetor de parâmetros

$p$-Coeficiente empírico da Lei de Archie [adimensional]

$P E$ - Poço de observação

$P P C$ - Subsistema do domínio aquífero fraturado Paranoá

$\operatorname{Pr}$ - Precipitação $\left[\mathrm{L}^{3} \mathrm{~T}^{-1}\right]$

$P 1, P 2, P 3$ e $P 4$ - Sistemas do domínio aquífero poroso

$Q$ - Vazão $\left[L^{3} T^{-1}\right]$

Q3/R3 - Subsistema do domínio aquífero fraturado Paranoá

$q$ - Velocidade de Darcy ou aparente $\left[L T^{l}\right]$

$q$-Coeficiente empírico da Lei de Archie [adimensional]

$q_{t}$ - Escoamento direto $\left[L^{3} T^{-1}\right]$

$R$ - Resistência elétrica $[\Omega]$

$r$ - Distância $[L]$

$R e-\operatorname{Recarga}\left[L^{3} T^{-1}\right]$

$R 4$ - Subsistema do domínio aquífero fraturado Paranoá

RMSE - Root mean squared error (Raiz do erro médio quadrático)

$S$ - Grau de saturação [\%]

$S$ - Operador diferencial

$S_{n}$ - distância ao longo do contorno $[L]$

$S_{r}$ - Saturação residual $\left[L^{3} \cdot L^{-3}\right]$

$S_{S}$ - Coeficiente de armazenamento específico $\left[\mathrm{L}^{-1}\right]$

$S_{S}$ - Saturação máxima $\left[L^{3} \cdot L^{-3}\right]$ 
$S_{y}$ - Capacidade de armazenamento específico $\left[\mathrm{L}^{-1}\right]$

S/A - Subsistema do domínio aquífero fraturado Paranoá

SEDHAB - Secretaria de Estado de Gestão do Território e Habitação

SEV - Sondagem elétrica vertical

SICAD - Sistema Cartográfico do Distrito Federal

$S I G$ - Sistema de Informação Geográfica

SWAT - Soil And Water Assessment Tool (Ferramenta de avaliação do solo e da água)

$T$ - Tensores de transmissividade nas direções x e y $\left[L^{2} T^{-1}\right]$

$t$ - Tempo [T]

TDR - Time Domain Reflectometry (Reflectometria no domínio do tempo)

TEM - Transient electromagnetic (Sinal eletromagnético transverso)

$U$ - Potencial elétrico $[V]$

$U A, U B, U C, U D, U E$ - Pontos de medição de umidade do solo

$u$ - Solução aproximada

$u_{0}$ - Solução exata

$\bar{u}$ - Condição de contorno

$u^{e}-$ Vetor de soluções

UnB - Universidade de Brasília

$V-$ Volts

$V-$ Volume $[V]$

$w$ - Fontes ou sumidouros de água no aquífero

$x$ - Direção $[L]$

$y$ - Direção $[L]$

$z$ - Elevação $[L]$

$\alpha$ - Parâmetro do tipo de solo para equação de van Genuchten (1980) $\left[L^{-1}\right]$

$\alpha$-Coeficiente de recessão [adimensional]

$\alpha$ - Parâmetro de calibração do filtro matemático de Eckhardt (2005)

$\alpha$ - Parâmetros da modelagem numérica

$\alpha$-Wenner - Arranjo de eletrodos alfa Wenner

$\beta$ - Parâmetro de suavização do ajuste de Arnold e Allen (1999) [adimensional]

$\beta$ - Função conhecida, incluída para satisfazer as condições de contorno não homogêneas

$\beta$-Wenner - Arranjo de eletrodos beta Wenner

$\delta_{S}-$ Função delta de Dirac 
$\theta$ - Umidade

$\theta_{g}$ - Umidade gravimétrica [M.M $\left.{ }^{-1}\right]$

$\theta_{r}$ - Umidade volumétrica residual do solo $\left[L^{3} \cdot L^{-3}\right]$

$\theta_{s}$ - Umidade volumétrica do solo saturado $\left[L^{3} . L^{-3}\right]$

$\theta_{v}$ - Umidade volumétrica $\left[L^{3} \cdot L^{-3}\right]$

$\Gamma-$ Contorno

$\Delta d$ - Diferença entre dados observados e calculados

$\phi_{i}-$ Funções de aproximação

$\varepsilon$-Constante dielétrica ou permissividade $\left[F . L^{-1}\right]$

$\varepsilon$ - Intensidade do campo elétrico

$\varepsilon-$ erro

$v$ - Velocidade verdadeira $\left[L T^{l}\right]$

$\rho$-Resistividade elétrica $[\Omega L]$

$\rho_{a}-$ Resistividade elétrica aparente $[\Omega L]$

$\rho_{w}-$ Resistividade elétrica da água $[\Omega L]$

$\sigma$ - Condutividade elétrica $\left[S L^{-1}\right]$

$\eta$ - Capacidade de água no solo $\left[\mathrm{L}^{-1}\right]$;

$\varphi$ - Porosidade [adimensional]

$\varphi_{e f}-$ Porosidade efetiva [adimensional]

$\psi$ - Potencial de pressão $[L]$

$\gamma$-Wenner - Arranjo de eletrodos gama Wenner 


\section{1 - INTRODUÇÃO}

Zonas ripárias são ecossistemas de interface terrestre e aquática que se caracterizam pela interação entre a vegetação, o solo e os recursos hídricos superficiais e subterrâneos (Lowrance et al., 1984; Zarroca et al., 2014). A estrutura desses ambientes permite o controle do movimento de massa, do microclima e da diversidade de espécies, bem como provê o serviço ecossistêmico de manutenção dos recursos hídricos (Naiman e Décamps, 1997). Diante disso, a abordagem dos processos hidrológicos em zonas ripárias favorece a percepção da importância desse ecossistema na proteção das águas, inclusive na escala de bacia hidrográfica, com relevância no contexto da gestão de recursos hídricos (Naiman et al., 2005; Jencso et al., 2010; von Freyberg et al., 2014; Poulsen et al., 2015).

A conectividade hidrológica estabelecida nas vertentes é essencial para a geração de escoamento e o transporte de solutos e nutrientes aos corpos hídricos superficiais (Burt et al., 2002; Jencso et al., 2010). Quanto à geração de escoamento, a conectividade é um mecanismo importante para determinação do comportamento das bacias hidrográficas em relação à precipitação (Detty e McGuire, 2010). Conforme Wienhofer et al. (2009), a relação chuva-vazão em pequenas bacias é controlada principalmente por processos hidrológicos na escala de encosta. Além disso, o escoamento subterrâneo nas vertentes é considerado significativo para ambientes lóticos de cabeceira por manter a disponibilidade hídrica dos canais superficiais (Brutsaert, 2005; Blumstock et al., 2015).

As formas de escoamento predominantes na vertente são controladas tanto pela duração e intensidade da precipitação quanto pelas características morfológicas e estruturais da vertente (Selby, 2005). Neste último caso, o conteúdo de água no solo e a profundidade do nível da água subterrânea são condições iniciais a serem consideradas no entendimento dos mecanismos de geração de escoamento (Selby, 2005). No entanto, dados de campo acerca das condições iniciais do nível freático, gradiente hidráulico e padrões de fluxo ainda são considerados escassos (Burt et al., 2002; Castelloé et al., 2015). Como afirmam MonteMor et al. (2012), estudos hidrológicos exigem redes de monitoramento com elevado custo de instalação e de manutenção, principalmente em casos de medição da umidade e pressão da água no solo, escoamento superficial em encostas, vazão sólida, precipitação, evaporação e vazão. Nas zonas ripárias esse cenário não se diferencia, especialmente pelo 
caráter invasivo e dispendioso das abordagens convencionais para aquisição de dados (Musgrave e Binley, 2011).

Em alternativa, métodos geofísicos e de modelagem matemática têm sido empregados no estudo do comportamento da água no solo (Andersen et al., 2013; Zarroca et al., 2014; Awan et al., 2015). Conforme Andersen et al. (2013), os modelos de simulação do fluxo subterrâneo em vertentes muitas vezes utilizam dados geofísicos, para além das informações obtidas pelo monitoramento direto em poços de observação. Zarroca et al. (2014) e Yeboah-Forson et al. (2014) ressaltam que levantamentos geofísicos contribuem para a elaboração de modelos conceituais representativos das características hidrogeológicas, permitindo estimativas indiretas de parâmetros do solo, tais como porosidade, salinidade, condutividade hidráulica, conteúdo de argila mineral e umidade. Dentre os métodos geofísicos, o mais empregado no estudo da água no solo baseia-se na medição da resistividade elétrica (Telford et al., 1990; Asawa, 2008).

Com relação aos modelos matemáticos, são observadas importantes aplicações na simulação do fluxo subterrâneo (Bahrami et al., 2014; Diersch, 2014; Doulatyari et al., 2014; Awan et al., 2015). De acordo com Fleckenstein et al. (2010), o aprimoramento dos modelos matemáticos desenvolvidos a partir da década de 1960 tem permitindo abordagens voltadas à compreensão dos processos hidrológicos característicos de zonas ripárias. Tal fato permitiu ainda o desenvolvimento de modelos conceituais capazes de retratarem a interação entre recursos hídricos superficiais e subterrâneos (Fleckenstein et al., 2010). Como afirmam Vidon e Hill (2004) e Attanásio et al. (2012), a caracterização hidrológica da zona ripária, diferindo-a do restante da paisagem, permite a compreensão do papel desse ambiente na escala de bacia hidrográfica e a obtenção de cenários frente às alterações de uso e cobertura do solo.

Desse modo, associar a caracterização hidrogeológica fornecida a partir da aplicação de métodos geofísicos à modelagem matemática pode ampliar a capacidade de representação do funcionamento hidrológico das zonas ripárias, a exemplo dos resultados apresentados em Andersen et al. (2013) e Ward et al. (2014). Diante do exposto, este trabalho consistiu no estudo do parâmetro resistividade elétrica como ferramenta de caracterização da zona ripária quanto ao comportamento da umidade do solo e do nível da água subterrânea, com estudo de caso na vertente do córrego Capetinga, Distrito Federal. Além disso, foi 
realizada modelagem numérica para simulação da carga hidráulica no domínio aquífero poroso na vertente selecionada.

Em resumo, o objetivo deste estudo foi caracterizar qualitativamente o comportamento da água no solo em zonas ripárias como subsídio à compreensão dos processos hidrológicos preponderantes. Finalizada a introdução (Capítulo 1), a dissertação foi estruturada em outros cinco capítulos. No Capítulo 2 foram listados os objetivos do projeto de pesquisa. Ao longo do Capítulo 3 delimitaram-se conceitos de revisão bibliográfica que subsidiaram a realização do trabalho. $\mathrm{O}$ quarto capítulo foi elaborado com intuito de apresentar a área física de desenvolvimento do estudo de caso e a metodologia utilizada. No quinto capítulo foram apresentados os resultados obtidos e as discussões desenvolvidas a partir dos mesmos. Conclusão e recomendações finais estão contidas no sexto capítulo da dissertação. 


\section{2 - OBJETIVOS}

\section{1 - GERAL}

Aplicação do método geofísico como subsídio a modelagem matemática do fluxo de água no solo em locais desprovidos de monitoramento hidrológico tradicional, com estudo de caso na bacia do córrego Capetinga, Distrito Federal.

\section{2 - ESPECÍFICOS}

- Analisar o comportamento da água no solo a partir dos monitoramentos temporal e espacial da resistividade elétrica na vertente do córrego Capetinga pelo método elétrico de corrente contínua.

- Modelar a carga hidráulica no domínio aquífero poroso na vertente do córrego Capetinga, considerando a interpretação dos dados geofísicos como subsídio à elaboração do modelo conceitual e como referência para análise da simulação. 


\section{3 - FUNDAMENTOS TEÓRICOS E REVISÃO DA LITERATURA}

As informações teóricas e de revisão da literatura selecionadas para embasamento deste estudo foram estruturadas em três seções. A primeira refere-se à hidrologia de vertentes, com destaque para as zonas ripárias. A segunda aborda a temática de geofísica aplicada pelo método elétrico de corrente contínua. Na última seção, por sua vez, foram apresentados conceitos relacionados à modelagem matemática, com ênfase em modelos numéricos de elementos finitos.

\section{1 - PROCESSOS HIDROLÓGICOS EM ZONAS RIPÁRIAS}

O comportamento hidrológico das vertentes em relação aos eventos de precipitação é estudado pela hidrologia de vertentes, considerando principalmente a variação da umidade do solo e a formação do escoamento (Freeze e Cherry, 1979; Anderson e Burt, 1990; Brutsaert, 2005). As zonas ripárias, localizadas na interface entre os ecossistemas terrestre e aquático, também são objeto de pesquisa desse ramo da ciência e favorecem a conectividade hidrológica da vertente com o corpo hídrico (Gregory e Ashkenas, 1990; Brutsaert, 2005). A definição do termo conectividade hidrológica, entendida como a transferência de energia e matéria entre duas unidades topográficas, remete aos trabalhos de Haught e van Meerveld (2011), Jiang et al. (2015) e Martínez-Carreras et al. (2015), como um controle dominante para a formação de escoamento na escala de encosta.

A resposta das vertentes à precipitação é mensurada pelos processos de escoamento superficial (overland flow), subsuperficial (stormflow ou interflow) e subterrâneo (groundwater flow) (Freeze e Cherry, 1979). Com a ocorrência do evento chuvoso, uma porção da água precipitada escoa superficialmente em direção aos corpos hídricos. A parcela restante infiltra no solo, podendo retornar a atmosfera por evaporação ou evapotranspiração, formar o escoamento subsuperficial ou percolar para zonas profundas, como recarga das águas subterrâneas (Figura 3.1). Quanto ao escoamento superficial, pode-se considerar aquele oriundo do excesso de infiltração, também denominando Hortoniano, ou por excesso de saturação do solo. 

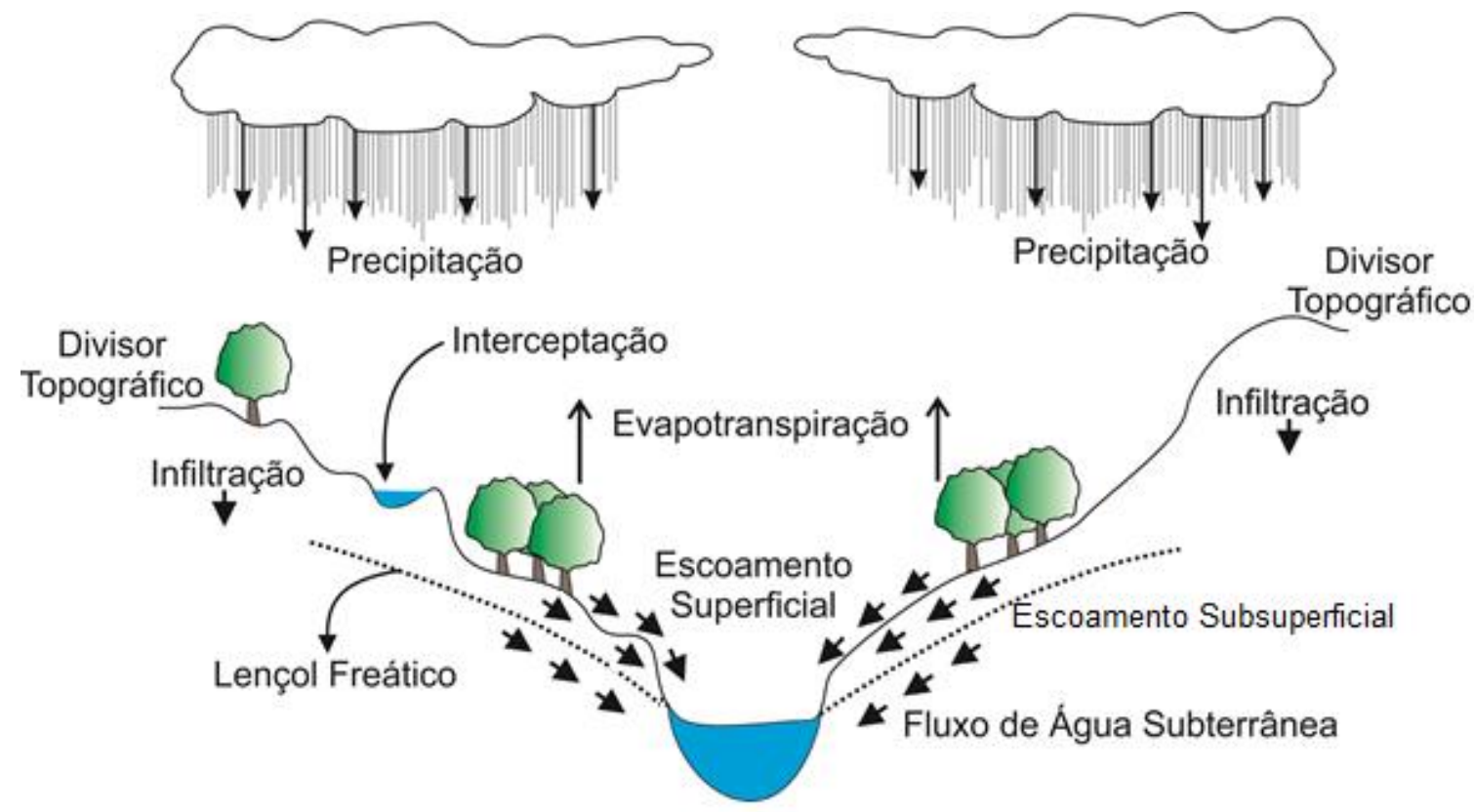

Figura 3.1 - Representação esquemática dos processos hidrológicos em escala de vertente. Adaptado de Cederstrom (1964).

O escoamento superficial, conforme Horton (1933), decorre de eventos chuvosos que excedem a capacidade de infiltração do solo. Contudo, esse processo é considerado pouco frequente, ocorrendo especialmente em ambientes semiáridos, com solos impermeáveis, rasos e cuja capacidade de armazenamento é reduzida; ou naqueles em que a estrutura do solo foi alterada pela remoção da vegetação nativa (Selby, 2005; Brutsaert, 2005). Em outras condições, o escoamento superficial pode derivar da saturação da umidade do solo, com posterior redução na capacidade de infiltração, sendo denominado escoamento superficial por excesso de saturação (Brutsaert, 2005).

Em regiões tropicais e subtropicais, os processos hidrológicos são controlados principalmente pelas características climáticas e geomorfológicas das encostas, como afirmam Sarkar e Dutta (2015). Nas zonas ripárias esse cenário se mantém, sendo observados os mesmos mecanismos de geração de escoamento identificados ao longo da vertente (Brutsaert, 2005). Contudo, como evidenciam Rodhe e Sibert (2011) e von Freyberg et al. (2015), a acentuada umidade do solo conferida pela localização topográfica favorece respostas rápidas aos eventos de precipitação. Predominam, nesse caso, o escoamento superficial por excesso de saturação e subsuperficial (Brutsaert, 2005). Nas regiões mais elevadas da vertente, a infiltração é significativa, contribuindo para a recarga 
do aquífero e o escoamento subterrâneo, que posteriormente será convertido a escoamento de base (von Freyberg et al., 2015).

Freeze e Cherry (1979) ressaltam que o principal papel do sistema de fluxo subterrâneo regional, isto é, na escala de vertente, diz respeito ao escoamento de base. A conectividade entre as águas subterrâneas e superficiais por meio do escoamento de base intensifica as reações biogeoquímicas que influenciam a qualidade da água superficial (Jones e Mulholland, 2000). Além do aspecto qualitativo, o escoamento subterrâneo representa uma das principais contribuições para a vazão dos corpos hídricos superficiais (Castelloé et al., 2015). Em alguns casos, como afirmam Freeze e Cherry (1979) e Blumstock et al. (2015), essa parcela de escoamento consiste na única fonte de água para manutenção dos corpos hídricos durante o período de estiagem.

Para Bronstert et al. (1998), a partir da década de 1970 a hidrologia de vertentes tornou-se um ramo expoente da ciência hidrológica, com experimentos de campo acoplados ao desenvolvimento, teste e aplicação de modelos hidrológicos. Essa abordagem foi estabelecida a partir da necessidade de se estimar processos hidrológicos e compreender suas inter-relações na escala de vertente, com efeitos no planejamento ambiental e em obras de engenharia. Desse modo, até meados da década de 1990, os estudos de hidrologia de vertente foram centrados, em sua maioria, no processo de infiltração, com reflexos para análise de susceptibilidade à erosão, balanço hídrico em escala de vertente e efeitos da urbanização nas paisagens montanhosas (Bronstert et al., 1998).

Atualmente, a produção científica acerca da hidrologia de vertentes tem ressaltado o papel da conectividade hidrológica e das alterações antrópicas na geração de escoamento e transporte de solutos, com influências na escala de bacia hidrográfica. Detty e McGuire (2010), por exemplo, avaliaram a dinâmica entre águas subterrâneas e superficiais em função das características topográficas da vertente. Nesse estudo, padrões de conectividade hidrológica foram investigados numa pequena bacia hidrográfica florestada (aproximadamente $0,6 \mathrm{~km}^{2}$ ) com monitoramento da flutuação da água subterrânea rasa, ao longo da vertente, incluindo as porções côncava, inclinada e convexa (footslopebackslope-shoulder). 
Jencso et al. (2010) também analisaram a conectividade das águas subterrâneas rasas e a dinâmica de solutos entre a vertente, a zona ripária e o corpo hídrico superficial (HRS: hillslope-riparian-stream). Lopes et al. (2013) se propuseram a estudar os padrões espacial e temporal da conectividade e estimar a capacidade de transporte de sedimentos na bacia de Madalena, no Ceará, semiárido brasileiro. Bachmair e Weiler (2014) analisaram o escoamento subsuperficial ao longo da vertente e sua contribuição para a vazão, numa bacia hidrográfica da Floresta Negra, localizada na Alemanha, com monitoramento da flutuação do nível da água subterrânea e por intermédio de trincheiras para coleta do escoamento subsuperficial.

Em von Freyberg et al. (2014) a conectividade hidrológica foi estudada com atenção à variação temporal da profundidade de águas subterrâneas rasas e sua implicação na exportação de nutrientes a partir de áreas agrícolas numa bacia alpina. Von Freyberger et al. (2014) ressaltam que compreender a conectividade hidrológica entre encostas e o sistema hídrico e as vias de fluxo subterrâneo dominantes auxilia na avaliação da qualidade da água em decorrência de alterações nas classes de uso e cobertura do solo. Birkel et al. (2015), ao elaborarem um modelo conceitual para estudo do escoamento e armazenamento e da dinâmica de traçadores como estimativa da idade da água na bacia de Girnock, na Escócia, observaram a importância da conectividade hidrológica para manutenção hídrica entre eventos chuvosos, além de ressaltarem o papel das zonas ripárias na integração com o ambiente aquático.

Apesar dos avanços, as vertentes ainda são consideradas áreas críticas quanto ao conhecimento dos processos hidrológicos nela estabelecidos (Hill, 2000; Jencso et al., 2010). Entender a ocorrência e interação desses processos com os demais elementos da paisagem é importante para descrever a geração de vazão e o transporte de solutos, especialmente em ambientes alterados e degradados (Brutsaert, 2005). Além disso, a aplicação de modelos que representem a relação precipitação-escoamento na escala de vertente requer informações desse caráter (Sarkar e Dutta, 2015). Com isso, as variações temporal e espacial da água no solo é uma informação de base para estudos hidrológicos, implicando na necessidade de monitoramento da umidade e das flutuações do nível da água subterrânea na escala de vertente (McMillan e Srinivassan, 2015). 


\subsection{1 - Água no Solo}

A água que infiltra no solo pode ser analisada em três recortes. $\mathrm{O}$ primeiro considera a fração contida na zona não saturada ou zona de aeração, isto é, na região onde os vazios do solo estão parcialmente preenchidos por água e ar, acima do nível freático (Figura 3.2). A zona não saturada se subdivide em uma camada superior de umidade do solo, uma zona intermediária e uma zona de capilaridade (Cederstrom, 1964; Lima, 2008). O segundo recorte diz respeito à água que infiltra e flui lateralmente na zona não saturada, em pequenas profundidades, originando o interfluxo ou escoamento subsuperficial. Nesse caso, quando existem níveis pouco permeáveis abaixo da superfície, uma porção da água que infiltra torna-se escoamento subsuperficial e pode alcançar o leito dos cursos d'água.

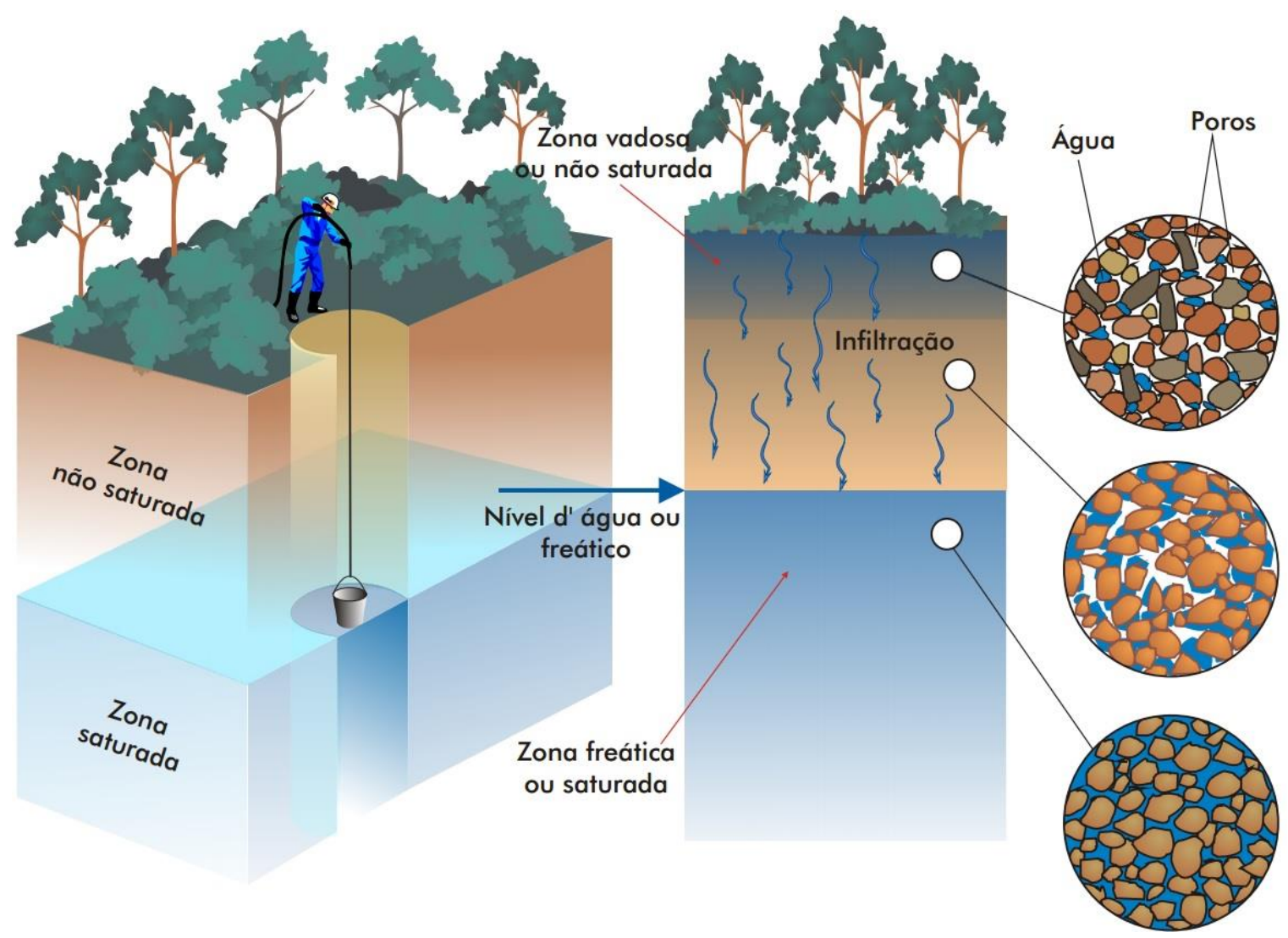

Figura 3.2 - Representação das zonas de aeração e saturação do subsolo. Fonte: Karmann (2008).

No terceiro recorte, considera-se a água que percola até o nível freático, atuando como fonte de recarga dos aquíferos. Apesar da água contida no subsolo ser considerada, em sua totalidade, água subterrânea, este conceito é usualmente aplicado à água que ocorre em formações geológicas saturadas, denominadas aquíferos (Freeze e Cherry, 1979). Os aquíferos possuem permeabilidade e porosidade que possibilitam o armazenamento e a 
transmissão de quantidades significativas de água sob gradientes hidráulicos naturais (Cleary, 1989). Desse modo, a água que circula na zona de saturação pode eventualmente alcançar os leitos dos rios, formando o escoamento de base (Cleary, 1989; Karman, 2008).

Com relação à presença ou ausência de lençol freático os aquíferos podem ser caracterizados como confinados ou não confinados (livres). O aquífero confinado, também denominado sob pressão, ocorre quando uma camada permeável encontra-se entre duas camadas pouco permeáveis (Karman, 2008). Nesse caso a pressão no topo da água é maior do que a pressão atmosférica (Manoel-Filho, 1997b). Em aquíferos livres ou não confinados não há uma camada limitante em sua porção superior (Manoel-Filho, 1997b). O limite superior do aquífero livre é constituído pela superfície freática (Manoel-Filho, 1997b; Karman, 2009). Com isso, a posição do lençol depende do regime de fluxo subterrâneo, em função da pressão atmosférica, e dos fatores topográficos, uma vez que as águas subterrâneas tendem a acompanhar as irregularidades do terreno (Manoel-Filho, 1997b; Cleary, 1989).

Os aquíferos podem ser diferenciados ainda de acordo com a porosidade do material constituinte em intergranular (poroso), de fraturas (fraturado) ou de condutos (cársticos) (Karman, 2008). Os aquíferos porosos ocorrem em rochas sedimentares, sedimentos e solos arenosos, descompostos in situ. Aquíferos fraturados ou fissurais são identificados em rochas ígneas e metamórficas, cuja capacidade de armazenamento relaciona-se à quantidade de fraturas, aberturas e intercomunicações existentes (Manoel-Filho, 1997b). Os aquíferos cársticos, por sua vez, compõem um tipo peculiar de aquífero fraturado, onde rochas carbonatadas são dissolvidas, formando condutos preferenciais ao armazenamento de água subterrânea (Karman, 2009).

\subsubsection{1 - Potencial e Conteúdo de Água no Solo}

O estado de energia da água no solo, em uma determinada posição do seu perfil, é determinado em comparação com o da água pura com temperatura e pressão normais, sem influência do contato com o solo, e localizada a certa altura de referência (Brady e Weil, 2013). A diferença dos níveis de energia dessa água livre e da água do solo é denominada potencial ou pressão da água do solo (Brady e Weil, 2013). Por ser uma medida de energia, o potencial é expresso nas mesmas unidades $\left[M L^{2} T^{2}\right]$, podendo ainda ser dimensionado 
como potencial por unidade de volume $\left[M L^{-1} T^{-2}\right]$, potencial por unidade de massa $\left[L^{-2} T^{-2}\right]$ ou potencial por unidade de peso, também denominado carga $[L]$.

Como afirmam Yeh e Guzman-Guzman (2000) e Brady e Weil (2013), o potencial da água do solo é influenciado por diferentes componentes que resultam no potencial total da água do solo $\left(h_{T}\right)$. Esses componentes são representados especialmente pela atuação dos potenciais gravitacional $\left(h_{g}\right)$, matricial $\left(h_{m}\right)$, hidrostático $\left(h_{h}\right)$ e osmótico $\left(h_{O}\right)$ (Equação (3.1)).

$$
h_{T}=h_{g}+h_{m}+h_{h}+h_{O}
$$

O potencial osmótico relaciona-se com a concentração de solutos orgânicos e inorgânicos no solo, sendo inversamente proporcional a tal concentração em decorrência da interferência de íons e moléculas de soluto na circulação da água (Brady e Weil, 2013). De modo geral, o potencial osmótico não afeta significativamente o movimento da água no solo, podendo ser ignorado (Yeh e Guzman-Guzman, 2000). O potencial gravitacional, por sua vez, resulta da atração da força gravitacional do centro da Terra na massa do fluido, sendo equivale ao produto entre a aceleração da gravidade e a altura da água no solo $(z)$ em relação a um plano de referência (Brady e Weil, 2013).

Além da gravidade e da concentração de solutos, os efeitos do potencial da água do solo decorrem do potencial de pressão $(\psi)$ que, na maioria das vezes, inclui as componentes matricial $\left(h_{m}\right)$ negativa, devido às forças de atração entre a água e a matriz do solo na zona não saturada, e hidrostática $\left(h_{h}\right)$ positiva, oriunda do peso da água em solos saturados (Brady e Weil, 2013). O sinal negativo do potencial matricial é determinado pelo fato da água atraída na matriz do solo apresentar estado de energia menor do que o da água livre, como resultado de forças adesivas e capilares que influenciam tanto a retenção quanto o movimento da água no solo. Com isso, em solos situados na mesma elevação (sob mesmo potencial gravitacional), porém com diferentes potenciais matriciais, o movimento da água ocorrerá a partir da área úmida (estado de alta energia) para área seca (baixa energia), ou dos poros grandes para poros pequenos (Yeh e Guzman-Guzman, 2000). 
De acordo com Yeh e Guzman-Guzman (2000), diferentes termos são adotados como sinônimo do potencial de pressão, tais como tensão ou sucção. Para solos parcialmente saturados é assumido como negativo, no entanto a tensão ou sucção são expressas com valores positivos (Brady e Weil, 2013). Por fim, negligenciando a fração de potencial osmótico e adotando o potencial de pressão em substituição às pressões matricial e hidrostática, o potencial total da água do solo é definido pela Equação (3.2) como resultado da atuação dos potenciais de elevação $(z)$ e de pressão $(\psi)$ (Brady e Weil, 2013).

$$
h_{T}=z+\psi
$$

Além do estado de energia, a umidade do solo $(\theta)$ também é um fator importante a se considerar em estudos hidrológicos (Brady e Weil, 2013). Os conceitos umidade, teor e conteúdo de água são sinônimos que definem a fração de água no solo em termos de volume ou massa. A umidade volumétrica $\left(\theta_{v}\right)$ é conhecida como o volume de água associado a determinado volume de solo seco. De modo semelhante, a umidade em massa, ou gravimétrica $\left(\theta_{g}\right)$, associa-se a massa de água presente em dada massa de solo seco. É importante considerar que a umidade $(\theta)$ e o potencial de pressão $(\psi)$ do solo mantêm uma relação inversa representada pela curva característica de retenção de água no solo (Brady e Weil, 2013).

\subsubsection{2 - Monitoramento da Água no Solo}

Freeze e Cherry (1979) afirmam que o entendimento dos processos de infiltração e recarga requerem observações em campo, com monitoramento da umidade do solo na zona não saturada e das flutuações no nível da água subterrânea, associado à obtenção de dados de carga hidráulica. Para determinação do teor de umidade do solo $(\theta)$, além da aplicação do método gravimétrico em laboratório, métodos indiretos são comumente empregados, com destaque para as sondas de nêutrons e de reflectometria no domínio do tempo (Time Domain Reflectometry - TDR), tensiômetros e blocos de resistência elétrica (Andrade et al., 1998). Estes dois últimos não fornecem informação direta do teor de umidade, mas sim do potencial de pressão da água do solo $(\psi)$. 
Por meio do método gravimétrico o conteúdo de umidade $\left(\theta_{g}\right)$ é obtido como a diferença entre as massas seca $\left(M_{s}\right)$ e úmida $\left(M_{u}\right)$ do solo, como observado na Equação (3.3), cujo resultado é expresso em percentagem. O processo de secagem das amostras é realizado em estufa com temperatura entre 60 e $110^{\circ} \mathrm{C}$ e tempo de secagem entre 24 e 48 horas, ou até que se obtenha massa constante nas amostras secas (Donagema et al., 2011). De acordo com Matthews (2010), apesar da perda de compostos orgânicos voláteis, temperaturas de secagem em torno de $105^{\circ} \mathrm{C}$ são recomendadas quando comparadas a temperaturas menores $\left(60,80\right.$ e $\left.100^{\circ} \mathrm{C}\right)$, considerando o mesmo intervalo de tempo para secagem. Essa afirmação baseia-se no fato de que, em seu experimento, a variação de umidade do ambiente apresentou efeito reduzido em relação às amostras de solo quando da utilização de temperaturas de secagem elevadas.

$$
\theta_{g}=\frac{M_{u}-M_{s}}{M_{s}} \times 100
$$

Esse método é amplamente utilizado por fornecer medição direta da umidade, necessária para a calibração dos métodos indiretos aplicados para a mesma finalidade (Johnson, 1992). Schunk et al. (2016) utilizaram sensores de permissividade e de resistividade elétrica em comparação com dados de umidade gravimétrica, para monitoramento de umidade na serapilheira numa floresta temperada da Alemanha, como indicativo do risco de incêndio. Foram obtidos coeficientes de correlação de Spearman satisfatórios para todos os sensores (acima de 0,70), especialmente para aqueles com medição da permissividade, quando comparados ao método gravimétrico. A variação significativa dos resultados obtidos pelos diferentes sensores, nas condições de elevada umidade, reforçou a necessidade de calibração dos métodos automáticos utilizando dados de gravimetria (Schunk et al., 2016).

A aplicação do método gravimétrico tem como desvantagens o esforço requerido para obtenção dos dados e o tempo exigido desde a coleta até a secagem das amostras de solo (Johnson, 1992). Com isso, métodos indiretos considerados não destrutivos e com aquisição de dados automatizada por maior período de tempo são utilizados para aferir a umidade do solo. Dentre os métodos indiretos, é sabido que o funcionamento das sondas de nêutrons depende do processo de moderação ou retardo de nêutrons rápidos, emitidos por 
fontes radioativas (Amerício e Berilo), a partir da colisão com átomos circundantes (Andrade et al., 1998; Kramer et al., 2000). Com a redução da velocidade após as colisões, os nêutrons, agora denominados termalizados, difundem-se no espaço atômico como partículas gasosas até que sejam absorvidos ou capturados por átomos receptivos.

A captura dos nêutrons emite um pulso de energia detectável pela sonda de nêutrons (Kramer et al., 2000). No processo de moderação de nêutrons predominam as colisões com átomos de hidrogênio. Isso ocorre porque a colisão de nêutrons rápidos com átomos pesados ocasiona perda de velocidade pequena, enquanto que a colisão com átomos de hidrogênio (de massa equivalente) resulta em desaceleração apreciável dos nêutrons. Sendo assim, maior densidade de hidrogênio permite que a moderação de nêutrons seja elevada. Como a água é quase sempre a maior fonte de hidrogênio no solo, quando este é umedecido, a densidade de nêutrons termalizados próximo à fonte de radiação se eleva (Kramer et al., 2000). Além do hidrogênio, cloro e boro são elementos com concentração elevada, especialmente nos solos com acúmulo de sal, e podem capturar nêutrons, reduzindo significativamente o efeito da contabilização pela sonda (Kramer et al., 2000).

As sondas de nêutrons utilizadas na determinação da umidade do solo expressam a quantidade de água por unidade de volume como uma medida diretamente proporcional à densidade de hidrogênio nas proximidades da fonte de radiação (Kramer et al., 2000). Para obtenção do percentual de umidade torna-se necessário determinar a densidade do solo seco (Johnson, 1992). Mesmo fornecendo medidas precisas, as sondas de nêutrons têm sido preteridas em decorrência dos riscos oriundos da utilização de fontes radioativas (Andrade et al., 1998). Pelo mesmo motivo, a utilização de equipamentos com esse princípio de funcionamento requer autorização, como afirmam Brady e Weil (2013).

Com relação à técnica de reflectometria no domínio do tempo (TDR), dentre outros métodos dielétricos, o parâmetro de interesse é a constante dielétrica $(\varepsilon)$, também denominada permissividade (White e Zegelin, 2000). Essa propriedade caracteriza a resposta de um determinado material quando submetido a um campo eletromagnético polarizado. Conhecendo-se o tempo $(t)$ de propagação das ondas eletromagnéticas, com frequência entre $1 \mathrm{MHz}$ a $1 \mathrm{GHz}$ e velocidade de $3,0 \times 10^{8} \mathrm{~ms}^{-1}(\mathrm{c})$, ao longo de uma haste metálica de comprimento conhecido $(L)$ inserida no solo, é possível estimar a permissividade do meio (Equação (3.4)) (White e Zegelin, 2000; Kaiser et al., 2010). 
Como a permissividade da água é cerca de $200 \%$ maior que a do solo e do ar $(81,4$, e 1 , respectivamente) a presença de umidade no solo altera sensivelmente sua permissividade, possibilitando que a referida grandeza possa ser utilizada como medida indireta do teor de umidade (White e Zegelin, 2000).

$$
\varepsilon=\left(\frac{c t}{2 L}\right)^{2}
$$

Equipamentos para medição de umidade do solo com princípio de funcionamento TDR são compostos basicamente por um gerador de impulsos de voltagem rápida e um analisador de sinais conectado a uma interface de leitura (White e Zegelin, 2000). Além de não apresentar riscos à saúde do operador, ao contrário da sonda de nêutrons, sondas TDR são altamente sensíveis às variações de umidade. Como afirmam Reeves e Smith (1992) a principal vantagem dessa técnica consiste na rápida obtenção de medidas da umidade volumétrica $\left(\theta_{v}\right)$. Nesse caso, o conteúdo de água pode ser correlacionado com a permissividade por meio da função empírica proposta por Topp et al. (1980), que independe de características pedológicas tais como densidade, temperatura do solo e conteúdo de sais em solução (Equação (3.5) (Menziani et al., 1996; Michot et al., 2003).

$$
\theta_{v}=-5,3 \times 10^{-2}+2,92 \times 10^{-2} \varepsilon-5,5 \times 10^{-4} \varepsilon^{2}+4,3 \times 10^{-6} \varepsilon^{3}
$$

White e Zegelin (2000) recomendam a elaboração de curva de calibração relacionando umidade gravimétrica e permissividade, contudo Reeves e Smith (1992) afirmam que a calibração é necessária apenas para solos arenosos ou salinos. Porém, a operação das sondas $T D R$ é restrita à propagação do sinal eletromagnético transverso (TEM), limitando a atuação em amostras de solo com cerca de $20 \mathrm{~cm}$ de diâmetro (White e Zegelin, 2000). Ainda com relação à sonda, vale ressaltar que diâmetros maiores podem ocasionar perturbação na estrutura do solo a ser aferido, enquanto que a utilização de equipamentos com diâmetros menores implica em redução na sensibilidade do volume a ser monitorado (White e Zegelin, 2000). Além disso, sondas TDR apresentam custo de aquisição relativamente elevado quando comparado aos de equipamentos tais como as sondas de nêutrons (Brady e Weil, 2013). 
Além dos métodos anteriormente descritos para determinação da umidade, o potencial da água no solo também pode ser mensurado utilizando, por exemplo, tensiômetros e blocos de resistência elétrica e então correlacionado à umidade. Sabendo-se que a água é atraída pelas partículas do solo em função do seu potencial matricial, os tensiômetros são instrumentos destinados à mensuração dessa força (Yeh e Guzman-Guzman, 2000). São constituídos por um tubo preenchido com água, fechado na sua extremidade inferior com uma cápsula porosa de cerâmica e hermeticamente selado na extremidade superior. Quando instalados, considerando que o potencial de água no solo é baixo, a água contida no tubo se desloca para fora da cápsula, buscando equilíbrio (Yeh e Guzman-Guzman, 2000). Como o tensiômetro é vedado, o fluxo de saída da água reduz a pressão no interior do equipamento, desenvolvendo um vácuo em relação à pressão atmosférica inicial que pode ser medido por um vacuômetro (Yeh e Guzman-Guzman, 2000).

Desse modo, a redução do potencial da água no tensiômetro é igual à soma da pressão devido à coluna de água acima da cápsula porosa e o potencial matricial da água do solo. $\mathrm{O}$ potencial matricial, ou a tensão de água no solo, será representado pela subtração da coluna de água na leitura do tensiômetro. Determinar o potencial matricial do solo é, então, registrar a redução da pressão (vácuo) no interior do tensiômetro, normalmente por meio de um manômetro (Yeh e Guzman-Guzman, 2000). Diferentes equipamentos mensuram o potencial matricial no solo; contudo, para uma faixa de tensão entre 0 e $8 \mathrm{~m}$, os tensiômetros são mais indicados (Yeh e Guzman-Guzman, 2000). Segundo Caicedo (2004), as principais limitações desse método são relacionadas ao intervalo de leitura das pressões, restrito a valores menores que uma atmosfera e ao tempo de resposta, uma vez que o registro da pressão de equilíbrio pode ser demorado.

Os blocos de resistência elétrica também são sensores utilizados na determinação da tensão da água no solo, sendo constituídos de eletrodos envolvidos em um bloco poroso de gesso, náilon ou fibra de vidro (Brady e Weil, 2013). Funcionam conforme o princípio da resistência à passagem de uma corrente em função do teor de umidade presente no solo. Quando inserido no solo úmido, o bloco poroso absorve água em uma quantidade proporcional à do potencial da água do solo, e a resistência elétrica entre os eletrodos diminui proporcionalmente. O equilíbrio entre o conteúdo de água do solo e do bloco, bem como as oscilações na resistência em função das alterações no conteúdo de água, indicam 
que os blocos respondem ao potencial de pressão do solo e não ao seu conteúdo de água (White e Zegelin, 2000).

No caso dos blocos de gesso, desenvolvidos por Bouyoucos e Mick (1940), o contato entre o equipamento e o solo é uniforme, pois o material poroso tende a permanecer em equilíbrio com o conteúdo de umidade do meio. Suas vantagens residem no preço, facilidade de instalação e operação, sendo atrativos para o uso na irrigação (White e Zegelin, 2000). Contudo, não são recomendados para solos arenosos devido ao fato de a textura grosseira da areia interferir na interação com o meio (Johnson, 1992). Em casos de incremento na salinidade do solo, promovendo o aumento na condutividade elétrica, leituras errôneas da resistência também poderão ser registradas. Outra desvantagem da utilização dos blocos de gesso é atribuída à solubilidade do material, ocasionando deterioração do gesso no solo (Hillel, 1998). Além disso, assim como os tensiômetros, os blocos também são afetados pela histerese, isto é, pelo sentido no qual se dá a variação da umidade do solo, seja aumentando ou diminuindo (Hillel, 1998).

Com relação à zona saturada, flutuações do nível da água são monitoradas por meio de piezômetros e poços de observação como alternativa importante para obtenção de dados em estudos (Freeze e Cherry, 1979). Dados de nível da água subterrânea permitem estimar carga e condutividade hidráulica e capacidade de armazenamento nos aquíferos (RabeloCoelho et al., 2012; Alo-Aho et al., 2015). Estudos voltados à estimativa da variação temporal e espacial da recarga, tais como os realizados por Rabelo-Coelho et al. (2012), na bacia representativa do rio Gramame no nordeste brasileiro, e Alo-Aho et al. (2015), no aquífero Rokua Esker no norte da Finlândia, fazem uso do método de flutuação do nível freático considerando observações diretas realizadas em poços freáticos.

Métodos geofísicos também podem ser aplicados ao monitoramento da água no solo, permitindo a determinação indireta da natureza de estruturas subsuperficiais, considerando medições periódicas dos parâmetros de interesse, tanto na superfície terrestre como por meio de poços (Neves e Luiz, 2015). Dentre os métodos geofísicos, o método elétrico de corrente contínua, que tem como parâmetro de interesse a resistividade elétrica, é o mais comumente utilizado em estudos de umidade do solo e identificação do nível da água subterrânea (Fetter, 1994; Singha et al., 2015), representando uma alternativa barata, não 
invasiva e simples de monitoramento geoelétrico da subsuperfície rasa (Loke, 2000; Ren e Tang, 2014; Yeboah-Forson et al., 2014).

Por meio da Lei de Archie, enunciada em 1942, é possível correlacionar a resistividade elétrica do solo ao conteúdo de água, sendo válida apenas para rochas e solos saturados e que não contenham argila (Equação (3.6)) (Keller e Frischknecht, 1977). Nessa equação, $\rho$ representa a resistividade elétrica da rocha ou solo, $\rho_{w}$ a resistividade elétrica da água intersticial e $\varphi$ a porosidade da rocha ou solo [\%]. Os coeficientes empíricos $n$ e $q$ também são considerados, sendo indicada a adoção de valor menor que um para rochas com porosidade intergranular ou maior que um para rochas com porosidade fissural; e maior que dois para sedimentos pouco porosos e com granulometria homogênea ou menor que dois para sedimentos porosos e com heterogeneidade de granulometrias, respectivamente (Keller e Frischknecht, 1977).

$$
\rho=\frac{n \times \rho_{w}}{\varphi^{q}}
$$

Em rochas e solos parcialmente saturados com água, a Lei de Archie adquire a forma apresentada na Equação (3.7), em que $S$ representa o grau de saturação do solo [\%] e $p$ é um coeficiente empírico para o qual usualmente se atribui o valor igual a dois (Mazac et $a l .$, 1987). No que diz respeito à determinação indireta do teor de umidade do solo com base nos dados de resistividade elétrica, tem sido avaliada ainda a aplicação de funções de pedotransferência, a exemplo de Brillante et al. (2014). Sabendo-se que a relação proposta pela Lei de Archie é sensível às variações no teor de argila e à saturação do solo, as funções de pedotransferência, ao considerarem outras propriedades do solo, tais como textura, conteúdo de cascalho e volume de água, podem aperfeiçoar a correlação entre as medidas de resistividade elétrica e o teor de umidade do solo (Brillante et al., 2014).

$$
\rho=\frac{n \times \rho_{w}}{\varphi^{q} \times S^{p}}
$$




\subsection{2 - Fluxo de Água no Solo}

A água flui no solo em decorrência da variação de energia buscando equilíbrio energético (Fetter, 1994; Mousinho, 2012). Na zona saturada, a equação diferencial que descreve o movimento da água subterrânea é obtida pela combinação da equação de Darcy com a equação da continuidade (Caicedo, 2004). De acordo com Lima (2010), a experiência de Darcy (1856) foi a primeira a possibilitar a quantificação da densidade de fluxo em meio poroso saturado. Darcy demostrou que o fluxo de água em tubos capilares preenchidos com areia variava diretamente com o gradiente hidráulico (Cederstrom, 1964). A partir dessa demonstração foi formulada a Lei de Darcy (Equação (3.11)).

$$
Q=K A \frac{\left(h_{1}-h_{2}\right)}{L}
$$

em que:

$K$ - condutividade hidráulica $\left[L T^{l}\right]$

$Q-$ Vazão $\left[L^{3} T^{-1}\right]$

$A-$ Área $\left[L^{2}\right]$

$h$ - Carga hidráulica $[L]$

$L$ - Comprimento da seção $[L]$

$\frac{\left(h_{1}-h_{2}\right)}{L}-$ Gradiente hidráulico $[L]$

A velocidade de Darcy (q), também conhecida como velocidade aparente ou descarga específica, é uma medida da vazão por unidade de área $\left[L T^{-1}\right]$ (Cabral, 1997) (Equação (3.9)). Diferindo-se do conceito tradicional, a velocidade de Darcy representa volume escoado por unidade de área total (grãos e vazios), por unidade de tempo (Caicedo, 2004).

$$
q=\frac{Q}{A}=K \frac{\Delta h}{L}
$$

Essa não condiz com a velocidade real do fluxo, uma vez que a seção considerada representa a área total $(A)$ do aquífero, incluindo espaços vazios e preenchidos. Contudo, a 
área do escoamento é menor que a área do aquífero e pode ser obtida multiplicando-se a área total pela porosidade efetiva do solo $\left(\varphi_{e f}\right)$ (Equação (3.10)).

$$
A_{\text {POROS }}=\varphi_{\text {ef }} \times A_{\text {TOTAL }}
$$

A velocidade linear média ou velocidade verdadeira de percolação (v) para o escoamento entre os poros é então descrita conforme a Equação (3.11).

$$
v=\frac{Q}{\varphi_{e f} A}
$$

A Lei de Darcy contida na Equação (3.9) aplica-se ao escoamento unidimensional, não podendo ser generalizada para o escoamento em mais de uma direção, como ocorre com o fluxo de água subterrânea nos aquíferos. Nesse caso, a Lei de Darcy é reescrita no formato da Equação (3.12).

$$
q=-K \frac{\partial h}{\partial x}
$$

Aplicando o Princípio da Conservação de Massa e a Lei de Darcy a um volume elementar representativo de um aquífero, pode-se realizar a derivada da Equação (3.13), como uma equação diferencial parcial tridimensional, heterogênea, anisotrópica e de estado não estacionário, para a distribuição da carga hidráulica, conforme Cleary (1989).

$$
\frac{\partial}{\partial y}\left(K_{x x} \frac{\partial h}{\partial x}\right)+\frac{\partial}{\partial y}\left(K_{y y} \frac{\partial h}{\partial y}\right)+\frac{\partial}{\partial z}\left(K_{z z} \frac{\partial h}{\partial z}\right)+w(x, y, z, t)=S_{s} \frac{\partial h}{\partial t}
$$

Nesse caso, $h$ representa a carga hidráulica; $K_{x x}, K_{y y}$ e $K_{z z}$ são os principais componentes do tensor da condutividade hidráulica; $S_{S}$ diz respeito ao coeficiente de armazenamento específico $\left[L^{-1}\right]$; enquanto que $w$ representa as fontes ou sumidouros de água no aquífero, tais como poços ou drenos (Cleary, 1989). Quando aplicada a aquíferos livres, com recarga oriunda da drenagem dos poros, a mudança no armazenamento pode ser calculada pelo 
volume do cone de depressão multiplicado pela capacidade de armazenamento específico $\left(S_{y}\right)$. Por apresentarem contorno móvel, em aquíferos freáticos é necessário utilizar aproximações de Dupui-Forchheimer (1863) e a equação não linear de Boussinesq (Equação (3.14)) (Cleary, 1989).

$$
\frac{\partial}{\partial x}\left(K_{x} h \frac{\partial h}{\partial x}\right)+\frac{\partial}{\partial y}\left(K_{y} h \frac{\partial h}{\partial y}\right)+w(x, y, z, t)=S_{y} \frac{\partial h}{\partial t}
$$

Quanto ao fluxo de água na zona não saturada, Buckingham (1907) é considerado pioneiro na aplicação dos princípios de Darcy. A extensão da Lei de Darcy para solos não saturados exige que sejam redefinidas a condutividade $(K)$ e a carga hidráulica $(h)$. No que diz respeito à condutividade, deve-se considerar que esta varia com o teor de umidade do solo, tendo como limite superior a condutividade hidráulica saturada. A carga, como sinônimo do potencial total da água do solo, passa a ser compreendida em função dos potenciais de pressão $(\psi)$ e de elevação $(z)$ (Caicedo, 2004).

No ano de 1921, Gardner e Widtsoe (1921) formularam as bases teóricas para descrição do fluxo de água em meio poroso não saturado por meio da Lei de Darcy-Buckingham. Posteriormente, utilizando os princípios da Continuidade e da Conservação de Massa, Richards (1931) demonstrou a equação geral do movimento da água em meio poroso não saturado (Equação (3.15)). Considerando-se um meio poroso anisotrópico, heterogêneo e compressível, em duas dimensões ( $x$ e $y$ ), com a direção dos componentes principais do tensor de condutividade hidráulica paralela ao eixo ortogonal de coordenadas $(z)$, tem-se:

$$
\frac{\partial}{\partial x}\left[K_{x}(\psi)\left(\frac{\partial \psi}{\partial x}\right)\right]+\frac{\partial}{\partial z}\left[K_{z}(\psi)\left(\frac{\partial \psi}{\partial z}+1\right)\right]=\eta \frac{\partial \psi}{\partial t}
$$

sendo:

$K_{x}$ e $K_{z}$ - Condutividade hidráulica do solo nas direções $x$ e $z\left[L T^{-1} ;\right]$;

$\psi$ - Potencial de pressão da água do solo $[L]$;

$t$ - Tempo [T];

$\eta=\frac{\theta v}{\varphi} S_{S}+\frac{\partial \theta v}{\partial \psi}-$ Capacidade de água no solo $\left[L^{-1}\right] ;$ 
$\theta_{v}$ - Umidade volumétrica $\left[L^{3} L^{-3}\right]$;

$\varphi$ - Porosidade [adimensional];

$S_{S}-$ Coeficiente de armazenamento específico $\left[L^{-1}\right]$.

Desde a formulação apresentada por Richards (1931), uma série de técnicas utilizando os métodos de elementos e de diferenças finitas tem sido empregada visando solucionar a equação de Richards, nas formas " $\psi$-based" e " $\theta$-based", tendo como variáveis dependentes a carga de pressão $(\psi)$ devido ao potencial matricial e o conteúdo de umidade do solo $(\theta)$, respectivamente (Bear e Cheng, 2010). A resolução da equação de Richards requer ainda relações constitutivas tais como entre $\theta$ e $\psi$ (curva de retenção da água) e $K$ e $\theta$, que podem ser representadas, entre outras, pelas Equações (3.16) (van Genuchten, 1980) e (3.17) (Mualem, 1976).

$$
\theta=\theta_{r}+\left(\theta_{s}-\theta_{r}\right)\left[\frac{1}{1+(-\alpha \psi)^{n}}\right]^{m}
$$

para:

$\psi \leq 0$

$m=1-\frac{1}{n}$

$$
K(\theta)=K_{s}\left(\frac{\theta-\theta_{r}}{\theta_{s}-\theta_{r}}\right)^{\frac{1}{2}}\left[1-\left(1-\left(\frac{\theta-\theta_{r}}{\theta_{s}-\theta_{r}}\right)^{\frac{1}{m}}\right)^{m}\right]^{2}
$$

Nesse caso, deve-se considerar a umidade volumétrica do solo saturado $(\theta s)$, a umidade volumétrica residual $(\theta r)$, a condutividade hidráulica saturada $(K s)$ e os parâmetros determinados em função das características do solo $(\alpha, m e n)$.

\subsection{3 - Relação entre Águas Superficiais e Subterrâneas}

A abordagem integrada dos recursos hídricos superficiais e subterrâneos se destacou nas duas últimas décadas em função, especialmente, das questões relacionadas à gestão 
sustentável dos recursos hídricos e dos ecossistemas a eles associados (Fleckenstein et al., 2010). As águas subterrâneas e superficiais não são recursos independentes, havendo relação, por exemplo, entre o nível freático dos aquíferos e o nível da água nos mananciais superficiais (Manoel-Filho, 1997; Hirata, 2008). Considerando-se que um dado corpo hídrico com seção transversal retangular intercepta um aquífero de extensão infinita com propriedades hidrogeológicas uniformes e constantes no tempo, tem-se que o fundo do canal é completamente penetrante e coincide com o "fundo" do aquífero (Caicedo, 2004).

A conexão entre os recursos hídricos subterrâneos e superficiais ocorre por intermédio da zona hiporreica, no leito dos mananciais que se sobrepõem a sedimentos permeáveis (Harvey et al., 2000; Jones e Mulholland, 2000; Boano et al., 2014). Para Maksoud (1961), nessa interface se estabelecem as percolações efluente e influente. O processo de influência diminui a vazão do rio a jusante, com infiltração da água para o aquífero. Nesse caso, o lençol freático encontra-se abaixo do nível da água superficial (Boano et al., 2014). No processo de percolação efluente a água dos aquíferos é transferida para os corpos hídricos, por meio do escoamento de base. Nessa situação a carga hidráulica do aquífero encontra-se elevada e, em função do gradiente hidráulico, as águas subterrâneas escoam para os corpos hídricos superficiais (Boano et al., 2014).

Embora pareça óbvio que a água subterrânea, quando presente em uma região, deva ser manejada em conjunto com a água superficial, ainda pode-se observar relutância na inclusão das discussões relacionadas à água subterrânea na pauta de planejamento e gestão de recursos hídricos (Manoel-Filho, 1997; Fleckenstein et al., 2010). O manejo dissociado dos recursos hídricos tem sido justificado pelo custo envolvido na exploração das águas subterrâneas, pela dificuldade de prever a resposta dos aquíferos frente às propostas de gestão e pelo propósito de uso individual atribuído a esse recurso em contrapartida aos usos múltiplos apresentados pelos recursos hídricos superficiais (Bear e Cheng, 2010).

Contudo, Bear e Cheng (2010) salientam que a comparação entre os custos anuais com investimentos nos projetos de engenharia voltados ao armazenamento e distribuição da água superficial podem superar aqueles voltados à explotação das águas subterrâneas. Verifica-se ainda que o conhecimento acerca do comportamento hidrológico subterrâneo tem sido ampliado gradativamente com desenvolvimento de ferramentas capazes de 
representar o comportamento de um sistema de águas subterrâneas em conjunto com as águas superficiais, tais como os modelos hidrológicos (Bear e Cheng, 2010).

A exploração das águas subterrâneas como solução para usos consuntivos não deve ser desvinculada dos recursos hídricos superficiais e, além disso, requer diretrizes voltadas a manutenção da floresta ripária que margeia os corpos hídricos (ANA, 2010). Desse modo, a necessidade de gestão integrada entre os recursos hídricos superficiais e subterrâneos, como previsto na Resolução $\mathrm{n}^{\circ} 15$ do Conselho Nacional de Recursos Hídricos (CNRH, 2001), torna-se evidente quando considerada a influência da água subterrânea nos corpos hídricos por meio do fluxo de base e sua contribuição para a qualidade da água, bem como para a manutenção ecológica dos ecossistemas de interface terrestre e aquático.

\subsubsection{1 - Determinação do Escoamento de Base}

O hidrograma de vazão de uma bacia hidrográfica reflete a contribuição da precipitação para os corpos hídricos superficiais. A região de pico representa o escoamento superficial e subsuperficial como resposta rápida ao evento de precipitação. O ponto de recessão, por sua vez, é caracterizado pela finalização do escoamento superficial e predomínio do escoamento de base, como resposta em longo prazo às mudanças no fluxo subterrâneo regional (Freeze e Cherry, 1979). A contribuição dominante no hidrograma dos corpos hídricos de baixa ordem durante períodos de estiagem deve-se ao escoamento de base (Bugan et al., 2012).

Desse modo, a separação do escoamento de base está relacionada à análise da curva de recessão do hidrograma, caracterizada, em geral, por um decaimento exponencial considerando um reservatório linear cuja descarga é proporcional ao armazenamento (Equação (3.18)). Nesse caso, tem-se que $Q_{t}$ equivale à vazão no tempo $t, Q_{0}$ indica a vazão no início da recessão e $\alpha$ é um coeficiente de recessão.

$$
Q_{t}=Q_{0} e^{-\alpha t}
$$

A interconexão existente entre os sistemas hídricos subterrâneos e superficiais, com contínua interação, segundo Costa e Bacellar (2010), possibilita investigar processos 
hidrológicos subterrâneos a partir de informações hídricas superficiais com métodos indiretos de caracterização hidrogeológica, como por meio da análise do hidrograma (Costa e Bacellar, 2010). Segundo Aksoy et al. (2009), a separação do hidrograma em escoamento de base e escoamento direto tem sido considerada satisfatória para o manejo dos recursos hídricos. Além do método de análise da conformação do hidrograma, Cartwright et al. (2014) enfatizam a utilização de traçadores e filtros automáticos, também denominados filtros matemáticos ou filtros recursivos digitais, como alternativas de determinação do escoamento de base.

A utilização de traçadores se baseia no pressuposto de que diferentes contribuições para a vazão têm assinaturas químicas e isotópicas distintas e invariantes, que podem ser identificadas separadamente. Blumstock et al. (2015), ao estudarem a dinâmica espacial e temporal da assinatura isotópica do escoamento de base por meio de traçadores, identificaram padrões para compreensão da contribuição das águas subterrâneas para os corpos hídricos superficiais. Castelloé et al. (2015) associaram traçadores ao filtro automático desenvolvido por Eckhardt (2005) (Equação (3.19)), identificando resultados considerados adequados para eventos extremos de escoamento de base.

O filtro matemático desenvolvido por Eckhardt (2005) é utilizado na determinação do escoamento de base $(b t)$ a partir dos dados de vazão do corpo hídrico e de dois parâmetros de calibração ( $\alpha$ e $B F I_{\max }$ ). Neste caso, $\alpha$ representa uma constante de recessão da vazão, enquanto que $B F I_{\max }$ diz respeito ao valor máximo do índice de escoamento de base, definido pela razão entre o escoamento de base e a vazão total (Eckhardt, 2005).

$$
\mathrm{b}_{\mathrm{t}}=\frac{\left(1-\mathrm{BFI}_{\max }\right) \alpha \mathrm{b}_{\mathrm{t}-1}+\left(1-\alpha^{\prime \prime}\right) \mathrm{BFI}_{\max } \mathrm{Q}}{1-\alpha \mathrm{BFI}_{\max }}
$$

Outro exemplo de filtro automático de base física foi proposto por Arnold e Allen (1999), sendo, inclusive, utilizado como referência para o trabalho desenvolvido por Eckhardt (2005). Nesse caso, estima-se o escoamento direto $q_{t}$ no intervalo de tempo $t$, por meio da vazão total $Q$, utilizando o parâmetro de suavização do ajuste $\beta$, que pode variar entre 0 e 1 (Figura (3.20)). Com isso, o escoamento de base $\left(b_{t}\right)$ é definido pela diferença entre o escoamento direto $q_{t}$ e a vazão total $Q$, conforme Equação (3.21) (Arnold e Allen, 1999). 


$$
\begin{gathered}
q_{t}=\frac{\left(\beta q_{t-1}\right)+(1+\beta)}{2\left(Q_{t}-Q_{t-1}\right)} \\
b_{t}=Q-q_{t}
\end{gathered}
$$

A validação dos dados de escoamento de base obtidos com o filtro de Arnold e Allen (1999), utilizando valores estimados em campo, demonstrou uma correlação significativa, com coeficiente de determinação igual a 0,86 (Arnold e Allen, 1999). Luo et al. (2012) compararam os resultados do escoamento de base obtidos pela ferramenta SWAT (Soil and Water Assessment Tool) às estimativas oriundas do filtro digital proposto por Arnold e Allen (1999), identificando valores de escoamento mais elevados quando determinados via filtro automático (58\% de escoamento de base, definido a partir do filtro automático, em comparação ao valor de $42 \%$ identificado no modelo). Contudo, a diferença não foi considerada significativa e deveu-se especialmente ao fato do armazenamento do aquífero raso simulado ter sido considerado esgotado durante o período inicial de simulação.

\section{2 - GEOFÍSICA APLICADA}

\subsection{1 - Método Elétrico de Corrente Contínua}

Os métodos geofísicos são utilizados para determinação indireta da natureza de estruturas subsuperficiais (Fetter, 1994). Fundamentam-se na detecção de alterações temporais e/ou espaciais nos parâmetros físicos da Terra em decorrência de fenômenos naturais (métodos passivos ou naturais) ou induzidas por fontes artificiais (métodos ativos ou artificiais) (Telford et al., 1990; Reynolds, 1997). De acordo com o parâmetro estudado, os métodos geofísicos podem ser classificados em quatro grandes categorias: potenciais, sísmicos, geoelétricos e geotérmicos (Telford et al., 1990). O método geofísico mais empregado em investigações relacionadas à água no solo baseia-se em medições da resistividade elétrica da subsuperfície, sendo denominado método da eletrorresistividade ou método elétrico de corrente contínua (Telford et al., 1990) (Figura 3.3). 


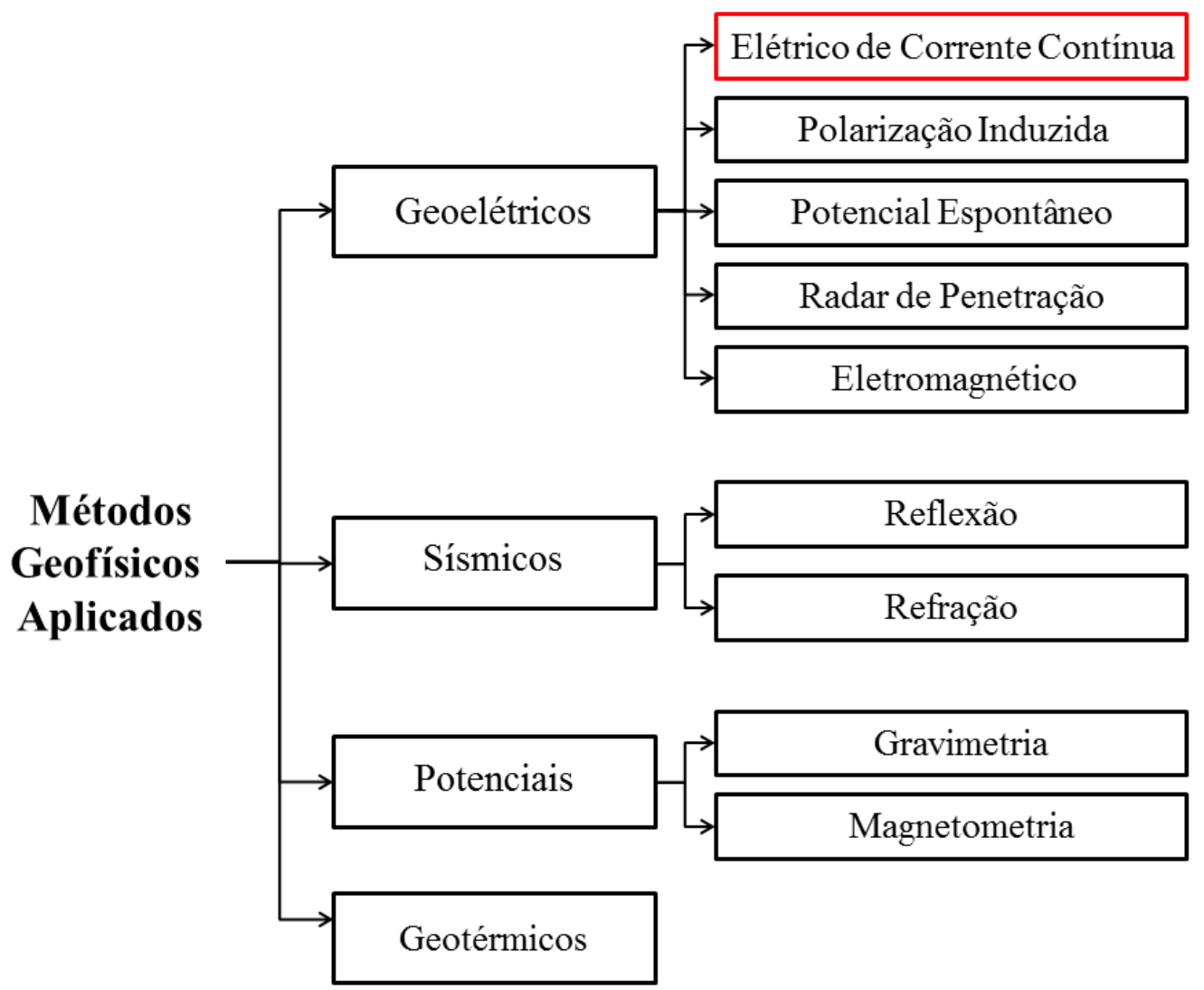

Figura 3.3 - Método Elétrico de Corrente Contínua no contexto dos métodos geofísicos de prospecção. Fonte: Telford et al. (1990).

O método elétrico de corrente contínua é voltado à investigação da resistividade elétrica, isto é, da resistência à passagem de corrente elétrica no subsolo (Telford et al., 1990). A resistividade elétrica é uma propriedade dos materiais geológicos controlada principalmente pela umidade e concentração de sólidos dissolvidos (Al-Othman, 2011). Seu valor é inversamente proporcional ao volume de água presente no solo ou rocha e ao conteúdo de material em solução na água (Orellana, 1972). No caso dos solos, a dimensão das partículas constituintes também tem influência no valor da resistividade, uma vez que, quanto menor seu tamanho, mais umidade será retida e, portanto, os valores de resistividade elétrica serão reduzidos. Além disso, esse parâmetro varia em função da porosidade e resistividade do fluido contido nos poros do solo (Loke, 2000; Asry et al., 2012).

A aquisição de dados de resistividade é uma prática consolidada nas áreas de mineração e investigação geotécnica, sendo recente sua utilização em estudos ambientais (Telford et al., 1990; Asawa, 2009; Bazin e Pfaffhuber, 2013). De acordo com Asry et al. (2012), o interesse crescente pelos recursos hídricos subterrâneos ocasionou estudos intensivos a 
respeito da geometria e das propriedades dos aquíferos, com papel de relevância para aplicação dos métodos geofísicos, especialmente na identificação da profundidade da água subterrânea. Devido à dificuldade de monitoramento direto das estruturas subsuperficiais, Brievré et al. (2012) ressaltam a importância da associação de dados hidrogeológicos e hidrogeofísicos no estudo do comportamento da água no solo.

Desse modo, o método elétrico de corrente contínua tem se mostrado adequado ao estudo do comportamento da água nas zonas não saturada e saturada do solo (Asry et al., 2012; Calamita et al., 2012; Chukwauma et al., 2015), somando-se a aplicações na identificação e delimitação de plumas de contaminantes (Nascimento et al., 2004; Eunice et al., 2011; Donohue et al., 2015). Além disso, a determinação quantitativa de parâmetros do solo a partir da correlação com dados de resistividade também pode ser observada, dentre outros casos, nos trabalhos de Knight et al. (2010) e Brillante et al. (2014).

Al-Othman (2011) fez uso do método elétrico de corrente contínua para avaliação da capacidade de recarga artificial de aquíferos rasos na Arábia Saudita. Nesse estudo, foi empregada a técnica de caminhamento elétrico para caracterização hidrogeológica com imageamento do perfil do solo. Asry et al. (2012) empregaram a mesma técnica a fim de delinear aquíferos e estimar a reserva hídrica subterrânea. Seções geoelétricas obtidas por Olasehinde et al. (2015) também favoreceram a caracterização de aquíferos em Agaie, na Nigéria. Chukwauma et al. (2015), ao avaliarem a vulnerabilidade de aquíferos, também na Nigéria, classificaram como solos saturados aqueles com resistividade elétrica abaixo de $3.500 \Omega . m$.

Neves e Luiz (2015) estimaram a velocidade do fluxo de água subterrânea utilizando a metodologia geofísica do imageamento elétrico. A distribuição da resistividade em subsuperfície foi obtida para diferentes períodos de tempo, por meio de medições realizadas ao longo de um perfil na superfície do solo. O fluxo subterrâneo foi rastreado pela observação da variação na resistividade em função do movimento de água salina injetada em dois poços rasos. A comparação entre valores de velocidade estimados pelo método geofísico e ensaios convencionais de permeabilidade (ensaios de rebaixamento) foi considerada satisfatória. 
Besson et al. (2010), por sua vez, descreveram a dinâmica de água no solo a partir do monitoramento temporal e espacial de alta resolução da resistividade elétrica em escala de campo. Andersen et al. (2013) utilizaram dados geofísicos de resistividade elétrica na geração de modelos hidrogeológicos integrados à modelagem numérica, com o objetivo de identificar zonas de recarga e estimar o tempo de descolamento da água subterrânea para os corpos hídricos superficiais. Crosbie et al. (2014) estudaram a infiltração em ambientes de vertente fazendo uso da resistividade elétrica integrada à modelagem numérica do fluxo de água no solo.

Bazin e Pfaffhuber (2013) apresentaram um estudo de caso na Noruega ilustrando como a tomografia bidimensional por resistividade elétrica $(E R T)$ pode ser utilizada no mapeamento de precisão da extensão de depósitos de argila. Moreira et al. (2012) ressaltaram que os métodos geofísicos fornecem informações satisfatórias para caracterização das propriedades hidráulicas dos aquíferos, tais como a condutividade hidráulica.

Com relação ao monitoramento de contaminantes pelo método elétrico de corrente contínua, no estudo desenvolvido por Donohue et al. (2015) foram identificadas fontes de percolação de efluente do sistema de tratamento de água residuária para a formação aquífera. Porciuncula e Lima (2012) identificaram, além da direção do fluxo, a existência de uma pluma de contaminantes por vazamento de combustível com cerca de $850 \mathrm{~m}$ de comprimento e $600 \mathrm{~m}$ de largura situada nas proximidades de um poço tubular profundo em operação, no município de Alagoinhas, Bahia.

Métodos hidrogeofísicos, conforme denominam Behroozmand et al. (2015), suprem o custo efetivo e a densidade espacial de informação acerca do comportamento da água no solo quando comparados com uma caracterização hidrogeológica direta, por exemplo, a partir da perfuração de poços de monitoramento. Os métodos convencionais são invasivos e fornecem dados pontuais, uma vez que aspectos financeiros e de tempo limitam o número de locais de medição e a descrição dos parâmetros de interesse na escala de campo (Besson et al., 2010). Contudo, deve-se considerar que as informações obtidas com métodos geofísicos não fornecem uma interpretação única do comportamento subsuperficial, sendo indiretamente sensíveis aos parâmetros hidrogeológicos de interesse (Behroozmand et al., 2015). 


\subsubsection{1 - Princípios Básicos Relacionados ao Método Elétrico de Corrente Contínua}

A aplicação do método elétrico de corrente contínua requer a passagem de uma corrente elétrica de intensidade $I$ no solo através de um par de eletrodos $(A$ e $B)$ fixados à superfície. Estacas de aço geralmente são empregadas como eletrodos, sendo enterradas a alguns centímetros da superfície do solo. A diferença de potencial $(\Delta U)$ que se forma é medida num segundo par de eletrodos $(M$ e $N)$. Conhecendo a corrente que percorre o subsolo, o fator geométrico que depende da disposição dos eletrodos $A B M N$ na superfície do terreno $(K)$ e o potencial medido, calcula-se a resistividade elétrica $\left(\rho_{a}\right)$ que, por ser medida em um meio heterogêneo e anisotrópico e ser função do arranjo de eletrodos, é dita aparente (Orellana, 1972; Telford et al., 1985) (Equação (3.22)).

$$
\rho_{a}=K \frac{\Delta \mathrm{U}}{I}
$$

Os equipamentos utilizados nos levantamentos geofísicos medem, em sua maioria, valores de resistência elétrica $(R)$, cuja unidade é $\operatorname{Ohm}(\Omega)$, e consiste na razão entre a diferença de potencial e a intensidade da corrente, conforme Equação (3.23). A resistividade elétrica $\left(\rho_{a}\right)$, por sua vez, é definida como o produto entre a resistência $(R)$ à passagem da corrente e o comprimento $(L)$ na direção perpendicular a uma das faces do volume unitário, resultando numa medida de resistência longitudinal de dado material à passagem da corrente elétrica, expressa em Ohm.m (S.m) (Koefoed, 1979) (Equação (3.24)).

$$
\begin{gathered}
R=\frac{\Delta U}{I} \\
\rho_{a}=L R
\end{gathered}
$$

A Lei de Ohm, contida na Equação (3.25), governa o fluxo de corrente no solo como a lei física fundamental em levantamentos geoelétricos. Nesse caso, a densidade de corrente num dado campo $(J)$ é representada pelo produto da condutividade do meio $(\sigma)$ com a intensidade do campo elétrico $(\varepsilon)$. Como, na prática, mede-se o potencial do campo (U), 
torna-se necessário relacionar a intensidade de corrente com o potencial elétrico (Equação (3.26)). Incluindo essa relação na lei de Ohm (Equação (3.25)), obtém-se a Equação (3.27).

$$
\begin{gathered}
J=\sigma \varepsilon \\
\varepsilon=-\nabla U \\
J=-\sigma \nabla U
\end{gathered}
$$

Em casos simples, onde a subsuperfície é considerada homogênea e havendo uma única fonte de corrente na superfície, pressupõe-se que essa corrente fluirá radialmente a partir da fonte e a diferença de potencial será inversamente proporcional à distância $(r)$ do indutor (eletrodo) (Equação (3.28)). Em geral, os levantamentos geoelétricos mensuram a diferença de potencial entre dois pontos. Por apresentar um padrão simétrico num ponto intermediário vertical entre dois eletrodos, a diferença de potencial pode ser indicada pela Equação (3.29), considerando $r_{A}$ e $r_{B}$ a distância de um dado ponto a partir dos eletrodos de corrente $A$ e $B$. Num arranjo típico com quatro eletrodos, a diferença de potencial $(\Delta U)$ é determinada pela Equação (3.30).

$$
\begin{gathered}
\Delta U=\frac{\rho I}{2 \pi r} \\
\Delta U=\frac{\rho I}{2 \pi}\left(\frac{1}{r_{A}}-\frac{1}{r_{B}}\right) \\
\Delta U=\frac{\rho I}{2 \pi}\left(\frac{1}{r_{A M}}-\frac{1}{r_{A N}}-\frac{1}{r_{B M}}+\frac{1}{r_{B N}}\right)
\end{gathered}
$$

Em condições reais, o meio submetido ao levantamento é essencialmente heterogêneo e os valores de resistividade estão distribuídos em três dimensões. Com isso, ao se considerar 
um volume $(\Delta V)$ circundante a uma fonte de corrente, nas coordenadas $x_{s}, y_{s}$ e $z_{s}$, a relação entre a densidade e a intensidade da corrente é dada pela Equação (3.31).

$$
\nabla J=\frac{I}{\Delta V} \delta\left(x-x_{s}\right) \delta\left(y-y_{s}\right) \delta\left(z-z_{s}\right)
$$

Substituindo a Equação (3.31) na Equação (3.27), tem-se a Equação (3.32), que representa a base da distribuição de potencial no solo devido a uma fonte de corrente. Genericamente, a Equação (3.32) pode ser reescrita na forma da Equação de Poisson, governante da distribuição de potencial no solo (Equação (3.33)). Nesse caso, $\nabla U^{T O T}$ é o potencial elétrico resultante total, enquanto que $\delta_{S}$ representa a função Delta de Dirac não nula apenas no ponto $x_{s}$ de ordenamento da corrente elétrica (Plattner et al., 2010).

$$
\begin{gathered}
-\nabla[\sigma(x, y, z) \nabla U(x, y, z)]=\frac{I}{\Delta V} \delta\left(x-x_{s}\right) \delta\left(y-y_{s}\right) \delta\left(z-z_{s}\right) \\
-\nabla\left(\sigma \nabla U^{T O T}\right)=I \delta_{S}
\end{gathered}
$$

\subsubsection{2 - Procedimento para Aquisição de Dados Geofísicos}

Além da escolha do método, o levantamento geofísico requer a definição do arranjo e da técnica empregados no trabalho em campo. Os arranjos, isto é, a forma de disposição dos eletrodos no terreno, mais comumente utilizados são os de Schlumberger e Wenner (Figura 3.4). No arranjo de Schlumberger, criado pelo geólogo Conrad Schlumberger em 1912, os eletrodos são distribuídos ao longo de uma linha reta, com distância entre os eletrodos de corrente maior ou igual a três vezes a distância entre os eletrodos de potencial (Koefoed, 1979). O arranjo de Wenner, por sua vez, criado em 1915 pelo físico norte-americano Frank Wenner, considera o espaçamento fixo $(a)$ entre os eletrodos de corrente $(A B)$ e de potencial $(M N)$ (Feitosa, 1997). 

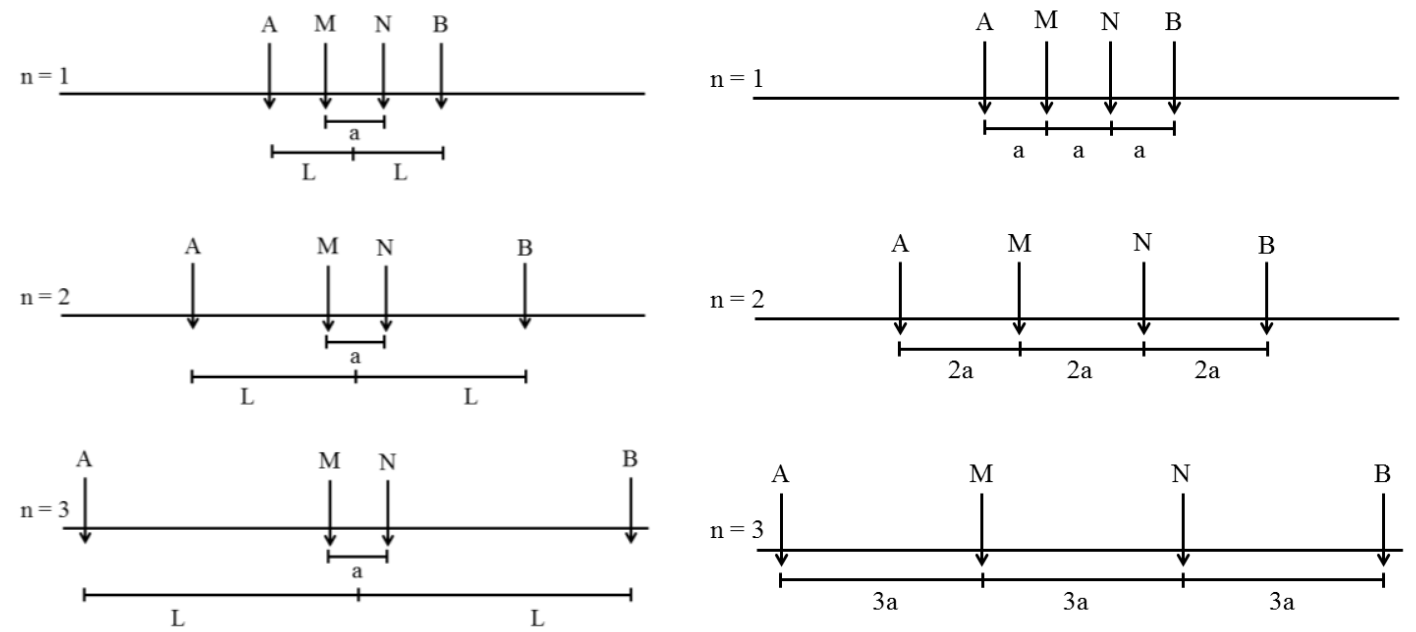

Figura 3.4 - Arranjos tipicamente utilizados para aquisição de dados geofísicos, com disposição dos eletrodos de corrente $(A$ e $B)$ e de potencial $(M$ e $N)$. a) Arranjo de Schlumberger, com distância $a$ fixa e $L$ crescente. b) Arranjo de Wenner, com distância $a$ constante. Adaptado de Braga (2007).

No arranjo de Schlumberger a resistividade aparente em um dado ponto do terreno é determinada pela Equação (3.34), onde $I$ representa a intensidade da corrente em amperes (A), $\Delta U$ diz respeito à diferença de potencial medida no terreno, em volts $(V), A B$ é a distância entre os eletrodos de corrente e $M N$ é a distância entre os eletrodos de potencial, ambos em metros $(m)$ (Fetter, 1994).

$$
\rho_{\alpha}=\frac{\left(\frac{A B}{2}\right)^{2}-\left(\frac{M N}{2}\right)^{2}}{M N}-\frac{(\pi \times \Delta U)}{I}
$$

Para o arranjo de Wenner, que apresenta três variações, o valor de resistividade aparente é obtido conforme Tabela 3.1 (Carpenter, 1955). Dentre as variações, o arranjo denominado $\alpha$-Wenner, com eletrodos de potencial situados entre os eletrodos de corrente, é utilizado de maneira mais ampla. Existem ainda os arranjos $\beta$-Wenner e $\gamma$-Wenner, nos quais os eletrodos de potencial e de corrente podem ser dispostos aos pares ou lado a lado, respectivamente. 
Tabela 3.1 - Variações do arranjo de Wenner.

Denominação Disposição dos eletrodos

\begin{tabular}{cccccc}
\hline$\alpha$-Wenner & $A$ & $M$ & $N$ & $B$ & $\rho \alpha=(2 \times a \times \pi \times \Delta U) / I$ \\
$\beta$-Wenner & $A$ & $B$ & $M$ & $N$ & $\rho \beta=(6 \times a \times \pi \times \Delta U) / I$ \\
$\gamma$-Wenner & $A$ & $M$ & $B$ & $N$ & $\rho \gamma=(3 \times a \times \pi \times \Delta U) / I$ \\
\hline
\end{tabular}

Fonte: Carpenter (1955).
Determinação da Resistividade aparente (Ohm.m)

A profundidade de investigação de um arranjo deve ser aquela para a qual a medida de resistividade pode ser melhor atribuída e depende das posições relativas dos quatro eletrodos do arranjo (Barker, 1989). No arranjo de Schlumberger, a profundidade teórica de investigação é determinada entre $A B / 2$ e $A B / 5$. Para o arranjo de Wenner a profundidade de uma medida é aproximadamente a metade do espaçamento entre os eletrodos $(a / 2)$ (Barker, 1989). A seleção do arranjo a ser empregado dependerá do objetivo ao qual se presta o levantamento, podendo ser considerados os critérios expostos por Reynolds (1997) (Tabela 3.2).

Tabela 3.2 - Análise comparativa entre os arranjos de Wenner e Schlumberger.

\begin{tabular}{ccc}
\hline Critério & Wenner & Schlumberger \\
\hline Resolução vertical & 3 & 2 \\
Profundidade de investigação & 1 & 2 \\
Adequação à sondagem elétrica $($ SEV $)$ & 2 & 3 \\
Adequação ao caminhamento elétrico $(C E)$ & 3 & $\mathrm{x}$ \\
Sensibilidade a variações laterais & 3 & 3 \\
Trabalho intensivo & $3(*)$ & $2(*)$ \\
Disponibilidade de meios de interpretação & 3 & 3 \\
\hline 1 = baixa; 2 = moderada; 3 = boa; x = não se aplica \\
*exceto quanto se utiliza cabo multieletrodo e arranjo automático de eletrodos
\end{tabular}

Fonte: Reynolds (1997).

Além da determinação do arranjo, o levantamento geofísico requer a seleção da técnica de investigação, que pode assumir as formas de sondagem, caminhamento ou perfilagem (Braga, 2007). A perfilagem elétrica consiste na investigação geoelétrica vertical no interior de furos de sondagem mecânica, conforme Braga (2007). No caso da sondagem elétrica vertical $(S E V)$ a investigação é realizada em profundidade a partir de um ponto fixo na superfície do terreno (Braga, 2007). Durante a $S E V$, os eletrodos $M$ e $N$ são mantidos fixos e os eletrodos $A$ e $B$ são deslocados lateralmente. Quanto maior a distância entre $A$ e 
$B$, maior a profundidade alcançada (Feitosa, 1997). Os valores de resistividade aparente obtidos são plotados em gráficos bilogarítmicos contra os respectivos valores da distância $A B / 2$, permitindo avaliar a natureza e a estrutura do subsolo (Feitosa, 1997).

Por fim, a técnica de caminhamento elétrico $(C E)$, também denominada perfilagem elétrica horizontal, é definida como a investigação lateral a partir de pontos não fixos na superfície, com uma ou mais profundidades constantes (Braga, 2007). Nessa técnica são efetuadas medições de resistividade aparente ao longo de um perfil, deslocando-se todo o arranjo de eletrodos a cada nova medida (Feitosa, 1997). Em geral o arranjo de Wenner é utilizado para aplicação dessa técnica, permitindo o mapeamento detalhado da resistividade (Asry et $a l .$, 2012). De acordo com Wunderlich et al. (2015), apesar da necessidade de instalação de perfis individuais que tornam a aquisição de dados mais demorada, a principal vantagem do caminhamento consiste na ampla distribuição dos dados de resistividade elétrica, com melhor resolução ao longo da profundidade investigada.

Os resultados obtidos por meio do caminhamento elétrico podem ser apresentados no formato de mapas (a uma ou mais profundidades determinadas) e de seções ou perfis geoelétricos (com várias profundidades de investigação) (Braga, 2007). Na literatura técnica e científica é comum a utilização do termo tomografia bidimensional por resistividade elétrica (Eletrical Resistivity Tomography - ERT) em denominação à técnica de caminhamento elétrico, como observado nos trabalho de Bazin e Pfaffhuber (2013) e Bharti et al. (2016). Contudo, como define Sheriff (2002), a aplicação do termo tomografia, em aspectos geofísicos, traduz a determinação da distribuição da resistividade com medidas utilizando transmissor em um furo de sondagem e receptor em outro, como observado em Bellmunt et al. (2012).

Reynolds (1997) atribuiu ao caminhamento elétrico a denominação constant separation traversing ou electrical resistivity traversing, que também permite o acrônimo ERT, definindo de maneira adequada a aquisição de dados em campo por meio dessa técnica que, quando não provida de sistemas automáticos, necessita de deslocamento (to traverse) ao longo de um perfil de solo. Por fim, como ressalta Loke (2000), os dados de resistividade aparente obtidos em campo devem ser submetidos ao processo de inversão para tornarem-se representativos do meio investigado. O produto da técnica de inversão, 
isto é, da análise quantitativa dos dados geoelétricos, é entendido como imageamento elétrico bidimensional (Asry et al., 2012; Brillante et al., 2015).

\subsubsection{3 - Teoria Básica para Inversão de Dados Geoelétricos}

A inversão dos dados geofísicos tem como objetivo estimar parâmetros para elaboração de um modelo cuja resposta se assemelhe a um conjunto de medições discretas em campo (Buettner et al., 1996; Akca et al., 2014). Os parâmetros relevantes nesse procedimento são os valores de resistividade aparente e espessura das camadas do solo, a partir dos quais são calculados novos valores de resistividade (Loke, 2000). Desse modo, a modelagem do comportamento geoelétrico, genericamente denominada inversão, consiste num procedimento indireto e iterativo de cálculo dos parâmetros do modelo (rotina de inversão) seguindo-se da aplicação da modelagem direta (Loke, 2000).

A técnica de otimização por mínimos quadrados não linear é considerada a rotina de inversão padrão para dados geoelétricos por serem governados por equação não linear (Loke, 2000). A inversão inicia-se com a linearização da Equação Poisson, apresentada no item 3.2.1 -, por meio do método Gauss-Newton e, em seguida, a técnica de mínimos quadrados é aplicada por meio da expressão recursiva apresentada na Equação (3.35). Nesse caso, $\Delta d$ representa a diferença entre os dados observados e calculados, $A$ é a matriz de sensibilidade e $P$ é o vetor de parâmetros do meio (Loke, 2000).

$$
P_{K+1}=P_{K}+\left(A^{T} A\right)^{-1} A^{T} \Delta d
$$

Desse modo, o modelo inicial gerado a partir dos dados de campo é sucessivamente ajustado por processo iterativo a fim de minimizar a diferença entre os dados observados e a pseudo-seção modelada (Reynolds, 1997). A função objetivo a ser otimizada é constituída pela soma ponderada do quadrado das diferenças entre os valores de resistividade observados e simulados (Anderson e Woessner, 2002).

A aplicação da modelagem direta consistirá no cálculo da resistividade num dado volume, a partir de um modelo sintético com configuração geológica idealizada (Loke, 2000). Como afirmam Zarroca et al. (2014), o principal objetivo da modelagem direta é verificar a 
consistência dos dados de resistividade medidos em campo. A comparação entre os valores calculados e medidos auxilia na diferenciação de características reais da área em estudo e desajustes decorrentes do processo de inversão. A diferença dos dados é convertida em parâmetro de discrepância que retroalimentam a inversão (Loke, 2000). O resultado é a representação da resistividade calculada a partir dos parâmetros estimados na rotina de inversão, que pode ser comparada com outra representação que contenha os dados reais medidos em campo (Zarroca et al., 2014).

A modelagem direta pode ser realizada por meio dos métodos de diferenças finitas ou elementos finitos, abordados de maneira aprofundada no item 3.3.1 -. Contudo, deve-se salientar que a escolha do método de elementos finitos em detrimento do método de diferenças finitas é vantajosa em situações nas quais dados de topografia estejam disponíveis (Loke, 2000). Caso contrário, o método de diferenças finitas é considerado satisfatório e produz respostas mais rápidas (Loke, 2000).

Por fim, o ruído gerado no processo de inversão é representado pela raiz do erro médio quadrático (RMSE) entre os dados simulados e observados em cada iteração (Loke, 2000). Loke (2000) sugere a seleção do modelo após a estabilização do RMSE, especialmente entre a terceira e quinta iterações. Porém, é importante considerar que nem sempre os menores valores de erro são considerados satisfatórios para avaliar a adequação do modelo sob a perspectiva de representação hidrogeológica (Loke, 2000).

\section{3 - MODELAGEM MATEMÁTICA DE PROCESSOS HIDROLÓGICOS}

\subsection{1 - Modelagem Matemática por Métodos Numéricos}

O comportamento do sistema real é complexo. Modelos matemáticos, por sua vez, são instrumentos voltados à representação aproximada e simplificada desse sistema (Beven, 1977). Em estudos hidrogeológicos, os modelos são aplicados especialmente aos problemas de fluxo de água subterrânea e transporte de solutos (Anderson e Woessner, 2002). No primeiro caso, a distribuição da carga hidráulica é o objeto de interesse, enquanto que, nos modelos de transporte, analisa-se a concentração de solutos em função dos fenômenos de advecção, dispersão e das reações químicas, exigindo o conhecimento prévio de distribuição das cargas hidráulicas do meio (Anderson e Woessner, 2002). 
A modelagem matemática hidrogeológica abrange ainda a identificação de alternativas locacionais para perfuração de poços de abastecimento, avaliação de técnicas de recuperação de água subterrânea, delimitação de zonas de contribuição de poços e otimização no gerenciamento dos recursos hídricos (Cleary, 1989; Gao, 2011; Levy e Xu, 2012; Kelson, 2012; Ireson et al., 2013). As vantagens dos modelos matemáticos residem em sua versatilidade, quando comparados aos modelos físicos e analógicos, e estrutura lógica e de fácil alteração, fornecendo resultados para diferentes cenários num mesmo sistema.

Em contraponto, a necessidade de discretização dos processos contínuos e a dificuldade de representação matemática de determinados processos físicos dificultam sua aplicação (Tucci, 1998). Os modelos matemáticos podem diferir em função dos critérios 1) intervalo de definição das variáveis (discreto ou contínuo); 2) variabilidade espacial (concentrado ou distribuído); 3) temporal (estacionário ou transiente) das variáveis; e 4) estrutura matemática adotada para solução do problema (determinístico ou probabilístico).

Dentre os modelos matemáticos determinísticos, aqueles que se baseiam na resolução de equações diferenciais parciais com aplicação de técnicas de aproximação numérica são ditos numéricos. Constumam ser utilizados com recorrência no estudo de aquíferos com características heterogêneas e condições de contorno e geometrias irregulares, que limitam a aplicação de modelos matemáticos analíticos (Diersh, 2014).

Os modelos numéricos apresentam como ideia central o processo de discretização espacial e temporal das variáveis de interesse a partir do qual um problema físico, contínuo, com número infinito de incógnitas, é convertido num problema discreto, considerado simplificado, com número finito de incógnitas (Wrobel, 1989). A aproximação das equações diferenciais permite que elas sejam substituídas por equações algébricas lineares, cuja resolução numérica ocorrerá de maneira menos complexa (Wrobel, 1989).

Zheng (2011) afirma que a partir de 1990 a capacidade de aplicação dos modelos de fluxo e transporte foi ampliada em função da integração com interfaces de $S I G$, sofisticação e facilidade de uso das interfaces gráficas dos programas de modelagem; aumento dos modelos com acoplagem dos processos hidrológicos subterrâneos e superficiais e de transporte; aumento na acessibilidade de bancos dados; e intensificação no 
desenvolvimento de alternativas de solução das equações diferenciais parciais. Atualmente os modelos numéricos têm demonstrado ampla utilização em estudos de fluxo de água no solo (Rodriguez et al., 2008; Gao, 2011; Levy e Xu, 2012; Kelson, 2012; Ireson et al., 2013).

\subsubsection{1 - Etapas de Modelagem Numérica}

A modelagem numérica requer uma sequência de ações que vão desde a definição do objetivo até a obtenção do resultado final, como observado em Anderson e Woessner (1992), Bear e Cheng (2010) e Diersh (2014). Os fluxogramas de ações apresentados pelos diferentes autores seguem procedimentos semelhantes sendo, neste estudo, adotado o esquema proposto por Bear e Cheng (2010) (Figura 3.5). A seleção dos objetivos, considerando as informações que se pretende obter por meio da simulação numérica, é a etapa inicial num modelo, com posterior coleta de dados primários e secundários. A partir daí são desenvolvidas as etapas de modelagem conceitual e matemática; seleção do método de resolução; simulação do modelo preditivo; com posteriores verificação, validação e calibração; e apresentação dos resultados (Bear e Cheng, 2010).

O modelo conceitual é composto por um conjunto de pressupostos que simplificam o problema e o domínio reais, levando em consideração os objetivos da modelagem e os dados disponíveis (Bear e Cheng, 2010). Para Bahrami et al. (2014) esse é um dos passos mais importantes no processo de modelagem. Nessa etapa são adotadas suposições a respeito do domínio modelado (hidrogeologia, estratigrafia, dentre outras); das dimensões, geometria e contorno de interesse; do comportamento do sistema em regime estacionário ou transiente; das propriedades dos materiais; das características pedológicas, incluindo aspectos de anisotropia e heterogeneidade; das condições iniciais dentro e no contorno do domínio; dentre outras informações que permitam a caracterização do problema (Bear e Cheng, 2010).

Os dados reunidos no modelo conceitual permitem a resolução das equações que regem o fenômeno em estudo. Como menciona Franke et al. (1987), equações governantes utilizadas na representação do fluxo de água no solo, dentre outros casos, possuem um número infinito de soluções, sendo necessária a definição de um problema específico em conformidade com os objetivos a serem alcançados. A aplicação do modelo matemático 
requer a definição da geometria das superfícies do domínio, das equações governantes (seja para fluxo ou transporte de contaminantes) e das condições iniciais e de contorno adotadas no modelo conceitual (Bear e Cheng, 2010).

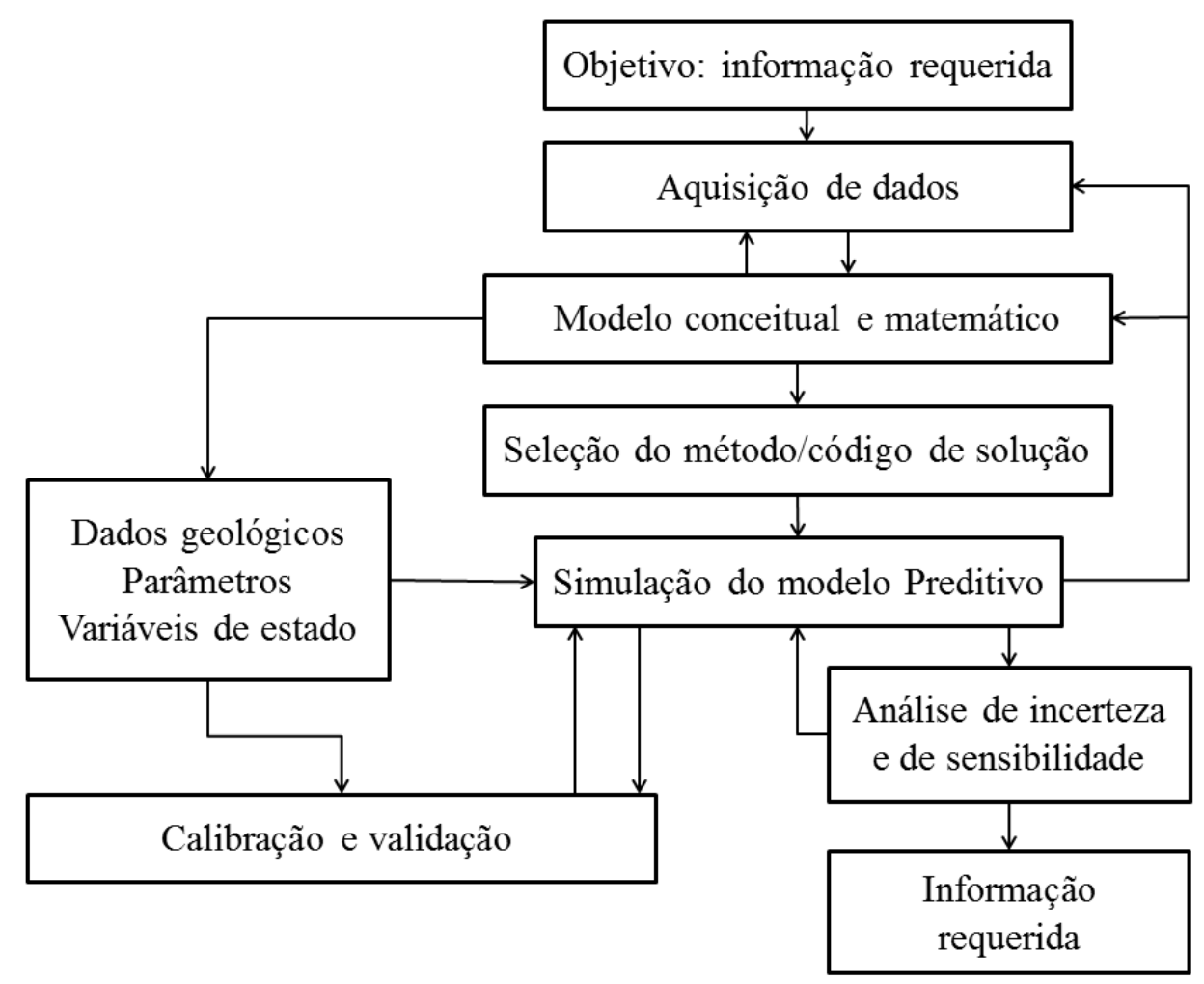

Figura 3.5 - Etapas para desenvolvimento do modelo. Modificado de Bear e Cheng (2010).

As condições iniciais descrevem o estado conhecido do sistema num dado tempo inicial, sendo componente importante na simulação em regime transiente (Bear e Cheng, 2010). Para tal simulação, diferentemente do regime estacionário, a magnitude ou direção da velocidade de fluxo muda ao longo do tempo, num ponto do campo de fluxo (Freeze e Cherry, 1979). Nos problemas hidrológicos, por exemplo, a aplicação do regime transiente requer distribuição inicial da carga hidráulica, uma vez que os valores de carga calculados em um determinado período de tempo são dependentes dos valores no passo anterior.

Na simulação em regime estacionário, contudo, o cálculo do modelo é realizado com base apenas nas condições de contorno e nas propriedades dos materiais constantes, sem considerar variações temporais. A modelagem do fluxo em regime estacionário é indicada como alternativa à obtenção das condições iniciais nas simulações em regime transiente, quando esses dados não se encontram disponíveis (Freeze e Cherry, 1979). Considerando, por exemplo, o domínio $D(x, y)$ para um problema de fluxo, com dimensões planas, 
contorno fechado $(\Gamma)$ e $F_{i}=F_{i}(x, y, t)$, a variável carga hidráulica $(h)$ será definida em estado estacionário, conforme a Equação (3.36).

$$
h=h(x, y, t)=f(x, y) \text {, no } D
$$

com

$f=f(x, y)$ sendo uma função conhecida.

As condições de contorno, por sua vez, são elementos que descrevem a interação do domínio com o ambiente externo (Bear e Cheng, 2010). Como afirmam Franke et al. (1987), essas podem ser de três tipos principais: Dirichlet, Neumann e Cauchy (Tabela 3.3). No primeiro caso, o valor da variável no contorno (carga hidráulica) é especificado. No segundo, a derivada da variável (fluxo) é especificada, podendo ser nula ou não. A equação expressa para a condição de Neumann (Tabela 3.3) poderá assumir ainda o formato apresentado nas Equações (3.37) e (3.38), quando aplicada para aquíferos confinados e freáticos, respectivamente.

Tabela 3.3 - Tipos de condições de contorno.

\begin{tabular}{|c|c|c|c|}
\hline Tipo & Tipo 1 ои de Dirichlet & Tipo 2 ou de Neumann & $\begin{array}{c}\text { Tipo } 3 \text { ou mista (Robin ou } \\
\text { Cauchy) }\end{array}$ \\
\hline Limite & Físico & Hidráulico & \multirow{2}{*}{$\begin{array}{c}\text { Combinação das condições } 1 \text { e } 2 . \text { O } \\
\text { fluxo é calculado com base na } \\
\text { diferença entre a carga hidráulica } \\
\text { especificada e a carga hidráulica } \\
\text { calculada pelo modelo }\end{array}$} \\
\hline Especificação & $\begin{array}{l}\text { Carga hidráulica } \\
\text { conhecida no contorno }\end{array}$ & $\begin{array}{l}\text { Fluxo conhecido no } \\
\text { contorno }\end{array}$ & \\
\hline Exemplo & $\begin{array}{l}\text { Lago (constante) Rio } \\
\text { (função do tempo e/ou } \\
\text { espaço) }\end{array}$ & $\begin{array}{c}\text { Fluxo zero ou não-fluxo } \\
\text { em divisores topográficos } \\
\text { e zonas impermeáveis, } \\
\text { recarga e } \\
\text { evapotranspiração } \\
\text { especificada na primeira } \\
\text { camada do modelo }\end{array}$ & $\begin{array}{l}\text { Drenagem atraves de contornos } \\
\text { semipermeáveis, drenos, nascentes e } \\
\text { rios }\end{array}$ \\
\hline Equação & $\begin{array}{c}h=f_{1}(x, y, t) \\
\text { com } \\
f_{1}=f_{1}(x, y, t) \\
\text { conhecido }\end{array}$ & $\begin{array}{c}Q_{n}^{\prime}=\boldsymbol{Q}^{\prime} \times \boldsymbol{n}= \\
f_{2}(x, y, t) \\
\quad \text { com } \\
f_{2}=f_{2}(x, y, t) \\
\quad \text { conhecido }\end{array}$ & $\begin{aligned} &\left(Q^{\prime}{ }_{n} \cong \boldsymbol{Q}^{\prime} \times \boldsymbol{n}\right)=-(K h \times \\
&\left.\nabla^{\prime} h\right) \times \boldsymbol{n}=\mathrm{h} \frac{h_{0}-h(x, y, t)}{c_{r}} \\
& \operatorname{com} \\
& c_{r}=\frac{K^{\prime}}{B^{\prime}}\end{aligned}$ \\
\hline
\end{tabular}

Fonte: Bear e Cheng (2010). 


$$
\begin{gathered}
Q^{\prime}=-T \times \nabla^{\prime} h \\
Q^{\prime}=-(h-\eta) K \times \nabla^{\prime} h
\end{gathered}
$$

Quando o meio poroso é tido como isotrópico, a condição de Neumann é reduzida à Equação (3.39), com $s_{n}$ indicando a distância ao longo do contorno. Em caso de fronteiras impermeáveis as funções $f_{2}$ e $f^{\prime}{ }_{2}$ assumem valor zero.

$$
\frac{\partial h}{\partial s_{n}}=f^{\prime}{ }_{2}(x, y, t)
$$

A condição de contorno de Cauchy, por sua vez, é uma combinação linear das condições dos tipos 1 e 2, e depende do valor da variável e da sua derivada (o fluxo analisado é dependente da carga hidráulica). Na simulação do fluxo em três dimensões essa condição de contorno ocorre quando o leito do rio semipermeável atua como uma fronteira ao fluxo, diferenciando a carga hidráulica no aquífero e no corpo hídrico superficial. Para aquíferos freáticos a condição de Cauchy é definida, conforme Tabela 3.3, enquanto para aquíferos confinados a relação $K h$ é substituída pela trasmissividade $(T)$, como produto da permeabilidade $(K)$ pela espessura saturada $(b)$ (Bear e Cheng, 2010).

Após estruturação do modelo matemático, considerando ainda as propriedades dos materiais relevantes, prossegue-se à seleção de um método de resolução do problema de interesse (Bear e Cheng, 2010). Devido à complexidade dos problemas reais, os métodos numéricos são mais amplamente aplicados em comparação aos analíticos. Nesse caso, o modelo matemático é transformado em modelo numérico, utilizando equações diferenciais parciais. Um programa ou código computacional são requeridos nessa etapa a fim de solucionar o modelo numérico. Cabral e Demétrio (1997) afirmam que essa fase tornou-se simplificada devido à existência de pacotes computacionais de fácil manuseio.

Após resolução do modelo numérico, as etapas de calibração, verificação e validação podem ser realizadas. A calibração consiste no ajuste dos parâmetros do modelo com a finalidade de aproximar os resultados aos dados medidos em campo. A identificação 
desses valores é um problema inverso ou de estimação de parâmetros, como no caso da inversão dos dados geofísicos (item 3.2.1.3 -). Anderson e Woessner (2002) mencionam que o objetivo da calibração é estabelecer um modelo que produza resultados condizentes aos medidos em campo. Essa etapa é realizada por tentativa-e-erro no ajuste de parâmetros, quer utilizando um código automático de estimativa ou de forma manual (Anderson e Woessner, 2002).

Os resultados da calibração são considerados adequados quando a correlação entre os valores dos parâmetros observados e modelados é tida como significativa. Além da calibração, coeficientes e parâmetros do modelo podem ser obtidos a partir de revisão da literatura, experimentos em laboratório e experimentos de campo em pequena escala. Depois de calibrado, o modelo é indicado para fornecer previsões a respeito de dado fenômeno.

$\mathrm{Na}$ etapa de verificação do código utilizado é estabelecida a comparação entre os resultados obtidos numericamente e aqueles identificados por métodos analíticos, sempre que tais soluções forem possíveis (Bear e Cheng, 2010). Geralmente, soluções analíticas não podem ser obtidas, sendo estabelecida comparação para soluções numéricas entre diferentes códigos computacionais (Bear e Cheng, 2010). A validação, por sua vez, consiste no processo de certificação do modelo quando à representatividade dos processos abordados (Bear e Cheng, 2010). Os resultados do modelo preditivo poderão ainda ser submetidos a análises de sensibilidade, avaliação da incerteza e análises estocásticas que expressam o intervalo de incerteza entre a entrada e a saída de dados, em medidas estatísticas (Bear e Cheng, 2010).

Por fim, é importante evidenciar as colocações de Bronstert et al. (1998). Para este, a qualidade dos resultados de um modelo, independente do método aplicado, é influenciada pela precisão dos dados de entrada e das condições de contorno, e sua resolução espacial e temporal, bem como pela adequada calibração dos parâmetros hidráulicos do solo. Quando se refere à modelagem hidrológica em vertentes, limitações nos resultados são decorrentes do conhecimento reduzido a respeito de certos processos hidrológicos; escassez de dados de campo; efeito estocástico na variabilidade de determinados processos; e restrições quanto ao aspecto operacional dos modelos (Bronstert et al, 1998). Zheng (2011) ressalta ainda que modelos sempre serão limitados por aspectos computacionais, suposições e 
lacunas no conhecimento, devendo ser vistos como ferramentas que auxiliam o processo de tomada de decisão, e não como uma representação exata do sistema real.

\subsection{2 - Modelagem Numérica pelo Método de Elementos Finitos}

Dentre os métodos numéricos, os de diferenças finitas $(D F M)$ e elementos finitos (FEM) são amplamente utilizados na resolução de problemas hidrogeológicos (Bear e Cheng, 2010). No primeiro método a região de interesse é representada como uma série de pontos (nós) e a relação entre seus valores é obtida por expansão da série de Taylor (Wrobel, 1989). A aplicação do método de elementos finitos, por sua vez, consiste na divisão da região de interesse em elementos (não infinitesimais) conectados a um conjunto de nós (Figura 3.6). Os elementos são abordados de maneira isolada, com posterior elaboração de equações para todos os elementos em uma matriz global (Anderson e Woessner, 2002). A relação entre os valores nodais é obtida por polinômios de interpolação, válidos para cada sub-região do elemento (Wrobel, 1989).

De maneira geral, o princípio de diferenças finitas é considerado mais simples, consistindo na substituição das derivadas parciais da equação contínua por fórmulas discretas de diferenças, e na aplicação da equação resultante em um número finito de pontos, com um sistema de equações algébricas. A discretização ocorre por meio de malhas com espaçamento regular constante (Wrobel, 1989). Em elementos finitos, por sua vez, a discretização em elementos permite a obtenção de formas geométricas diversas, com representação adequada dos problemas, tendo como contrapartida a exigência de formulações matemáticas complexas (Wrobel, 1989).

De acordo com Bear e Cheng (2010) a origem do método de elementos finitos remete aos trabalhos de Courant (1943), que, tendo como referência Ritz (1908) e Galerkin (1915), desenvolveu o conceito de representação integral da variação para obter soluções aproximadas das equações diferenciais parciais. Na solução aproximada de Courant, o domínio é subdividido em um número de subdomínios (elementos poligonais) e a solução é representada por partes, em cada subdomínio, como uma soma de funções de base simples, tais como polinômios (Bear e Cheng, 2010). Os elementos poligonais são tratados como regiões aproximadas para as quais o valor da variável de interesse (potencial de 
pressão ou carga hidráulica) é obtido localmente, utilizando funções de interpolação entre os nós.

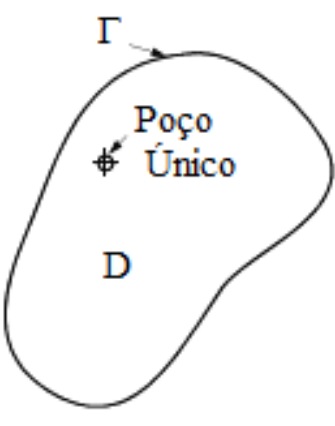

Dominio e

Contorno
Célula

Ativa

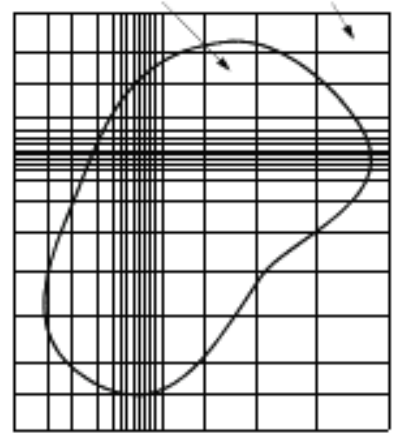

Abordagem por

Diferenças Finitas

(Rede Estruturada)
Elementos

Finitos

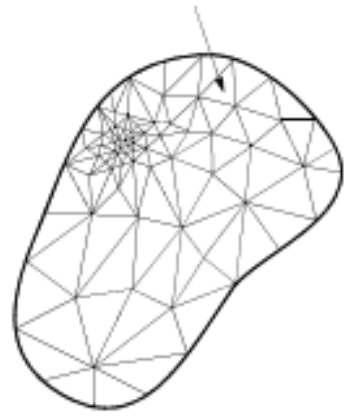

Abordagem por
Elementos Finitos
(Malha não
Estruturada)

Figura 3.6 - Exemplo de domínio $(D)$ bidimensional horizontal com contorno $(I)$ discretizado por diferenças finitas e por elementos finitos. Fonte: Diersch (2014).

Esse método se consolidou a partir do desenvolvimento dos computadores eletrônicos, impulsionado pelas necessidades da indústria aeroespacial. Clough et al. (1960), ao aplicarem essa abordagem na solução de problemas em mecânica estrutural, cunharam o termo método dos elementos finitos. Apesar do esforço computacional requerido em função de formulações matemáticas complexas, esse método apresenta vantagens relacionadas ao tipo de geometria adotado e a representação de meios heterogêneos e anisotrópicos (Wrobel, 1989). Devido à flexibilidade geométrica e precisão, o método de elementos finitos aplica-se às condições de contorno em domínios complexos, sendo mais eficiente quando comparado a outras estratégias numéricas (Diersh, 2014).

Beven (1997) ressalta que, por facilitar a abordagem de geometrias complexas, a modelagem por elementos finitos permite a representação da curvatura natural das regiões de vertente. $\mathrm{O}$ método possibilita ainda a manipulação de variações arbitrárias na condutividade hidráulica e anisotropia na região de fluxo, bem como adequa-se mais facilmente às condições de contorno de Dirichlet e Neumann (Beven, 1997; Wilson, 2010). 
Além disso, o refinamento da malha em regiões do domínio onde são esperadas alterações rápidas ou importantes é considerado adequado (Wilson, 2010).

\subsubsection{1 - Aplicação do Método de Elementos Finitos}

Considerando as explanações apresentadas em Wrobel (1989), a aplicação do método de elementos finitos em problemas bidimensionais consiste na resolução da Equação (3.40), generalizada para diversos problemas de importância prática.

$$
\frac{\partial}{\partial x}\left[K_{x}\left(\frac{\partial u}{\partial x}\right)\right]+\frac{\partial}{\partial y}\left[K_{y}\left(\frac{\partial u}{\partial y}\right)\right]+\lambda u-c=0 \text { no domínio } D
$$

Sua resolução requer que as condições de contorno sejam expressas segundo as Equações (3.41) e (3.42).

$$
\begin{gathered}
u=\bar{u} e m \Gamma_{1} \\
{\left[K_{x}\left(\frac{\partial u}{\partial x}\right) n_{x}\right]+\left[K_{y}\left(\frac{\partial u}{\partial y}\right) n_{y}\right]=f(x, y)+h(x, y) e m \Gamma_{2}}
\end{gathered}
$$

em que $K_{x}, K_{y}, \lambda, c, f$ e $h$ constantes ou funções conhecidas (bases), $n_{x}$ e $n_{y}$ são cossenos diretores da normal externa ao contorno $\Gamma=\Gamma_{1}+\Gamma_{2}$ e $\bar{u}$ é uma condição de contorno conhecida. Existem situações particulares da Equação (3.40), como, por exemplo, as Equações de Poisson, Laplace e Helmholtz. No primeiro caso a equação é reduzida ao formato expresso na Equação (3.43), uma vez que $K_{x}=K_{x}=K=$ constante e $\lambda=0$. Quando se tem, além das restrições acima, $c=0$, obtém-se a Equação de Laplace. Por fim, na Equação de Helmholtz, apenas $c=0$. Essas equações governam o comportamento de problemas como transferência de calor em sólidos, escoamento de fluidos perfeitos, condução elétrica e magnética, propagação de ondas, dentre outros.

$$
\nabla^{2} u=c / K
$$


O método de elementos finitos, conforme Chapra e Canale (2010), obedece às etapas de discretização; elaboração das matrizes locais para os elementos discretizados; construção da matriz global; inserção das condições de contorno; resolução dos sistemas de equações; e apresentação dos resultados. A principal dificuldade identificada na aplicação do método de elementos finitos consiste na seleção da função de aproximação a ser empregada num problema complexo. Essas funções, em geral, devem satisfazer às condições de contorno do problema e representar adequadamente a geometria e as propriedades físicas do meio (Wrobel, 1989).

Em termos computacionais, empregam-se funções de aproximação locais ao invés de funções globais. Com isso, após a discretização do domínio em elementos finitos, aplica-se uma aproximação local da variável do problema em cada um desses elementos. Com a junção dos elementos, tem-se um sistema de equações relativo ao modelo discreto, com número finito de incógnitas (Wrobel, 1989). Algumas formulações teóricas permitem a solução das equações diferenciais pelo método de elementos finitos, tais como os métodos de aproximação dos resíduos ponderados (Wrobel, 1989). Considerando de maneira genérica um problema bidimensional regido pela equação diferencial (3.44)

$$
L\left(u_{0}\right)=0
$$

com condições de contorno expressas pela Equação (3.45)

$$
S\left(u_{0}\right)=g
$$

para $L$ e $S$ operadores diferenciais e $u_{0}$ a solução exata do problema, obtida apenas em casos simples. Caso contrário a solução terá que ser aproximada $(u)$. Existem vários tipos de funções de aproximação, sendo as mais simples aquelas que utilizam uma sequência de funções com formato da Equação (3.46).

$$
u=\beta+\alpha_{1} \phi_{1}+\alpha_{2} \phi_{2}+\ldots+\alpha_{N} \phi_{N}
$$


Nesse caso, $\beta$ é uma função conhecida, incluída para satisfazer as condições de contorno não homogêneas, $\alpha_{i}(i=1,2, \ldots \mathrm{N})$ são parâmetros a determinar e $\phi_{i}$ são funções linearmente independentes e conhecidas, identicamente nulas no contorno, correspondentes à aproximação adotada. Por fim, uma sequência de funções $\phi_{i}(i=1,2, \ldots N)$ é dita linearmente independente se obedecer à formulação expressa pela Equação (3.47), com todos os $\alpha_{i}=0$.

$$
\alpha_{1} \phi_{1}+\alpha_{2} \phi_{2}+\ldots+\alpha_{N} \phi_{N}=0
$$

A substituição da função (3.47) nas Equações (3.44) e (3.45) produz um erro ( $\varepsilon$ ) ou resíduo expresso pelas Equações (3.54) e (3.55).

$$
\begin{aligned}
& \varepsilon=L\left(u_{0}\right) \neq 0 \\
& \varepsilon=S\left(u_{0}\right) \neq 0
\end{aligned}
$$

O objetivo de método de resíduos ponderados é a redução dos resíduos, distribuindo os erros no domínio do problema. A maneira como essa distribuição é realizada da origem ao diferentes métodos de resíduos ponderados. Podem ser utilizadas as funções de peso ou ponderação delta de Dirac, quando se aplica o método de Colocação; a função unitária, por meio do método do Subdomínio; e as próprias funções de aproximação $\phi_{i}$, conforme o método de Galerkin (Wrobel, 1989; Bear e Cheng, 2010). A aplicação do método de Galerkin inclui o erro cometido pela não-satisfação da condição de contorno natural expressa na Equação (3.45), obtendo-se a Equação (3.50).

$$
\begin{gathered}
\int D\left[\frac{\partial}{\partial x}\left[K_{x}\left(\frac{\partial u}{\partial x}\right)\right]+\frac{\partial}{\partial y}\left[K_{y}\left(\frac{\partial u}{\partial y}\right)\right]+\lambda u+c\right] \delta_{u} d D= \\
\int \Gamma_{2}\left[\left[K_{x}\left(\frac{\partial u}{\partial x}\right) n_{x}\right]+\left[K_{y}\left(\frac{\partial u}{\partial y}\right) n_{y}\right]-f-h u\right] \delta_{u} d \Gamma_{2}
\end{gathered}
$$


Em seguida, integram-se por partes os dois primeiros termos do lado esquerdo da Equação (3.50), uma vez que se pretende trabalhar com aproximações lineares para $u$ em cada elemento. Limitando-se ao termo $x$, por exemplo, pode-se escrever a Equação (3.51).

$$
\begin{gathered}
\int D\left[\frac{\partial}{\partial x}\left[K_{x}\left(\frac{\partial u}{\partial x}\right)\right]\right] \delta_{u} d D= \\
\int D\left[\frac{\partial}{\partial x}\left[K_{x}\left(\frac{\partial u}{\partial x}\right)\right]\right] d D-\int D\left[K_{x}\left(\frac{\partial u}{\partial x} \frac{\partial \delta_{u}}{\partial x}\right)\right] d D
\end{gathered}
$$

Aplicando o teorema de divergência ao primeiro termo do lado direito, obtém-se a Equação (3.52).

$$
\int D\left[\frac{\partial}{\partial x}\left[K_{x}\left(\frac{\partial u}{\partial x}\right)\right]\right] d D=\int \Gamma\left[K_{x}\left(\frac{\partial u}{\partial x}\right)\right] \delta_{u} n_{x} d \Gamma
$$

Procedendo de maneira análoga com o termo $y$ da Equação (3.50), considerando $\delta_{u}=$ 0 em $\Gamma_{1}$, onde são aplicadas condições especiais, determina-se a Equação (3.53)

$$
\begin{gathered}
\int D\left[\left[K_{x}\left(\frac{\partial u}{\partial x} \frac{\partial \delta_{u}}{\partial x}\right)\right]+\left[K_{y}\left(\frac{\partial u}{\partial y} \frac{\partial \delta_{u}}{\partial y}\right)\right]-(\lambda u-c) \delta_{u}\right] d D- \\
\int \Gamma_{2}(f+h u) \delta_{u} d \Gamma_{2}=0
\end{gathered}
$$

A etapa seguinte requer a discretização do contínuo e a aproximação da variação de $u$ em cada elemento que pode ser introduzia na forma matricial, para um elemento genérico, conforme Equação (3.54), relacionando o valor da incógnita $u$ em qualquer ponto do elemento com os valores nos pontos nodais, representados pelo vetor $u^{e}$ e a matriz de funções de interpolação $N$.

$$
u=N u^{e}
$$


Com a Equação (3.54) podem ser obtidas as seguintes aproximações

$$
\begin{gathered}
\delta u=N \delta u^{e}=\delta u^{e, T} N^{T} \\
\frac{\delta u}{\delta x}=\frac{\delta N}{\delta x} u^{e}=N_{x} u^{e} \\
\frac{\delta u}{\delta y}=\frac{\delta N}{\delta y} u^{e}=N_{y} u^{e} \\
\frac{\partial \delta u}{\partial \delta x}=\delta u^{e, T} N_{x}^{T}, \quad \frac{\partial \delta u}{\partial \delta y}=\delta u^{e, T} N_{y}^{T}
\end{gathered}
$$

que, ao serem introduzidas na Equação (3.53), fornece a Equação (3.55).

$$
\begin{gathered}
\int D_{e}\left(K_{x} \delta u^{e, T} N_{x}^{T} N_{x} u^{e}+K_{y} \delta u^{e, T} N_{y}^{T} N_{y} u^{e}-\lambda \delta u^{e, T} N^{T} N u^{e}+e \delta u^{e, T} N^{T}\right) d D \\
-\int \Gamma_{2}\left(f \delta u^{e, T} N^{T}+h \delta u^{e, T} N^{T} N u^{e}\right) d \Gamma_{2}=0
\end{gathered}
$$

Onde $D_{e}$ é a área do elemento e $\Gamma_{2, e}$ é a parte do contorno do elemento com condições de contorno naturais. Quando não há contornos naturais para o elemento em questão a segunda integral da equação é anulada. Considerando-se que os vetores $u^{e}$ e $\delta u^{e}$ contêm apenas valores pontuais a Equação (3.55) pode assumir a forma expressa pela Equação (3.56).

$$
\begin{gathered}
\left\{\left[\int D_{e}\left(K_{x} N_{x}^{T} N_{x} u^{e}+K_{y} N_{y}^{T} N_{y}\right) d D-\int D_{e} \lambda N^{T} N d D-\int \Gamma_{2, e} h N^{T} N d \Gamma_{2}\right] u^{e}+\right. \\
\int D_{e} c N^{T} d D-\int \Gamma_{2, e} f N^{T} d \Gamma_{2, e}=0
\end{gathered}
$$

Sabendo-se que as variações de $\delta u^{e}$ são arbitrárias, a identidade acima só é válida se o termo entre chaves for identicamente nulo. Em seguida são definidas as matrizes e vetores apresentados na Equação (3.57).

$$
K^{e}=\int D_{e}\left(K_{x} N_{x}^{T} N_{x} u^{e}+K_{y} N_{y}^{T} N_{y}\right) d D
$$




$$
\begin{aligned}
M^{e} & =\int D_{e} N^{T} N d D \\
H^{e} & =\int \Gamma_{2, \mathrm{e}} h N^{T} N d \Gamma_{2} \\
P_{c}^{e} & =\int D_{e} c N^{T} d D \\
P_{f}^{e} & =\int \Gamma_{2, \mathrm{e}} f N^{T} d \Gamma_{2}
\end{aligned}
$$

Considerando as definições anteriores, chega-se à equação matricial para cada elemento (Equação (3.58)). Desse modo, a Equação (3.58) deve ser explicitada em função do tipo de elemento adotado e a combinação das matrizes nela contida fornecerá uma matriz global de solução do problema adotado. A aplicação do método numérica de elementos finitos resulta então em valores conhecidos nos nós da malha e que serão interpolados no interior dos elementos (Diersch, 1998).

$$
\left(K^{e}-\lambda M^{e}-H^{e}\right) u^{e}=P_{f}^{e}-P_{c}^{e}
$$

\subsubsection{2 - Confiabilidade dos Resultados obtidos por Aproximação Numérica}

A confiabilidade dos resultados obtidos por aproximação numérica é avaliada em termos de consistência, convergência e estabilidade. Essas propriedades apresentam correlação na solução numérica e são funções dos erros envolvidos. A consistência diz respeito à aproximação do sistema contínuo de equações por um sistema discreto. Isso significa que, quando incrementos espacial e temporal tendem a zero, os erros obtidos na solução aproximada também tendem a zero (Wrobel, 1989).

Convergência é a condição em relação à qual a solução aproximada tende para a solução exata da equação diferencial, à medida que se diminuem os incrementos espacial e temporal. Desse modo, ao considerar a solução exata $u_{0}$ no ponto $x=x_{i}$ e $u$ a solução numérica no mesmo ponto, o esquema é convergente quando o erro de discretização $\varepsilon=u_{0}$ - $u$ tende a zero em qualquer ponto $i$ do domínio. A solução aproximada fornecida pelos métodos de modelagem numérica repercute em erros que são inerentes à solução, sendo 
atribuição dos métodos numéricos minimizarem tais resíduos e tornarem a solução mais adequada e robusta (Diersh, 2014).

A estabilidade, por sua vez, é uma propriedade relacionada ao esquema de integração no tempo. Desse modo, quando um método numérico é considerado instável uma perturbação pequena, tal como um erro de truncamento, tende a crescer na medida em que o processo de cálculo avança no tempo. Na maioria das vezes essa amplificação é exponencial e o erro cresce acima dos limites razoáveis num pequeno número de passos do processo computacional (Wrobel, 1989).

\subsubsection{3 - Pacote Computacional FEFLOW}

Uma série de códigos computacionais, tanto comerciais quanto de domínio público, tais como o FEMWATER, FEFLOW, HYDRUS e SUTRA, é destinada à resolução de problemas de fluxo de água nas zonas saturada e não saturada do solo (Bear e Cheng, 2010). O FEFLOW (Finite Element Subsurface Flow and Transport Simulation System) é um programa comercial que realiza simulações bidimensionais e tridimensionais do fluxo da água no solo, além de possibilitar simulações de transporte de contaminantes e de calor, fluxo dependente da densidade e reações químicas em águas subterrâneas, utilizando o método numérico de elementos finitos para resolução de equações diferenciais parciais (Dierch, 2014).

A modelagem numérica no FEFLOW requer a definição do tipo de problema a ser abordado (fluxo ou transporte), da projeção do modelo (horizontal, vertical planar ou vertical assimétrico), da equação governante a ser solucionada (Darcy/Continuidade ou Richards) e do regime de simulação adotado (estacionário ou transiente). Com relação aos problemas de fluxo de água são aplicadas as equações de Darcy e da Continuidade, em condições saturadas, enquanto que para fluxo não saturado e em superfície de saturação variável utiliza-se a equação de Richards (Awan et al., 2015; Diersch, 2014).

O FEFLOW realiza modelagem matemática considerando as variáveis de estado discretizadas no tempo e espacialmente distribuídas, tanto em regime estacionário quanto transiente. Na simulação em regime transiente o FEFLOW possibilita a escolha de 
diferentes opções de discretização temporal, incluindo esquemas de intervalo de tempo constantes, variáveis ou por cálculo automático. Os intervalos de tempo calculados automaticamente são executados com integração do tempo de $1^{\mathrm{a}}$ ordem (Forward Euler/Backward Euler - FE/BE) ou um esquema de integração do tempo de $2^{\text {a }}$ ordem (Forward Adams Bashforth/Backward Trapezoid - AB/TR). Diersch (1998) ressalta que a escolha de intervalos de tempo automáticos do tipo $F E / B E$ é a mais adequada para uma diversidade de problemas.

Por basear-se no método de elementos finitos o FEFLOW possibilita uma definição facilitada das condições de contorno complexas dos problemas hidrogeológicos. Nesse caso, os nós que interligam os elementos finitos favorecem a representação de rios e poços quando comparados à discretização em células (diferenças finitas). Sua formulação permite ainda uma análise de meios não saturados e saturados, concomitantemente, bem como a integração dos recursos hídricos superficiais e subterrâneos, acoplando diferentes fases do ciclo hidrológico (Diersch, 2014).

Podem ser encontradas aplicações desse programa voltadas ao manejo de águas subterrâneas regionais (Awan et al., 2015), interação entre águas subterrâneas e superficiais (Hanspal et al., 2013), intrusão salina em aquíferos (Loáiciga et al., 2012) dentre outras. Awan et al. (2015), por exemplo, utilizaram o pacote computacional FEFLOW para elaboração de modelo numérico por elementos finitos a fim de simular níveis de águas subterrâneas para quatro cenários de melhoria na eficiência da irrigação em campos agrícolas, visando quantificar o impacto da irrigação sobre a dinâmica da água subterrânea. Bahrami et al. (2014), utilizando o mesmo recurso, simularam as condições aquíferas sob a premissa de interação entre as águas subterrâneas e superficiais em áreas de escavação por empresas mineradoras. 


\section{4 - MATERIAL E MÉTODOS}

\section{1 - ÁREA DE ESTUDO}

A fase experimental deste estudo foi realizada num trecho na vertente do córrego Capetinga (Figura 4.1). A bacia do córrego Capetinga encontra-se, em sua maior parte, na Fazenda Água Limpa (FAL), na porção sudoeste do Distrito Federal (Figura 4.1). A FAL é uma fazenda experimental, administrada pela Universidade de Brasília $(U n B)$, com área aproximada de $43 \mathrm{~km}^{2}$, destinada à preservação $\left(23 \mathrm{~km}^{2}\right)$, conservação $\left(8 \mathrm{~km}^{2}\right)$ e produção agropecuária $\left(12 \mathrm{~km}^{2}\right)$. A fazenda integra a Área de Proteção Ambiental $(A P A)$ da bacia hidrográfica Gama e Cabeça-de-Veado, tributária do Lago Paranoá, que, por sua vez, pertence à região hidrográfica do Paraná (UnB, 2009).

Além disso, uma porção da Fazenda é constituída pela Área de Relevante Interesse Ecológico (ARIE) Capetinga/Taquara, também denominada Estação Ecológica da Universidade de Brasília, constituída pelas bacias hidrográficas dos córregos Taquara e Capetinga (UnB, 2009). A seleção dessa área para realização do estudo fundamentou-se na necessidade de reduzir interferências antrópicas na estrutura e no funcionamento do ambiente de vertente, sendo importante a escolha de um local com cobertura do solo nativa.

A bacia do córrego Capetinga foi delimitada considerando como exutório a Estação de Monitoramento Fluviométrico $F A L$ - UnB (Código: 60478482), apresentada na Figura 4.2, em conjunto com a Estação Pluviométrica. A área de contribuição da bacia até o exutório é de aproximadamente $10 \mathrm{~km}^{2}$ (Figura 4.1c). O trecho de vertente selecionado para instalação do experimento geofísico, por sua vez, apresentou área aproximada de 136.000 $\mathrm{m}^{2}$ (cerca de 0,10 $\mathrm{km}^{2}$ ) (Figura 4.1d). Nos item 4.1.1 - e 4.1.2 - foram elencadas informações sobre o desenho experimental e a caracterização fisiográfica da área, respectivamente. 

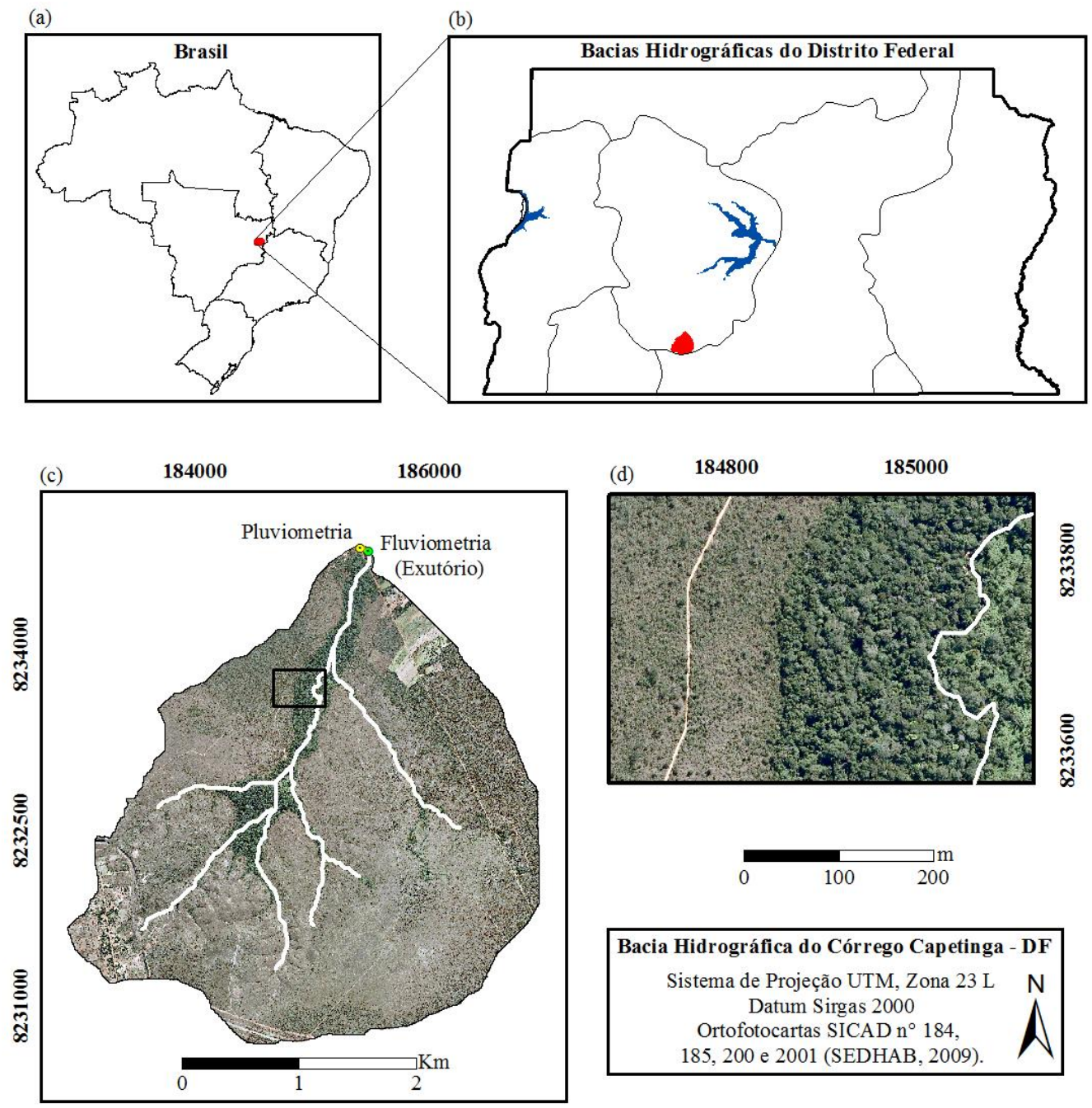

Figura 4.1 - Localização da área de estudo. b) Bacia hidrográfica do córrego Capetinga no DF. c) Bacia do córrego Capetinga em escala de 1:45000, com exutório na Estação Fluviométrica $F A L$ $U n B$. d) Visualização detalhada da vertente em estudo, com escala de 1:5000. O Córrego Capetinga foi representado pelo traçado branco para contraste.

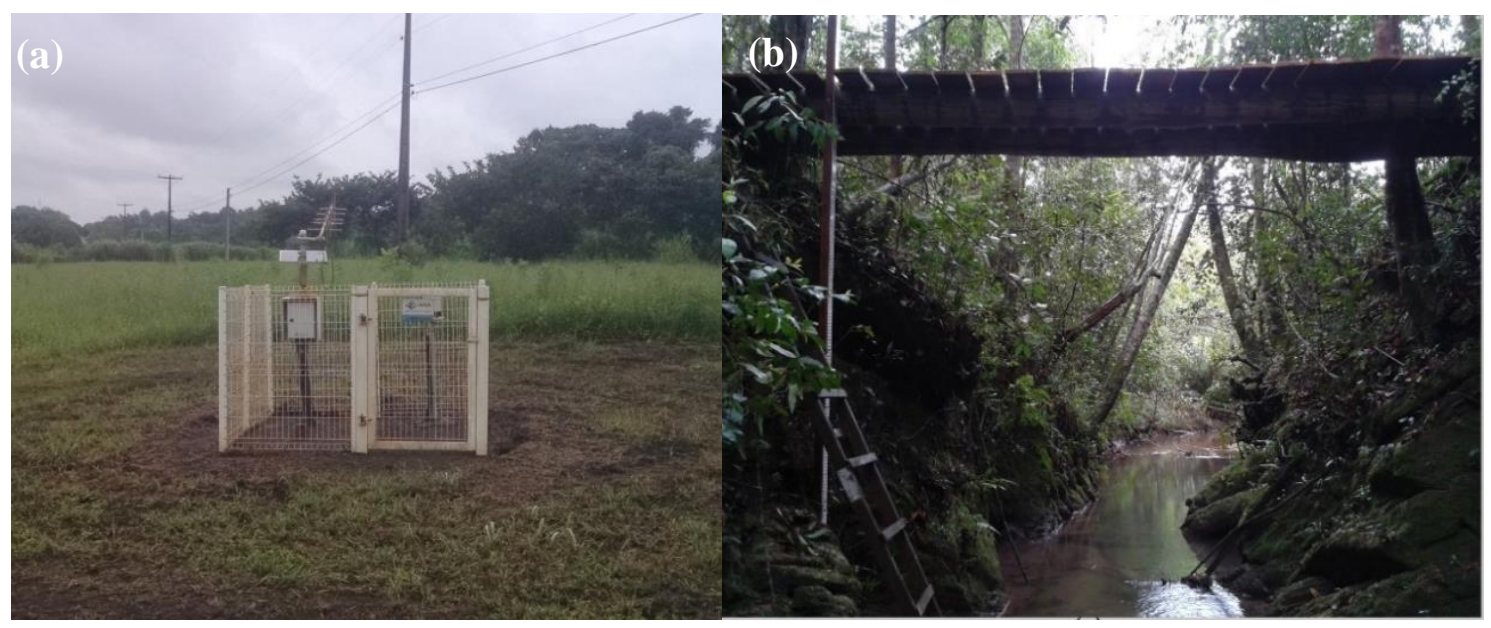

Figura 4.2 - a) Estações Pluviométrica e b) Fluviométrica automáticas $F A L-U n B$ (Código: 60478482). Fonte: Távora (2016). 


\subsection{1 - Desenho Experimental}

Os dados de resistividade elétrica e umidade do solo foram adquiridos no experimento instalado na vertente do córrego Capetinga, como apresentado na Figura 4.3b. Seis linhas de monitoramento geofísico foram esquematizadas, com $200 \mathrm{~m}$ de comprimento cada. Dessas, cinco foram distribuídas em paralelo ao córrego a partir da estrada até o limiar do corpo hídrico $(A, B, C, D$ e $E$ ), espaçadas 50 metros entre si. A sexta linha $(F)$ foi posicionada no sentido transversal às demais, interceptando-as no ponto central, num gradiente entre o cerradão e a mata de galeria.

Além disso, foram realizadas coletas de amostras de solo para determinação da umidade gravimétrica nos pontos $U A, U C$ e $U E$. Nos demais pontos centrais de cada linha, incluindo aqueles com coleta de solo, foram obtidos dados de umidade por meio da sonda $T D R$ e dos blocos de resistência elétrica. Por fim, realizou-se a abertura de um poço de observação $(P E)$ da água subterrânea no domínio aquífero poroso no ponto central da linha E.
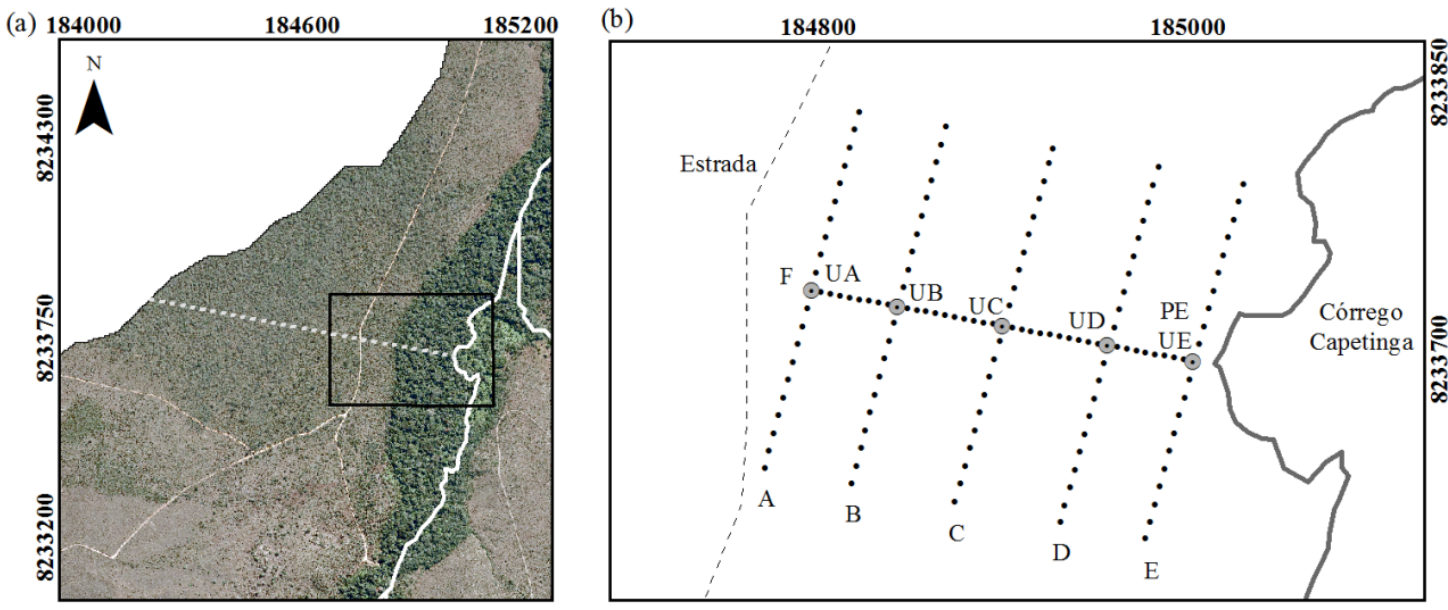

(c)

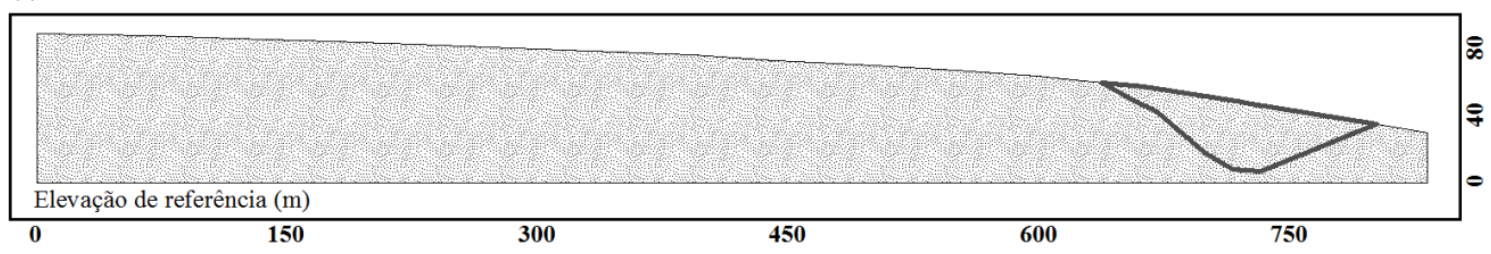

Figura 4.3 - a) Delimitação do desenho experimental (retângulo em negrito) e do perfil selecionado para modelagem numérica (tracejado cinza). b) Ilustração esquemática do desenho experimental adotado nos levantamentos geofísicos. c) Vista bidimensional do perfil utilizado na modelagem numérica, com informação de altitude $(m)$ no eixo $y$ e extensão longitudinal do perfil no eixo $x$. $\mathrm{O}$ destaque refere-se ao posicionamento da linha $F$ de monitoramento geofísico. 
Para simulação da carga hidráulica na vertente foi adotado o domínio bidimensional vertical apresentado na Figura $4.3 \mathrm{c}$, com $830 \mathrm{~m}$ de comprimento e $90 \mathrm{~m}$ de altura. Esse perfil resultou da extensão lateral da linha de monitoramento geofísico $F$ até o divisor topográfico de bacia. Optou-se por antecipar a apresentação do desenho experimental à caracterização da área com o objetivo de facilitar a visualização dos atributos fisiográficos junto à vertente em estudo.

\subsection{2 - Aspectos Fisiográficos}

\subsubsection{1 - Características Climáticas}

Considerando o sistema climático de Koppen, a bacia do córrego Capetinga possui clima tropical de altitude $(\mathrm{Cwa})$, com temperatura média mensal superior a $22^{\circ} \mathrm{C}$ na maior parte do ano (CODEPLAN, 1984). Quanto à precipitação, são observados valores em torno de $1.500 \mathrm{~mm}$ anuais, com ocorrência predominante entre os meses de outubro e março (Figura 4.4) (Maia e Baptista, 2008). A Figura 4.4 caracteriza o comportamento médio anual das variáveis precipitação e temperatura na área em estudo a partir do Banco de Dados Meteorológicos para Ensino e Pesquisa $(B D M E P)$ do Instituto Nacional de Meteorologia (INMET). Por meio desse banco de dados foi obtida série histórica com 50 anos (19652015) de médias mensais de precipitação $(\mathrm{mm})$ e temperatura $\left({ }^{\circ} \mathrm{C}\right)$, registradas pela Estação Automática de Brasília (Código: 86715; latitude/longitude: 8252183.91/186524.75 UTM).

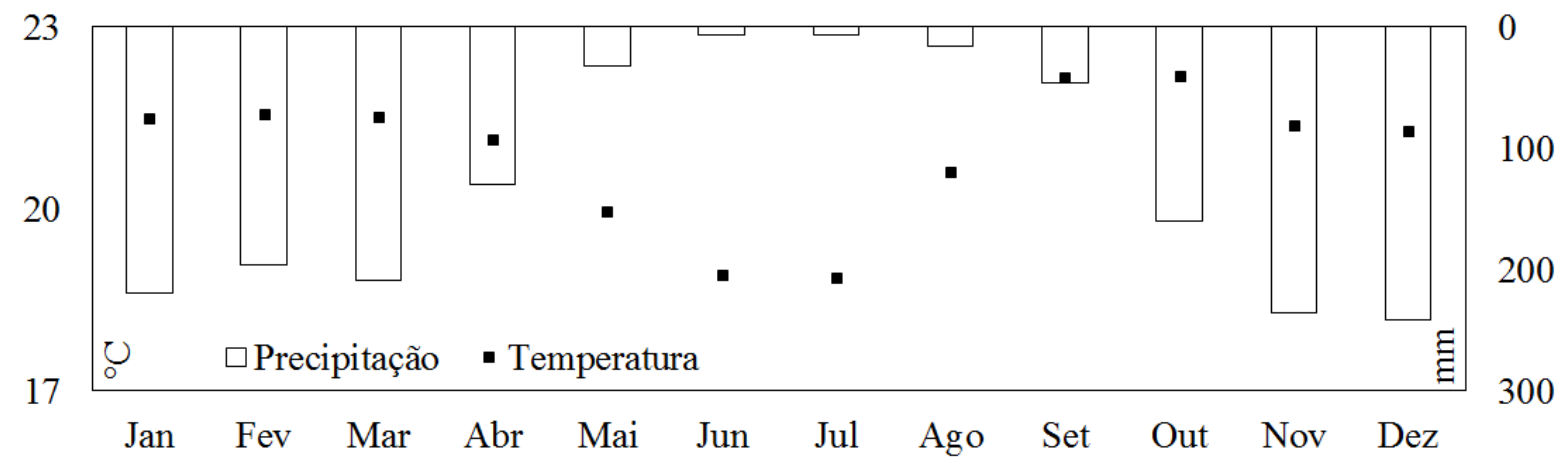

Figura 4.4 - Comportamento médio mensal dos valores de temperatura $\left({ }^{\circ} \mathrm{C}\right)$ e precipitação $(\mathrm{mm})$ entre os anos de 1965 e 2015. Fonte: INMET (2016). 


\subsubsection{2 - Conformação Topográfica e Aspectos de Uso e Cobertura do solo}

A bacia do córrego Capetinga localiza-se numa região com altitude média de $1.100 \mathrm{~m} \mathrm{e}$ amplitude de variação de 160 m, com cotas topográficas máxima e mínima equivalentes a 1.210 e 1.050 m, respectivamente (Figura 4.5). Com relação à inclinação, os valores mais acentuados de declividade (acima de 15\%) são observados nas proximidades do córrego, especialmente na cabeceira posicionada na região sudoeste da bacia (Figura 4.6).

Valores de altimetria extraídos da base de dados $\operatorname{SICAD}(\operatorname{SEDHAB}, 2009)$ foram utilizados para caracterização da declividade e da topografia da área de estudo; esses dados não permitiram um detalhamento preciso da vertente em estudo. Nesse caso, a região mais declivosa da vertente $(15-25 \%)$ encontra-se entre as linhas $C$ e $E$ (Figura 4.6). De maneira geral, observa-se uma variação entre 5 e $15 \%$ nos valores de declividade na zona ripária em destaque.
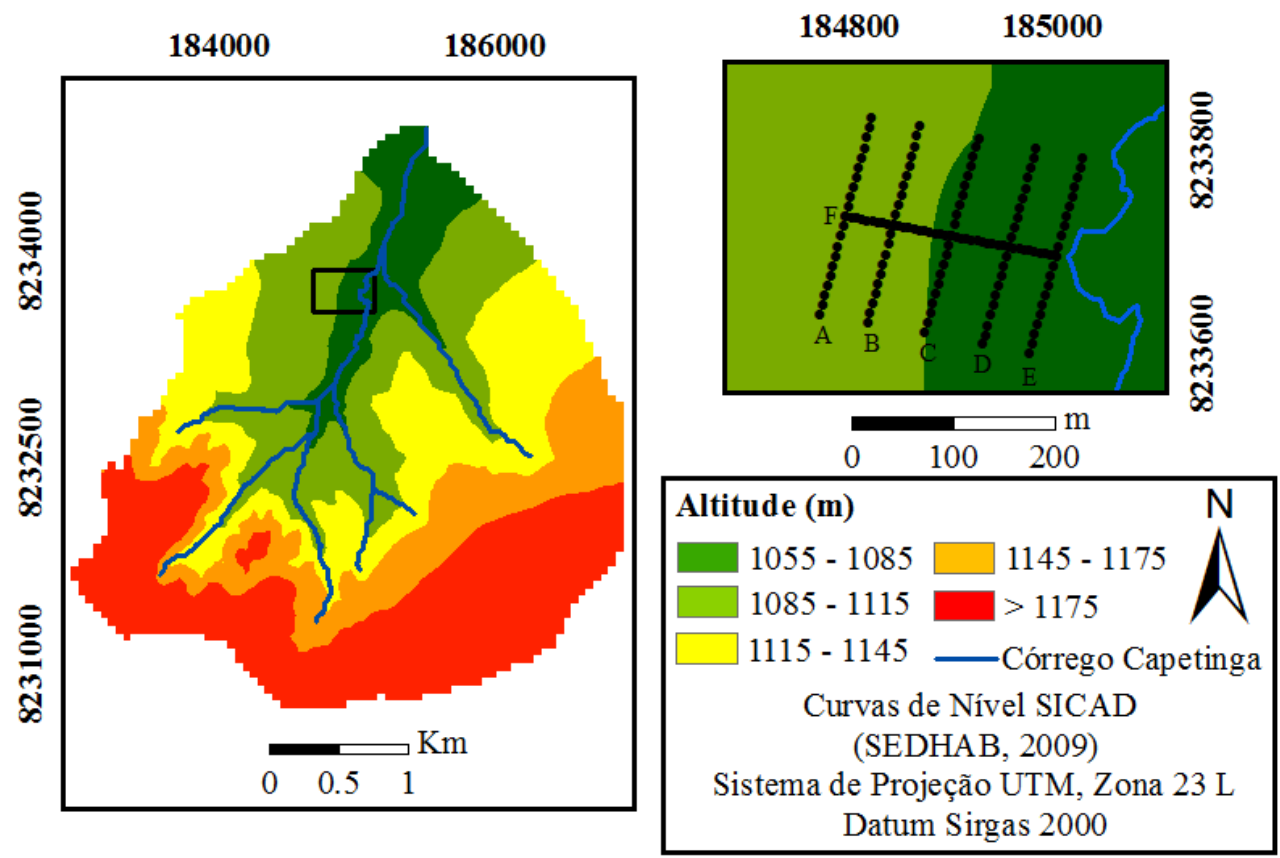

Figura 4.5 - Conformação topográfica da bacia do córrego Capetinga. Fonte: SEDHAB (2009).

A análise de uso e cobertura do solo na bacia foi realizada a partir da classificação supervisionada com aplicação do método da Máxima Verossimilhança, utilizando as ortofotocartas SICAD n ${ }^{\circ}$ 184, 185, 200 e 201 (SEDHAB, 2009) (Figura 4.7). As classes foram definidas a partir do Manual Técnico de Uso da Terra (IBGE, 2013). Contudo, a 
denominação cerrado foi adotada genericamente para as formações savânicas e campestres, com padrão de cor definido de maneira independente ao manual.
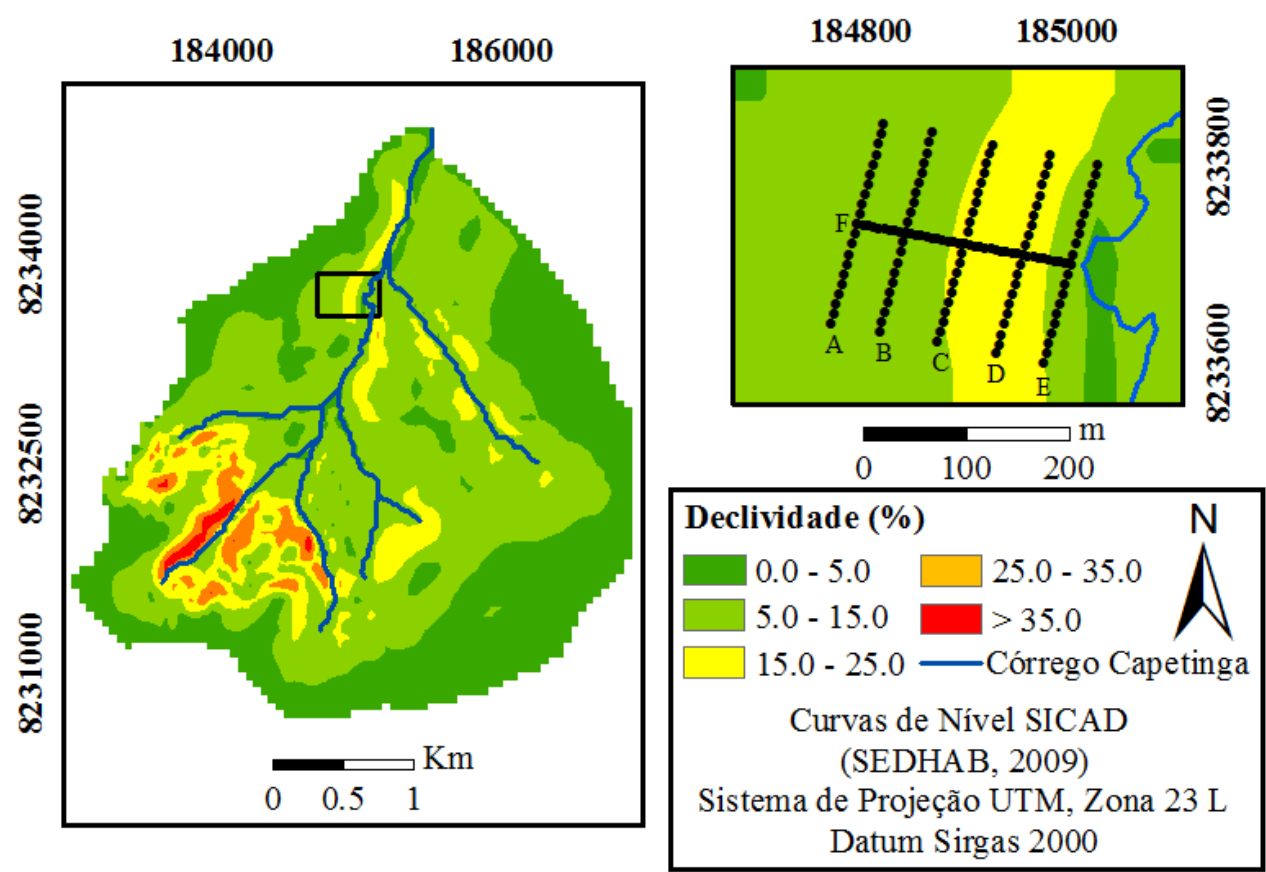

Figura 4.6 - Classes de declividade (\%) na área de estudo. Fonte: SEDHAB (2009).
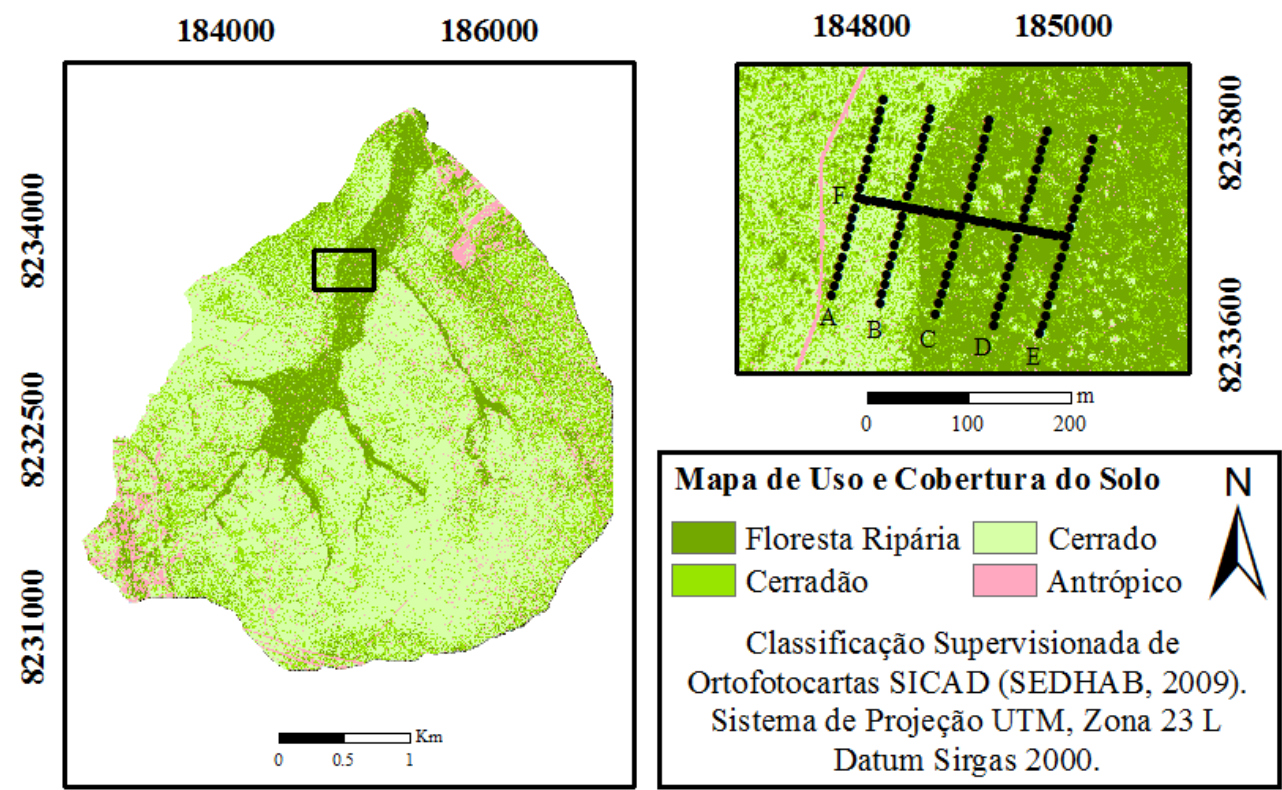

Figura 4.7 - Uso e cobertura do solo na bacia do córrego Capetinga. O traçado do córrego não foi inserido nesse mapa, ao contrário dos demais, para facilitar a visualização da cobertura do solo. Fonte: SEDHAB (2009).

Como observado na Figura 4.7, a cobertura do solo na bacia é predominantemente natural. Considerando toda a área da bacia, apenas $3 \%$ são destinadas à atividade antrópica (cerca 
de $0,30 \mathrm{~km}^{2}$ ). Nessa classe de uso podem ser incluídas a sede e as instalações destinadas à produção agropecuária da $F A L$, ao norte da bacia, assim como as estradas não pavimentadas no interior da Fazenda, a estrada férrea e as chácaras que circundam a porção sudoeste da bacia. A área restante é ocupada por vegetação nativa do Cerrado, incluindo formações florestais, savânicas e campestres.

Dentre as formações florestais, $10 \%$ da bacia são compostas por cerradão (aproximadamente $1 \mathrm{~km}^{2}$ ) e $12 \%$ por vegetação ripária (cerca de $1,20 \mathrm{~km}^{2}$ ). A classe definida como cerrado totalizou $75 \%$ de cobertura da bacia (aproximadamente $7,50 \mathrm{~km}^{2}$ ). $\mathrm{Na}$ zona de vertente, por sua vez, houve predomínio da Floresta Ripária (60\%) (Figura 4.8), em detrimento das formações Cerradão (22\%) e Cerrado (18\%) (Figura 4.9a e Figura $4.9 b)$. A classe de uso antrópico foi identificada apenas pela estrada não pavimentada na porção oeste da vertente, correspondendo a menos de $1 \%$ da área total.

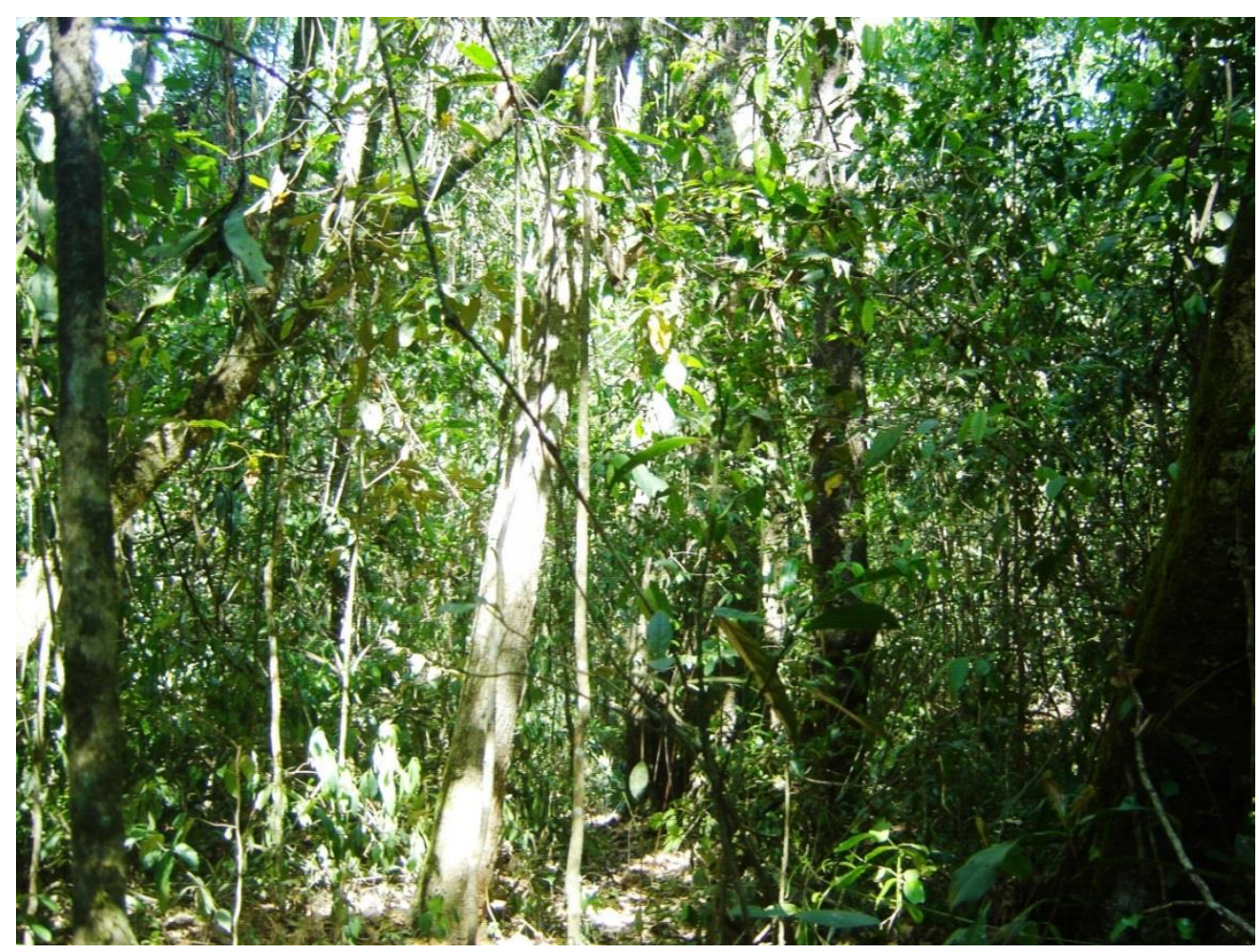

Figura 4.8 - Composição da vegetação ripária predominante na área em estudo. 

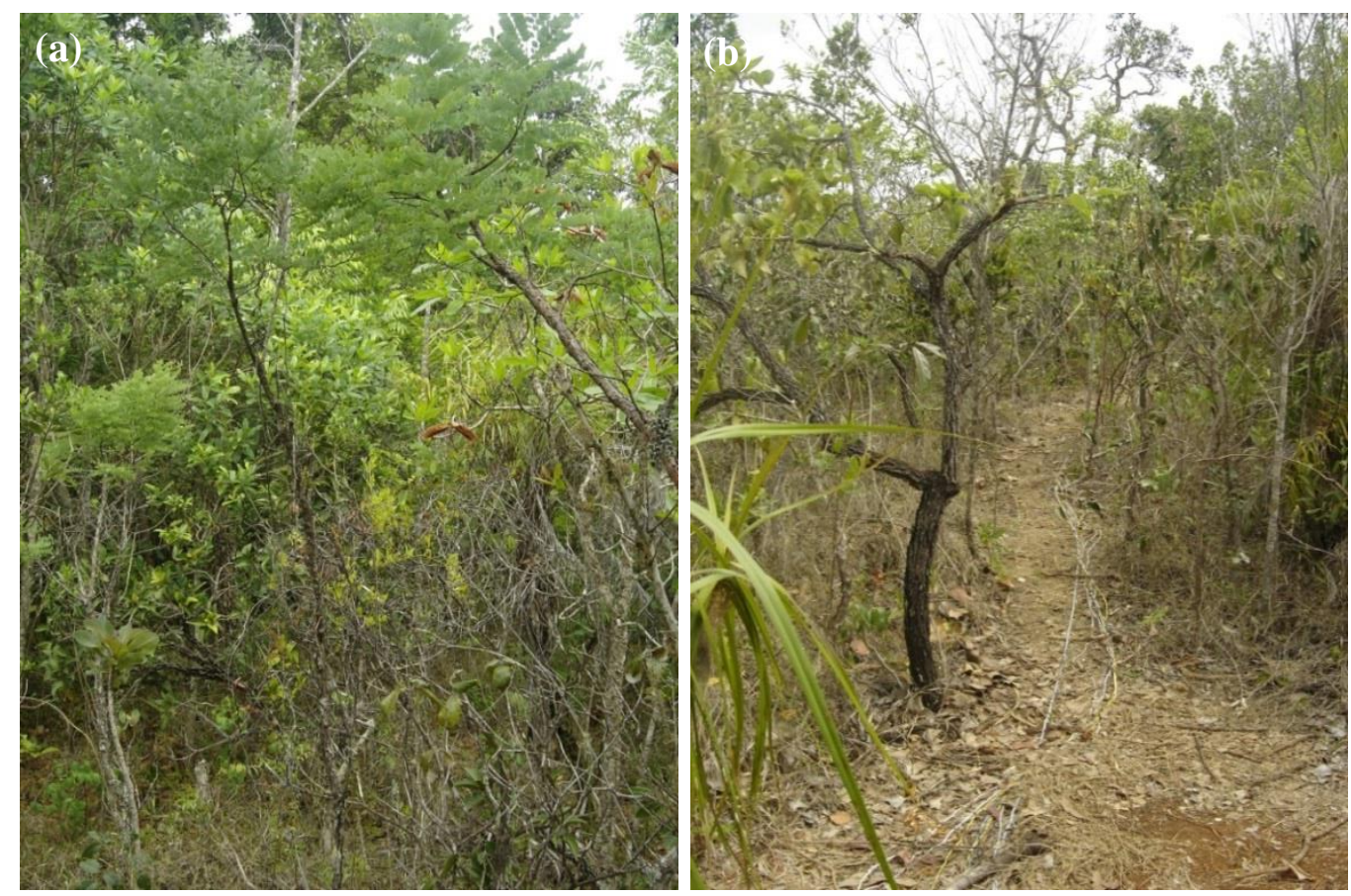

Figura 4.9 - Vegetação identificada na vertente em estudo. a) Formação florestal Cerradão. b) Formações savânica e campestre, denominadas conjuntamente de Cerrado.

\subsubsection{3 - Pedologia}

Considerando o levantamento pedológico realizado pela Embrapa (1978) e os trabalhos de Macedo (1996) e Reatto et al. (2004), o Distrito Federal apresenta as principais classes de solos presentes no Cerrado brasileiro, com predomínio de Latossolos Vermelho, Latossolos Vermelho-Amarelo e Cambissolos, que ocupam cerca de $85 \%$ da área do $D F$. A bacia do córrego Capetinga, por sua vez, possui Latossolos Vermelho e Vermelho-Amarelo, além de Cambissolo Háplico e solos Hidromórficos (Figura 4.10).

Os latossolos são intemperizados, profundos e com elevada capacidade de drenagem. Caracterizam-se por grande homogeneidade de características ao longo do perfil, mineralogia da fração argila predominantemente caulinítica ou caulinítica-oxídica, com baixa predominância de minerais primários de fácil intemperização. A diferença entre os Latossolos Vermelho e Vermelho-Amarelo ocorre especialmente em função dos teores mais acentuados de óxido de ferro que conferem a coloração mais escura aos Latossolos Vermelhos (IBGE, 2007; Santos et al., 2013). 

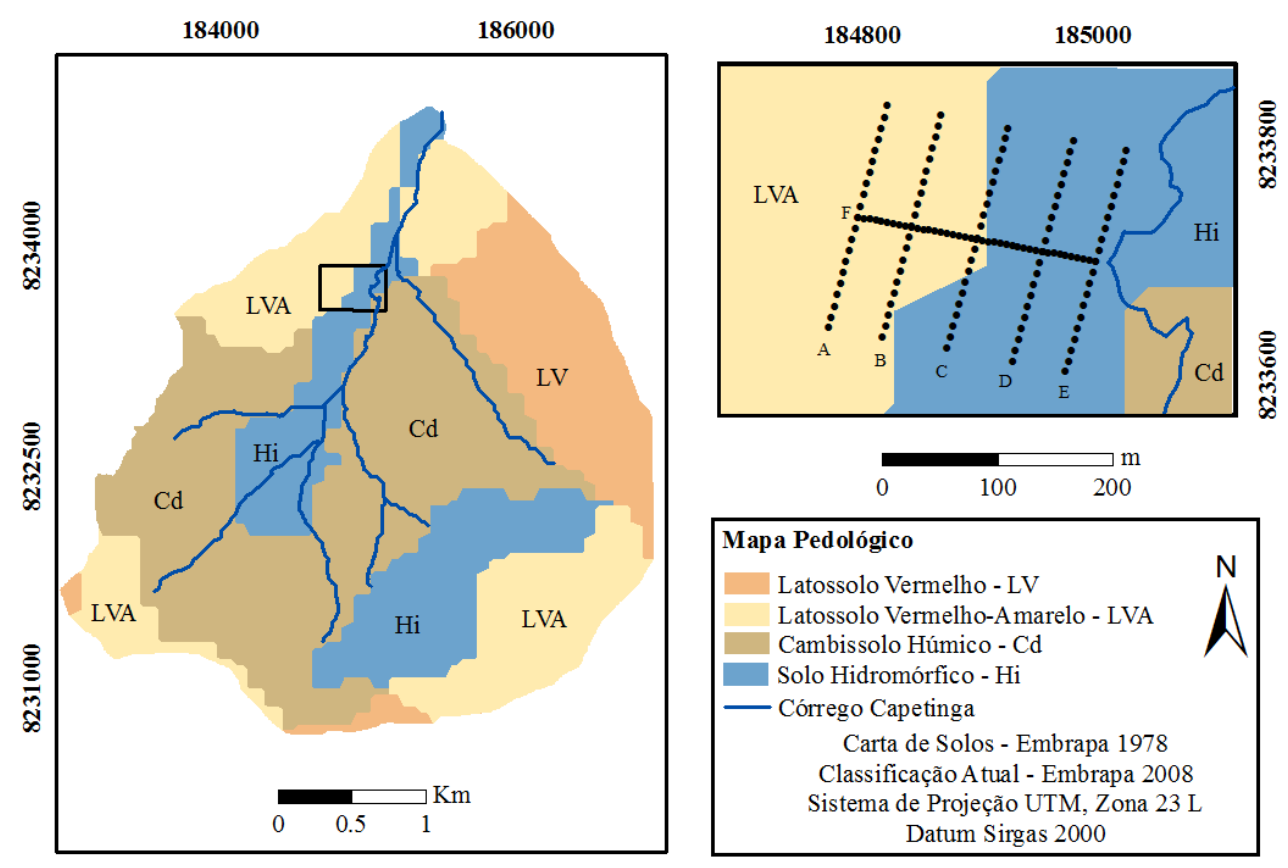

Figura 4.10 - Mapa pedológico. Fonte: Embrapa (1978).

Conforme Reatto et al. (2004), os solos hidromórficos são característicos de áreas alagadas ou sujeitas a alagamento (margens de rios, ilhas, grandes planícies). Apresentam cores acinzentadas, azuladas ou esverdeadas num intervalo de até $50 \mathrm{~cm}$ a partir da superfície e possuem baixa permeabilidade (Reatto et al., 2004). Os Cambissolos, por sua vez, possuem horizontes texturais com espessuras variáveis, podendo atingir 1,5 m (Santos et al., 2013). Muitas vezes são pedregosos, cascalhentos e mesmo rochosos, ocorrendo especialmente em regiões serranas e montanhosas (Santos et al., 2013; Reatto et al., 2004).

\subsubsection{4 - Geologia}

Conforme estudos de Moraes e Campos (2008), no Distrito Federal ocorrem rochas atribuídas aos grupos Canastra, Paranoá, Bambuí e Araxá. Os grupos referem-se a um conjunto de rochas com mesma idade, formadas em ambientes semelhantes e em geral subdivididos em unidades ou formações (Moraes e Campos, 2008). Os grupos Canastra e Paranoá apresentam idades de formação de cerca de um bilhão de anos, enquanto que os grupos Bambuí e Araxá foram originados entre 800 e 650 milhões de anos atrás (Martins et al., 2002).

$\mathrm{Na}$ bacia do córrego Capetinga existem formações geológicas das unidades Ardósia (MNPpr4) e Metarritmito Arenoso (MNPpq3), ambas pertencentes ao grupo Paranoá 
(Figura 4.11). A unidade MNPpr4 é caracterizada pela presença de metarritmitos com fração pelítica (predomínio de silte e argila), enquanto que a unidade MNPpq3 apresenta metarritmitos com frações arenosas (Freitas-Silva e Campos, 1998).
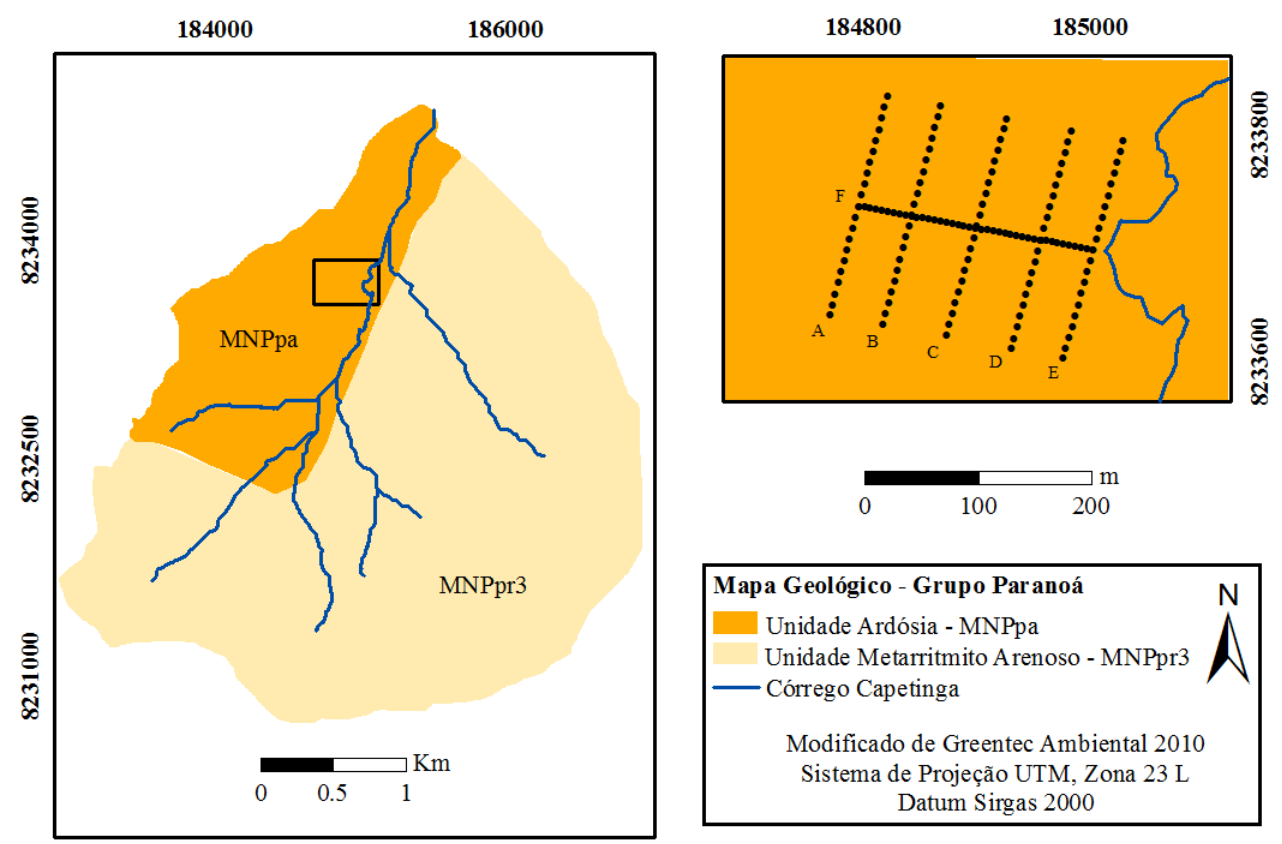

Figura 4.11 - Mapa geológico. Fonte: Greentec Ambiental (2010).

\subsubsection{5 - Hidrogeologia}

O contexto hidrogeológico do Distrito Federal, segundo Lousada e Campos (2005), é definido pela ocorrência de dois domínios, um poroso e outro fraturado (Figura 4.12). O domínio poroso é representado pelo manto de intemperismo (solo e saprolito) com aquíferos livres de grande continuidade lateral (Zoby e Duarte, 2001). A importância desses aquíferos no $D F$ está vinculada, principalmente, ao fato de a espessura da camada saturada e a condutividade hidráulica $(K)$ favorecerem o escoamento de base nos períodos de estiagem e ainda por representarem uma interface entre a zona não saturada e os aquíferos profundos do domínio fraturado (Campos e Freitas-Silva, 1998; Bugan et al., 2012). 


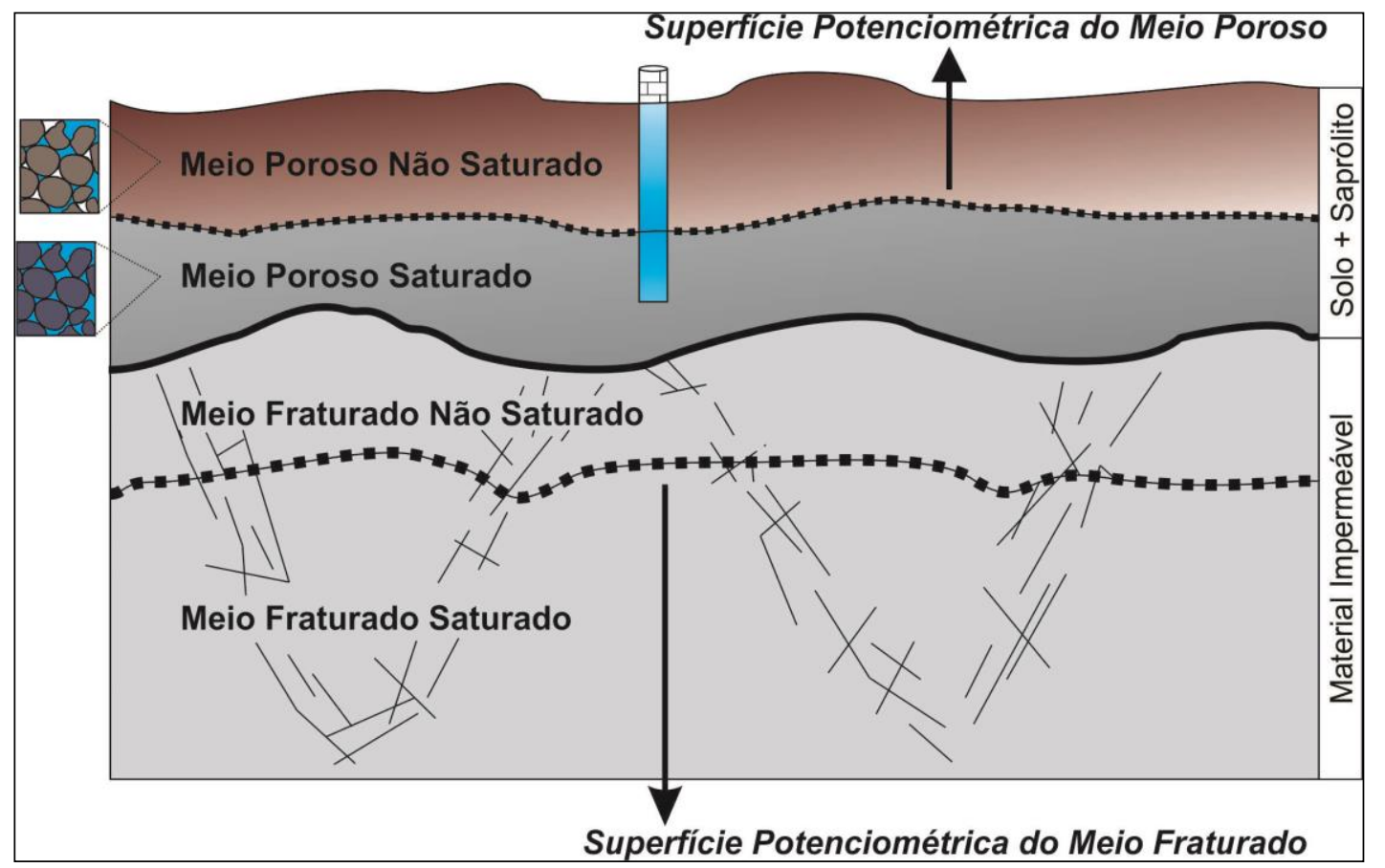

Figura 4.12 - Domínios aquíferos poroso e fraturado do Distrito Federal. Adaptado de Lousada e Campos (2005).

Em função dos parâmetros espessura e condutividade hidráulica, Campos e Freitas-Silva (1998) subdividiram o domínio poroso em quatro sistemas $(P 1, P 2, P 3$ e $P 4)$ cujas características podem ser observadas na Tabela 4.1.

O domínio fraturado ocorre em meio rochoso, onde os espaços ocupados pela água são representados pelas fraturas, microfraturas, diáclases, juntas, zonas de cisalhamentos e falhas (Lousada e Campos, 2005; Martins et al., 2002). Em função das características geológicas, feições estruturais e vazões dos poços, o domínio fraturado foi delimitado em quatro sistemas aquíferos no Distrito Federal, denominados Paranoá (subsistemas $S / A ; A$; $Q 3 / R 3 ; R 4$ e $P P C$ ), Canastra (subsistemas $F$ e $F / Q / M$ ), Araxá e Bambuí (Martins et al., 2002) (Tabela 4.2). 
Tabela 4.1 - Características do domínio aquífero poroso no $D F$.

\begin{tabular}{|c|c|c|c|c|c|}
\hline $\begin{array}{l}\text { Siste } \\
\text { ma }\end{array}$ & Subsistemas & $\begin{array}{l}\text { Condutividade } \\
\text { Hidráulica }\end{array}$ & $\begin{array}{r}\text { Vazão dos } \\
\operatorname{poços~}(\mathrm{L} / \mathrm{s})\end{array}$ & $\begin{array}{l}\text { Importância } \\
\text { Hidrogeológica }\end{array}$ & Solos \\
\hline$P_{1}$ & $\begin{array}{c}\text { Intergranulares, } \\
\text { contínuos, livres e } \\
\text { grande extensão } \\
\text { lateral }\end{array}$ & $\begin{array}{c}\text { Alta }\left(2,8 \times 10^{-4} \mathrm{a}\right. \\
\left.1,7 \times 10^{-5} \mathrm{~m} / \mathrm{s}\right)\end{array}$ & $<800$ & Elevada & $\begin{array}{c}\text { Latossolo Vermelho } \\
\text { Amarelo (arenoso) } \\
\text { e Neossolo } \\
\text { Quartzarênico }\end{array}$ \\
\hline$P_{2}$ & $\begin{array}{c}\text { Intergranulares, } \\
\text { contínuos, livres e } \\
\text { grande distribuição } \\
\text { lateral }\end{array}$ & $\begin{array}{c}\text { Média }\left(10^{-5} \text { a } 10^{-6}\right. \\
\mathrm{m} / \mathrm{s})\end{array}$ & $<800$ & Mediana & $\begin{array}{c}\text { Latossolo Vermelho } \\
\text { Amarelo (argiloso) }\end{array}$ \\
\hline$P_{3}$ & $\begin{array}{c}\text { Intergranulares, } \\
\text { descontínuos, } \\
\text { livres e distribuição } \\
\text { lateral ampla }\end{array}$ & $\begin{array}{l}\text { Baixa }\left(2,3 \times 10^{-6} \mathrm{a}\right. \\
\left.1,4 \times 10^{-7} \mathrm{~m} / \mathrm{s}\right)\end{array}$ & $<800$ & Pequena & $\begin{array}{c}\text { Latossolo Vermelho } \\
\text { Amarelo (argiloso) } \\
\text { e Cambissolos }\end{array}$ \\
\hline$P_{4}$ & $\begin{array}{c}\text { Intergranulares, } \\
\text { descontínuos, } \\
\text { livres e muito } \\
\text { restritos } \\
\text { lateralmente }\end{array}$ & $\begin{array}{l}\text { Muito Baixa }(1,4 \mathrm{x} \\
\left.10^{-7} \mathrm{~m} / \mathrm{s}\right)\end{array}$ & $<800$ & Muito Pequena & Cambissolos \\
\hline
\end{tabular}

Fonte: Souza e Campos (2001).

Tabela 4.2 - Características do domínio aquífero fraturado no $D F$.

\begin{tabular}{|c|c|c|c|c|c|}
\hline Sistema & Subsistemas & $\begin{array}{l}\text { Condutividade } \\
\text { Hidráulica }\end{array}$ & $\begin{array}{l}\text { Vazão Média } \\
\text { dos poços } \\
(\mathrm{L} / \mathbf{s})\end{array}$ & $\begin{array}{l}\text { Importância } \\
\text { Hidrogeológica }\end{array}$ & Tipo de Aquífero \\
\hline \multirow{5}{*}{ Paranoá } & $S / A$ & $\begin{array}{c}2,5 \times 10^{-6} \text { a } 1,7 \times 10^{-7} \\
(\mathrm{~m} / \mathrm{s})\end{array}$ & 12.500 & Elevada & $\begin{array}{l}\text { Livres ou confinados, } \\
\text { descontínuos, de meios } \\
\text { anisotrópicos fissurais }\end{array}$ \\
\hline & $A$ & Pequena & 4.500 & Muito Pequena & $\begin{array}{c}\text { Descontínuos, livres, com } \\
\text { extensão lateral restrita }\end{array}$ \\
\hline & $Q_{3} / R_{3}$ & $\begin{array}{c}1,7 \times 10^{-5} \text { a } 5,3 \times 10^{-7} \\
(\mathrm{~m} / \mathrm{s})\end{array}$ & 12.500 & Muito Alta & $\begin{array}{l}\text { Descontínuos, com extensão } \\
\text { lateral variável, livres ou } \\
\text { confinados e anisotrópicos. }\end{array}$ \\
\hline & $R_{4}$ & Baixa & 6.500 & Mediana & $\begin{array}{l}\text { Restritos lateralmente, } \\
\text { descontínuos e livres }\end{array}$ \\
\hline & $P P C$ & Baixa à elevada & 9.000 & Variável & $\begin{array}{l}\text { Descontínuos com alta } \\
\text { variabilidade lateral }\end{array}$ \\
\hline \multirow[b]{2}{*}{ Canastra } & $F$ & Baixa & 7.500 & Média a Moderada & Descontínuos e livres. \\
\hline & $F / Q / M$ & Muito Elevada & 33.000 & Muito Grande & $\begin{array}{l}\text { Restritos lateralmente, livres } \\
\text { ou confinados, descontínuo, } \\
\text { heterogêneos e anisotrópicos }\end{array}$ \\
\hline Bambuí & & Média a baixa & 6.500 & Mediana & $\begin{array}{l}\text { Livres, descontínuos } \\
\text { lateralmente e anisotrópicos }\end{array}$ \\
\hline Araxá & & Muito Baixa & 3.500 & Muito Pequena & $\begin{array}{l}\text { Descontínuos livres e } \\
\text { anisotrópicos }\end{array}$ \\
\hline
\end{tabular}

Fonte: Souza e Campos (2001). 
Com relação ao domínio fraturado (Figura 4.13) a bacia do córrego Capetinga está inserida no sistema Paranoá (subsistemas $A$ e $R 3 / Q 3$ ). Quanto ao domínio poroso, são identificados os sistemas $P 1, P 3$ e $P 4$. O sistema $P 1$ é considerado heterogêneo e pouco anisotrópico e pode ser visualizado na extensão leste da área de estudo, com espessura da zona saturada de até 30 m (Freitas-Silva e Campos, 1998). Os sistemas P3 e P4 caracterizam-se por aquíferos heterogêneos e anisotrópicos (Freitas-Silva e Campos, 1998). Neste estudo, apenas o domínio aquífero poroso foi considerado, havendo predomínio do sistema P4 junto à vertente de interesse (Figura 4.13).
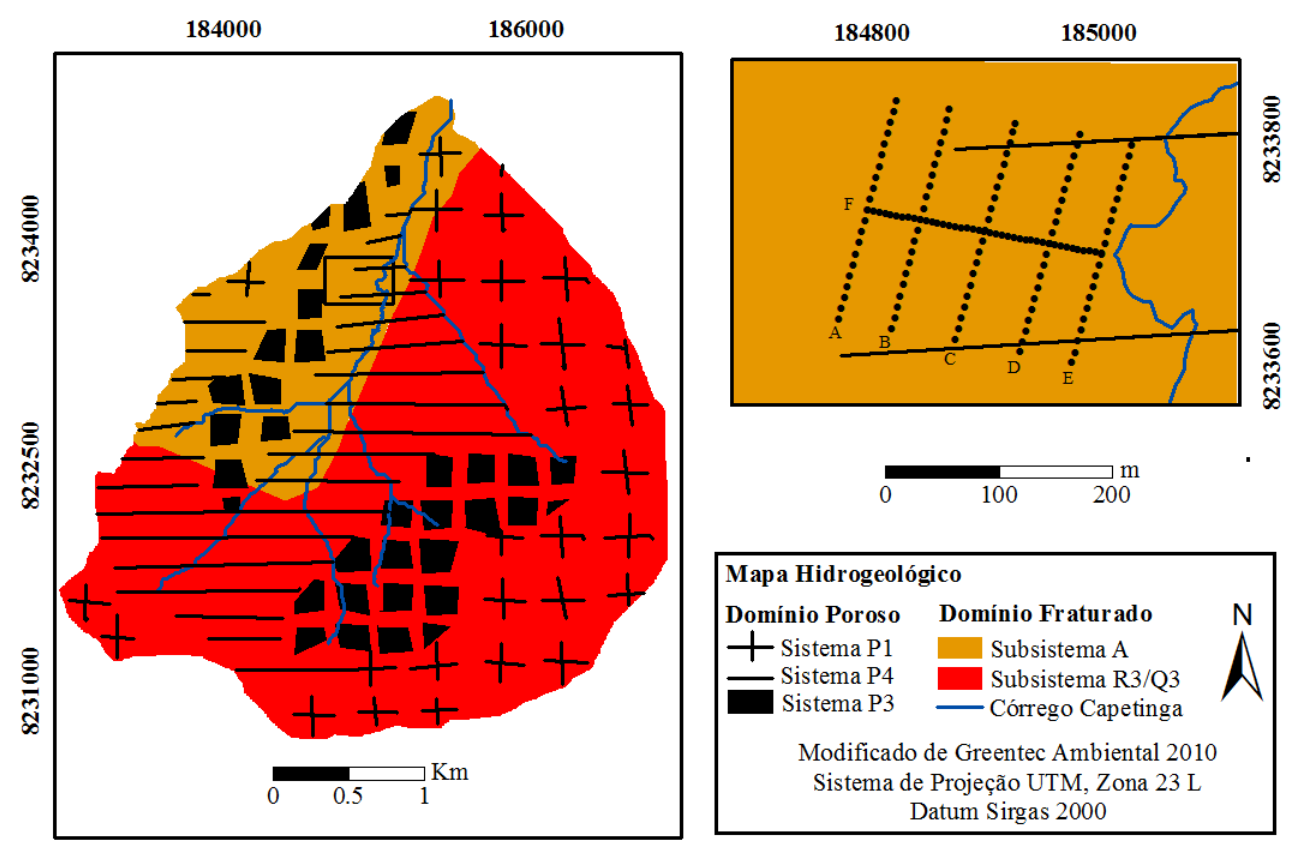

Figura 4.13 - Mapa hidrogeológico da área de estudo, com espacialização dos domínios aquíferos poroso e fraturado. Fonte: Greentec Ambiental (2010).

\section{2 - METODOLOGIA}

A proposta metodológica adotada neste trabalho foi centrada na aquisição de dados geofísicos para caracterização geoelétrica do solo, bem como na aplicação de um modelo matemático numérico voltado à simulação da carga hidráulica no domínio aquífero poroso. Informações complementares, tais como umidade do solo, precipitação, interceptação, evapotranspiração real, vazão, escoamento de base, nível da água do córrego Capetinga e dados altimétricos, também foram adquiridas. 
Os levantamentos geofísicos foram realizados como alternativa à caracterização da vertente quanto ao comportamento da umidade do solo e das flutuações da água subterrânea. Como já explanado no Capítulo 3, o método elétrico de corrente contínua é adequado ao objetivo do estudo, a exemplo dos trabalhos desenvolvidos por Asry et al. (2012), Andersen et al. (2013) e Zarroca et al. (2014). Como afirmam Nascimento et al. (2001), esse método responde rapidamente a variações de umidade no solo. Desse modo, por possuir natureza não invasiva, de baixo custo e fornecer medidas sensíveis às características do meio, o método elétrico de corrente contínua foi selecionado para diagnosticar, de maneira indireta, variações de umidade do solo e o nível do lençol freático.

Quanto ao modelo numérico, sua aplicação permitiu obter valores de carga hidráulica considerando a variabilidade espacial e temporal do fluxo de água ao longo da vertente. Nesse caso, a aplicação do pacote computacional FEFLOW decorreu da adequação do método de elementos finitos à modelagem numérica de contornos irregulares e da possibilidade de simulação conjunta das zonas não saturada e saturada do solo. Associar a caracterização do solo obtida por meio da análise dos dados de resistividade elétrica à modelagem foi um artifício para obtenção das condições iniciais e comparação com os resultados do modelo, uma vez que não há informação de campo quanto à variação da carga hidráulica na área em estudo.

\subsection{1 - Imageamento Elétrico do Solo}

\subsubsection{1 - Instalação do Experimento e Aquisição de Dados}

A instalação do experimento apresentado no item 4.1.1 - ocorreu entre janeiro e agosto de 2015. Inicialmente o traçado do córrego Capetinga foi levantado para permitir a correta localização do experimento, sendo utilizado um GPS modelo Etrex da Garmin, com precisão de $5 \mathrm{~m}$. Em seguida, seis trilhas, com $200 \mathrm{~m}$ de comprimento cada, sendo cinco paralelas ao córrego e uma ortogonal, foram abertas para permitir a disposição dos eletrodos e fios utilizados no levantamento geofísico.

Após a remoção da vegetação rasteira e da serapilheira sobreposta ao solo, foram posicionadas duas trenas com $100 \mathrm{~m}$ de comprimento cada, a partir do centro da trilha, 
visando o posicionamento dos eletrodos e posterior instalação dos fios. Nas cinco linhas paralelas ao córrego foi adotado espaçamento de $10 \mathrm{~m}$ entre os eletrodos (21 eletrodos entre os pontos 0 e $200 \mathrm{~m}$ de cada linha). Na linha ortogonal, por sua vez, os eletrodos foram instalados a cada $5 \mathrm{~m}$ (41 eletrodos entre os pontos 0 e $200 \mathrm{~m}$ de cada linha) com o intuito de aumentar a discretização e, consequentemente a resolução dos dados de resistividade elétrica nas camadas superficiais.

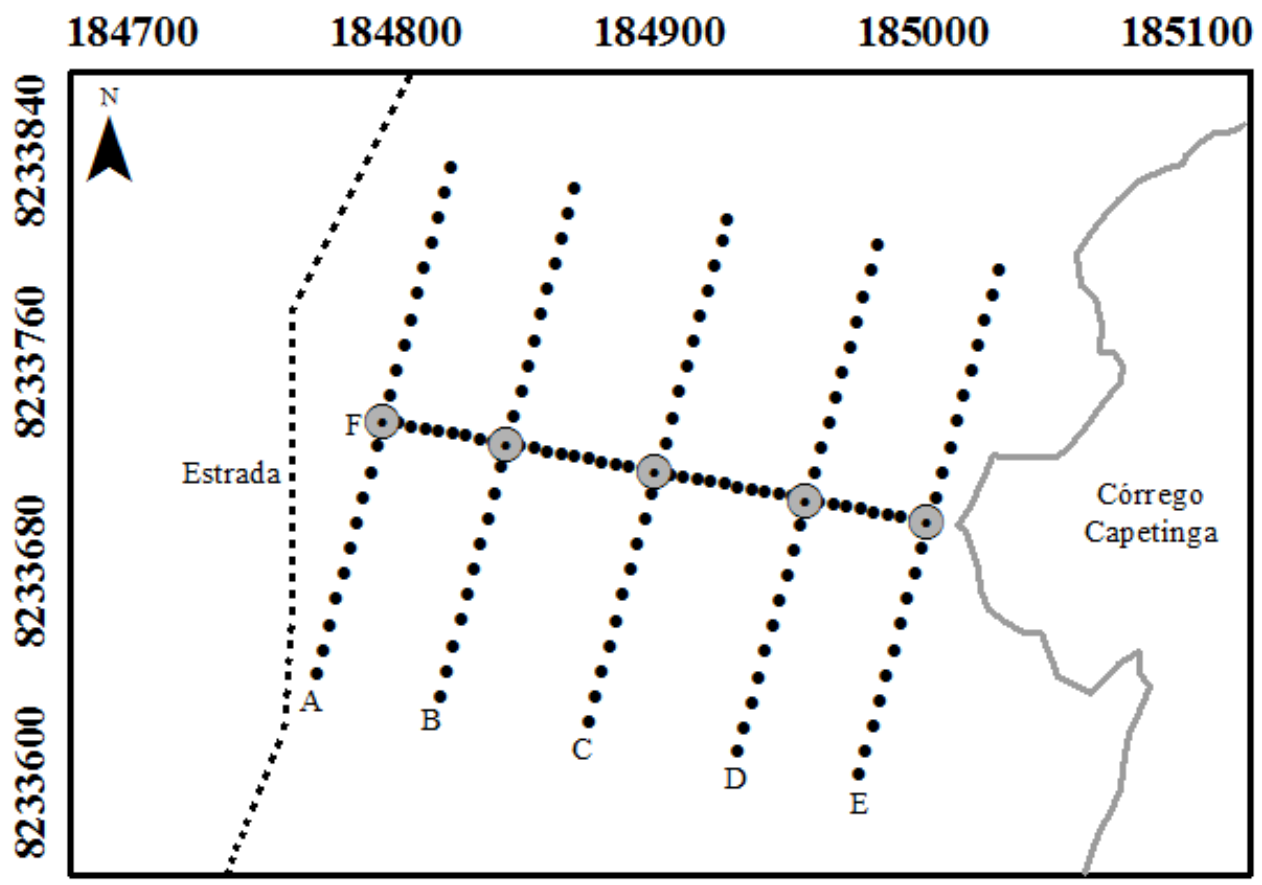

Figura 4.14 - Ilustração esquemática do desenho experimental, sendo seis linhas de monitoramento com $200 \mathrm{~m}$ cada. As letras de " $A$ " a " $E$ " designam as seções paralelas ao córrego, com eletrodos espaçados $10 \mathrm{~m}$ entre si. A letra " $F$ " denomina a seção transversal ao córrego, com eletrodos distribuídos a cada $5 \mathrm{~m}$.

Como eletrodos foram utilizadas barras de aço inox com diâmetro de $1 / 4$ de polegada e 50 $\mathrm{cm}$ de comprimento, cravados no solo a $20 \mathrm{~cm}$ de profundidade. Em cada eletrodo foi fixado um fio que se estendeu pelo chão no alinhamento até o ponto central. Para cada uma das linhas paralelas ao córrego foram empregados $5.500 \mathrm{~m}$ de fio, enquanto que para a linha $F$ utilizaram-se $2.100 \mathrm{~m}$. Os fios interligados aos eletrodos foram estendidos ao longo da trilha e depois reunidos numa placa de conexão construída para facilitar a instalação do experimento, ordenando a disposição dos cabos, e para permitir a rápida identificação dos pontos de interesse durante o levantamento de dados (Figura 4.15a).

As placas de conexão foram elaboradas em placas de polietileno (tábua de corte de cozinha) de fácil perfuração, nas quais foram instalados parafusos onde foram fixados os 
fios. Cada placa foi armazenada em uma caixa plástica a fim reduzir as interferências da umidade e da ação direta da luz solar nas conexões (Figura 4.15b). O preparo das seis placas de conexão exigiu $300 \mathrm{~m}$ adicionais de fio ao todo. Vale ressaltar que a placa de conexão utilizada na linha $F$ exigiu 20 parafusos a mais em comparação àquelas elaboradas para as linhas de $A$ a $E$, totalizando 41 parafusos para a linha $F$ e 21 para as demais.

Após instalação das placas (Figura 4.15b; Figura 4.16, Figura 4.17 e Figura 4.18a), as medições foram realizadas por meio do resistivímetro Geopulse (Figura 4.18b). O Geopulse possui seleção manual de intensidade de corrente entre 0,5 e $100 \mathrm{~mA}$. Além disso, o equipamento opera com corrente contínua e é alimentado por uma bateria de $12 \mathrm{~V}$ recarregável. Durante sua operação, pode-se optar pela medição da diferença de potencial $(\Delta U)$ ou da resistência elétrica $(R)$. O intervalo de leituras de $R$ varia entre $0,001 \Omega$ e 360 $K \Omega$.

Para obtenção do parâmetro resistividade elétrica foi empregado o método elétrico de corrente contínua. Utilizou-se a técnica de caminhamento elétrico ou perfilagem elétrica horizontal, possibilitando o conhecimento da variação horizontal da resistividade a partir de pontos não fixos na superfície do terreno, em seis profundidades constantes para as linhas paralelas e doze para a linha ortogonal. Por meio da técnica selecionada pode-se realizar o imageamento elétrico do solo em seções bidimensionais. Para desenvolvimento da técnica de aquisição foi adotado o arranjo $\alpha$-Wenner, identificado genericamente como arranjo de Wenner, com espaçamento equidistante dos eletrodos em cada nível de investigação.

Nas linhas paralelas ao córrego Capetinga foi adotado espaçamento de $10 \mathrm{~m}$ entre os quatros eletrodos no primeiro nível de investigação, $20 \mathrm{~m}$ para o segundo, e assim consecutivamente até o sexto nível, com 60 m de espaçamento (Figura 4.19). Para a linha $F$ foram adotados espaçamentos múltiplos de $5 \mathrm{~m}$ a partir do nível 1 , com $5 \mathrm{~m}$ de espaçamento (Figura 4.20). A profundidade teórica de investigação no arranjo de Wenner consiste em metade da máxima distância $(a)$ entre os eletrodos constitutivos do arranjo. Considerando o espaçamento máximo de $60 \mathrm{~m}$, as investigações foram realizadas à profundidade teórica de $30 \mathrm{~m}$. 


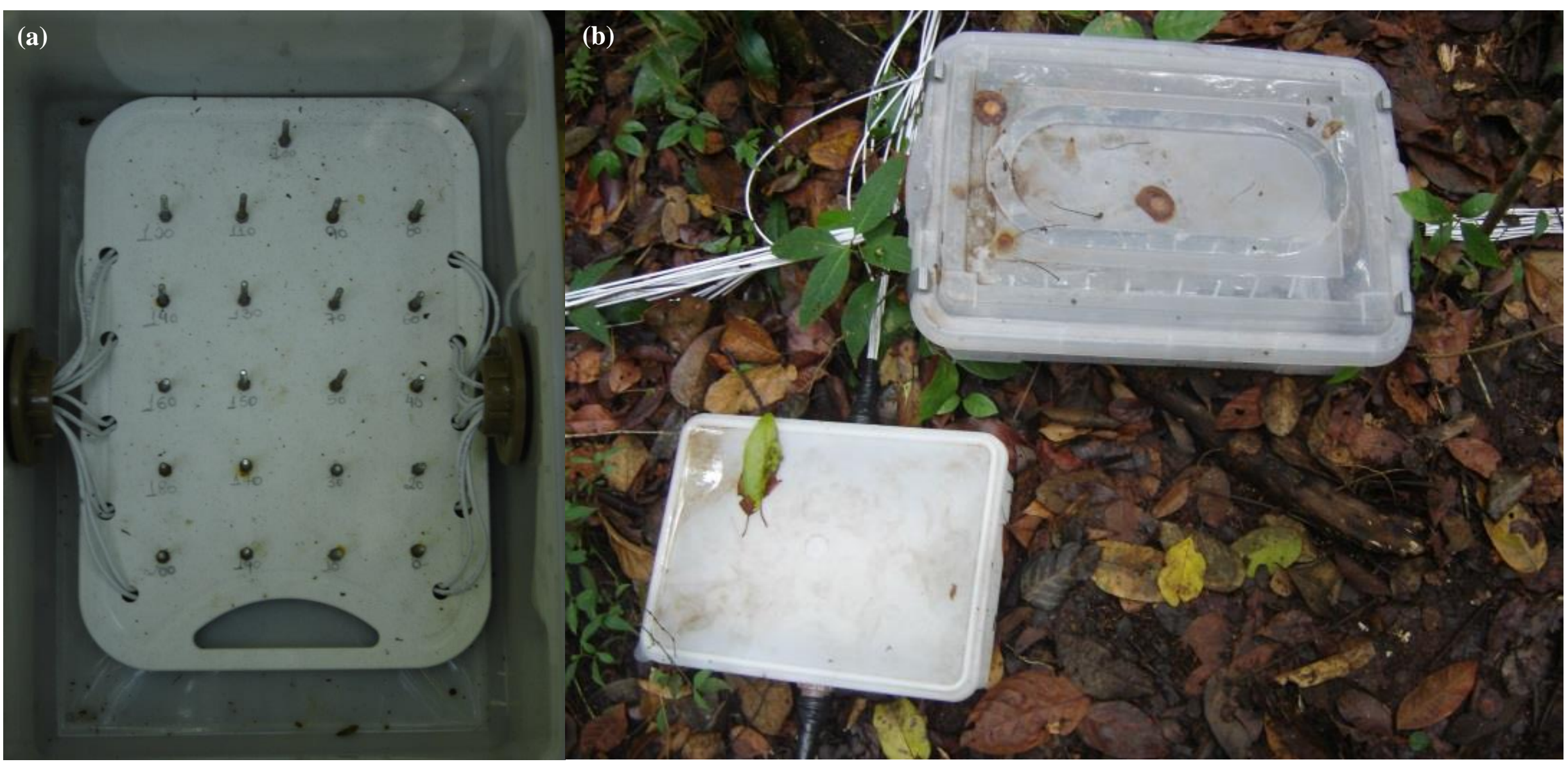

Figura 4.15 - a) Placa de conexão posicionada no ponto central de cada linha. Os parafusos fixados nas tábuas foram identificados com numeração sequencial indicativa da posição dos fios a eles associados. b) Caixas plásticas contendo a placa de conexão dos elétrodos. Neste caso, é observada a interceptação entre as linhas $C$ (caixa menor, abaixo), paralela ao córrego; e $F$ (caixa maior, acima), transversal ao córrego. 


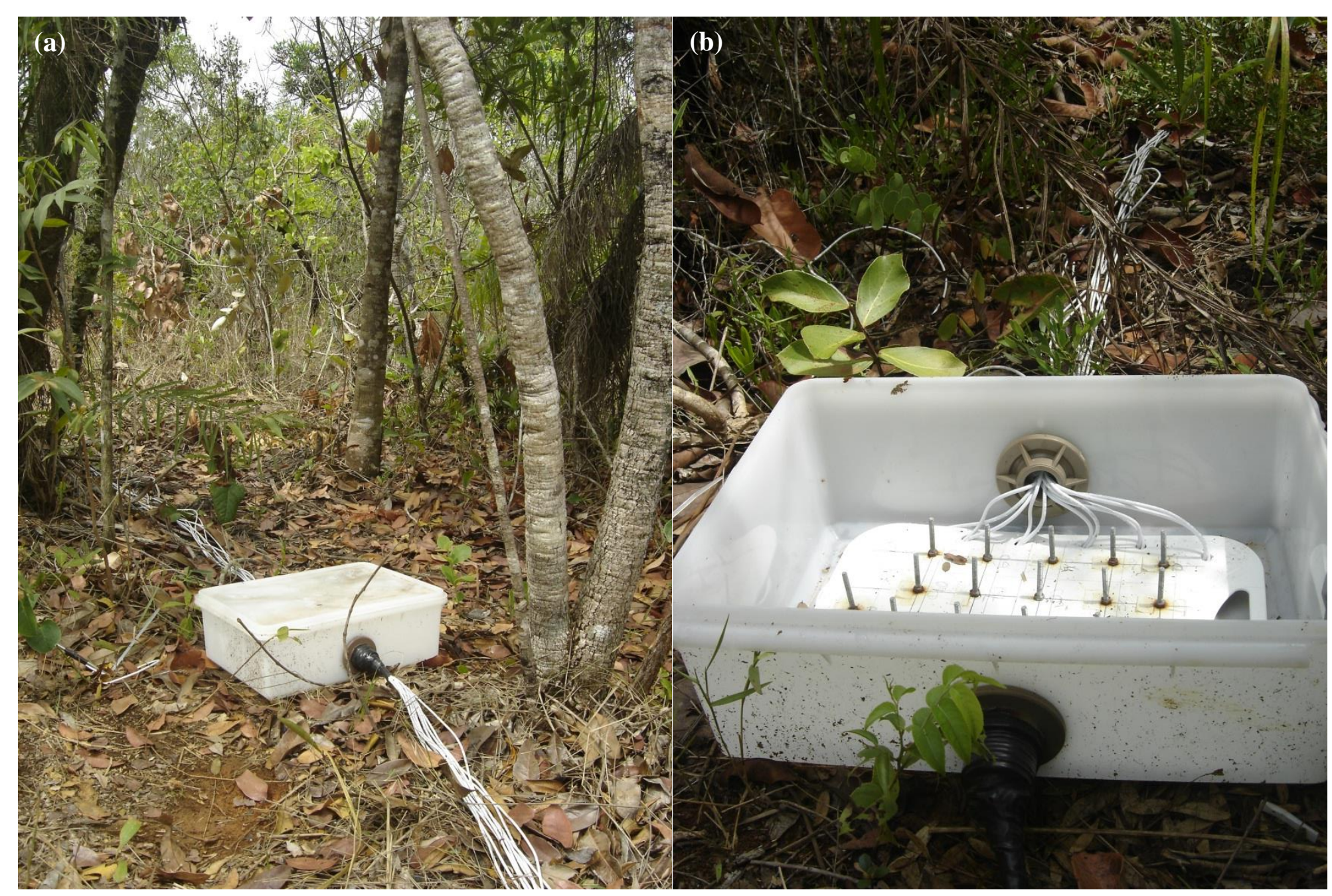

Figura 4.16 - a) Visualização de um trecho da linha $A$, com a vegetação circundante. b) Disposição da linha $B$. 


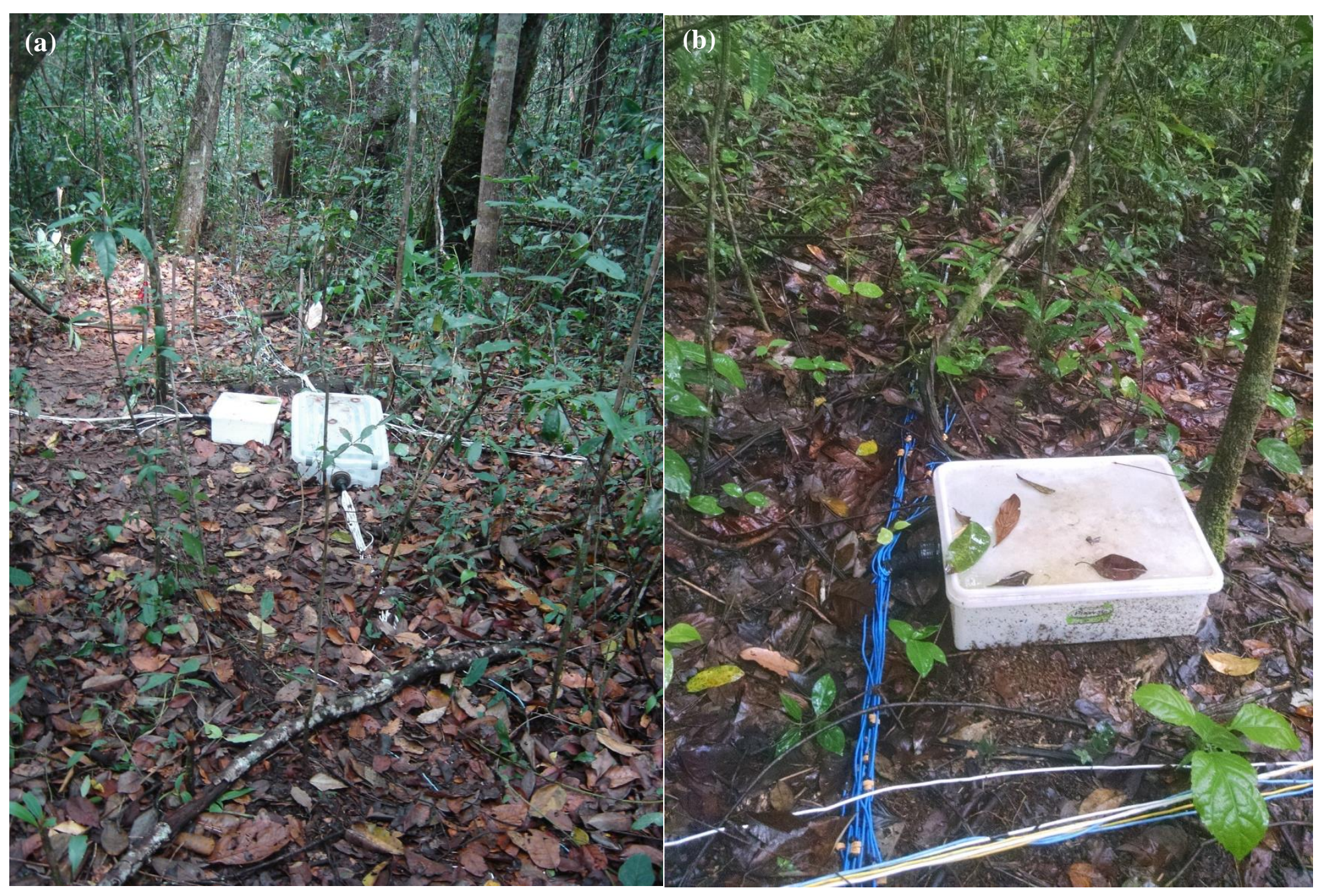

Figura 4.17 - a) Interceptação das linhas $C$ (paralela ao córrego Capetinga) e $F$ (ortogonal ao córrego Capetinga). b) Visualização da linha $D$. 


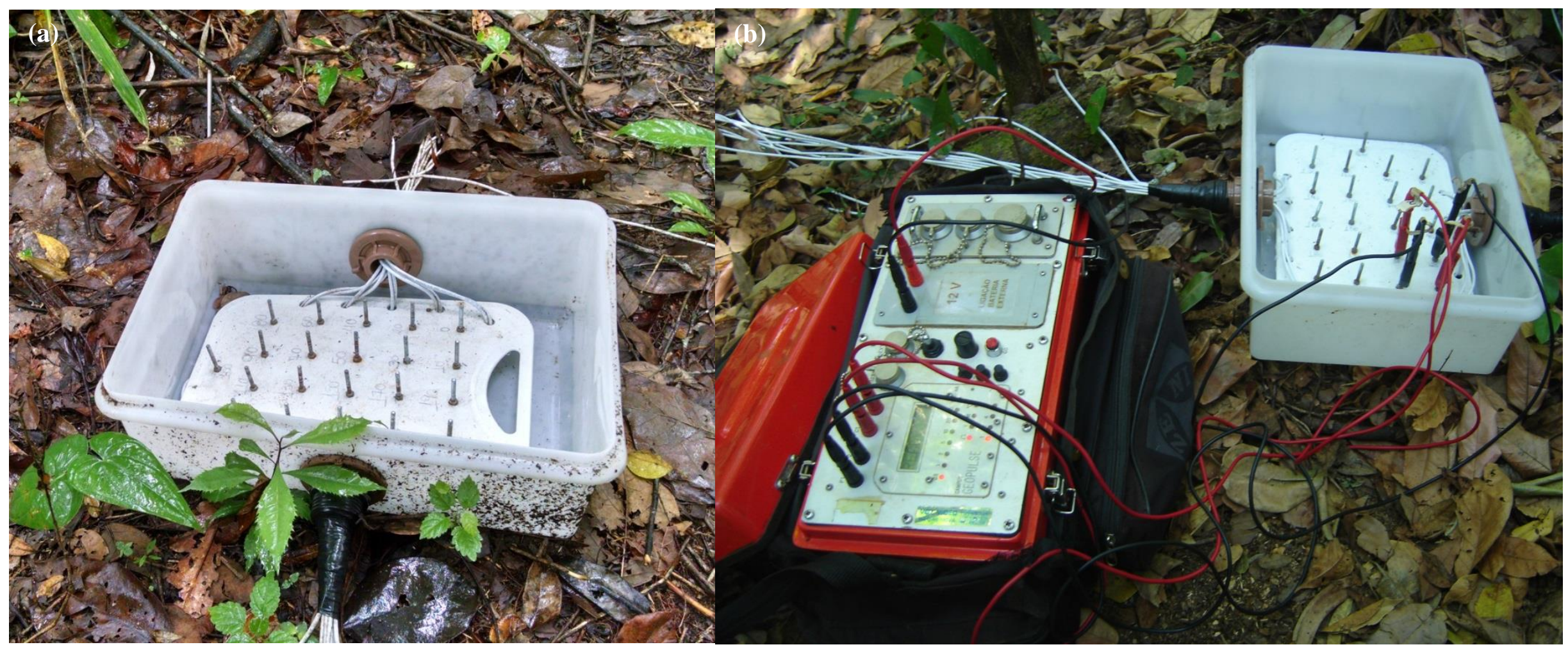

Figura 4.18 - a) Linha $E$, com ênfase para a placa de conexão. b) Aquisição dos dados em campo, com destaque para o resistivímetro Geopulse interligado à placa de conexão dos eletrodos. 


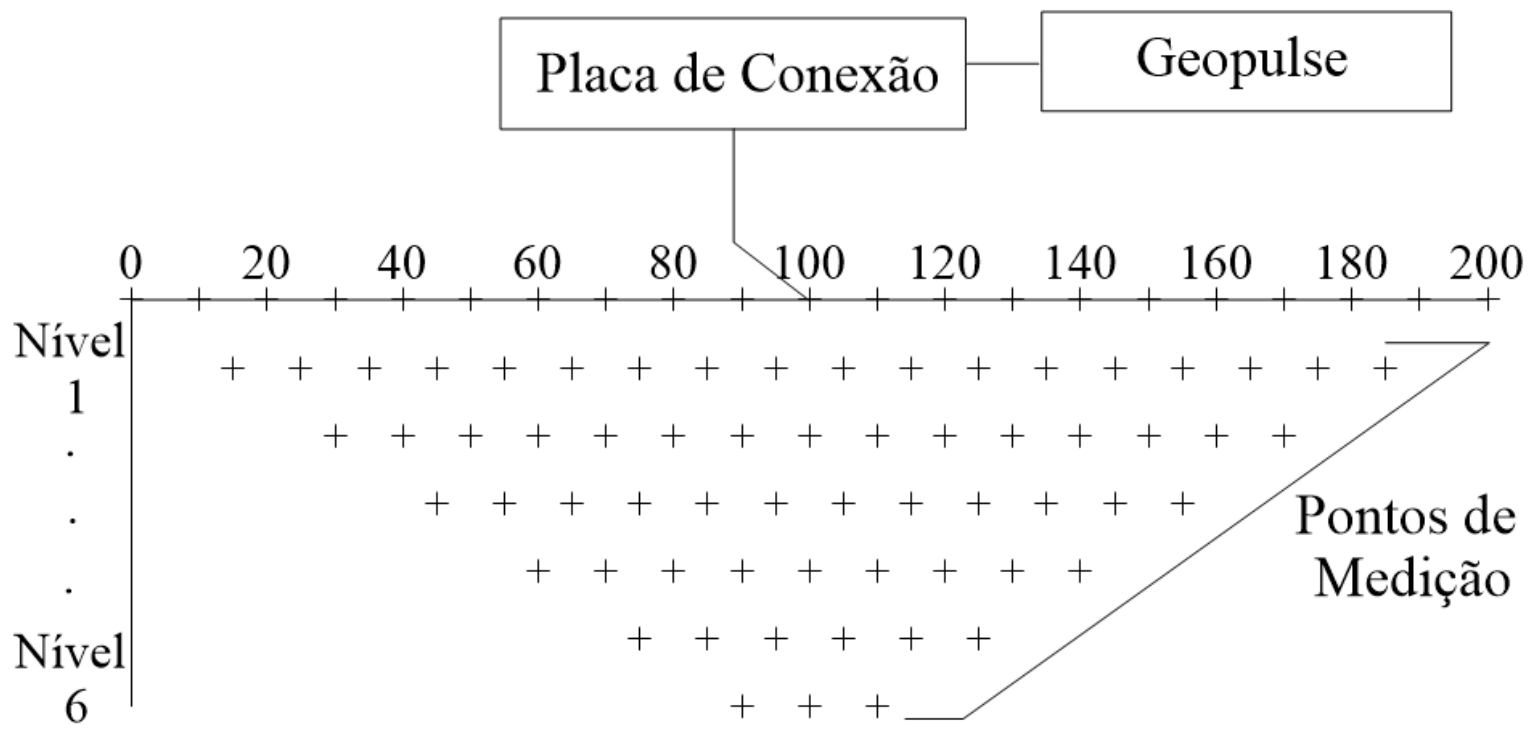

Figura 4.19 - Representação esquemática da aquisição de dados nas seções $A, B, C, D$ e $E$, com espaçamento de $10 \mathrm{~m}$ entre os eletrodos a partir do nível 1, totalizando 76 pontos de medição em cada seção.

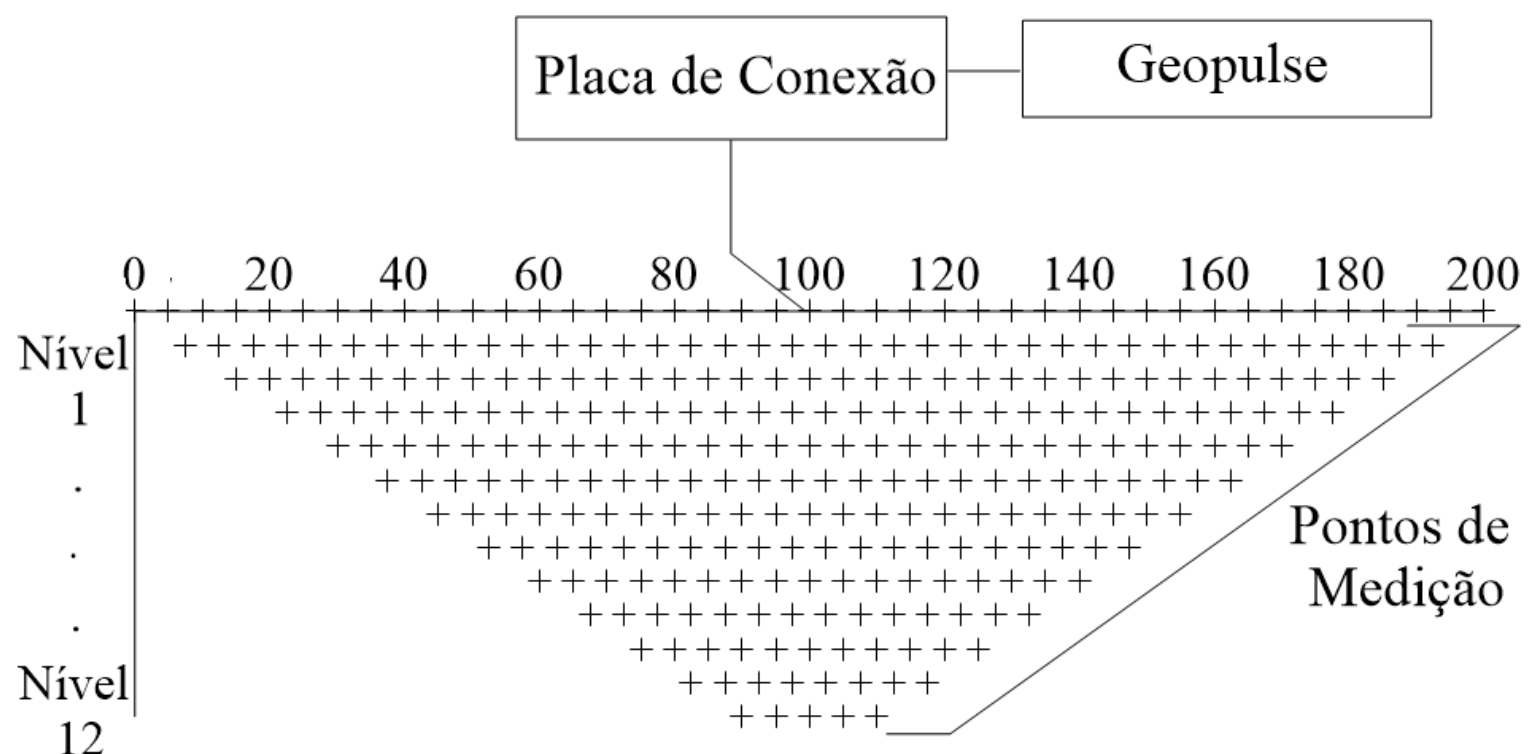

Figura 4.20 - Representação esquemática da aquisição de dados na seção $F$, com espaçamento de 5 m entre os eletrodos para o nível 1, totalizando 168 pontos de medição em cada seção.

Os levantamentos ocorreram no período de agosto de 2015 a fevereiro de 2016, totalizando nove semanas de monitoramento. Na Tabela 4.3 são apresentadas as datas de realização dos levantamentos, com a respectiva nomenclatura adotada para apresentação dos resultados. As leituras foram realizadas em todas as seções, exceto nas semanas 3 (linhas $B, D$ e $F$ não foram monitoradas) e 5 (linha $F$ não foi monitorada). Em média, foi demandada uma hora para aquisição dos dados nas linhas de $A$ a $E$, totalizando cinco horas 
por dia de levantamento, enquanto que, para a linha $F$, foram empregadas cerca de quatro horas no levantamento geofísico.

\begin{tabular}{cc} 
Tabela 4.3 - Data de aquisição dos dados em campo. \\
\hline Nomenclatura Adotada & Data do Levantamento \\
\hline Semana 1 & 19,20 e $21 / 08 / 2015$ \\
Semana 2 & 01 e $02 / 09 / 2015$ \\
Semana $3 *$ & $17 / 09 / 2015$ \\
Semana 4 & $29 / 09 / 2015$ e $01 / 10 / 2015$ \\
Semana $5 *$ & $15 / 10 / 2015$ \\
Semana 6 & 26 e $28 / 10 / 2015$ \\
Semana 7 & 10 e $13 / 11 / 2015$ \\
Semana 8 & 09 e $15 / 12 / 2015$ \\
Semana 9 & $04 / 02 / 2016$ \\
\hline
\end{tabular}

\subsubsection{2 - Análise dos Dados Geofísicos}

Os valores de resistência $(R)$ obtidos em campo foram convertidos em resistividade aparente $\left(\rho_{a}\right)(\Omega . m)$, considerando as deduções da lei de Ohm e o espaçamento entre os eletrodos (a) no arranjo de Wenner, conforme Equação (4.1).

$$
\rho_{a}=2 \times a \times \pi \times R
$$

Posteriormente, o conjunto de dados foi filtrado com substituição manual dos valores discrepantes pela média dos vizinhos mais próximos. Após a filtragem, os valores de resistividade aparente foram invertidos por meio da técnica de otimização não linear de mínimos quadrados, seguida da modelagem direta pelo método de diferenças finitas. Tanto a filtragem quanto a inversão foram realizadas na versão demonstrativa do programa RES2DINV (versão 4.00; Geotomo Software; Loke, 2000), que permite a elaboração de um modelo bidimensional para espacialização dos valores de resistividade no subsolo (Griffiths e Barker, 1993).

Por se tratar de uma versão limitada, as configurações padrão do RES2DINV tiveram de ser mantidas. Desse modo, foram realizadas três iterações para cada seção geoelétrica e o ruído existente entre os dados observados e modelados foi expresso pela raiz do erro médio quadrático. Os valores de resistividade modelados foram interpolados no programa Surfer 
(versão 9.11) (Golden Software, 2002) para padronização da escala de cores, uma vez que a versão demonstrativa do RES2DINV não possibilita tal função.

Com a interpolação foram obtidas seções geoelétricas bidimensionais e mapas de resistividade modelada. No primeiro caso, a variação bidimensional vertical da resistividade foi espacializada para cada linha de monitoramento em cada semana (recriação das seções geradas no RES2DINV). Para tanto, os valores de resistividade das seções $A, B, C, D, E$ e $F$ foram distribuídos numa malha trapezoidal, com resolução de 5 por $5 \mathrm{~m}$, e interpolados pelo método de triangulação.

Como afirma Kresic (2007), a triangulação é um interpolador linear exato entre três pontos. Tal característica permitiu manter os valores interpolados no contorno da seção trapezoidal. Dados de altimetria (m) extraídos das curvas de nível SICAD (SEDHAB, 2009) foram incorporados às seções. Para fins de padronização os termos seção, perfil e linha foram adotados como sinônimos na apresentação dos resultados, indicando a imagem bidimensional acima descrita.

A segunda abordagem consistiu na espacialização dos valores de resistividade modelada para cada profundidade de investigação ao longo da vertente, obtendo-se mapas de resistividade elétrica do solo. O mapeamento da resistividade nas diferentes profundidades foi realizado numa malha retangular discretizada em células com área de $25 \mathrm{~m}^{2}$ cada. Os valores de resistividade da linha " $F$ ” não foram incluídos na elaboração dos mapas devido à diferença nos níveis de investigação em relação às demais.

Nesse caso foi selecionado o método geoestatístico de krigagem ordinária, que admite a influência da correlação espacial na variável interpolada (Silva e Malagutti-Filho, 2010; Kresic, 2007). A seleção da krigagem decorreu do fato desse interpolador expressar a tendência geral dos dados, evitando o efeito bull's-eyes, que indica a formação de contornos pontuais não representativos para o conjunto de dados (Nusret e Dug, 2012; Golden Software, 2002).

A variação temporal dos valores de resistividade foi quantificada, em porcentagem, a partir da diferença entre o conjunto de dados obtido em cada intervalo de tempo $t_{1}\left(\rho_{1}\right)$ e aquele atribuído ao tempo inicial $t_{0}\left(\rho_{0}\right)$ (Equação (4.2)). Desse modo, as seções geoelétricas 
foram comparadas àquelas obtidas no mês de agosto de 2015. Essa metodologia foi adotada com base no trabalho realizado por Bellmunt et al. (2012). Vale destacar que a comparação em relação ao período inicial de monitoramento geofísico foi estabelecida com o intuito de identificar a variação da resistividade do solo na transição entre o período de estiagem e o início do período chuvoso, considerando a influência da precipitação nos valores de resistividade elétrica do solo.

$$
\% \Delta_{\rho}=\left(\frac{\rho_{1}-\rho_{0}}{\rho_{0}}\right) \times 100
$$

Por fim, análises estatísticas foram realizadas no programa $R$ (versão 3.2.3, The $R$ Foundation for Statistical Computing). A variabilidade dos dados de resistividade foi representada com gráficos de caixa (box plot), adotando a mediana como medida de tendência central, uma vez que o teste de normalidade Shapiro-Wilk (função shapiro.test) aplicado a um nível de significância de 5\%, indicou distribuição não normal para a maioria dos dados (Birnbaum e Tingey, 1951).

Foi utilizado o teste de hipótese não paramétrico Wilcoxon Mann Whitney por meio da função "wilcox.test" com índice de significância de 0,05 a fim de verificar a ocorrência de diferenças significativas nas seções $A, B, C, D$ e $E$ ao longo do tempo a partir dos dados de resistividade modelados (Bauer, 1972). O teste de hipótese não foi aplicado à linha $F$ em função das diferenças contidas na própria linha, estabelecida no gradiente da vertente.

A metodologia adotada para caracterização geoelétricas da vertente, desde a aquisição dos dados à apresentação dos resultados finais, consta de maneira resumida na Figura 4.21. 


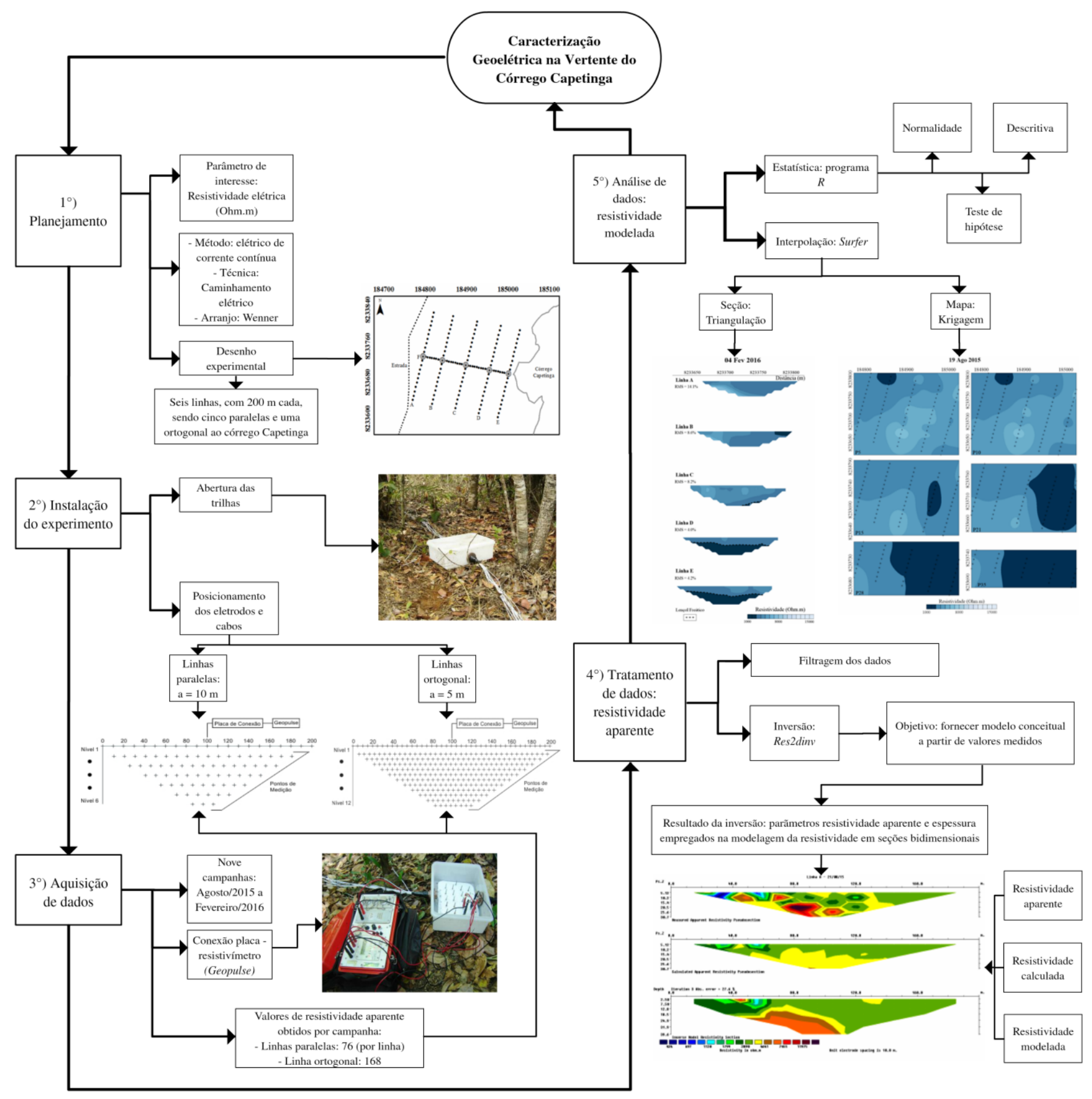

Figura 4.21 - Representação esquemática da metodologia adotada para caracterização geoelétrica da vertente. 


\subsection{2 - Monitoramento da Água na Zona Não Saturada}

A umidade do solo foi determinada utilizando os métodos gravimétrico, TDR e blocos de resistência elétrica (Figura 4.22, Tabela 4.4). No primeiro caso, amostras de solo foram coletadas nos pontos $U A, U C$ e $U E$. Os dias de coleta coincidiram com as datas de levantamento geofísico para possibilitar a comparação dos dados. Nos outros pontos centrais de cada linha, incluindo aqueles com coleta de solo, a umidade foi determinada indiretamente com emprego de sonda $T D R$ e blocos de resistência elétrica.

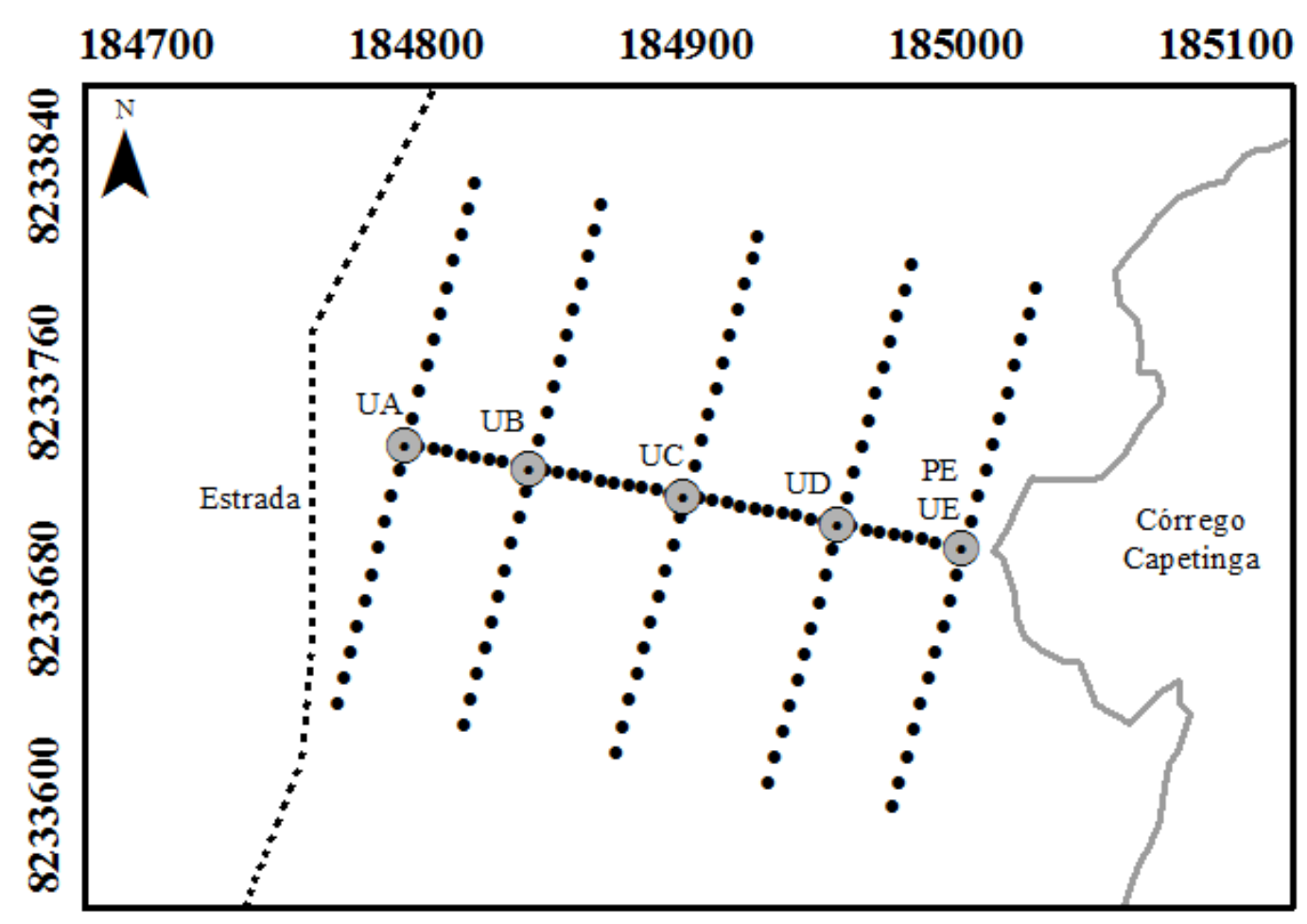

Figura 4.22 - Monitoramento da umidade do solo. $U A, U C$ e $U E$ - pontos de coleta de amostras de solo para determinação da umidade gravimétrica. $U A$ a $U E$ - determinação da umidade por TDR e blocos de resistência elétrica. $P E$ - poço de monitoramento no domínio aquífero poroso.

Cabe mencionar que houve um esforço para obtenção dos dados geofísicos e de umidade do solo no mesmo dia de monitoramento. Contudo, não foi possível realizar coleta de solo na primeira semana de estudo em função da necessidade de finalização do experimento geofísico. Com relação à umidade volumétrica obtida por meio da sonda Delta-T, em função de problemas no leitor do equipamento, só foram obtidos dados a partir da sétima semana (10/11/2015). Os blocos de gesso, por sua vez, foram instalados na quinta semana de estudo, como observado na Tabela 4.5. 
Tabela 4.4 - Detalhes a respeito dos métodos aplicados.

\begin{tabular}{|c|c|c|c|c|}
\hline \multirow{2}{*}{ Método } & \multicolumn{2}{|c|}{ Água no Solo } & \multirow{2}{*}{$\begin{array}{l}\text { Alcance Útil } \\
\text { de Ação } \\
(k P a)\end{array}$} & \multirow{2}{*}{ Observações } \\
\hline & Teor & Potencial & & \\
\hline Gravimetria & $\mathrm{x}$ & & 0 a 10.000 & $\begin{array}{l}\text { Amostras pesadas em balança } \\
\text { com duas casas de precisão }\end{array}$ \\
\hline \multicolumn{5}{|l|}{ Reflectometria } \\
\hline $\begin{array}{l}\text { no Domínio do } \\
\text { Tempo (TDR) - }\end{array}$ & & $X$ & 0 a 10.000 & $\begin{array}{l}\text { Precisão de } \pm 1 \text { a } 2 \% \text { do teor } \\
\text { volumétrico de água }\end{array}$ \\
\hline \multicolumn{5}{|l|}{ Sonda Delta-T } \\
\hline Blocos de & & & & \\
\hline $\begin{array}{l}\text { Resistência - } \\
\text { Sistema }\end{array}$ & & $X$ & -90 a 1.500 & $\begin{array}{c}\text { Apenas leituras entre } 5 \text { e } 100 \text { são } \\
\text { válidas }\end{array}$ \\
\hline Delmhorst & & & & \\
\hline
\end{tabular}

Fonte: Brady e Weil (2013) e Delmhorst Instrument Co. (1999).

Além do monitoramento da umidade, um poço de observação do domínio aquífero poroso $(P E)$ foi instalado no ponto central da linha $E$ entre os meses de outubro e dezembro de 2015 (Figura 4.23). Em função da curta série de dados quanto às flutuações do nível da água subterrânea (com início em dezembro de 2015), a profundidade do lençol em relação à superfície $(11 \mathrm{~m})$ foi utilizada para vinculação com a estratigrafia geoelétrica da linha $E$ apenas no referido mês.

Tabela 4.5 - Data de coleta das amostras de solo e de medição da umidade em campo.

\begin{tabular}{ccccc}
$\begin{array}{c}\text { Nomenclatura } \\
\text { Adotada }\end{array}$ & $\begin{array}{c}\text { Data de } \\
\text { Aquisição }\end{array}$ & $\begin{array}{c}\text { Umidade } \\
\text { Gravimétrica }\end{array}$ & $\begin{array}{c}\text { Umidade } \\
\text { Volumétrica }\end{array}$ & $\begin{array}{c}\text { Blocos de } \\
\text { Gesso }\end{array}$ \\
\hline Semana 1 & $19 / 08 / 2015$ & & & \\
Semana 2 & $01 / 09 / 2015$ & $\mathrm{x}$ & & \\
Semana 3 & $17 / 09 / 2015$ & $\mathrm{x}$ & & \\
Semana 4 & $29 / 09 / 2015$ & $\mathrm{x}$ & & \\
Semana 5 & $15 / 10 / 2015$ & $\mathrm{x}$ & & $\mathrm{x}$ \\
Semana 6 & $26 / 10 / 2015$ & $\mathrm{x}$ & & $\mathrm{x}$ \\
Semana 7 & $10 / 11 / 2015$ & $\mathrm{x}$ & $\mathrm{x}$ & $\mathrm{x}$ \\
Semana 8 & $09 / 12 / 2015$ & $\mathrm{x}$ & $\mathrm{x}$ & \\
Semana 9 & $04 / 02 / 2016$ & $\mathrm{x}$ & $\mathrm{x}$ & $\mathrm{x}$ \\
\hline
\end{tabular}




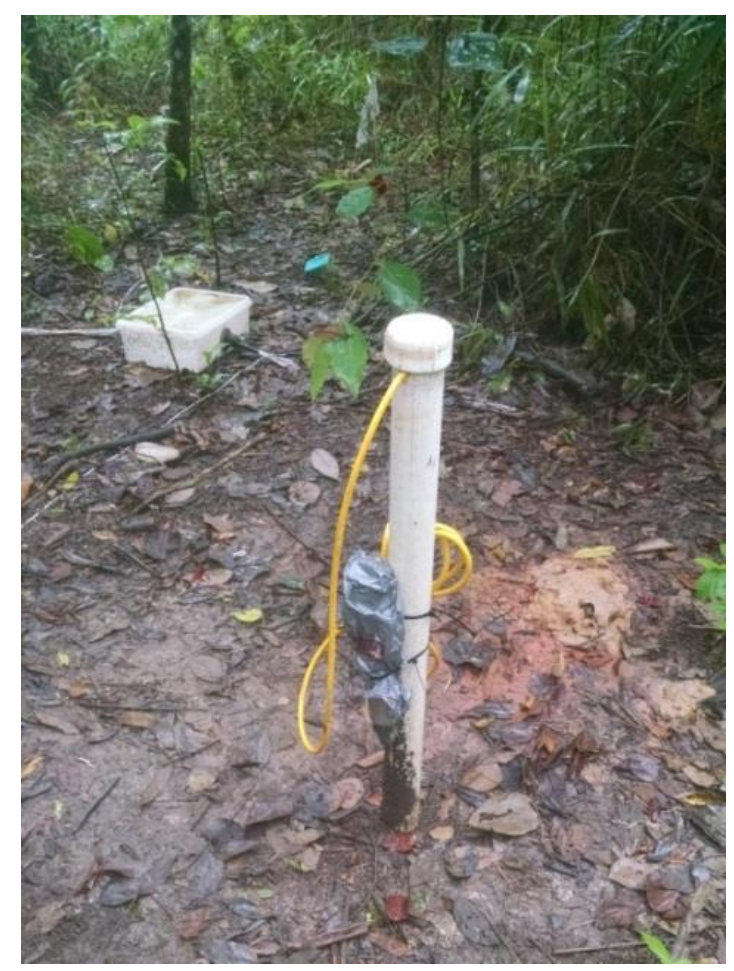

Figura 4.23 - Poço de observação dotado de linígrafo para monitoramento do nível da água no domínio aquífero poroso, instalado próximo à seção geofísica $E$ (ao fundo).

\subsubsection{1 - Determinação da Umidade Gravimétrica}

Amostras de solo foram coletadas, com trado manual de quatro polegadas, nos pontos $U A$, $U C$ e $U E$. A definição das profundidades de coleta obedeceu ao critério de viabilidade, tanto para coleta quanto para posterior determinação da umidade. Em cada ponto foram coletadas sete amostras de solo, sendo a primeira obtida na superfície abaixo da camada de serapilheira, denominada solo superficial ou $0 \mathrm{~m}$. Seguindo-se a essa, foram obtidas amostras nas profundidades 0,20,0,40,0,60, 0,80 e 1,00 m. Todas foram devidamente armazenadas em sacos plásticos e encaminhadas ao laboratório de Geotecnia da $U n B$.

No laboratório, amostras com aproximadamente 300 g, tiveram sua massa aferida e, em seguida, foram secas em estufa a $110^{\circ} \mathrm{C}$ até obtenção de massa constante. Após a secagem, as amostras tiveram sua massa novamente aferida para determinação da umidade gravimétrica $(\mathrm{g} / \mathrm{g})$. A fração de matéria orgânica também foi determinada, porém apenas nas amostras da oitava semana, por não haver possibilidade de análise nas datas anteriores. Nesse caso, foi aplicado o método de calcinação, também denominado método de perda de massa por ignição, em que a amostra de solo é previamente seca a $60^{\circ} \mathrm{C}$ e depois calcinada na mufla por 5 horas a $250^{\circ} \mathrm{C}$ (Escosteguy et al., 2007). 
4.2.2.2 - Monitoramento da Umidade pelo Método de Reflectometria no Domínio do Tempo $(T D R)$

O monitoramento indireto da umidade do solo pelo método TDR foi realizado com sonda Delta-T, modelo PR2. Sua utilização necessitou de abertura de furos com 1,0 m de profundidade e posterior instalação de tubos de acesso constituídos de fibra de vidro. Os tubos permitem a aquisição de dados nas profundidades $0,10,0,30,0,40,0,60$ e 1,0 m (Figura 4.24). O conjunto de itens para aquisição de dados com a sonda Delta-T é composto pela sonda emissora/receptora; sistema digital portátil $(H H 2)$ para entrada de informações, leitura e armazenamento de dados; além dos equipamentos auxiliares para instalação dos tubos de acesso no campo (trado, base niveladora e marreta percussiva).

A leitura dos dados em campo forneceram medidas do potencial elétrico (em milivolts) e de umidade volumétrica $\left(\mathrm{m}^{3} / \mathrm{m}^{3}\right)$ do solo. O equipamento foi utilizado com a opção genérica de calibração sugerida pelo fabricante. Desse modo, caso o ajuste entre os valores de umidade gravimétrica e volumétrica, obtida com calibração automática, não apresentem correlação significativa ( $\mathrm{r} \geq 0,7)$, os parâmetros de ajuste serão estimados por meio da "raiz quadrada da permissividade", utilizando a Equação (4.3), fornecida pelo fabricante,

$$
\sqrt{\varepsilon}=0,37+4,43 V
$$

em que $\varepsilon$ expressa a permissividade do meio e $V$ diz respeito ao potencial elétrico do solo, transformado em volts. Obtendo-se a "raiz quadrada da permissividade" é possível estabelecer a relação com a umidade gravimétrica, gerando uma equação com formato " $Y$ $=a+b X$ ". Nesse caso, " $Y$ " representa a "raiz quadrada da permissividade" e " $X$ " a umidade determinada via método gravimétrico. Os parâmetros “ $a$ " e " $b$ ", por sua vez, são ajustados para permitirem a obtenção do teor de umidade em porcentagem diretamente no leitor do equipamento Delta-T. 


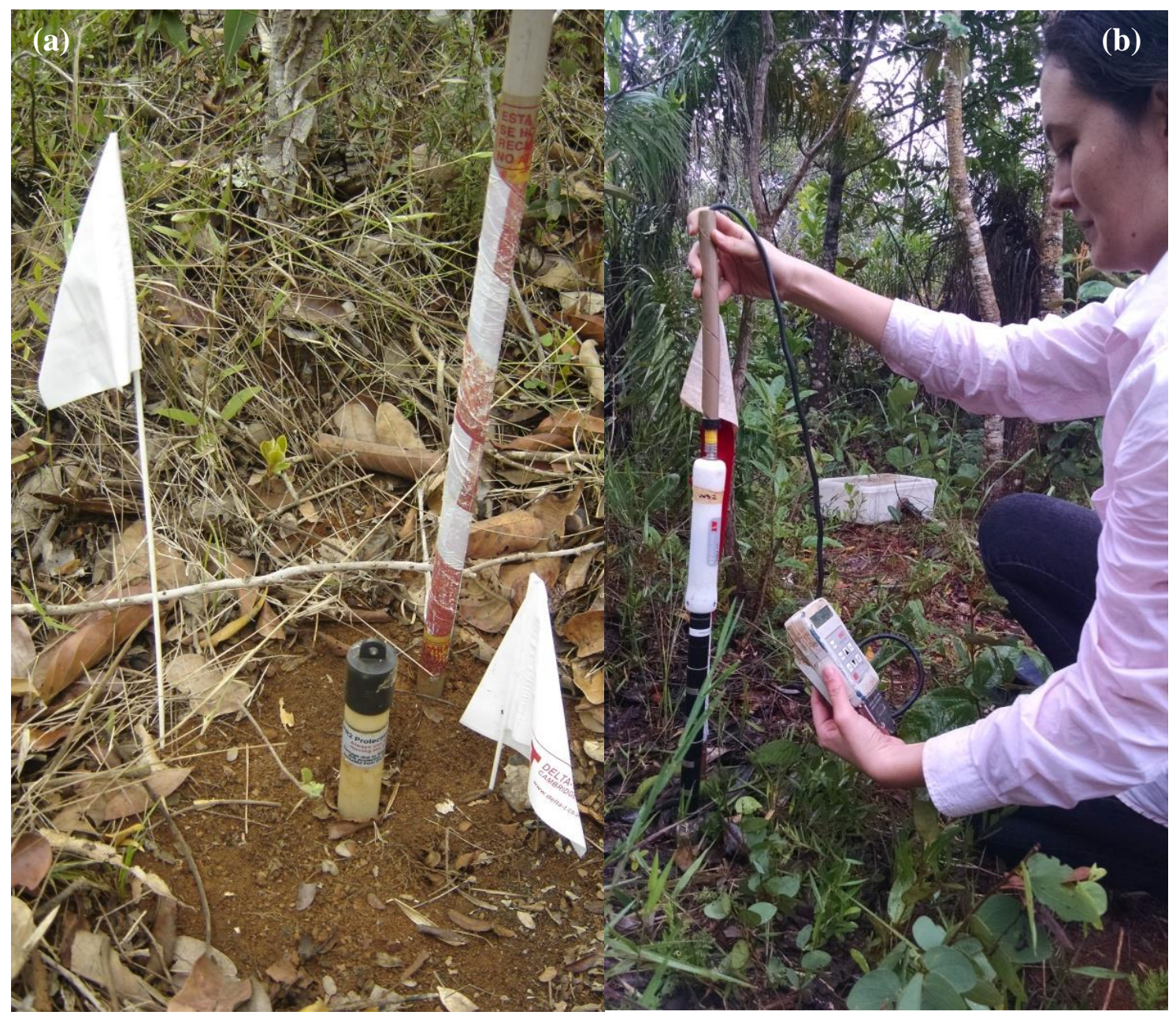

Figura 4.24 - a) Tubo de fibra de vidro instalado em campo para acesso da sonda TDR. b) Procedimento para aquisição dos dados.

4.2.2.3 - Determinação do Potencial de Água do Solo com Blocos de Resistência Elétrica

Blocos de resistência elétrica de gesso foram instalados nas profundidades $0,5,1,0$ e 1,5 m, sendo necessária a abertura de furo com trado manual atingindo a profundidade máxima de 1,5 m. Os blocos devem ser instalados nas profundidades requeridas envoltos na mistura de solo saturado, permitindo homogeneização do gesso com o meio. Os cabos utilizados na leitura foram armazenados em recipiente plástico, como observado na Figura 4.25a, para garantir a integridade dos mesmos. Na aquisição dos dados, as extremidades dos fios foram conectadas à interface de leitura modelo KS-D1 (Delmhorst Instrument Co., 1999).

O equipamento $K S-D 1$ fornece um resultado específico do medidor (meter reading), adimensional e válido num intervalo entre 5 e 100, que pode ser correlacionado à resistência elétrica do gesso e ao potencial de água no solo, em termos de sucção 
necessária para drenagem da umidade (Delmhorst Instrument Co., 1999). A partir dessas propriedades estima-se o percentual de umidade disponível no solo, considerando que o bloco esteja em equilíbrio com o meio (Delmhorst Instrument Co., 1999).

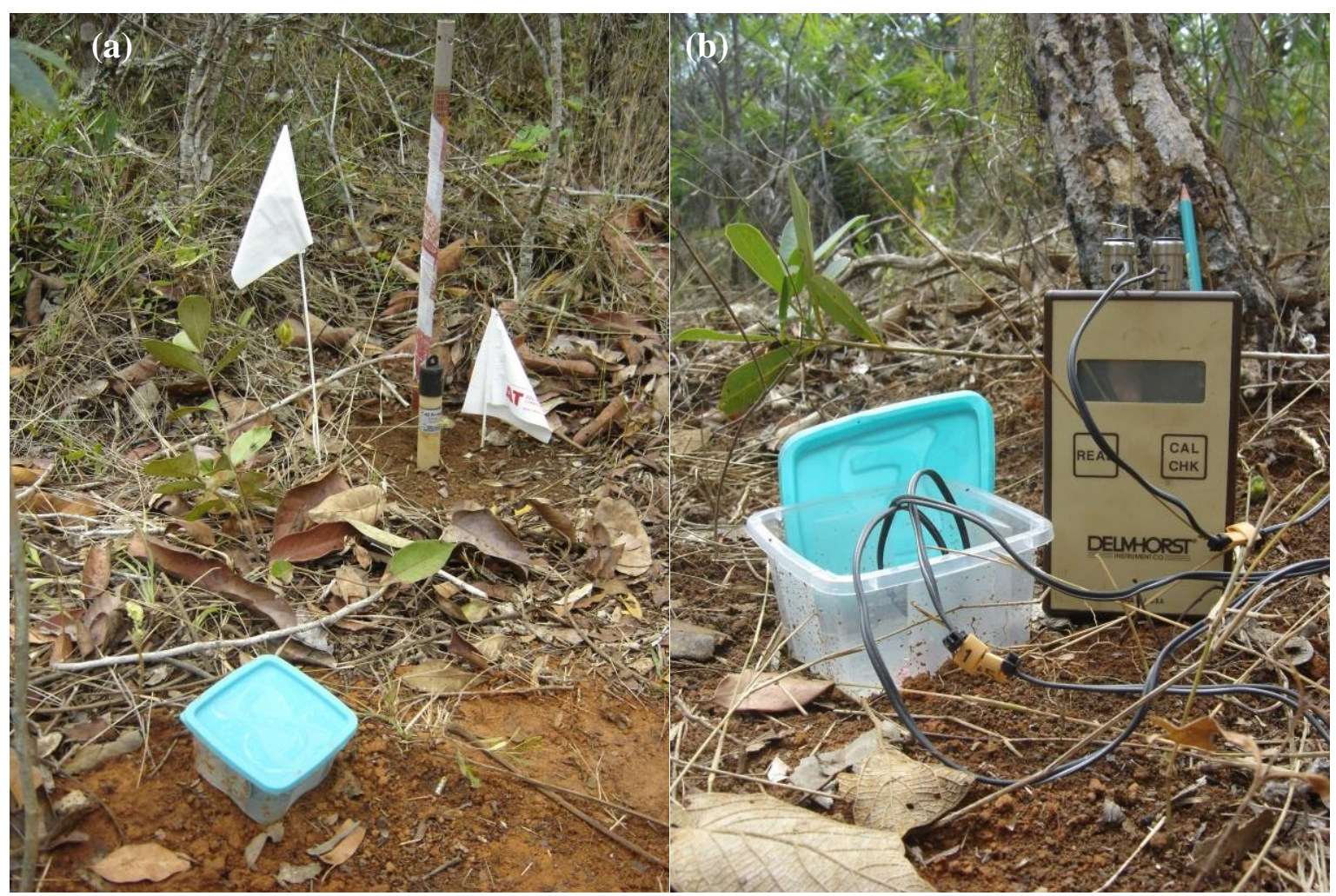

Figura 4.25 - a) Recipiente para armazenamento dos fios conectados aos blocos. b) Equipamento utilizado para leitura dos blocos de gesso.

\subsection{3 - Simulação Hidrológica da Carga Hidráulica}

\subsubsection{1 - Elaboração do Modelo Conceitual e Matemático}

A distribuição dos valores de carga hidráulica na vertente do córrego Capetinga foi obtida por modelagem numérica, considerando os pressupostos adotados no estudo de Beven (1977), com aplicação do método de elementos finitos. O programa FEFLOW foi selecionado para desenvolvimento dessa etapa do estudo. Como modelo conceitual foi assumida uma representação bidimensional vertical da vertente, considerando as camadas não saturada e saturada do solo sobrepostas a uma camada impermeável (Figura 4.26). A zona saturada engloba as águas subterrâneas rasas do domínio aquífero poroso, cujo fluxo geralmente tende a acompanhar a superfície do terreno. Apenas a direção do fluxo da água, 
com densidade e viscosidade constantes, em resposta ao gradiente hidráulico, foi considerada.

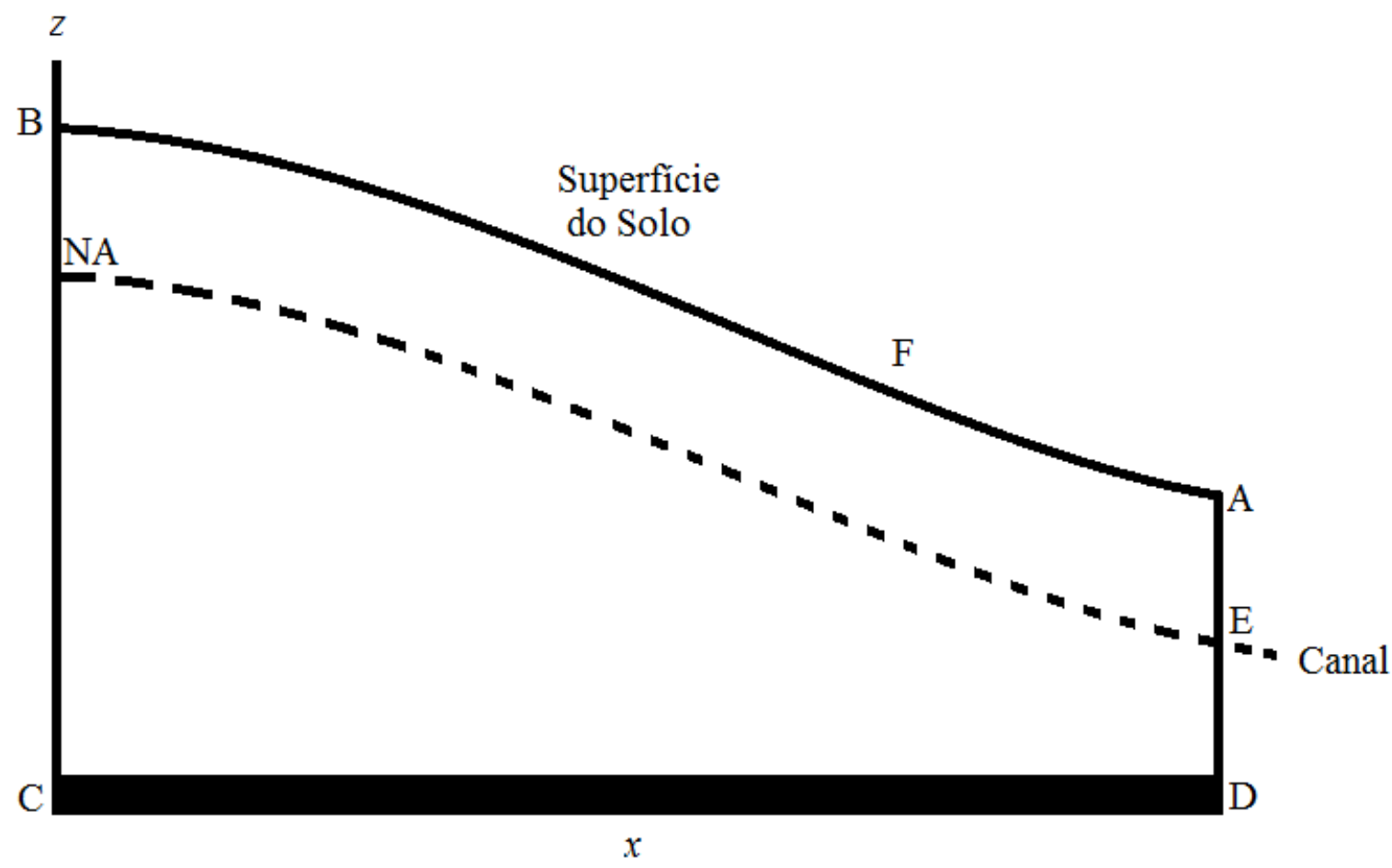

Figura 4.26 - Modelo conceitual da vertente em estudo, com indicação das direções $x$ (coordenada longitudinal) e $y$ (altitude, indicada pela letra $z$ ), condições de contorno de fluxo nulo (divisor topográfico e camada impermeável), e o canal do córrego Capetinga, representado pela condição de contorno de carga hidráulica conhecida.

O modelo foi aplicado considerando a vertente com área superficial de $830 \mathrm{~m}^{2}$, abrangendo desde o divisor topográfico até o córrego Capetinga. Foram atribuídas as condições de contorno de Neuman e Dirichlet no domínio do modelo. Ao divisor topográfico $(B C)$ localizado na borda oeste e ao limite inferior impermeável $(C D)$ foram aplicadas as condições de contorno de Neuman como regiões de "não-fluxo" ou fluxo nulo $(q=0)$. Dados de recarga também foram aplicados ao modelo por meio da condição de contorno de Neuman, no segmento $A B$ (Figura 4.26). Para representação dos valores de carga hidráulica conhecidos no córrego Capetinga $(E)$ utilizou-se a condição de contorno de Dirichlet no segmento $A D$.

As características do solo foram adotadas considerando um domínio homogêneo e isotrópico. Os parâmetros para resolução da equação de Richards são padronizados no FEFLOW conforme Tabela 4.6. Como tais parâmetros não puderam ser determinados 
experimentalmente para a vertente em estudo, foram aplicados os valores apresentados em Carducci et al. (2011), específicos para Latossolos do Cerrado (Tabela 4.6). Souza e Campos (2001) definiram um valor de condutividade hidráulica equivalente a $0,1 \mathrm{~m} / \mathrm{d}$ para o domínio aquífero poroso característico da área de interesse. Porém, na ausência do processo de calibração automático, foram testados manualmente valores de condutividade num intervalo de 0,01 a $1,0 \mathrm{~m} / \mathrm{d}$.

Tabela 4.6 - Propriedades hidráulicas adotadas no modelo.

\begin{tabular}{cccc}
\hline Parâmetros & FEFLOW & $\begin{array}{c}\text { Carducci } \boldsymbol{e t} \\
\boldsymbol{a l} . \mathbf{( 2 0 1 1 )}\end{array}$ & $\begin{array}{c}\text { Souza e } \\
\text { Campos } \\
\mathbf{( 2 0 0 1 )}\end{array}$ \\
\hline$\alpha\left[m^{-1}\right]$ & 4,10 & 1,60 & \\
$m$ & 0,49 & 0,30 & \\
$n$ & 1,96 & 1,50 & - \\
$S_{r}\left(\theta_{r}\right)$ & 0,00 & 0,01 & \\
& & & \\
$S_{S}\left(\theta_{s}\right)$ & 1,00 & 0,60 & 0,10 \\
& & & \\
$K[m / d]$ & 1,00 & - & \\
\hline
\end{tabular}

\subsubsection{2 - Aplicação do Modelo Numérico de Elementos Finitos}

A modelagem da carga hidráulica foi realizada com o código computacional FEFLOW (versão 6.2; DHI - WASY; Diersch, 2014) em três etapas: I) Simulação das condições iniciais de carga hidráulica em regime estacionário; II) Simulação da carga hidráulica em regime transiente ao longo de 35 anos (1980-2015); e III) Simulação da carga hidráulica em regime transiente durante 365 dias (2015-2016).

Tratando-se de um problema de fluxo na zona não saturada e variavelmente saturada acoplada à zona saturada, a solução por elementos finitos foi direcionada a equação de Richards. Definidas as características do problema, a modelagem foi iniciada com elaboração da malha de elementos finitos. O tipo de elemento da malha pode ser selecionado de acordo com a projeção do modelo e da adequação ao domínio. Neste estudo foi definida uma malha de 5.000 elementos triangulares com três nós. 
Para identificação da condição inicial de carga hidráulica na vertente foi realizada uma simulação em regime estacionário, considerando a media anual de recarga e carga hidráulica do córrego para o período de 2000 a 2016. Na simulação em estado estacionário, a condição de carga hidráulica inicial foi admitida como uniforme no domínio, tendo como base informações de levantamento geofísico $(N A=25 \mathrm{~m})$. Como condições de contorno foram adotados valores de fluxo zero em $B C$ e $C D$; fluxo de $140 \mathrm{~mm} / \mathrm{ano}$ em $B F$ (recarga média em cerrado na região); e $50 \mathrm{~mm} /$ ano em $A F$ (recarga média para zona riparia). Em $A E$ uma carga hidráulica média de 25,24 m foi adotada (córrego com nível constante).

A simulação em regime transiente foi realizada com esquema de discretização temporal automático $F E / B E$ adotando as condições iniciais de carga hidráulica obtidas na simulação em regime estacionário. No primeiro caso, as séries históricas de recarga e carga hidráulica, para o intervalo de tempo de 2000 a 2010, foram replicadas em dois intervalos de tempo, constituindo uma série de dados fictícia para um período de 20 anos, acrescida dos dados reais registrados entre 2000 e 2015 , totalizando 12.783 dias simulados entre 05 de fevereiro de 1980 e 04 de fevereiro de 2015.

Os valores de carga hidráulica obtidos ao final dos 35 anos foram adotados como condição inicial para a segunda etapa de simulação em regime transiente. Essa alternativa foi adotada para garantir maior estabilidade ao resultado final do modelo. Assim, o período de interesse a ser comparado com os dados de levantamento geofísico, entre agosto de 2015 e fevereiro de 2016, foi simulado considerando um período de 365 dias (05 de fevereiro de 2015 a 04 de fevereiro de 2016), tendo como valores iniciais os resultados obtidos ao final da simulação dos 35 anos.

\subsubsection{3 - Construção da Base de Dados}

O domínio do modelo conceitual foi delimitado em ambiente $S I G$, com formato bidimensional vertical, como apresentado no item 4.1.1 - e na Figura 4.27. Valores de elevação foram processados a partir das curvas de nível contidas na base de dados da articulação SICAD, espacializadas num intervalo de cinco metros (SEDHAB, 2009). Além do contorno e dos dados de elevação do terreno, elementos vetoriais foram preparados para atribuição das séries temporais no domínio modelado. A recarga, tanto no cerrado quanto na zona ripária, foi representada em formato de linha no topo do modelo, bem como as 
informações carga hidráulica no córrego associada a um vetor de linha na lateral direita do domínio.

Os dados de entrada do modelo foram obtidos com series históricas de precipitação $(\mathrm{mm})$ e vazão no córrego Capetinga (m), disponibilizadas pelo Laboratório de Hidroclimatologia da FAL, no período de 2000 a 2011, e por meio das Estações Fluviométrica e Pluviométrica FAL - UnB (Código: 60478482), entre 2011 e 2016 (Figura 4.2). A aquisição de dados em ambos os casos (2000-2011 e 2015-2016) ocorreu no exutório da bacia, como apresentado na Figura 4.1. O nível da água no córrego, por sua vez, foi reconstituído a partir da curva-chave elaborada por Silva (2003) e da seérie de vazões.

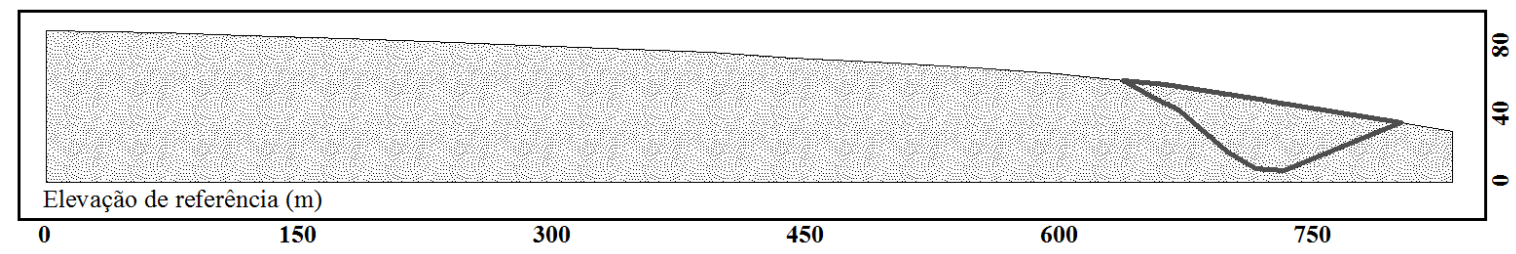

Figura 4.27 - Perfil bidimensional utilizado na modelagem numérica. A área destacada corresponde à seção $F$ de monitoramento geofísico.

A vazão calculada a partir das informações do exutório, como contribuição da bacia do Capetinga, foi transferida para a vertente em estudo considerando apenas a contribuição da vertente na geração de escoamento. Para tanto, adotou-se a relação expressa na Equação (4.4), entre as áreas de contribuição, em que $Q_{A}$ representa a vazão no ponto de interesse, com área $A_{A}$, enquanto $Q_{B}$ diz respeito aos valores de vazão do ponto medido, cuja área de influência é igual a $A_{B}$. Nesse caso, $A_{B}$ foi equivalente à área da bacia até o exutório na estação fluviométrica $\left(10 \mathrm{~km}^{2}\right)$, enquanto que a área $A_{A}$ foi atribuída à vertente em estudo $\left(830 \mathrm{~m}^{2}\right)$.

$$
Q_{A}=Q_{B} \frac{A_{A}}{A_{B}}
$$

Para execução do modelo matemático valores de recarga do aquífero e carga hidráulica do córrego Capetinga foram necessários. A recarga $(R e)(\mathrm{mm} / \mathrm{dia})$ foi estimada pelo método do balanço hídrico (Equação (4.5)) como a parcela de precipitação (Pr) excedente aos 
processos de escoamento direto (escoamento superficial e subsuperficial, $\left(q_{t}\right)$, interceptação (In) e evapotranspiração real $(E T r)$, todos em mm/dia.

$$
\operatorname{Re}=\operatorname{Pr}-q_{t}-\operatorname{In}-E T r
$$

O escoamento direto foi determinado pela diferença entre os valores de vazão no córrego e o escoamento de base estimado pelo filtro automático de Arnold e Allen (1999). Com relação à interceptação foi adotado percentual de aproximadamente $23 \%$ da precipitação diária, como estimado por Távora (2016). A evapotranspiração real (ETr) foi estimada com base em dados do Tanque Classe A (Conceição, 2001; Guerra et al., 2002). Para tanto, a evapotranspiração de referência (ETo) foi calculada como o produto entre a evaporação do tanque e o coeficiente do tanque (Kp) (Conceição, 2001).

Valores de $K p$ foram considerados em função da umidade relativa do ar (\%) e da velocidade do vento $(\mathrm{m} / \mathrm{s})$, além da bordadura no entorno do tanque $(1000 \mathrm{~m})$. Os dados meteorológicos, incluindo a evaporação no Tanque Classe A, foram obtidos no Laboratório de Hidroclimatologia da FAL (2000 a 2013). A falha existente entre os anos de 2014 e 2016 foi preenchida a partir dos dados dos anos anteriores. Os valores de evapotranspiração de referência calculados pelo método do Tanque foram convertidos à evapotranspiração real com a Equação (4.6), descrita em Bernardo (1995):

$$
E T r=E T o \times K c \times K s
$$

em que:

$K c$ - coeficiente da vegetação ou cultura; e

$K s$ - coeficiente dependente da umidade do solo.

O coeficiente $K s$ teve seus valores determinados com base no trabalho de Lima et al. (2001), sendo considerado constante ao longo do mês. Para o coeficiente de cultura $(K c)$ foram adotados os valores de 0,8 , nas áreas com formação florestal de cerrado e cerradão, e 1,0, para a floresta de galeria, conforme Lima et al. (2001). Desse modo, foram obtidos dois conjuntos de dados referentes à evapotranspiração real e, consequentemente, à recarga. 
A carga hidráulica no córrego, por sua vez, foi determinada como a variação do nível da água acrescida da cota do fundo do córrego. Nesse caso, como não havia dado topográfico do fundo do córrego, a continuidade da zona saturada identificada no levantamento geofísico foi utilizada para determinação da carga hidráulica no instante inicial da modelagem $(25 \mathrm{~m})$. Desse modo, as informações geoelétricas da vertente subsidiaram a elaboração do modelo conceitual, especialmente no que diz respeito à identificação da profundidade da zona saturada do solo na simulação em regime estacionário.

Cabe ressaltar que, apesar do domínio simulado abranger toda a vertente desde o divisor até o córrego Capetinga, a área de interesse para este estudo é aquela que coincide com a realização dos levantamentos geofísicos, destacada na Figura 4.27, para permitir a comparação dos resultados obtidos em ambos os métodos. 
4.2.4 - Representação Esquemática da Metodologia

\begin{tabular}{|c|c|c|c|c|c|}
\hline & $\begin{array}{l}\text { Componente de } \\
\text { Interesse }\end{array}$ & Objetivo & Resolução & Forma de Aquisição & $\begin{array}{l}\text { Local de Aquisição / Disposição Espacial / Duração da } \\
\text { Série }\end{array}$ \\
\hline \multirow[t]{13}{*}{ Hidrologia } & \multirow{2}{*}{ Precipitação (mm) } & \multirow{10}{*}{$\begin{array}{c}\text { Fornecer dados de } \\
\text { entrada para o modelo } \\
\text { numérico }\end{array}$} & \multirow{10}{*}{ Diária } & \multirow{2}{*}{ Pluviógrafo de Báscula } & Laboratório de Hidroclimatologia FAL: 2000 a 2011 \\
\hline & & & & & Estação Pluviométrica FAL: 2011 a 2016 \\
\hline & \multirow{2}{*}{$\begin{array}{l}\text { Nível da água no } \\
\text { córrego }(\mathrm{m})\end{array}$} & & & \multirow{2}{*}{ Sensor de nível } & Laboratório de Hidroclimatologia FAL: 2000 a 2011 \\
\hline & & & & & Estação Fluviométrica FAL: 2011 a 2016 \\
\hline & Vazão (mm) & & & Curva-chave (Silva, 2013) & Nível da água: 2000-2016 \\
\hline & $\begin{array}{l}\text { Escoamento de } \\
\text { base }(\mathrm{mm})\end{array}$ & & & $\begin{array}{c}\text { Filtro automático (Arnold } \\
\text { e Allen, 1999) }\end{array}$ & Vazão calculada pela curva-chave: $2000-2016$ \\
\hline & $\begin{array}{l}\text { Escoamento } \\
\text { direto }(\mathrm{mm})\end{array}$ & & & $\begin{array}{l}\text { Diferença entre vazão e } \\
\text { escoamento de base }\end{array}$ & Vazão e escoamento de base: $2000-2016$ \\
\hline & $\begin{array}{l}\text { Evapotranspiração } \\
\text { real }(\mathrm{mm})\end{array}$ & & & $\begin{array}{l}\text { Evaporação do Tanque } \\
\text { Classe A (Conceição, } \\
\text { 2001); Correlação com } \\
\text { ETr (Guerra } \text { et al., 2002) }\end{array}$ & Laboratório de Hidroclimatologia FAL: 2000 a 2013 \\
\hline & $\begin{array}{l}\text { Interceptação } \\
\quad(\mathrm{mm})\end{array}$ & & & $\begin{array}{l}\text { 23\% da precipitação } \\
\text { (Távora, 2016) }\end{array}$ & Precipitação: 2000-2016 \\
\hline & Recarga (mm) & & & Balanço Hídrico & $R=P-E d-I n-E v: 2000-2016$ \\
\hline & \multirow{3}{*}{$\begin{array}{l}\text { Umidade do solo } \\
\left(\mathrm{g} / \mathrm{g} ; \mathrm{m}^{3} / \mathrm{m}^{3} \text { e } \%\right)\end{array}$} & \multirow{3}{*}{$\begin{array}{l}\text { Demonstrar variação } \\
\text { espacial e temporal da } \\
\text { umidade do solo }\end{array}$} & \multirow{3}{*}{ Quinzenal $^{1}$} & Gravimetria & Pontos $U A, U C$ e $U E$ na vertente do córrego Capetinga \\
\hline & & & & Sonda $T D R$ & \multirow{2}{*}{$\begin{array}{l}\text { Pontos } U A, U B, U C, U D \text { e } U E \text { na vertente do córrego } \\
\text { Capetinga }\end{array}$} \\
\hline & & & & $\begin{array}{l}\text { Blocos de Resistência } \\
\text { Elétrica }\end{array}$ & \\
\hline Geofísica & $\begin{array}{l}\text { Resistividade } \\
\text { elétrica }(\Omega . \mathrm{m})\end{array}$ & $\begin{array}{c}\text { Caracterizar } \\
\text { comportamento da água } \\
\text { no solo }\end{array}$ & Quinzenal $^{1}$ & $\begin{array}{l}\text { Método elétrico de } \\
\text { corrente contínua }\end{array}$ & $\begin{array}{c}\text { Linhas } A, B, C, D, E \text { e } F \text { na vertente do córrego } \\
\text { Capetinga }\end{array}$ \\
\hline
\end{tabular}




\begin{tabular}{|c|c|c|c|c|c|}
\hline \multirow{3}{*}{ Modelagem } & \multirow{3}{*}{$\begin{array}{c}\text { Carga hidráulica } \\
\text { (m) }\end{array}$} & $\begin{array}{l}\text { Gerar condições iniciais } \\
\text { de carga hidráulica }\end{array}$ & Estacionário & \multirow{3}{*}{$\begin{array}{l}\text { Método de elementos } \\
\text { Finitos: função de } \\
\text { aproximação de Galerkin } \\
\text { para solução da equação } \\
\text { de Richards para o fluxo } \\
\text { na zona não saturada e } \\
\text { variavelmente saturada }\end{array}$} & \multirow{3}{*}{ Domínio bidimensional vertical da Vertente } \\
\hline & & $\begin{array}{l}\text { Aquecer o modelo por } \\
35 \text { anos }\end{array}$ & $\begin{array}{l}\text { Transiente: } \\
\text { 1980-2015 }\end{array}$ & & \\
\hline & & $\begin{array}{l}\text { Obter carga hidráulica } \\
\text { considerando a } \\
\text { simulação transiente } \\
\text { 1980-2015 como } \\
\text { condição inicial }\end{array}$ & $\begin{array}{l}\text { Transiente: } \\
\text { 2015-2016 }\end{array}$ & & \\
\hline
\end{tabular}

${ }^{1}$ Alterações na periodicidade de coleta dos dados foram apresentadas ao longo da metodologia, uma vez que a resolução quinzenal nem sempre pode ser adotada. 


\section{5 - RESULTADOS E DISCUSSÃO}

\section{1 - CARACTERIZAÇÃo GEOELÉTRICA NA VERTENTE DO CÓRREgo CAPETINGA}

A resistividade elétrica do solo foi monitorada ao longo de nove levantamentos geofísicos. Nas linhas paralelas ao córrego Capetinga foram adquiridos dados de resistividade aparente em 76 pontos na subsuperfície, para cada seção em cada levantamento. Na linha ortogonal, por sua vez, a medição da resistividade elétrica abrangeu 168 pontos em subsuperfície por campanha de monitoramento. Com o procedimento de inversão, esses dados foram convertidos em valores de resistividade ditos modelados, posteriormente utilizados na elaboração das seções bidimensionais de imageamento elétrico e dos mapas geoelétricos. Esses produtos possibilitaram identificar o comportamento espacial e temporal da vertente em relação à resistividade do meio.

Para fins de padronização, a expressão resistividade, quando não acompanhada do termo aparente, diz respeito aos valores de resistividade submetidos à inversão. Além disso, os termos seção, linha, perfil e imageamento elétrico fazem referência aos dados de resistividade dispostos no formato bidimensional vertical em função da profundidade de investigação. O mapeamento geoelétrico, por sua vez, apresenta a variação da resistividade em cada nível investigado ao longo do tempo.

\subsection{1 - Imageamento Elétrico do Solo}

Os dados de resistividade elétrica modelados apresentaram distribuição não normal. Com isso, para análise descritiva, foram adotadas as medidas de mediana e amplitude (máximo e mínimo) (Apêndice A). Os valores de resistividade nas seis linhas permaneceram em torno de 4.000 S.m, correspondendo a um valor típico de solos arenosos (Asawa, 2008). Considerando-se apenas as linhas paralelas ao córrego Capetinga, a seção $C$ foi identificada como mais resistiva em comparação às demais (4.004 $\Omega . \mathrm{m}$ ), seguida pela seção $A$ (3.728 $\Omega$.m). Menores valores de resistividade foram obtidos nas linhas $D$ (3.266 $\Omega . \mathrm{m})$ e $B(3.588 \Omega . \mathrm{m})$. A linha $E$, por sua vez, apresentou mediana igual a $3.577 \Omega . \mathrm{m}$. 
Valores de resistividade inferiores a 3.000 S.m foram associados à zona saturada do solo, considerando a análise conjunta dos dados com subsídio da literatura associada. Chukwauma et al. (2015), por exemplo, ao estudarem a vulnerabilidade de aquíferos sedimentares em solos arenosos na Nigéria, identificaram água subterrânea nos solos com resistividade elétrica inferior a 3.800 S.m. Amorim-Junior e Lima (2007) também identificaram valores de resistividade em torno de $3.000 \Omega . m$ na formação aquífera Urucuia, na bacia do rio das Fêmeas. Nesse caso, os autores associaram o elevado valor de resistividade da camada saturada ao solo com predomínio de arenito, em detrimento da fração argilosa, bem como à baixa salinidade da água na camada saturada.

O imageamento elétrico do solo na vertente do córrego Capetinga pode ser visualizado na Figura 5.1. A disposição das seções foi realizada de acordo com a data de aquisição, considerando ainda sua localização geográfica ao longo da vertente. Desse modo, a linha $A$, posicionada na parte superior da Figura 5.1, encontra-se mais distante do córrego (200 $\mathrm{m})$, enquanto que a Linha $E$ encontra-se mais próxima $(5 \mathrm{~m})$. $\mathrm{O}$ erro resultante do processo de inversão dos dados foi apresentado em cada seção. Além disso, após a interpolação, as escalas de cores foram padronizadas, com linhas de contorno de igual resistividade num intervalo de $1.000 \Omega . m$.

Por meio dos modelos bidimensionais padronizados a informação que se extrai diz respeito à variação da resistividade elétrica em subsuperfície com relação às profundidades investigadas $(5,10,15,21,28$ e $35 \mathrm{~m})$ a partir da superfície do solo. É importante considerar que o primeiro nível observado nas linhas paralelas está posicionando $5 \mathrm{~m}$ abaixo da superfície do solo. A porção de solo contida entre 0 e $5 \mathrm{~m}$ é entendida como a extensão vertical dos dados apresentados na profundidade de investigação equivalente à 5 m. 

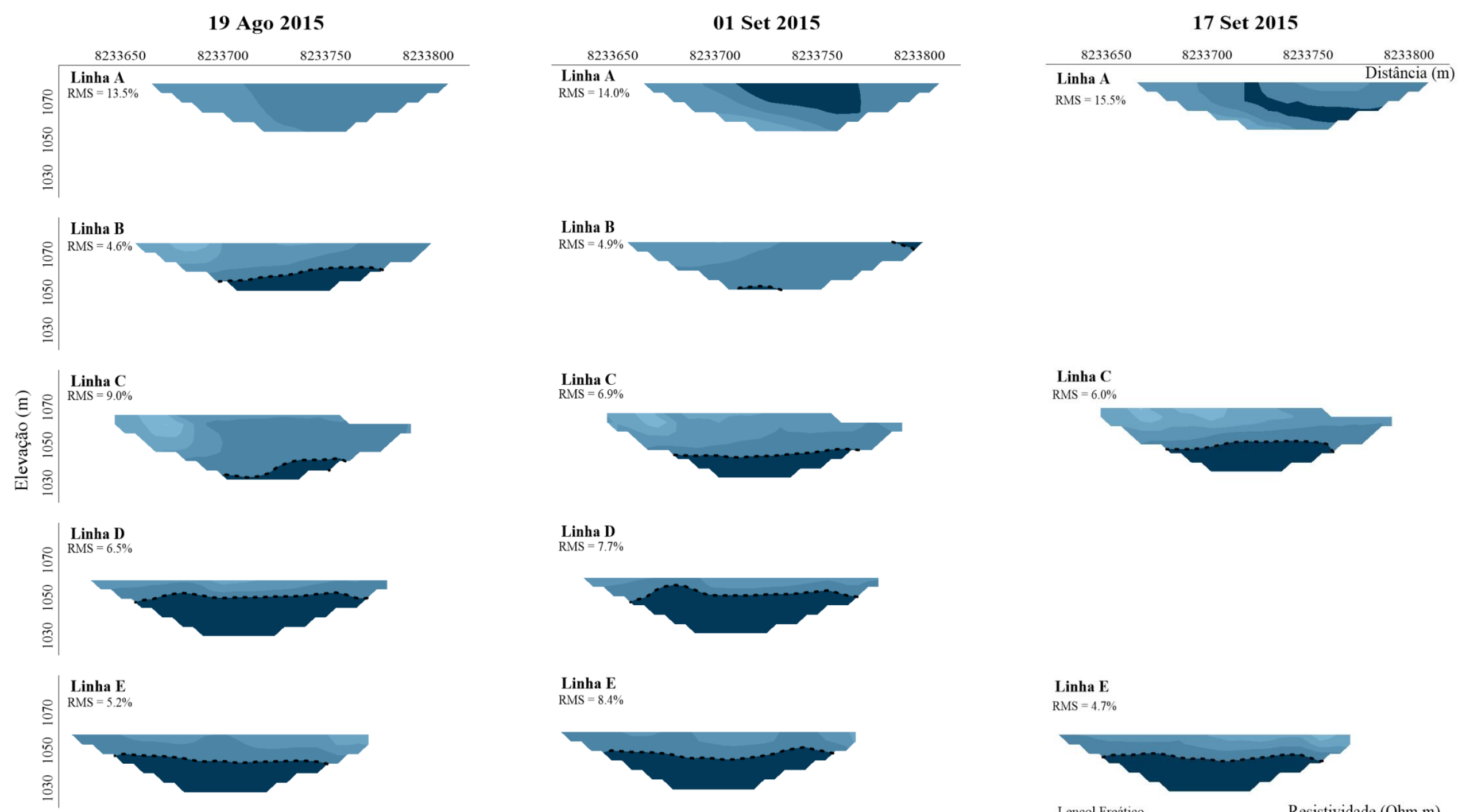

Linha C
RMS $=6.0 \%$

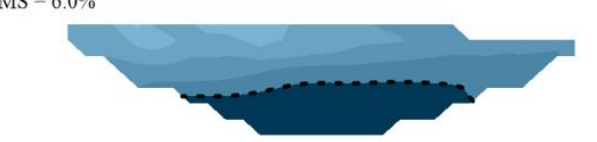

Linha E
RMS $=4.7 \%$

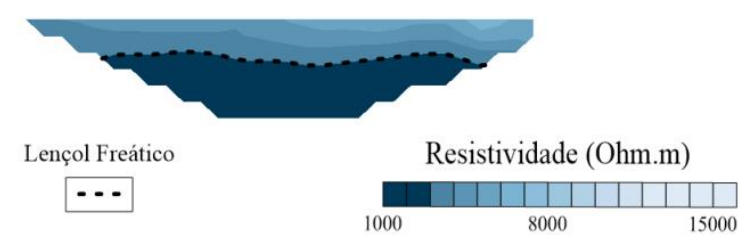




\section{Set 2015}
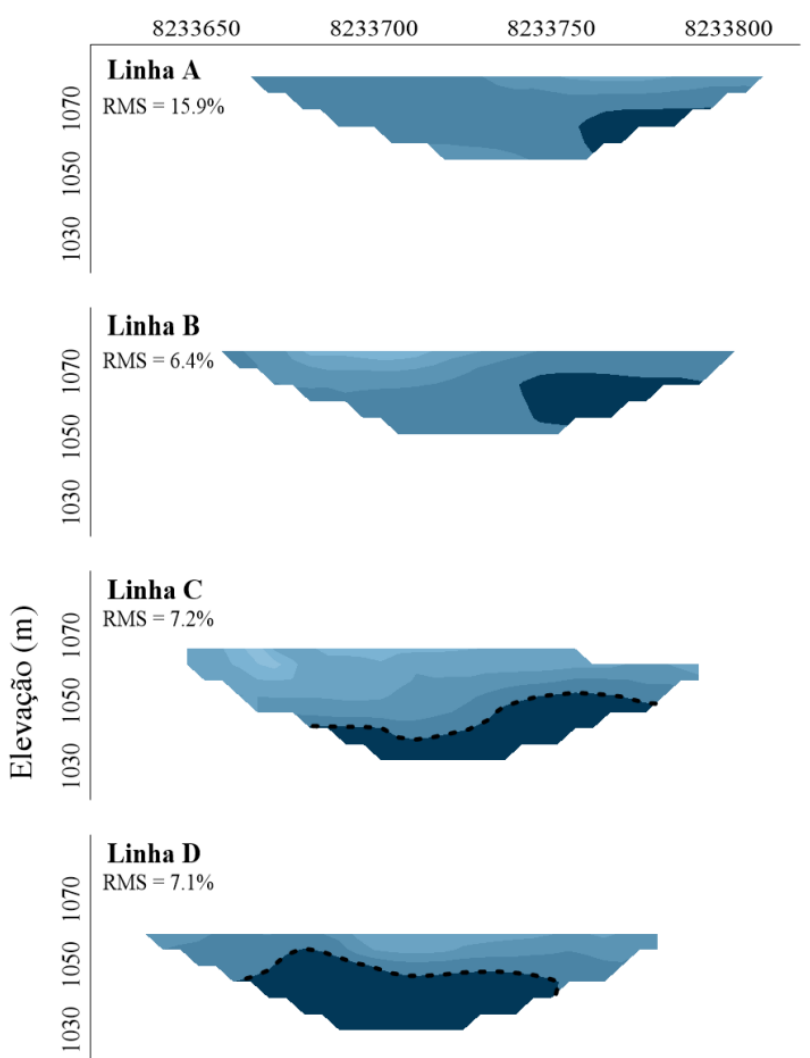

Linha E

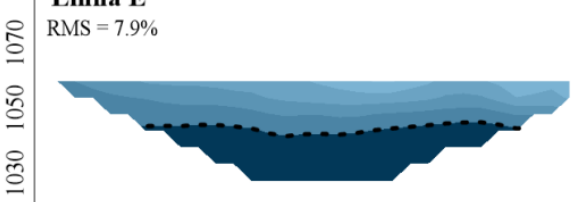

15 Out 2015

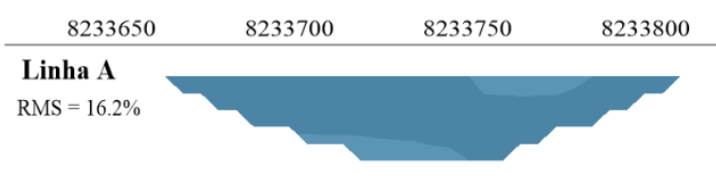

Linha B

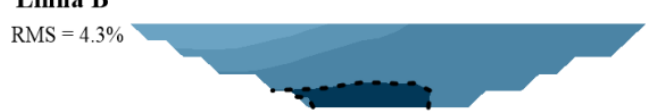

Linha C

RMS $=7.4^{\circ}$

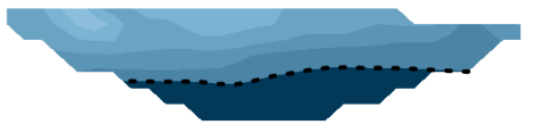

Linha D

$\mathrm{RMS}=4.3 \%$

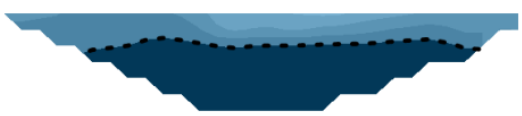

Linha E

RMS $=63 \%$

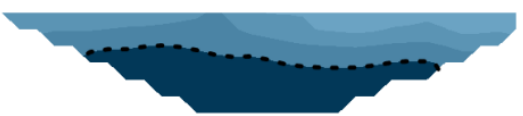

26 Out 2015

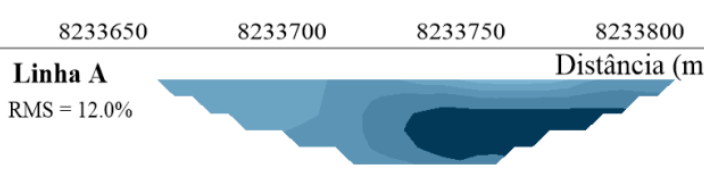

Linha B

RMS $=4.8 \%$

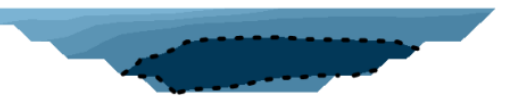

Linha C

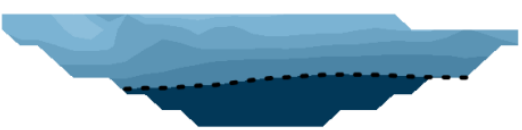

Linha D

RMS $=5.7 \%$

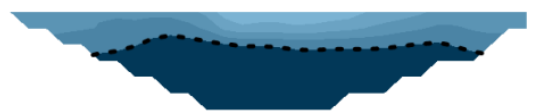

Linha E

RMS $=8.8 \%$

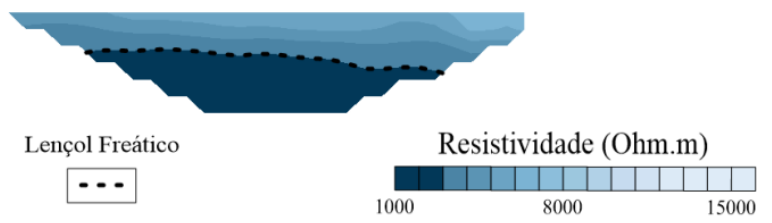


10 Nov 2015
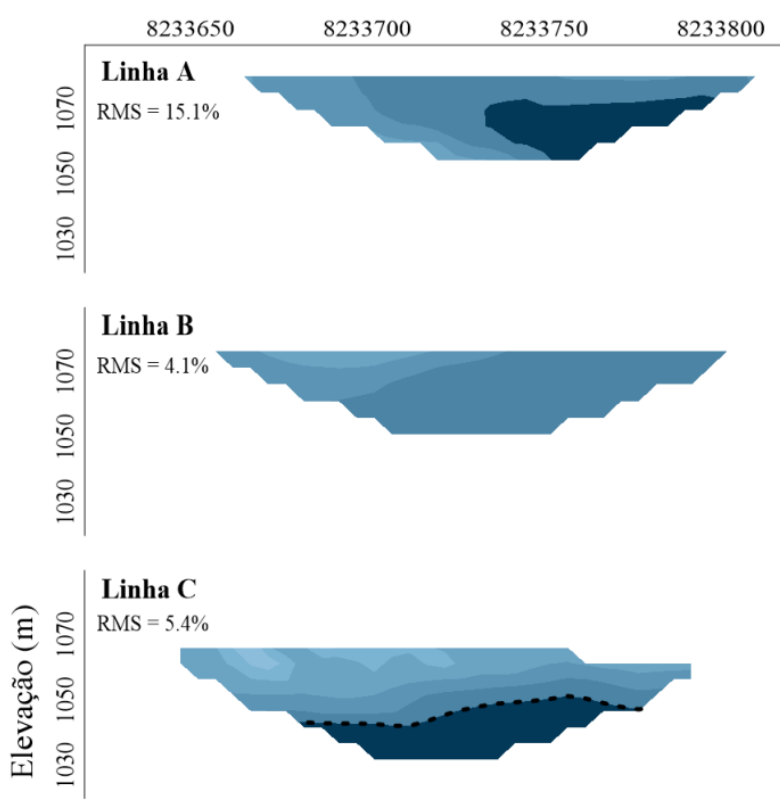

Linha D

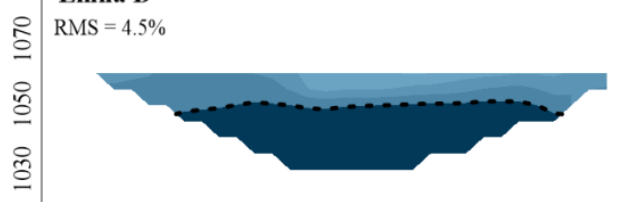

Linha E

ก. $\mathrm{RMS}=6.6 \%$

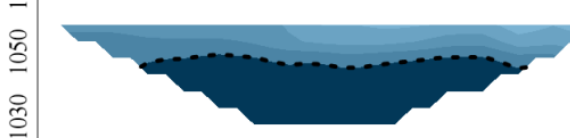

09 Dez 2015

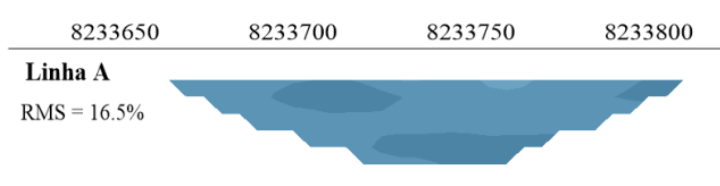

Linha B

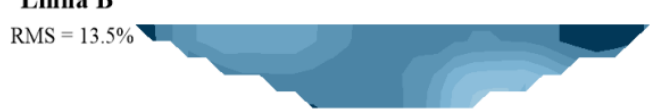

Linha C

$\mathrm{RMS}=4.0^{\circ}$

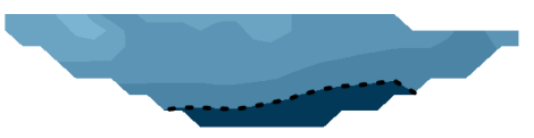

Linha D

$\mathrm{RMS}=6.9 \%$

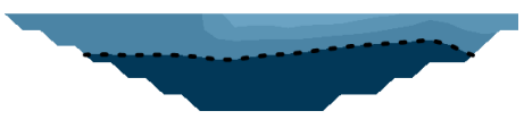

Linha E

RMS $=3.8 \%$

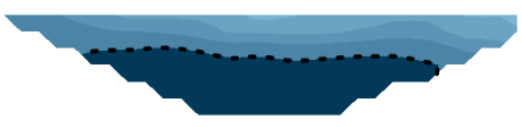

04 Fev 2016

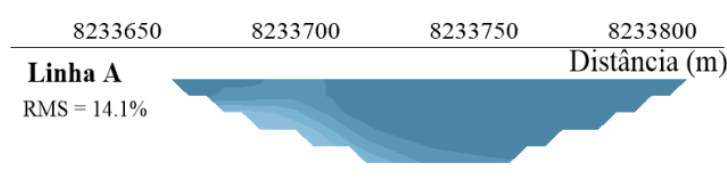

Linha B

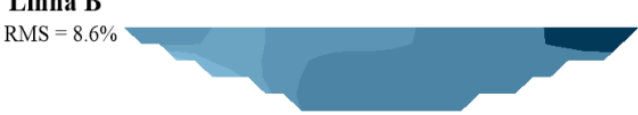

Linha C

RMS $=8.2 \%$

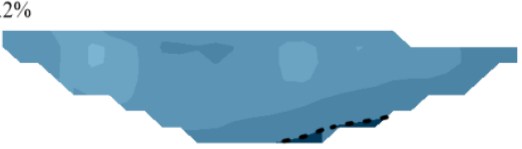

Linha D RMS $=4.0 \%$

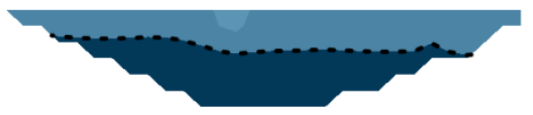

Linha E

RMS $=4.2 \%$

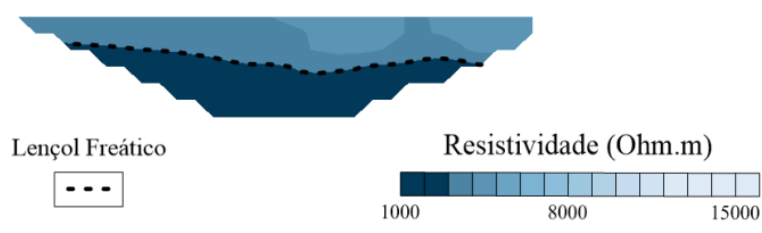

Figura 5.1 - Imageamento elétrico bidimensional das linhas " $A$ ” a " $E$ ”. 
Como afirmam Solberg et al. (2012), os dados mais confiáveis das seções geoelétricas estão posicionado no centro do perfil devido à maior resolução do método de caminhamento elétrico com arranjo de Wenner nessa porção do terreno. Desse modo, ao se observar a porção central dos perfis é possível identificar camadas horizontalmente estendidas em subsuperfície e anomalias de baixa resistividade (abaixo de $3.000 \Omega . m$ ) nas linhas $C, D$ e $E$. Esse comportamento foi recorrente ao longo das semanas de investigação. Nas Linhas $A$ e $B$, por sua vez, a estratigrafia geoelétrica não pode ser igualmente identificada, ocorrendo apenas na Linha $B$, nas semanas 1 e 6 . Além disso, as zonas de baixa resistividade, quando identificadas, concentraram-se na porção leste dessas seções.

A variação dos valores de resistividade ao longo das profundidades de investigação, em cada uma das linhas, pode ser compreendida com a observação conjunta entre as seções geoelétricas e os gráficos contidos na Figura 5.2. Nesta, é possível verificar que os valores de resistividade elétrica variaram de maneira semelhante em todas as seções até a profundidade de investigação de $10 \mathrm{~m}$. A resistividade nessa porção do solo foi caracterizada com valores elevados e com maior amplitude de variação. Desse modo, infere-se que o solo não saturado confere valores de resistividade que equiparam as cinco linhas na fração até $10 \mathrm{~m}$ de profundidade, fornecendo uma ideia relativa do teor de umidade do solo (Figura 5.2).

Nas profundidades de investigação abaixo de $10 \mathrm{~m}$ as seções passam a ser diferenciadas (Figura 5.2). Em $C, D$ e $E$ a resistividade do solo tem seus valores progressivamente reduzidos em conjunto com a diminuição da amplitude de distribuição dos dados. Na linha $B$, observa-se um comportamento semelhante, porém a elevada amplitude de variação e a ocorrência de valores de resistividade máximos destoantes (outliers) tendem a diferenciar essa seção das anteriores. Para a linha $A$, os valores de resistividade mantiveram-se semelhantes àqueles até $10 \mathrm{~m}$ de profundidade em todo o perfil (Figura 5.2).

Os valores elevados de resistividade da seção $A$ são indicativos de que o teor de água no solo se mantém reduzido em todo o domínio em comparação às demais seções. Além disso, anomalias indicativas do nível da água subterrânea não foram observadas para essa seção numa profundidade máxima de investigação de $35 \mathrm{~m}$. Nas demais linhas, ainda que de maneira menos perceptível em $B$, a redução gradual nos valores de resistividade elétrica 
pode ser resultado do aumento na quantidade de água no solo, que favorece ainda a menor amplitude de distribuição dos dados de resistividade nas camadas.

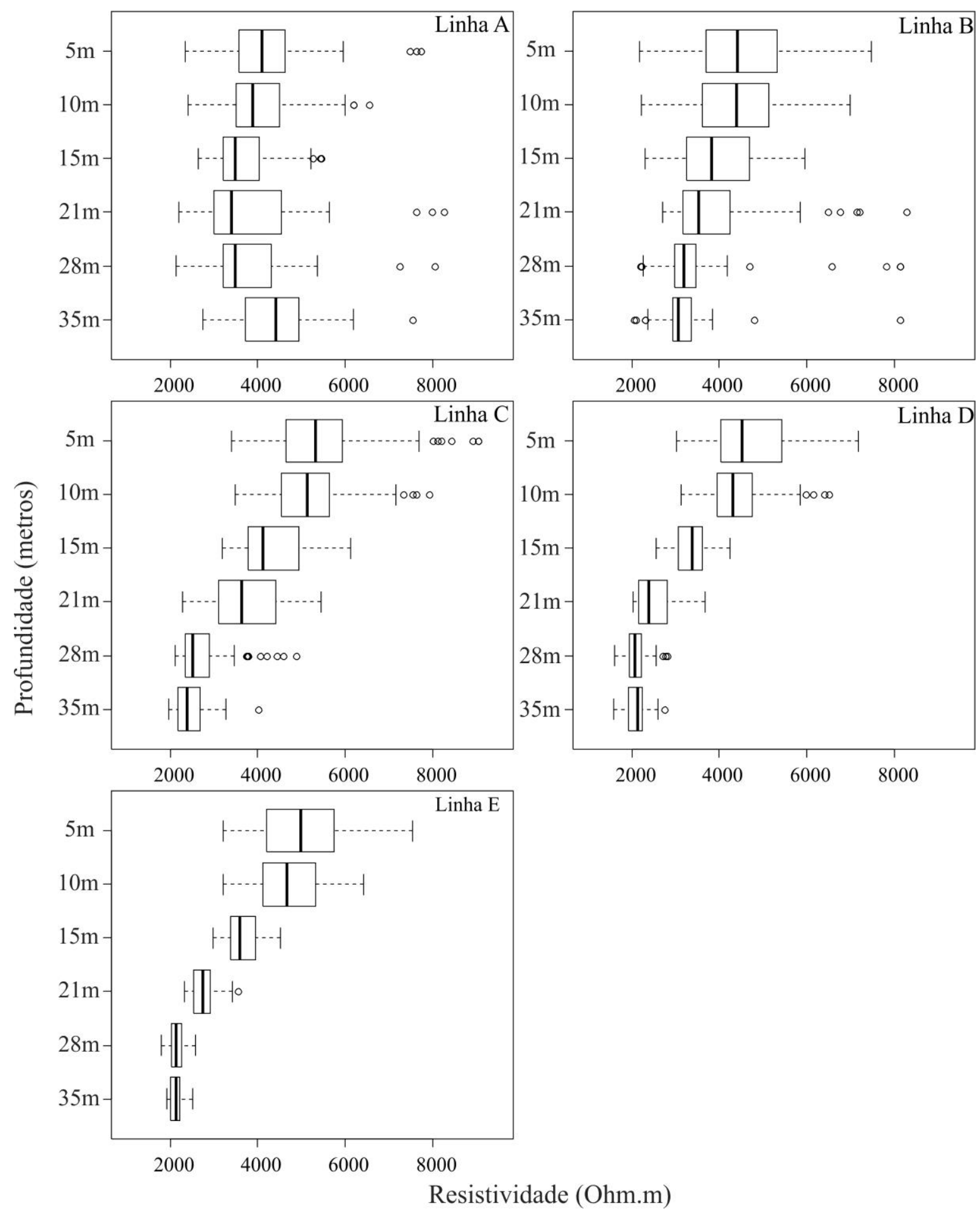

Figura 5.2 - Gráficos box plot da variação nos valores de resistividade para as linhas " $A$ ", " $B$ ", " $C$ ", " $D$ "e " $E$ " em função das profundidades investigadas.

Infere-se, então, que a zona saturada do solo pode ser observada a partir da linha $B$, na profundidade de $28 \mathrm{~m}$, com gradiente hidráulico estabelecido em direção à linha $E$, cuja 
profundidade da zona menos resistiva permanece em torno de $15 \mathrm{~m}$. Quanto à profundidade do nível freático atribuída à linha $E$, cabe ressaltar que o poço de observação perfurado na mesma localidade forneceu profundidade do nível da água em torno de $11 \mathrm{~m}$. Contudo, em função da curta série de dados e da ausência de poços nas demais seções, não se pode discorrer a respeito da consistência dessa afirmação.

A linha $F$, disposta separadamente em função da discretização diferenciada, permitiu a observação do comportamento da resistividade na seção transversal ao córrego. Seus valores de resistividade foram associados às profundidades entre 2,5 e $30 \mathrm{~m}$, como apresentado no Apêndice A. Desse modo, o primeiro nível a conter informação de resistividade elétrica está posicionado a 2,5 m abaixo da superfície do solo. Assim como para as linhas descritas inicialmente, a porção de solo entre 0 e 2,5 m é entendida como a extensão vertical dos dados apresentados na profundidade equivalente à $2,5 \mathrm{~m}$.

Nesse caso, foi obtido valor de mediana igual a 4.589 S.m, com amplitude de variação de aproximadamente $14.000 \Omega . m$ (Apêndice A). Em comparação aos perfis traçados em paralelo ao córrego, foi observada a ocorrência de valores mais elevados de resistividade. Tal fato deveu-se possivelmente ao refinamento na aquisição dos dados entre 2,5 (menor distância entre os eletrodos) e $5 \mathrm{~m}$ de profundidade, que apresentaram valores de resistividade predominantemente mais elevados ao longo das semanas, em comparação com as demais profundidades (Figura 5.3 e Figura 5.4). A estratigrafia geoelétrica observada nas linhas $C, D$ e $E$ também pode ser observada em $F$, com progressiva redução dos valores de resistividade ao longo das profundidades e expressão horizontal de camadas geoelétricas uniformes.

Como mencionado acima, valores elevados de resistividade (6.596 $\Omega . m$ ) foram identificados nas camadas superficiais do solo (até $5 \mathrm{~m}$ ), sobrepostas a camadas progressivamente menos resistivas $(2.989$ S.m) (Figura 5.4). A região menos resistiva foi identificada na porção leste do perfil, próxima ao córrego Capetinga e, possivelmente, ao nível do lençol freático. Desse modo, a anomalia de baixa resistividade também pode ser associada com a posição do nível da água subterrânea. Na porção oeste na seção, uma anomalia isolada recorrente entre os dias 01 de setembro e 10 de novembro de 2015 e, posteriormente, no dia 04 de fevereiro de 2016, pode estar associada a variações pontuais 
da resistividade na zona não saturada do solo ou ainda a uma lente de aquífero suspenso, a respeito da qual não foram obtidas informações adicionais.

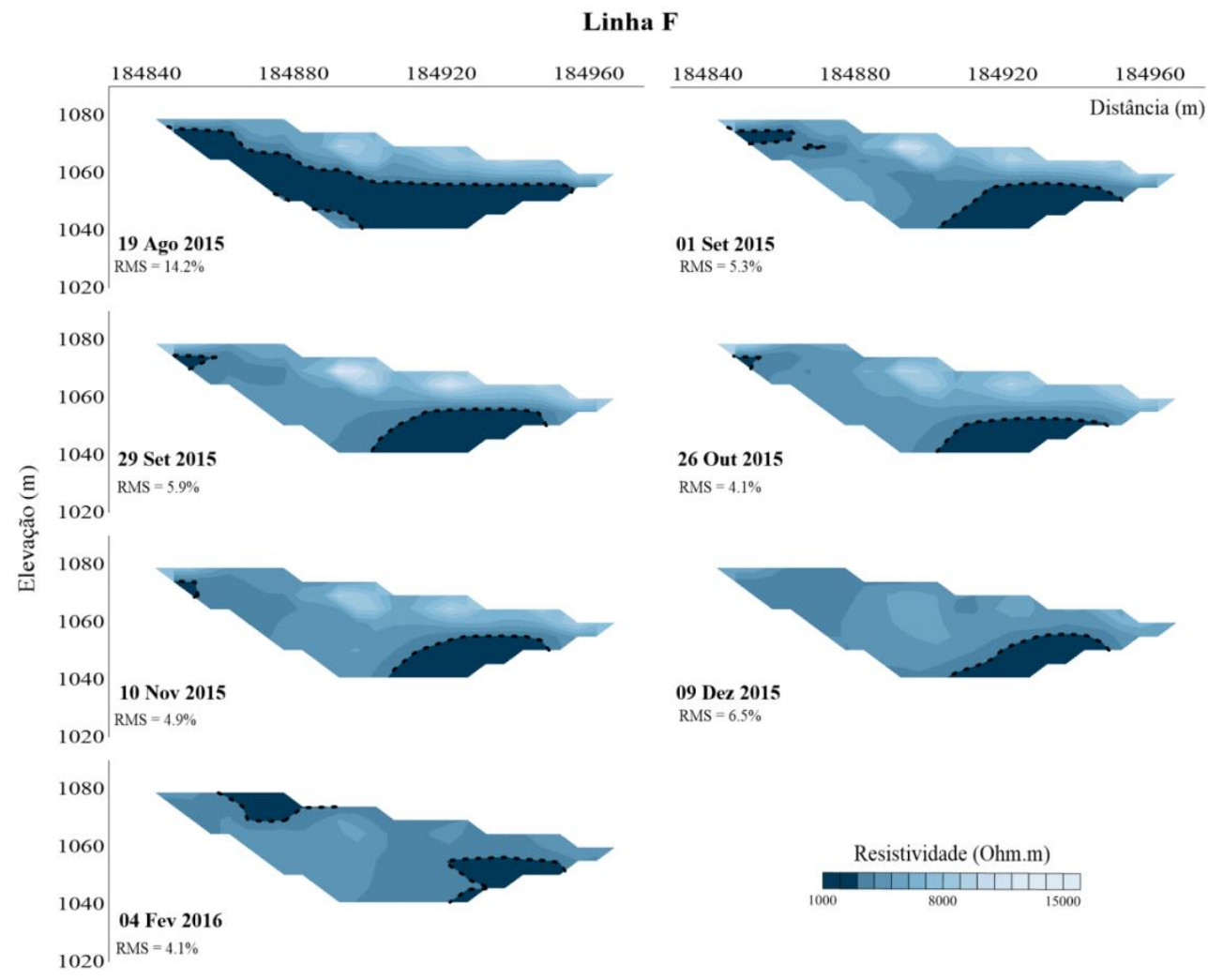

Figura 5.3 - Variação vertical dos valores de resistividade na seção " $F$ ”, desde a estrada (fração à esquerda, com maior elevação) até a proximidade do córrego Capetinga.

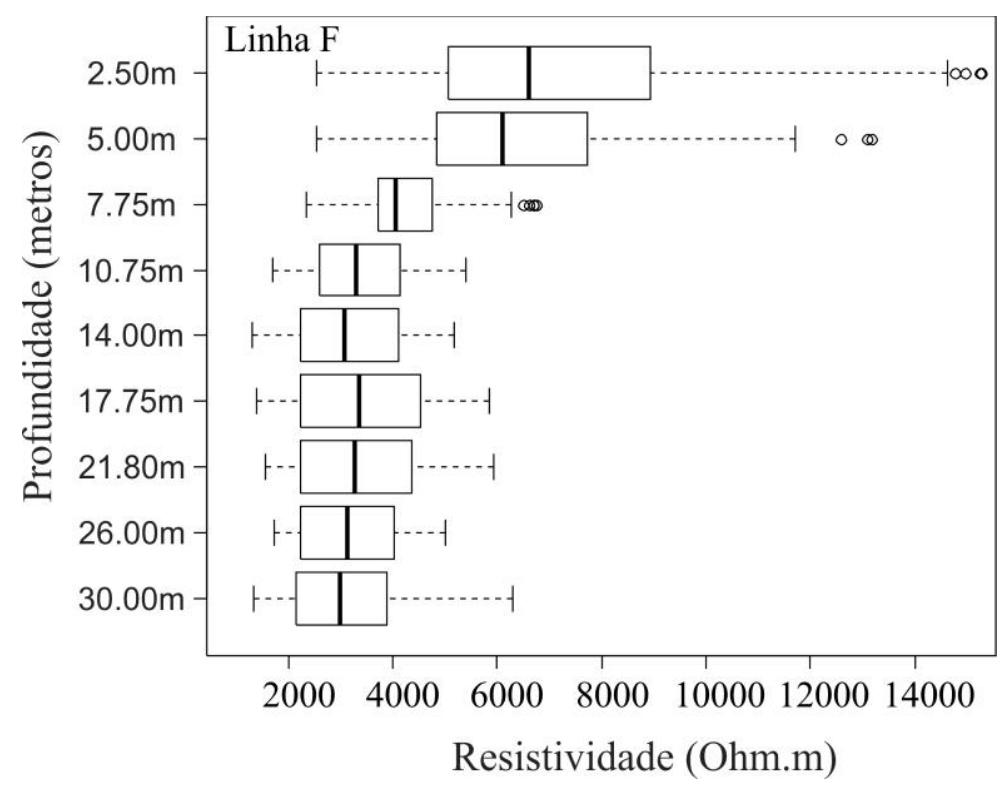

Figura 5.4 - Variação dos valores de resistividade para a linha “ $F$ ” em gráfico box plot. 
Sabe-se que a variabilidade temporal e espacial da resistividade elétrica do solo pode ser relacionada às variações no conteúdo de água presente em seus espaços intersticiais. Desse modo, infere-se que a estratigrafia geoelétrica nas linhas $C, D$ e $E$, com valores de resistividade uniformes ao longo de camadas horizontais e reduzidos progressivamente a cada profundidade de investigação, esteja relacionada ao comportamento da água no solo. Variações pedológicas e de cobertura do solo entre as linhas $A-B$ e $C-D-E$ podem reforçar essa afirmação, indicando maior proximidade do lençol freático com a superfície do solo nas últimas três linhas, com reflexos no comportamento geoelétrico da vertente.

Desse modo, a linha $A$ demonstra o comportamento geoelétrico do solo fora da zona ripária (50 m), a linha B representa a transição de uma região da vertente com predomínio de latossolo vermelho-amarelo e presença de Cerradão e Cerrado para a zona ripária, com ocorrência de solo dito hidromórfico. Para as demais linhas $(C, D$ e $E)$, contidas na zona ripária, considera-se que o nível da água subterrânea foi identificado.

Os métodos geofísicos permitem a obtenção de um denso conjunto de informações acerca do comportamento da água no solo quando comparados com a caracterização hidrogeológica direta, por exemplo, por meio da perfuração de poços (Wennigar et al., 2008). Contudo, deve-se salientar que o método elétrico de corrente contínua apresenta limitações quanto à interpretação, sendo dependente de parâmetros hidrogeológicos, tais como teor de umidade do solo, condutividade hidráulica, transmissividade e porosidade (Behroozmand, Keating e Auken, 2015). Além disso, a obtenção de dados do nível da água no domínio aquífero poroso é indicada para validação dos modelos admitidos como representativos da camada saturada do solo.

Os dados de umidade gravimétrica obtidos na vertente do córrego Capetinga não puderam ser correlacionados aos de resistividade, pois não houve correspondência entre as profundidades investigadas pelos métodos geofísico e gravimétrico. Contudo, Calamita et al. (2012) demonstraram, por meio do monitoramento simultâneo da resistividade elétrica e da umidade do solo, que o método elétrico de corrente contínua pode ser considerado uma alternativa no monitoramento da umidade do solo em bacias hidrográficas pequenas e médias. Os resultados obtidos nesse estudo demonstraram uma boa correlação entre a resistividade e a umidade do solo, com erro associado de 4,4\% vol/vol (Calamita et al., 2012). 
Uma abordagem alternativa, a exemplo do trabalho desenvolvido por Brillante et al., (2014), é a correlação entre os valores de resistividade e teor de água no solo por meio das funções de pedotransferência, que consideram a influência conjunta da resistividade com outras características do solo. Contudo, a utilização dessa ferramenta exige determinação de propriedades do solo, tais como granulometria, matéria orgânica e capacidade de troca catiônica, que limitaram sua aplicação neste estudo. A necessidade de se obter informações a respeito da umidade do solo deve-se ao fato dessa ser um fator chave na resposta do escoamento para um dado evento de precipitação, sendo uma variável de estado natural da superfície terrestre, que se altera espacialmente e temporalmente sobre a área da bacia (Monte-Mor et al., 2012).

Em suma, a exemplo de Wennigar et al. (2008), a aplicação da técnica de caminhamento para determinação da resistividade elétrica do solo permitiu a caracterização da subsuperfície da vertente como uma medida indireta do comportamento da água no solo até $35 \mathrm{~m}$ de profundidade, sendo identificada uma formação aquífera associada a valores de resistividade inferiores a 3000 S.m. Uma importante contribuição do presente estudo está relacionada ao fato de que o método geofísico aplicado, considerado relativamente simples, forneceu informações que podem subsidiar um estudo continuado dos processos hidrológicos em ambientes de vertente, onde dados relacionados ao comportamento da água no solo são considerados escassos.

\subsection{2 - Mapeamento dos Valores de Resistividade Elétrica do Solo}

As perfilagens executadas na área possibilitaram construir mapas de resistividade elétrica em diferentes profundidades para cada semana de investigação. Por meio dos mapas podese observar a variação da resistividade ao longo da vertente. Desse modo, para cada semana foram elaborados seis mapas associados às profundidades de investigação entre 5,0 e 35,0 m (Figura 5.5). A área dos mapas se torna menor para aqueles relacionados às regiões mais profundas, uma vez que decorrem dos dados obtidos na seção trapezoidal discutidos no item anterior e apresentados no Apêndice A. Sendo assim, para os níveis mais profundos são fornecidos dados em menor quantidade devido à ampliação no espaçamento entre os eletrodos ao longo do levantamento geofísico. 
As cinco seções geoelétricas dispostas paralelamente ao córrego demonstram uma progressiva definição da zona de baixa resistividade (abaixo de 3.000 $\Omega . m$ ) nos níveis mais profundos de investigação. Esse padrão foi mantido ao longo das semanas, tornando evidente a existência de uma zona menos resistiva a partir da seção $C$ e em direção ao córrego Capetinga (Figura 5.5). As zonas mais resistivas (acima de $5.000 \Omega . m$ ) foram observadas até $10 \mathrm{~m}$ de profundidade, especialmente na proximidade da linha $C$, exceto durante as semanas 8 e 9, quando foram identificadas zonas de resistividade elevada nas profundidades abaixo de $21,5 \mathrm{~m}$ para as linhas $A$ e $B$.

Esse comportamento pode ser visualizado graficamente por meio da Figura 5.6, onde o valor mediano de resistividade para a linha $C$ mantendo-se superior aos demais na maior parte do tempo até a profundidade de $21 \mathrm{~m}$. A partir deste ponto a linha $C$ torna-se menos resistiva, enquanto que as linhas $A$ e $B$ mantêm valores elevados de resistividade. O que se observa de modo geral nos mapas e gráficos (Figura 5.5 e Figura 5.6) é a prevalência de valores elevados de resistividade nas camadas superficiais (até $10 \mathrm{~m}$ ), com progressiva redução entre as linhas $B$ e $E$, ao longo das camadas mais profundas. A partir de $28 \mathrm{~m}$ de profundidade apenas a linha $A$ mantém valores superiores a $3.000 \Omega . m$. As linhas $A$ e $B$, em sua porção norte, destoam nesse aspecto pelos valores menos resistivos apresentados nas camadas de 5 e $10 \mathrm{~m}$.

Esse comportamento pode estar associado às variações texturais do solo, uma vez que, nas camadas mais profundas os valores de resistividade mostram-se elevados, sem indicativo de proximidade com nível da água subterrânea, especialmente para a linha $A$. Nascimento et al. (2001) ressaltam que, para a região do Distrito Federal, variações no teor de areia fina de $10 \%$ podem causar oscilações de 10.000 S.m nos Latossolos. Desse modo, também é possível que pequenas mudanças na composição da textura dos solos estejam influenciando os valores de resistividade, especialmente na zona não saturada. 
19 Ago 2015
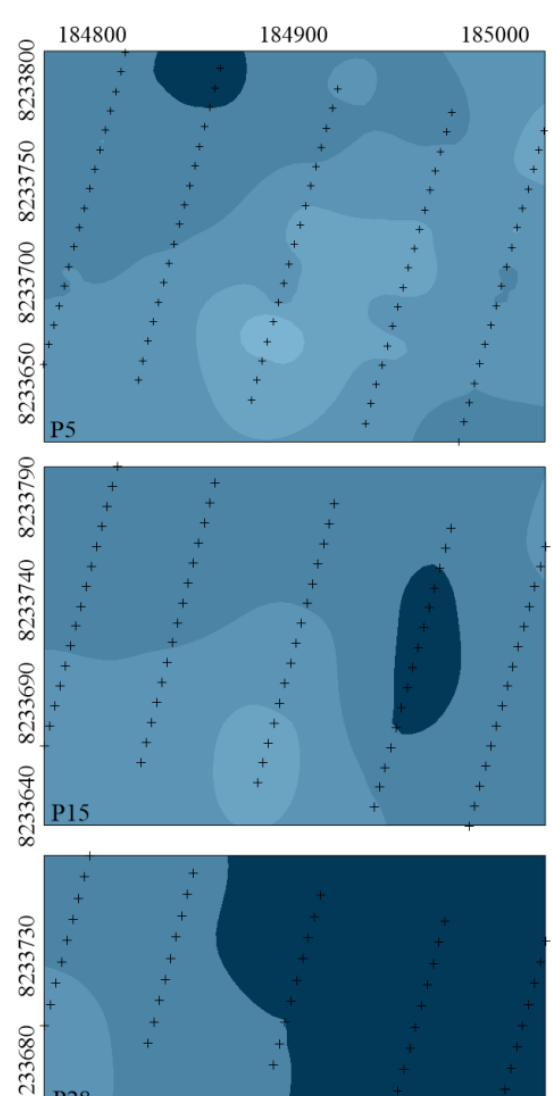

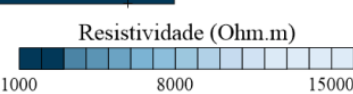

01 Set 2015
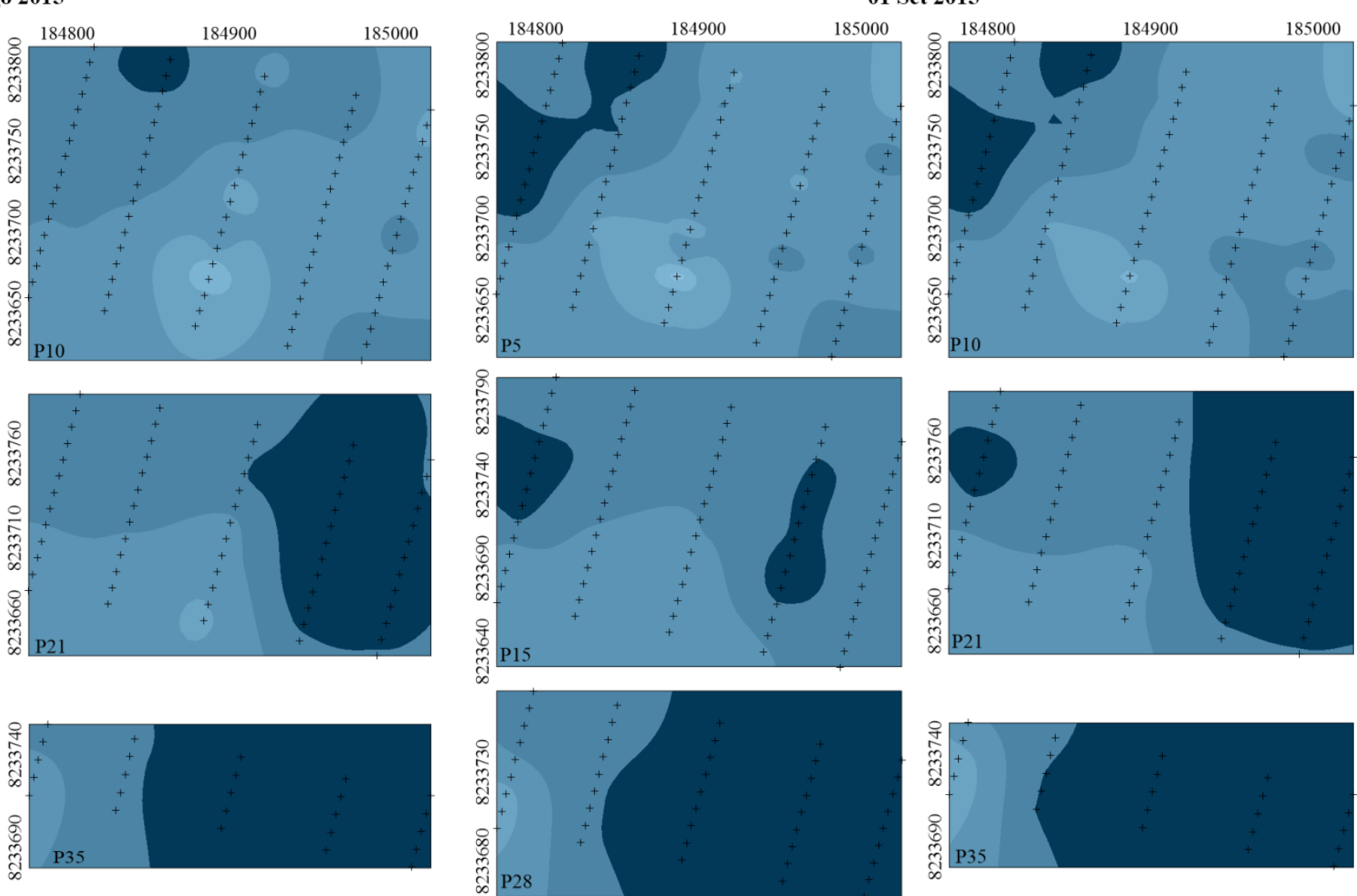

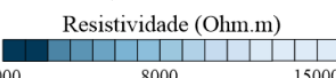


17 Set 2015
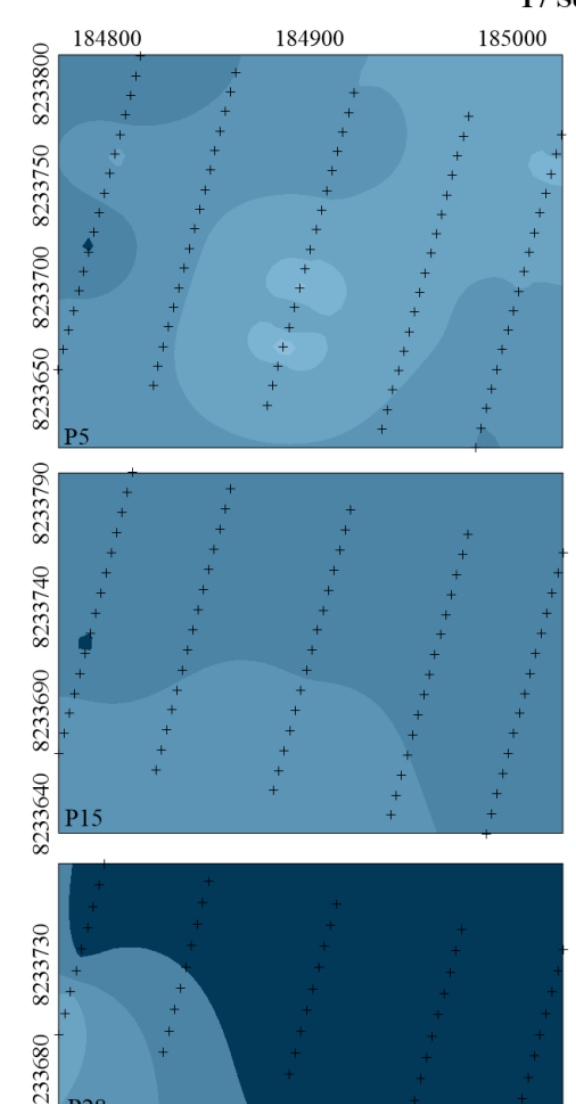

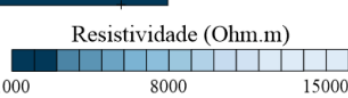

29 Set 2015
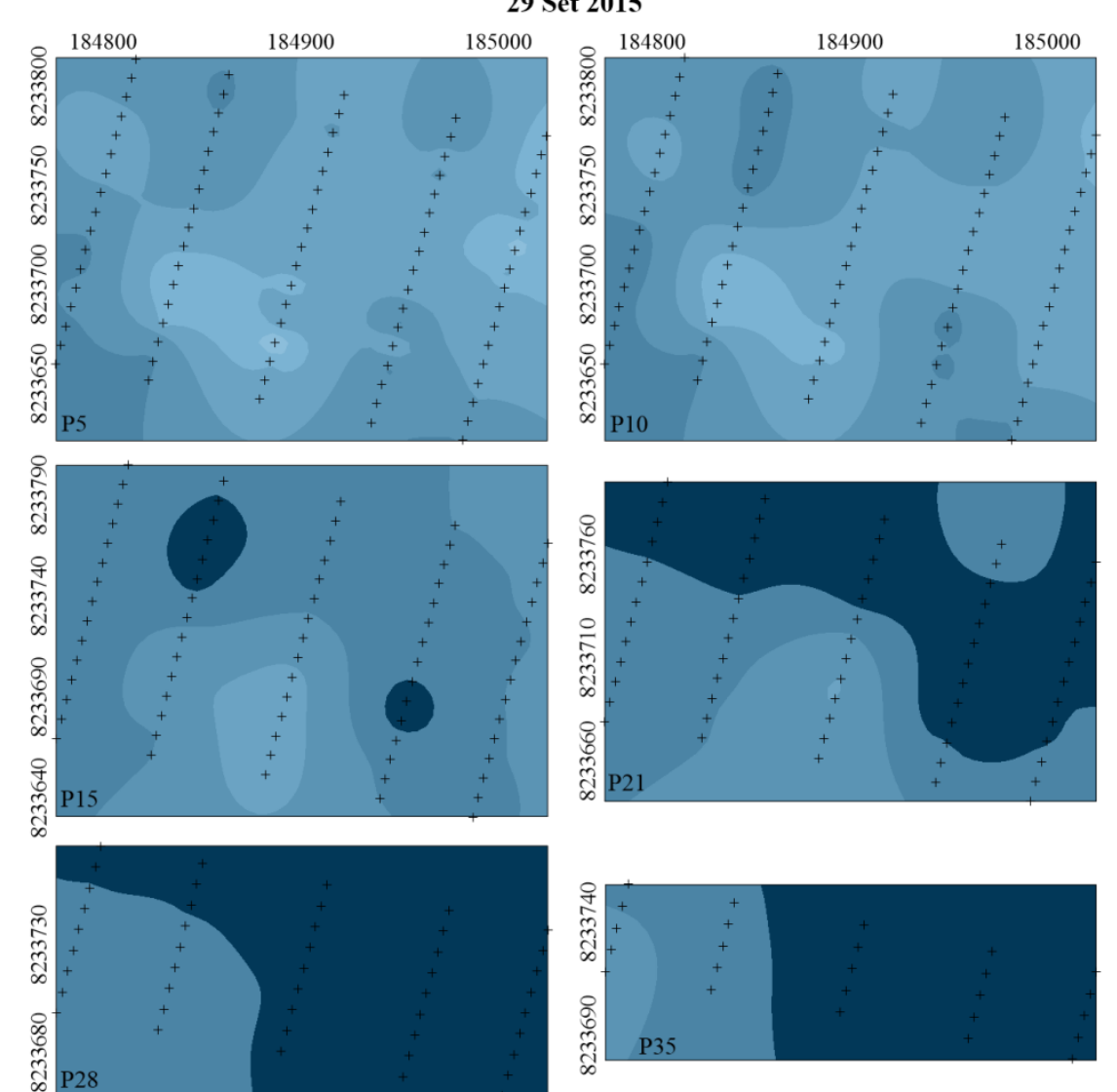

Resistividade (Ohm.m)
0 

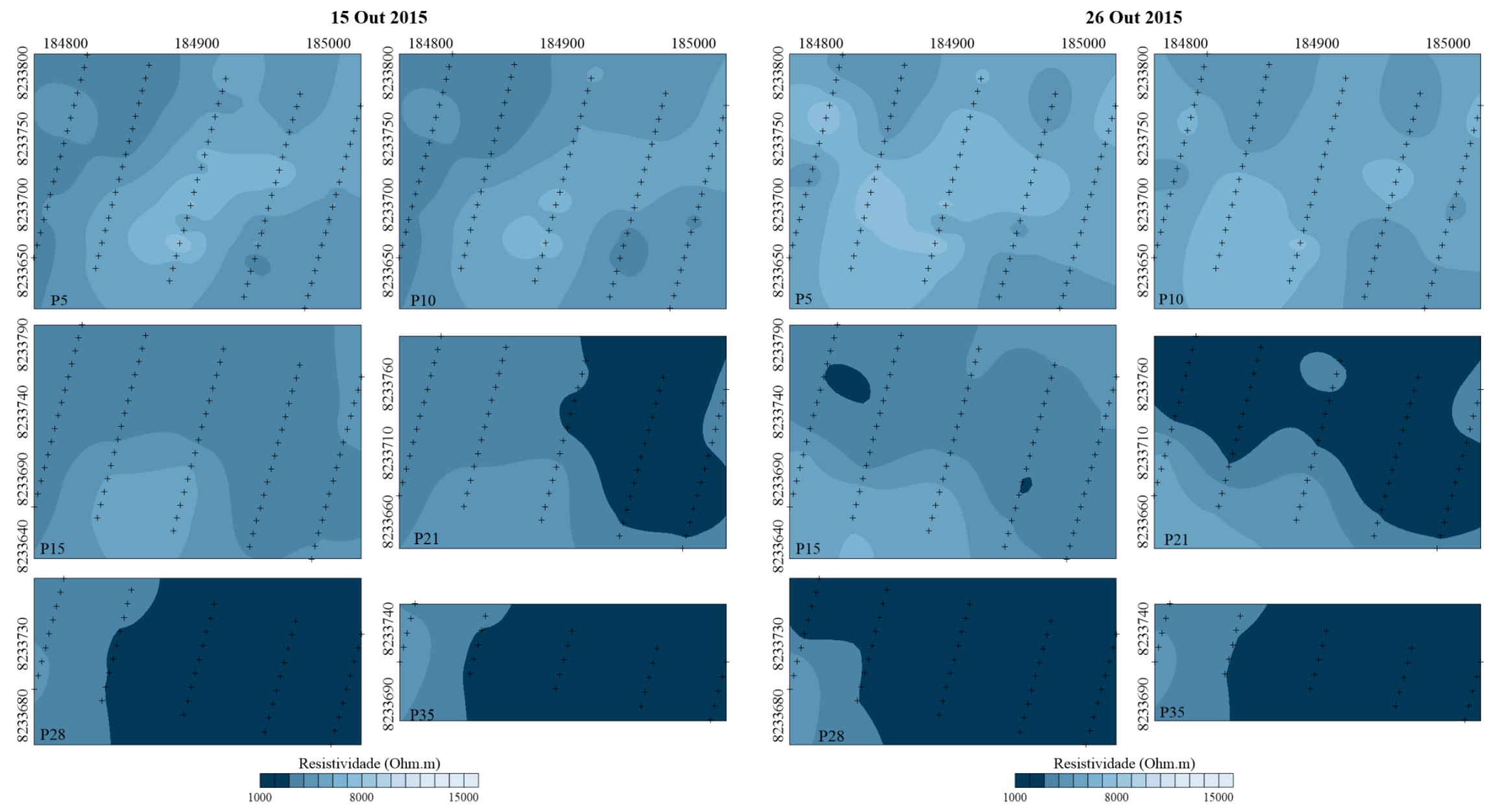

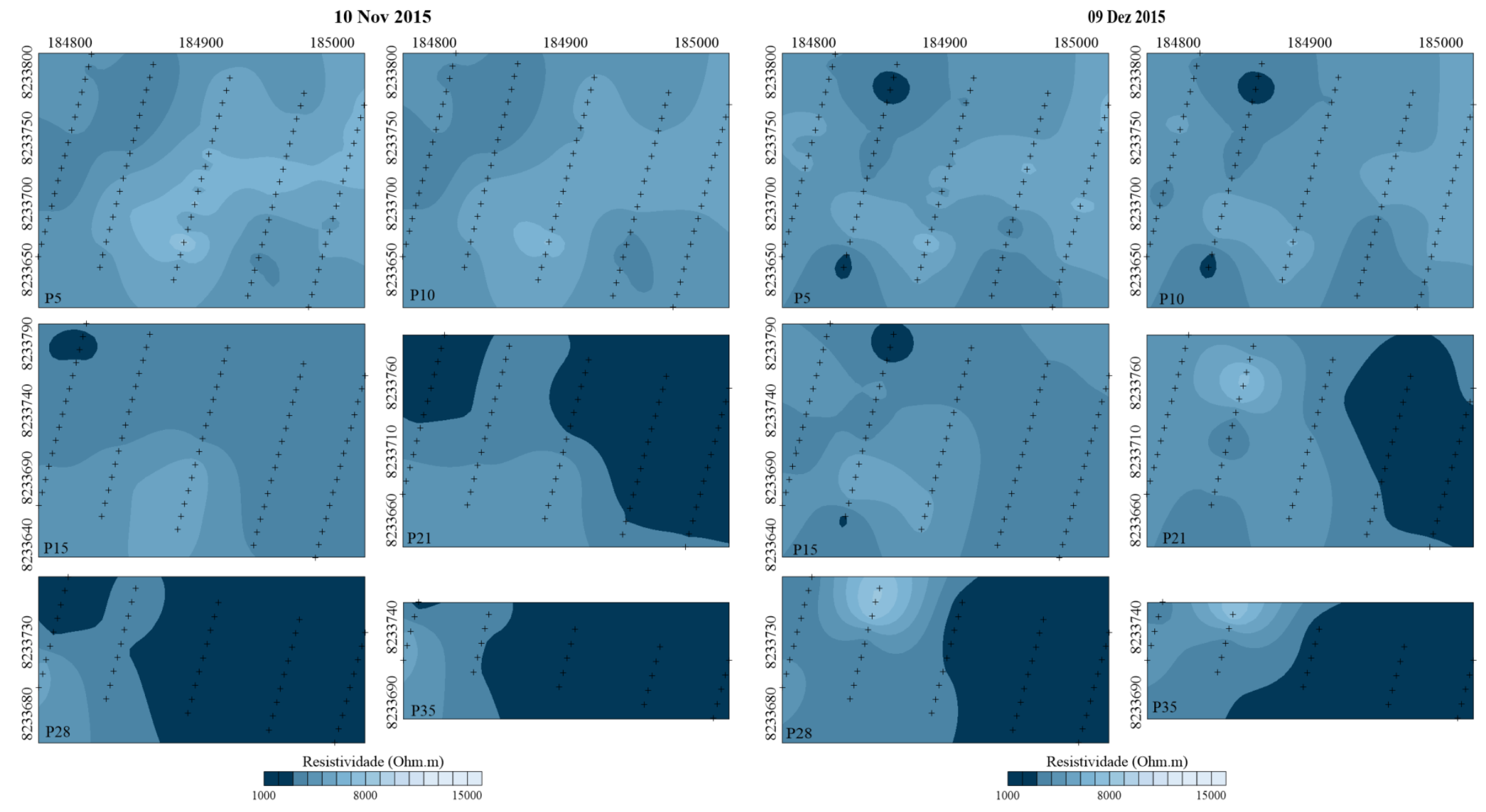
04 Fev 2016

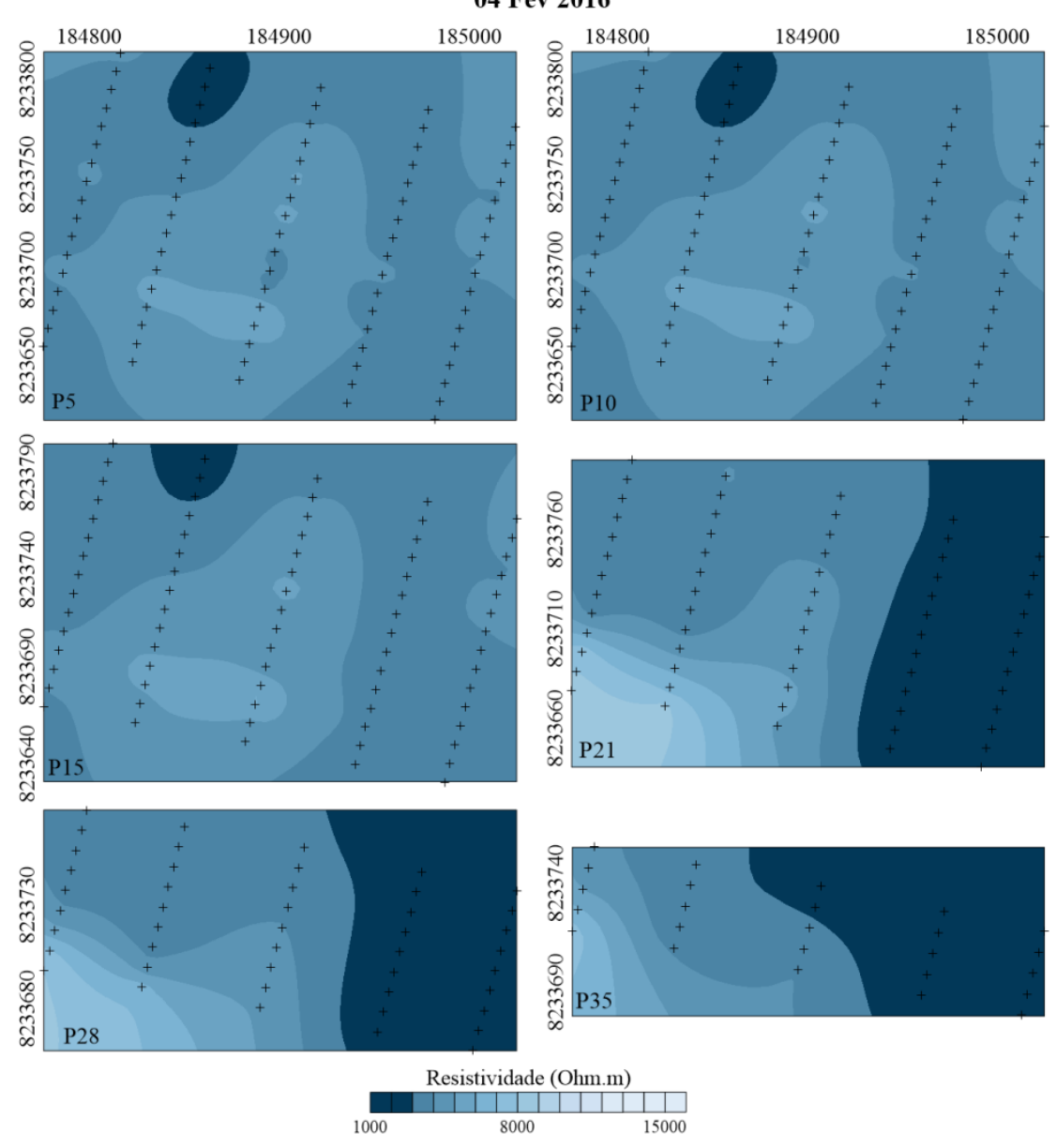

Figura 5.5 - Mapas de resistividade calculada $(\Omega . \mathrm{m})$. As siglas P5, P10, P15,5, P21,5, P28 e P35,5 indicam as profundidades investigadas. As linhas tracejadas e em negrito indicam a posição das seções geolétricas ao longo da vertente do córrego Capetinga, no sentido da Seção $A$ (primeira à esquerda) à $E$ (primeira à direita). 


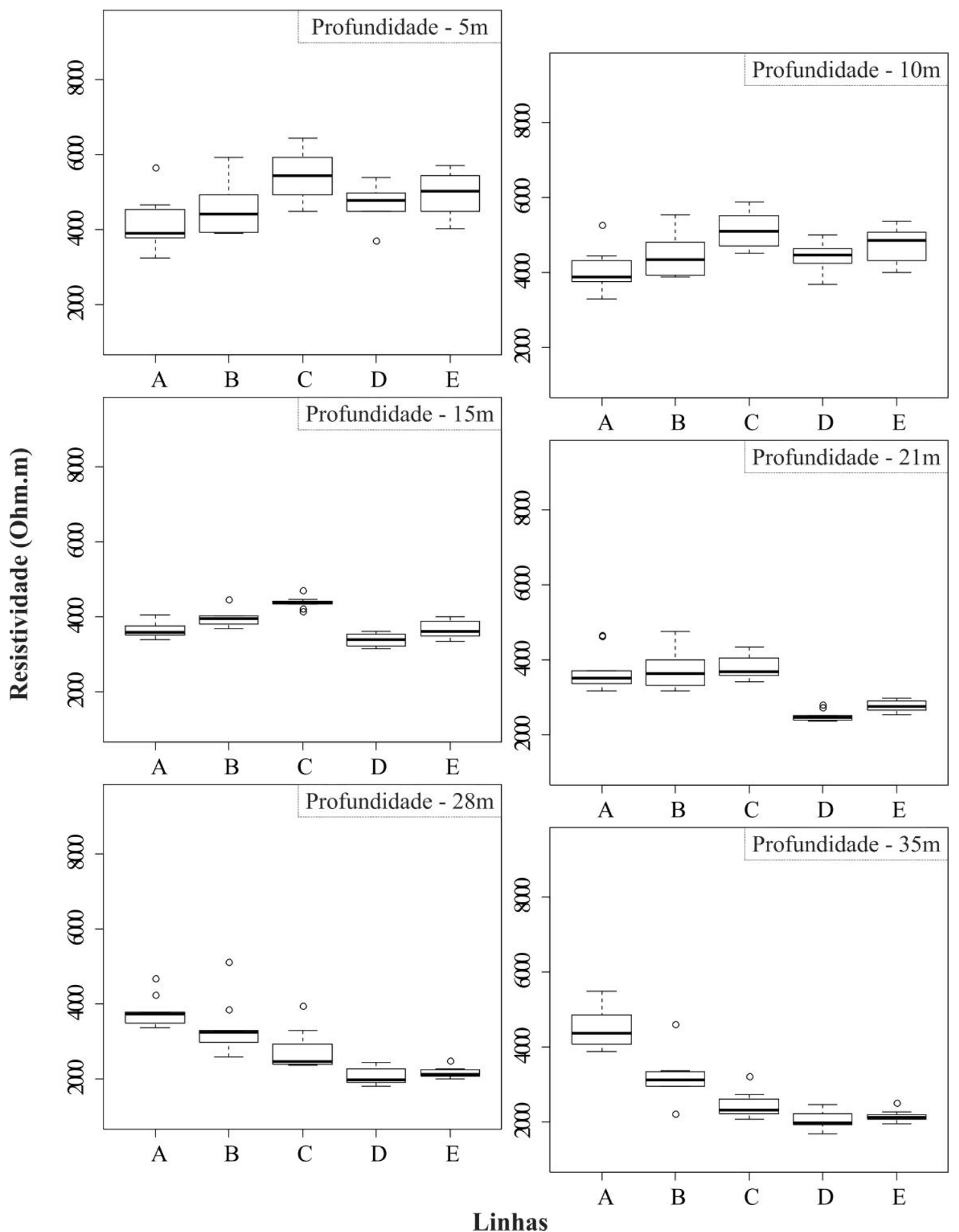

Figura 5.6 - Variação espacial e temporal da resistividade modelada $(\Omega . m)$ para cada profundidade de investigação nas seções " $A$ " a " $E$ ".

\subsection{3 - Variação Temporal dos Valores de Resistividade Elétrica}

A variação temporal dos valores de resistividade foi determinada a partir da diferença entre os dados de resistividade para cada intervalo de tempo e aqueles obtidos no tempo inicial (19 de agosto de 2015). Essa variação foi apresentada na Figura 5.7 como a 
porcentagem de diferença em relação à seção obtida em 19 de agosto de 2015, numa escala de -70 a 170. A variação negativa indica uma redução da resistividade em relação ao período inicial de monitoramento, podendo estar relacionada ao aumento na umidade do solo em comparação ao período inicial de estudo. De modo geral, as seções apresentam maior contraste em termos de aumento da resistividade, o qual é visível especialmente nas seções $C, D$ e $E$, até 26 de outubro de 2015, na zona não saturada do solo, com ampliação da região mais clara nas seções geoelétricas.

Com isso, pode-se inferir que a redução da umidade do solo em função do período de estiagem refletiu no aumento dos valores de resistividade elétrica nas camadas superficiais do solo. As seções obtidas a partir de 10 de novembro de 2015, sob influência dos primeiros eventos chuvosos, indicam uma redução da resistividade na zona não saturada em função, provavelmente, do aumento no teor de água no solo (Figura 5.8). Desse modo, com o início do período chuvoso, o que se observou foi a redução da resistividade a partir de $5 \mathrm{~m}$ de profundidade em contraponto aos valores elevados nas camadas mais profundas, com indicativo da redução do nível da água subterrânea, também nas seções de $C$ a $E$.

Para verificar a ocorrência de diferenças significativas entre as seções em relação ao tempo inicial aplicou-se o teste de hipótese de Mann-Whitney, cujo resultado foi apresentado na Figura 5.9, com diferença representada a um nível de 0,05. Desse modo, as semanas 2, 4, 6 e 8 foram aquelas cujas seções apresentaram maiores diferenças em comparação a agosto de 2015. No caso das semanas 2, 4 e 6 a diferença demonstra relação com aumento da resistividade elétrica, enquanto que para a semana 8 os valores de resistividade aparentam redução eventualmente relacionada à ocorrência de um longo período chuvoso. Contudo, vale ressaltar que o teste de hipótese demonstrou diferenças significativas apenas para a linha $A$, nas semanas 2,6 e $8 ; B$ na semana 2 ; $C$ na semana 6; e $E$ na semana 4. 


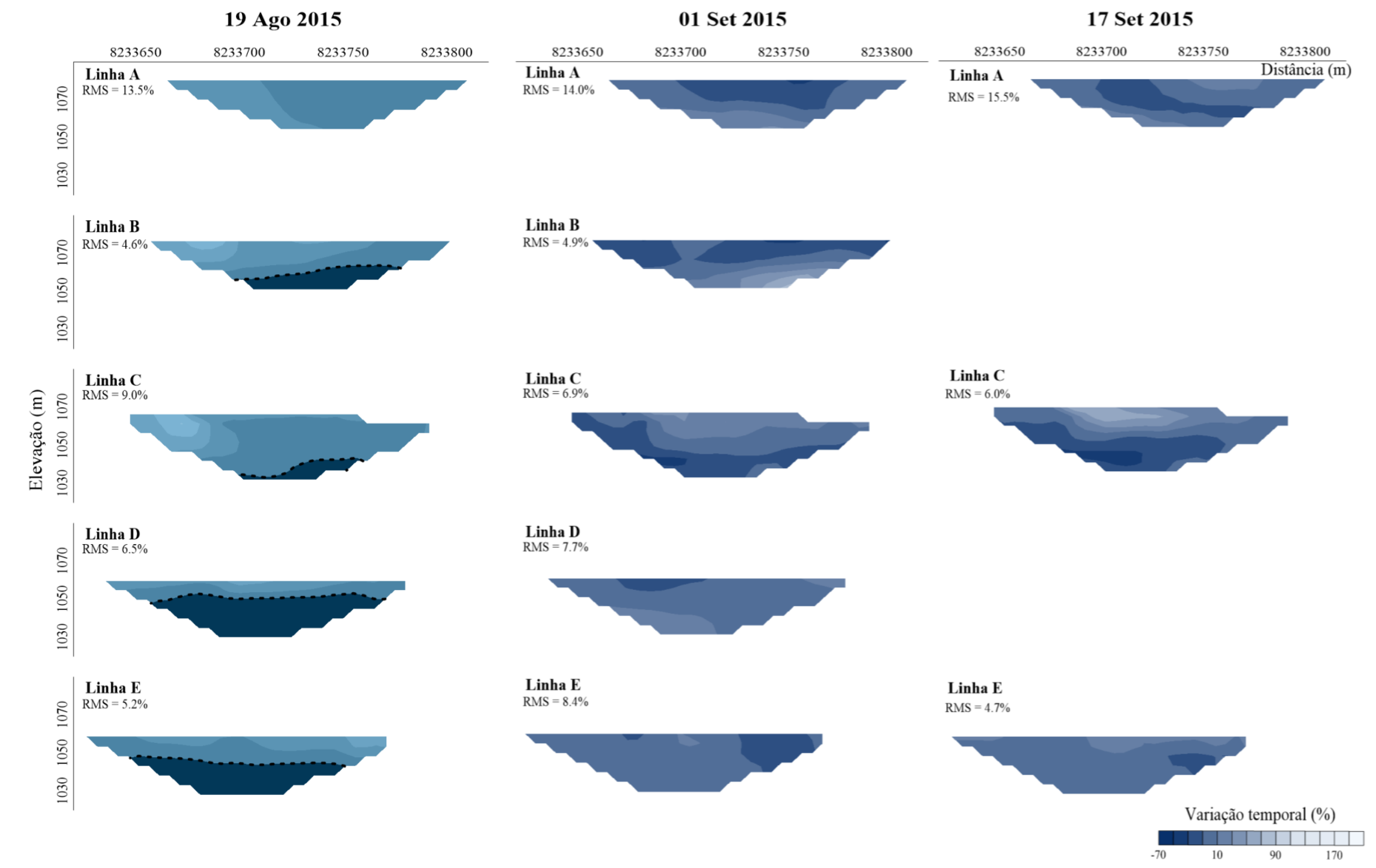


29 Set 2015

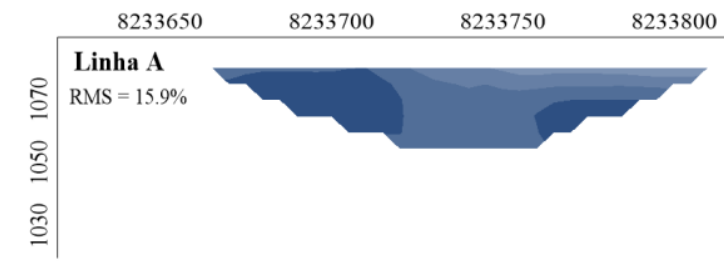

Linha B
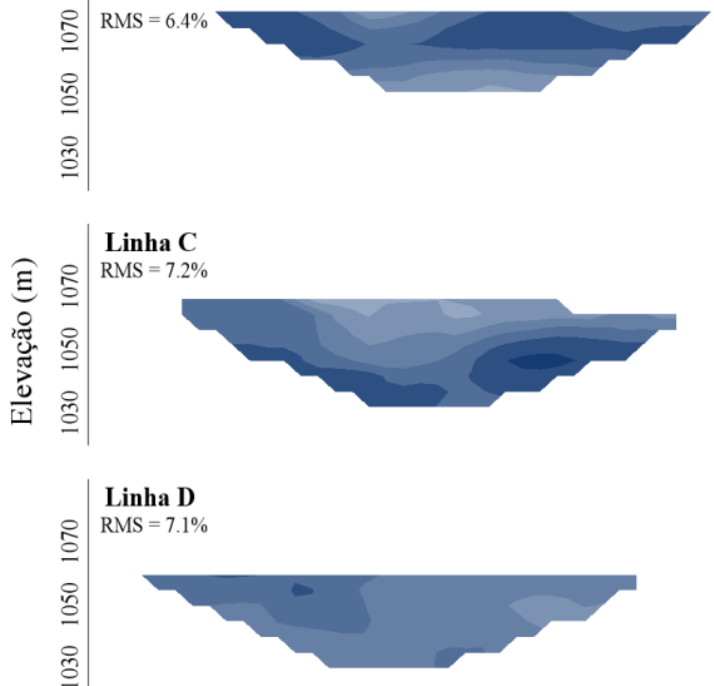

Linha E

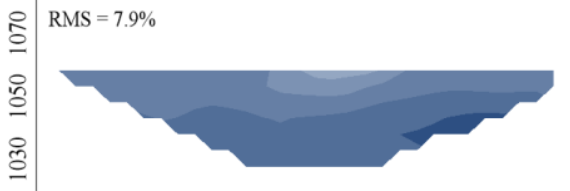

15 Out 2015

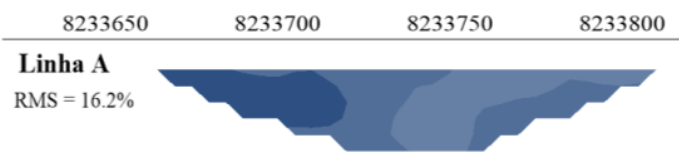

Linha B

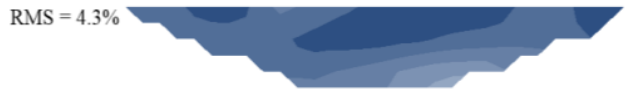

Linha C

IS $=7.4 \%$

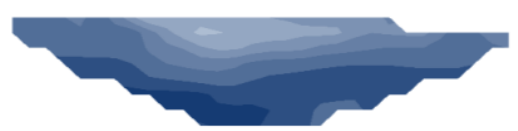

Linha D

$\mathrm{RMS}=4.3 \%$

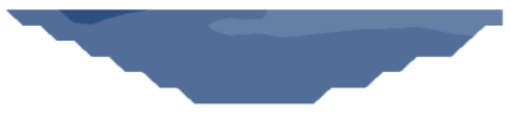

Linha E

RMS $=6.3 \%$

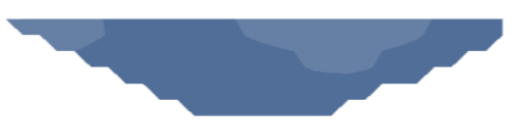

26 Out 2015

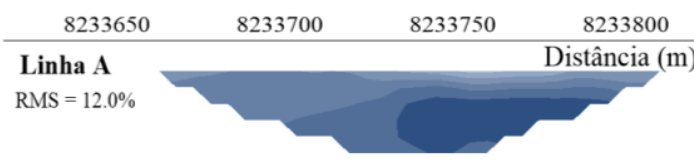

Linha B

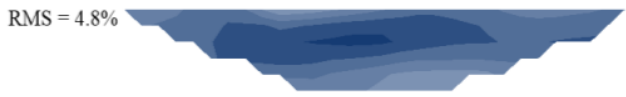

Linha C

RMS $=5.9 \%$

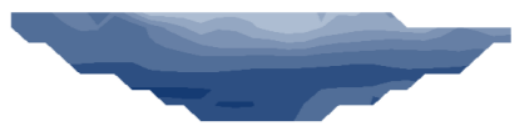

Linha D

$\mathrm{RMS}=5.7 \%$

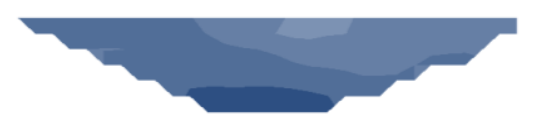

Linha E

RMS $=8.8 \%$

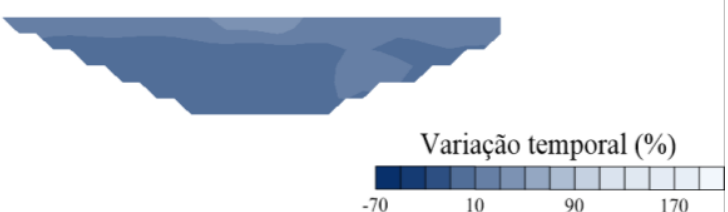


10 Nov 2015
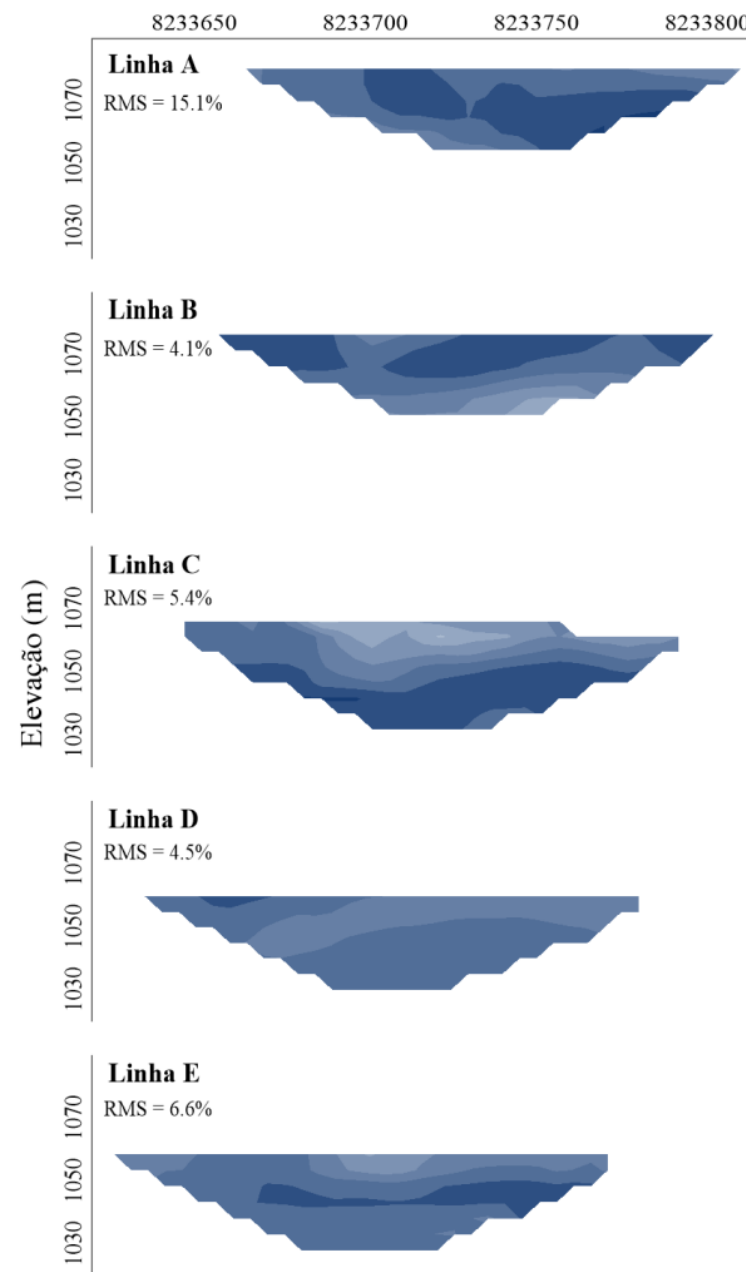

09 Dez 2015

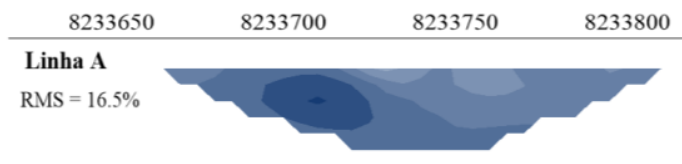

Linha B

RMS $=13.5 \%$

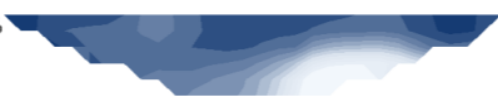

Linha C

RMS $=4.0 \%$

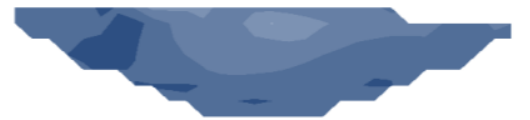

Linha D

RMS $=6.9 \%$

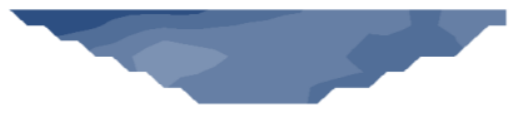

Linha $\mathbf{E}$
RMS $=3.8^{\circ}$

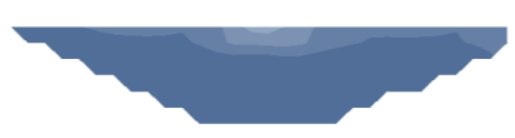

04 Fev 2016

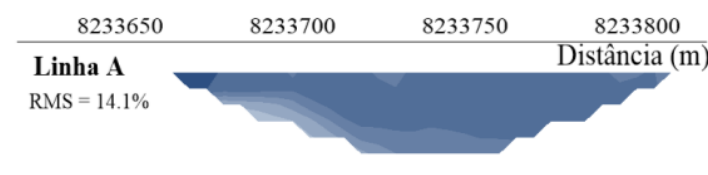

Linha B

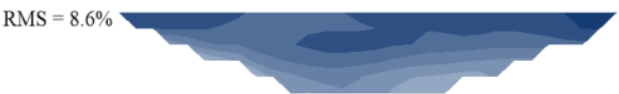

Linha C

RMS $=8.2 \%$

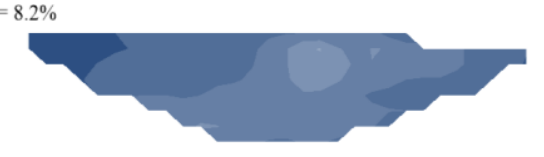

Linha D

RMS $=4.0 \%$

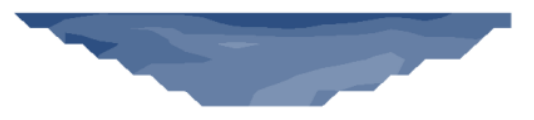

Linha E

RMS $=4.2 \%$

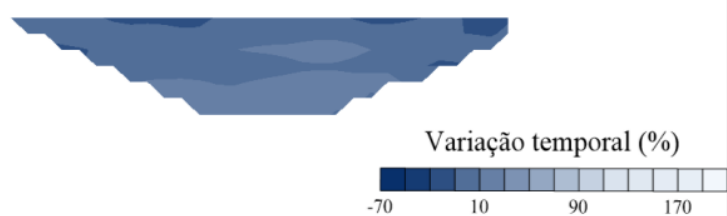

Figura 5.7 - Variação temporal dos valores de resistividade nas seções " $A$ " a " $E$ ”. 


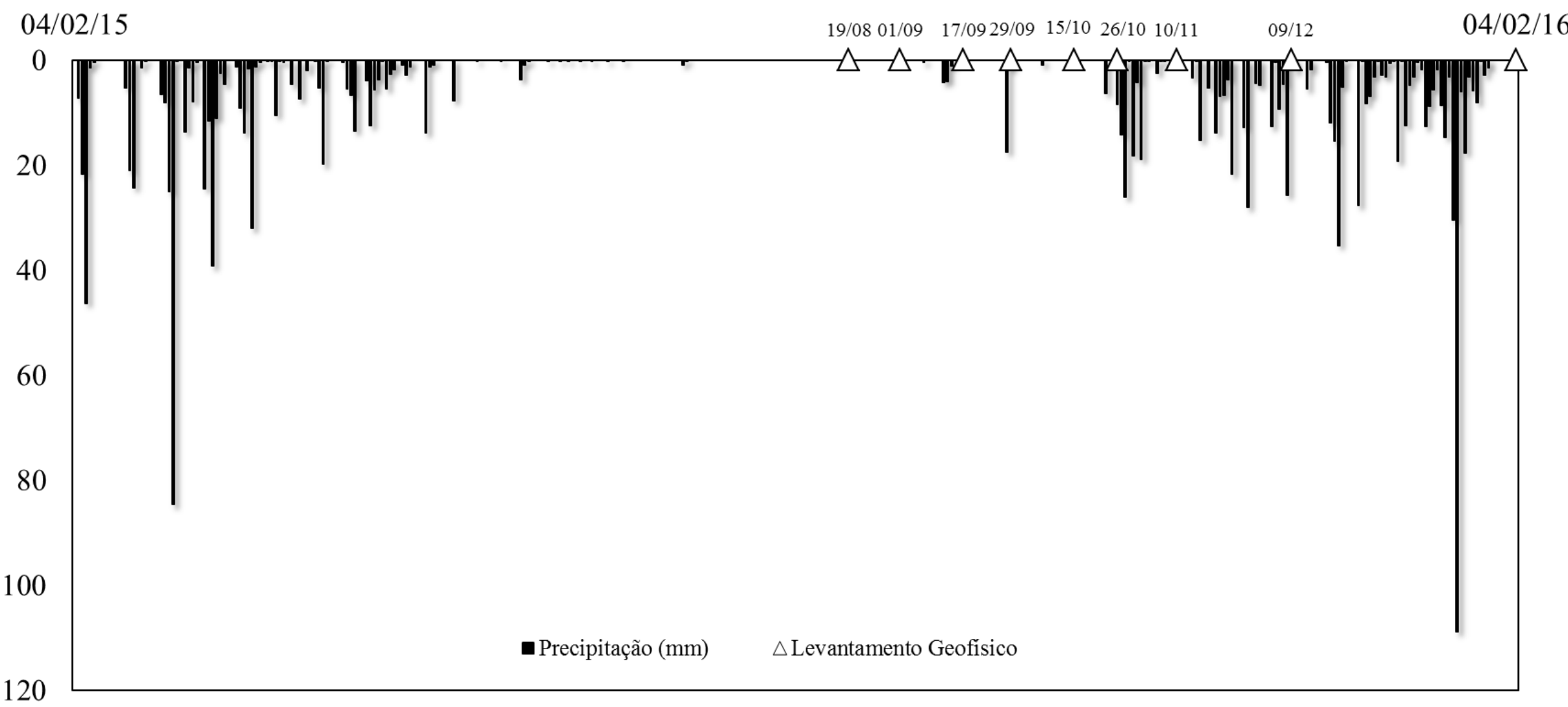

Figura 5.8 - Precipitação diária (mm/d) ao longo do período de estudo (agosto de 2015 a fevereiro de 2016), com indicação da data de ocorrência dos levantamentos geofísicos. 

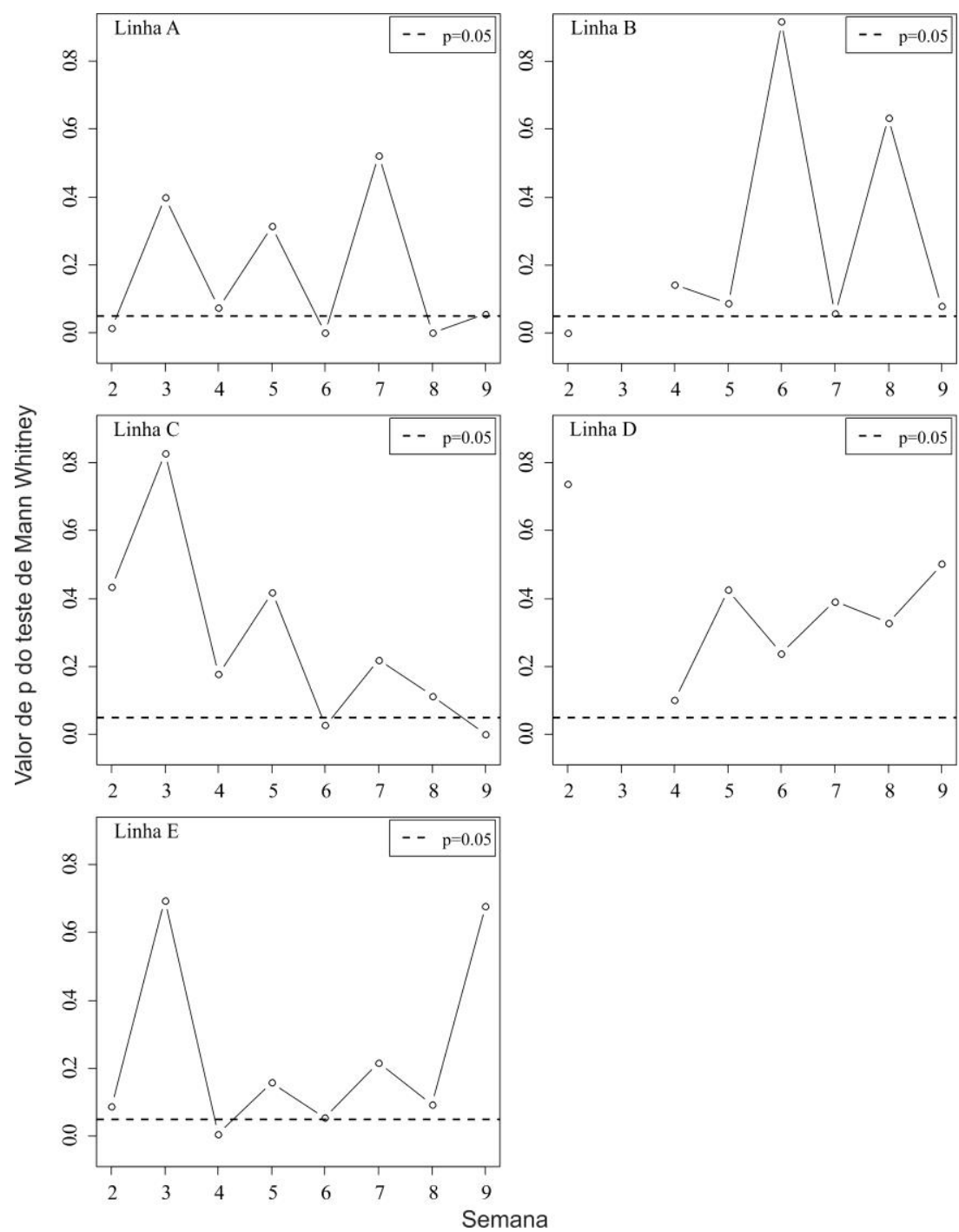

Figura 5.9 - Teste de hipótese de Mann-Whitney aplicado para as seções de $A$ a $E$ considerando a diferença em função da variação temporal para cada seção.

Nos demais casos, valores elevados de $p$ indicam comportamento geoelétrico semelhante em comparação ao do dia 19 de agosto de 2015. Na linha $B$ as diferenças temporais são menos perceptíveis durante as semanas 6 e 8, ao contrário das demais, bem como nas linhas $C$ e $D$, cuja semana 2 indicou comportamento semelhante quanto aos valores de resistividade da semana 1. É importante ressaltar que o teste de hipótese foi aplicado considerando a seção em sua totalidade. Desse modo, a diferenciação obtida em camadas específicas do solo pode não ter sido devidamente abordada.

Para tanto, a variação temporal dos níveis geoelétricos foi obtida a partir do teste de hipótese comparando cada nível de profundidade àquele representativo da semana 1 (Figura 5.10). Nesse caso, diferenças significativas entre os valores de resistividade registrados na primeira semana e aqueles obtidos a partir da terceira semana, até $10 \mathrm{~m}$ 
de profundidade, foram identificadas por meio do teste de hipótese. Entre 15 e $21 \mathrm{~m}$ as diferenças são significativas apenas nas semanas 9 e 8, respectivamente. Abaixo de 28 m a variação temporal da resistividade é significativamente alterada a partir da oitava semana.

Esses dados refletem o comportamento individual das seções, com redução gradual da umidade e consequente elevação da resistividade elétrica do solo, ocasionando diferenças significativas a partir da terceira semana de monitoramento. $\mathrm{Na}$ zona saturada, por sua vez, o aumento da resistividade é retardado temporalmente, ocorrendo a partir de 10 de novembro de 2015, com redução da zona de baixa resistividade, indicando redução do nível freático em decorrência da estação seca.

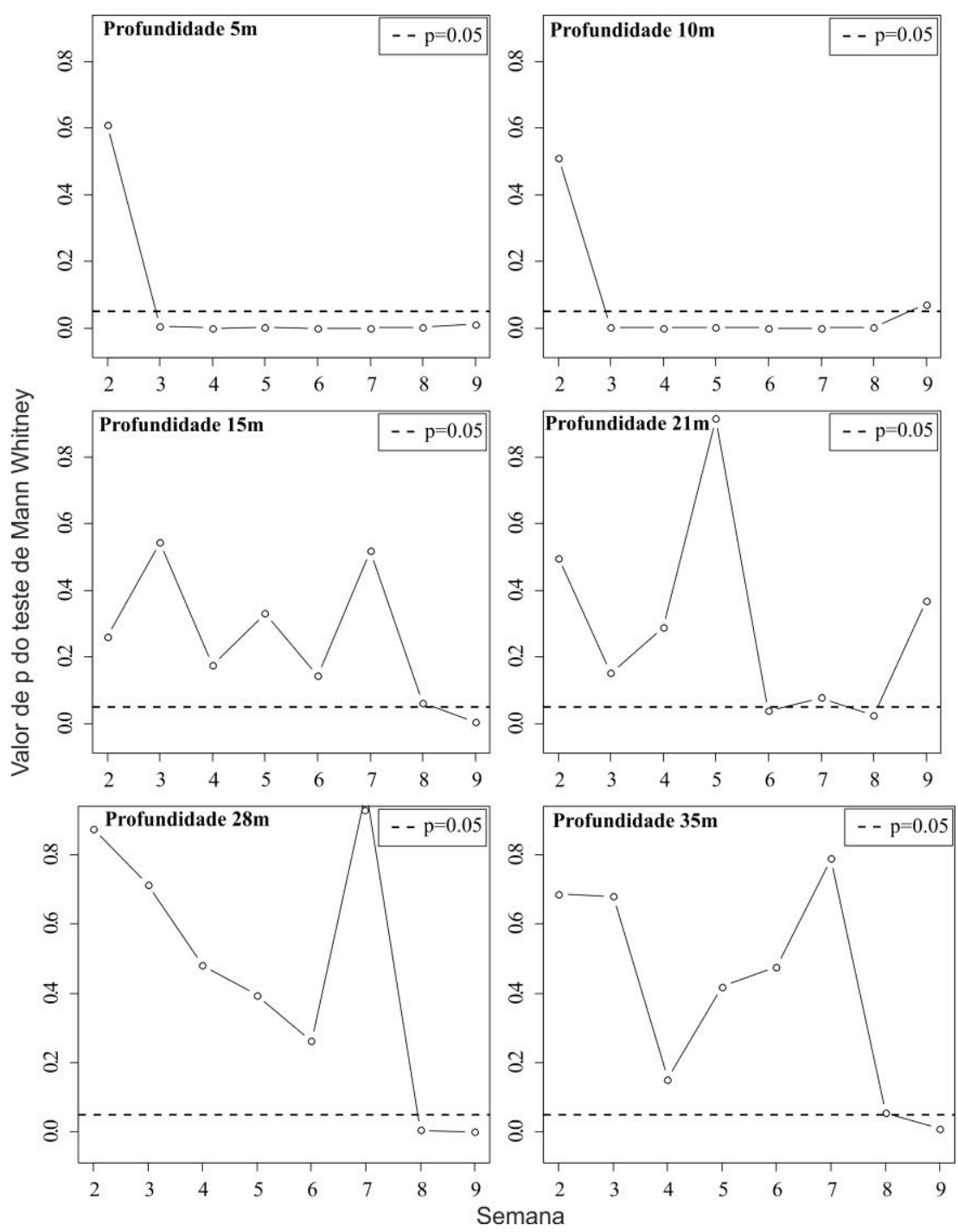

Figura 5.10 - Teste de hipótese de Mann-Whitney aplicado para as profundidades de 5 a $35 \mathrm{~m}$ considerando a diferença em função da variação temporal em cada seção. 
Para a seção $F$, os maiores contrastes são identificados na zona saturada do solo, correspondendo à elevação da resistividade elétrica em função da redução no nível freático ao longo da vertente em comparação com o imageamento de referência (19/08/2015) (Figura 5.11). Para a zona não saturada observa-se um aumento gradual nos valores de resistividade, também refletido pela redução dos tons de azul na camada superficial. Contudo, assim como para as demais seções, a resistividade do solo superficial tende a reduzir a partir de 10 de novembro, com intensificação do período chuvoso, enquanto que a resistividade da zona saturada permanece elevada até fevereiro de 2016, data do último levantamento.

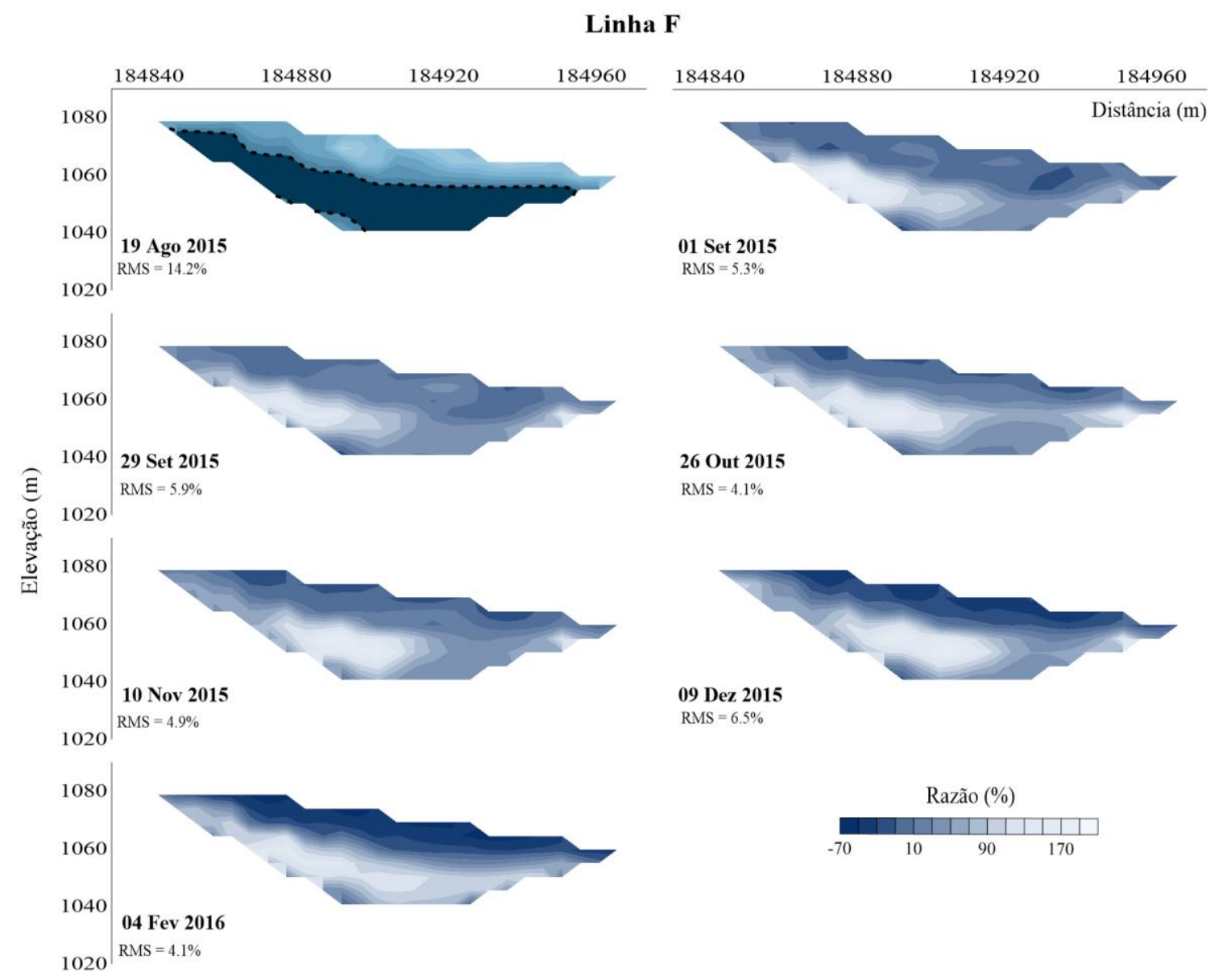

Figura 5.11 - Variação temporal dos valores de resistividade elétrica na seção $F$. 


\section{2 - COMPORTAMENTO DA ÁGUA NA ZONA NÃO SATURADA}

\subsection{1 - Monitoramento da Umidade Gravimétrica}

A umidade gravimétrica determinada em laboratório retratou a variação da umidade do solo nos pontos $U A, U C$ e $U E$, no período de 01 de setembro de 2015 a 04 de fevereiro de 2016 (Tabela 5.2). O ponto $U C$ apresentou maiores valores de umidade $(0,28 \mathrm{~g} / \mathrm{g})$, seguindo-se pelos pontos $U E(0,26 \mathrm{~g} / \mathrm{g})$ e $U A(0,24 \mathrm{~g} / \mathrm{g})$, não sendo observadas diferenças significativas entre os pontos monitorados, como observado na Tabela 5.2. Esta tabela apresenta os dados brutos de umidade gravimétrica $(\mathrm{g} / \mathrm{g})$, além dos valores de mediana e amplitude (máximo e mínimo), tanto para cada profundidade ao longo das semanas (Profundidades* $(\mathrm{n}=8)$ ), quanto entre as profundidades, em cada semana de monitoramento (Local* $(n=6))$. As células destacadas com borda referem-se à mediana de cada local ao longo do período de aquisição de dados.

A maior amplitude de distribuição dos dados de umidade foi identificada em $U E(0,31$ g/g). Na Figura 5.12, há um contraste nos valores máximo e mínimo de umidade do solo no perfil com até $1 \mathrm{~m}$ de profundidade. $\mathrm{O}$ aumento da profundidade de coleta demonstrou redução do teor de água no solo, em comparação aos valores observados no solo superficial no ponto $U E$. Esse comportamento também ocorreu no ponto $U C$, porém com menor amplitude de variação $(0,29 \mathrm{~g} / \mathrm{g})$. Em $U A$, por sua vez, o teor de umidade do solo permaneceu constante em todo o perfil em comparação às demais linhas, com maior amplitude de variação no solo superficial, com mínimo de $0,11 \mathrm{~g} / \mathrm{g}$ e máximo de 0,34 g/g (Figura 5.12). 
Tabela 5.1 - Umidade gravimétrica (g/g) determinada para os pontos $U A, U C$ e $U E$. Na semana 1 (19/08/2015) não foram obtidos dados de umidade gravimétrica.

\begin{tabular}{|c|c|c|c|c|c|c|c|c|c|c|}
\hline \multirow{2}{*}{ Local } & \multirow{2}{*}{ Profundidade (m) } & \multicolumn{8}{|c|}{ Semana } & \multirow{2}{*}{ Profundidades* $(n=8)$} \\
\hline & & $02 / 09 / 2015$ & $17 / 09 / 2015$ & $29 / 09 / 2015$ & $15 / 10 / 2015$ & $26 / 10 / 2015$ & $10 / 11 / 2015$ & $09 / 12 / 2015$ & $04 / 02 / 2016$ & \\
\hline \multirow{7}{*}{$A(n=48)$} & 0,00 & 0,22 & 0,24 & 0,32 & 0,11 & 0,34 & 0,18 & 0,30 & 0,20 & $0,23(0,34-0,11)$ \\
\hline & 0,20 & 0,23 & 0,25 & 0,25 & 0,23 & 0,25 & 0,26 & 0,34 & 0,28 & $0,25(0,34-0,23)$ \\
\hline & 0,40 & 0,23 & 0,23 & 0,24 & 0,23 & 0,24 & 0,27 & 0,34 & 0,30 & $0,24(0,34-0,23)$ \\
\hline & 0,60 & 0,23 & 0,23 & 0,24 & 0,22 & 0,23 & 0,28 & 0,33 & 0,30 & $0,23(0,33-0,22)$ \\
\hline & 0,80 & 0,23 & 0,23 & 0,23 & 0,22 & 0,23 & 0,28 & 0,34 & 0,28 & $0,23(0,34-0,22)$ \\
\hline & 1,00 & 0,23 & 0,23 & 0,24 & 0,23 & 0,23 & 0,26 & 0,32 & 0,29 & $0,23(0,32-0,23)$ \\
\hline & $\operatorname{Local}^{*}(n=6)$ & $\begin{array}{c}0,23(0,23- \\
0,22)\end{array}$ & $\begin{array}{c}0,23(0,25- \\
0,23)\end{array}$ & $\begin{array}{c}0,24(0,32- \\
0,23)\end{array}$ & $\begin{array}{c}0,22(0,23- \\
0,11)\end{array}$ & $\begin{array}{c}0,24(0,34- \\
0,23)\end{array}$ & $\begin{array}{c}0,27(0,28- \\
0,18)\end{array}$ & $\begin{array}{c}0,33(0,34- \\
0,30)\end{array}$ & $\begin{array}{c}0,29(0,30- \\
0,20)\end{array}$ & $0,24(0,34-0,11)$ \\
\hline \multirow{7}{*}{$C(n=48)$} & 0,00 & 0,29 & 0,28 & 0,30 & 0,24 & 0,29 & 0,31 & 0,53 & 0,36 & $0,30(0,53-0,24)$ \\
\hline & 0,20 & 0,28 & 0,28 & 0,29 & 0,28 & 0,29 & 0,29 & 0,38 & 0,35 & $0,29(0,38-0,28)$ \\
\hline & 0,40 & 0,26 & 0,26 & 0,28 & 0,27 & 0,27 & 0,29 & 0,35 & 0,32 & $0,28(0,35-0,26)$ \\
\hline & 0,60 & 0,25 & 0,26 & 0,25 & 0,24 & 0,25 & 0,28 & 0,35 & 0,32 & $0,26(0,35-0,24)$ \\
\hline & 0,80 & 0,24 & 0,24 & 0,25 & 0,24 & 0,24 & 0,27 & 0,33 & 0,31 & $0,25(0,33-0,24)$ \\
\hline & 1,00 & 0,24 & 0,24 & 0,24 & 0,24 & 0,24 & 0,26 & 0,29 & 0,30 & $0,24(0,3-0,24)$ \\
\hline & $\operatorname{Local}^{*}(n=6)$ & $\begin{array}{c}0,25(0,29- \\
0,24)\end{array}$ & $\begin{array}{c}0,26(0,28- \\
0,24)\end{array}$ & $\begin{array}{c}0,27(0,3- \\
0,24)\end{array}$ & $\begin{array}{c}0,24(0,28- \\
0,24)\end{array}$ & $\begin{array}{c}0,26(0,29- \\
0,24)\end{array}$ & $\begin{array}{c}0,28(0,31- \\
0,26)\end{array}$ & $\begin{array}{c}0,35(0,53- \\
0,29)\end{array}$ & $\begin{array}{c}0,32(0,36- \\
0,3)\end{array}$ & $0,28(0,53-0,24)$ \\
\hline \multirow{7}{*}{$E(n=48)$} & 0,00 & 0,30 & 0,33 & 0,33 & 0,22 & 0,26 & 0,30 & 0,50 & 0,44 & $0,32(0,5-0,22)$ \\
\hline & 0,20 & 0,27 & 0,26 & 0,32 & 0,28 & 0,26 & 0,31 & 0,45 & 0,41 & $0,29(0,45-0,26)$ \\
\hline & 0,40 & 0,25 & 0,24 & 0,25 & 0,27 & 0,24 & 0,29 & 0,41 & 0,37 & $0,26(0,41-0,24)$ \\
\hline & 0,60 & 0,24 & 0,22 & 0,23 & 0,23 & 0,23 & 0,27 & 0,39 & 0,39 & $0,24(0,39-0,22)$ \\
\hline & 0,80 & 0,21 & 0,22 & 0,23 & 0,20 & 0,23 & 0,23 & 0,37 & 0,40 & $0,23(0,40-0,20)$ \\
\hline & 1,00 & 0,21 & 0,20 & 0,21 & 0,19 & 0,21 & 0,22 & 0,25 & 0,35 & $0,21(0,35-0,19)$ \\
\hline & $\operatorname{Local}^{*}(n=6)$ & $\begin{array}{c}0,25(0,3- \\
0,21)\end{array}$ & $\begin{array}{c}0,23(0,33- \\
0,2)\end{array}$ & $\begin{array}{c}0,24(0,33- \\
0,21)\end{array}$ & $\begin{array}{c}0,23(0,28- \\
0,19)\end{array}$ & $\begin{array}{c}0,23(0,26- \\
0,21)\end{array}$ & $\begin{array}{c}0,28(0,31- \\
0,22)\end{array}$ & $\begin{array}{c}0,40(0,5- \\
0,25)\end{array}$ & $\begin{array}{c}0,39(0,44- \\
0,35)\end{array}$ & $0,26(0,50-0,19)$ \\
\hline
\end{tabular}




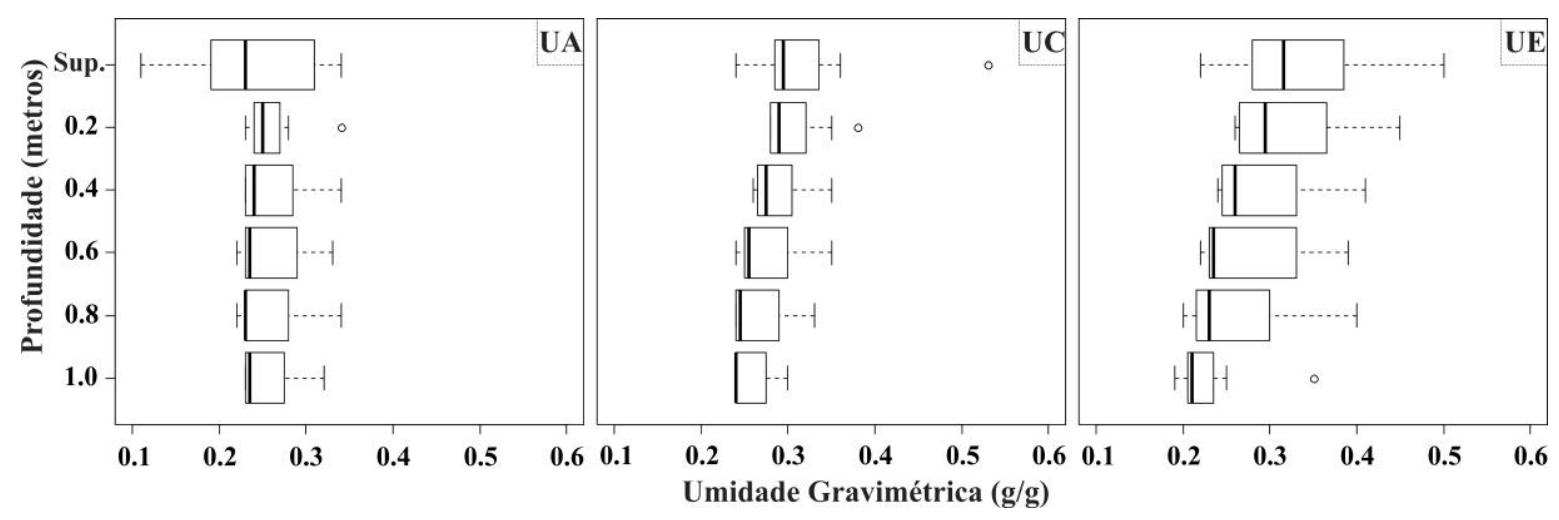

Figura 5.12 - Umidade gravimétrica nos $U A, U C$ e $U E$ nas profundidades de 0,0 a $1,0 \mathrm{~m}$.

A comparação visual das amostras em função da cor, após secagem em estufa a $110^{\circ} \mathrm{C}$, possibilitou a identificação de diferenças entre os pontos e as profundidades coletados (Figura 5.13). Com isso, as amostras obtidas em $U E$ apresentaram tonalidade acinzentada, enquanto que para aquelas coletadas em $U C$ e $U A$ a coloração avermelhada e amarelada foram características, respectivamente. Além disso, nos três casos, ao longo das profundidades foi possível observar que as amostras tenderam a tons mais claros. De acordo com Teixeira et al. (2008) os solos com maiores quantidades de matéria orgânica apresentam uma tonalidade mais escura, enquanto aqueles ricos em argilominerais e óxihidróxidos de ferro e de alumínio são mais avermelhados e amarelados.

Pode-se considerar que os pontos $U A$ e $U C$ indicam a ocorrência de Latossolo VermelhoAmarelo, enquanto que no ponto $U E$ o solo hidromórfico pode ser identificado, em correspondência ao mapeamento pedológico da Embrapa (1978). Contudo, como mencionado na descrição da metodologia, a ausência de análises granulométricas impede considerações adicionais a respeito das características físicas do solo, bem como limita sua correlação com dados de umidade e resistividade elétrica.

A determinação da umidade do solo pelo método gravimétrico é considerada adequada a fim de se obter um padrão que representa as condições reais do teor de água no solo. Contudo, deve-se salientar que esse método resulta em valores de umidade superestimados pelo fato da secagem em estufa propiciar a queima de outros componentes do solo, especialmente de sua fração orgânica, além da redução no conteúdo de água. Nesse caso, com determinação da matéria orgânica no conjunto de amostras referente à semana 8 (09/12/2015), pode-se observar nos pontos $U A$ e $U C$ quantidades médias de $0,55 \mathrm{~g} / \mathrm{g}$ (com desvio padrão de $0,20 \mathrm{~g} / \mathrm{g}$ ) de matéria orgânica no solo a até um metro de profundidade, e 
de $0,33 \mathrm{~g} / \mathrm{g}$ (com desvio padrão de $0,10 \mathrm{~g} / \mathrm{g}$ ) para o ponto UE. Esses valores podem ser indicativos da margem de superestimação no processo de determinação da umidade gravimétrica do solo.

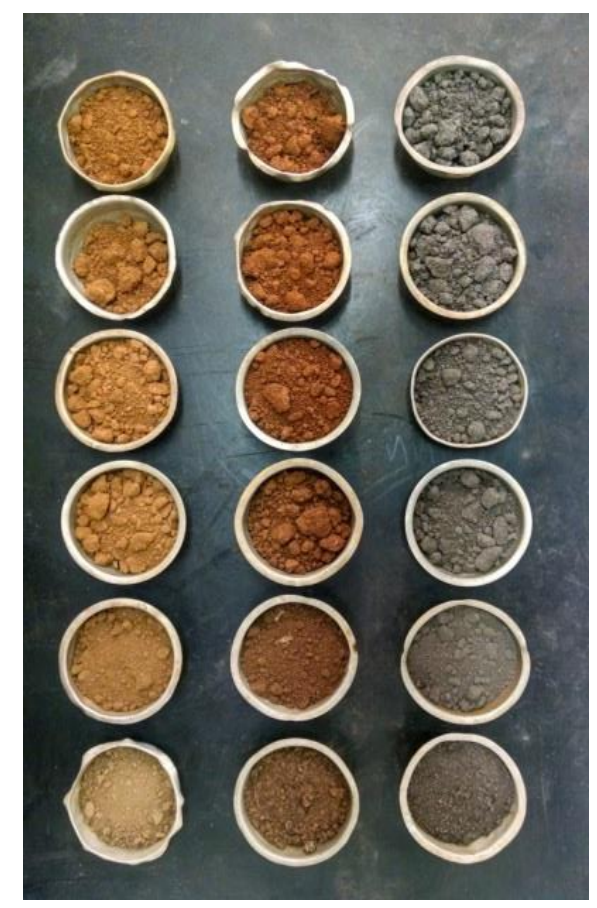

Figura 5.13 - Amostras de solo coletadas nos pontos $U A, U C$ e $U E$ (da esquerda para a direita), dispostas de modo que a primeira linha (de cima para baixo) representa a porção de solo superficial, enquanto que a última é formada pelas amostras de solo a $1 \mathrm{~m}$ de profundidade.

\subsection{2 - Umidade Volumétrica com Aplicação do Método TDR}

Os valores de umidade volumétrica $\left(\mathrm{m}^{3} / \mathrm{m}^{3}\right)$ e potencial elétrico $(\mathrm{mV})$ foram apresentados na Tabela 5.2. Nos pontos $U C, U D$ e $U E$ os valores de umidade foram elevados em comparação aos demais. Em alguns casos, as leituras de umidade volumétrica não foram indicadas $(u-r)$ por estarem fora da faixa de aquisição de dados do equipamento, que teoricamente permite a leitura entre 0,0 e $1,0 \mathrm{~m}^{3} / \mathrm{m}^{3}$, com acurácia aproximada em 0,04 $\mathrm{m}^{3} / \mathrm{m}^{3}$ (Delta-T Devices Ltd., 2008).

Apesar do conjunto amostral limitado, foi estabelecida uma correlação entre os valores de umidade gravimetria e aqueles obtidos pela sonda TDR. Para tanto, a conversão dos dados de umidade gravimétrica em umidade volumétrica se fez necessária. Desse modo, os valores de umidade gravimétrica $(\mathrm{g} / \mathrm{g}$ ) foram multiplicados pela massa específica do solo $\left[M L^{-3}\right]$ para obtenção da umidade volumétrica. Como a massa específica não pode ser 
determinada em laboratório, adotou-se o valor de $0,95 \mathrm{~g} / \mathrm{cm}^{3}$, típico de solos de Cerrado, de acordo com Lima (2010).

Tabela 5.2 - Valores de umidade volumétrica $\left(\mathrm{m}^{3} / \mathrm{m}^{3}\right)$ e tensão da água no solo $(\mathrm{mV})$.

\begin{tabular}{|c|c|c|c|c|c|c|c|}
\hline \multirow{3}{*}{ Local } & \multirow{3}{*}{$\begin{array}{l}\text { Profundidade } \\
\text { (m) }\end{array}$} & \multicolumn{6}{|c|}{ Semanas } \\
\hline & & \multicolumn{2}{|c|}{$13 / 11 / 2015$} & \multicolumn{2}{|c|}{$18 / 01 / 2016$} & \multicolumn{2}{|c|}{$04 / 02 / 2016$} \\
\hline & & $m^{3} / m^{3}$ & $m V$ & $m^{3} / m^{3}$ & $m V$ & $m^{3} / m^{3}$ & $m V$ \\
\hline \multirow{6}{*}{$U A$} & 0,10 & 0,04 & 357,00 & 0,13 & 558,00 & 0,04 & 364,00 \\
\hline & 0,20 & 0,16 & 617,00 & 0,23 & 721,00 & 0,19 & 664,00 \\
\hline & 0,30 & 0,03 & 343,00 & 0,05 & 380,00 & 0,05 & 385,00 \\
\hline & 0,40 & $u-r$ & 216,00 & $u-r$ & 254,00 & $u-r$ & 224,00 \\
\hline & 0,60 & 0,00 & 258,00 & 0,02 & 313,00 & $u-r$ & 217,00 \\
\hline & 1,00 & 0,06 & 398,00 & 0,08 & 444,00 & 0,06 & 408,00 \\
\hline \multirow{6}{*}{$U B$} & 0,10 & 0,01 & 293,00 & 0,26 & 760,00 & 0,08 & 441,00 \\
\hline & 0,20 & 0,13 & 552,00 & 0,31 & 824,00 & 0,23 & 717,00 \\
\hline & 0,30 & 0,07 & 430,00 & 0,19 & 657,00 & 0,16 & 608,00 \\
\hline & 0,40 & 0,02 & 312,00 & 0,09 & 476,00 & 0,07 & 424,00 \\
\hline & 0,60 & 0,01 & 287,00 & 0,05 & 384,00 & 0,04 & 346,00 \\
\hline & 1,00 & 0,06 & 412,00 & 0,13 & 552,00 & 0,07 & 434,00 \\
\hline \multirow{6}{*}{$U C$} & 0,10 & $u-r$ & 254,00 & $u-r$ & 241,00 & 0,04 & 348,00 \\
\hline & 0,20 & 0,08 & 452,00 & 0,06 & 393,00 & 0,22 & 709,00 \\
\hline & 0,30 & 0,11 & 514,00 & 0,20 & 677,00 & 0,24 & 736,00 \\
\hline & 0,40 & 0,10 & 489,00 & 0,26 & 763,00 & 0,14 & 576,00 \\
\hline & 0,60 & 0,01 & 270,00 & 0,03 & 327,00 & 0,01 & 285,00 \\
\hline & 1,00 & 0,08 & 449,00 & 0,11 & 505,00 & 0,12 & 544,00 \\
\hline \multirow{6}{*}{$U D$} & 0,10 & $u-r$ & 127,00 & 0,07 & 435,00 & $u-r$ & 195,00 \\
\hline & 0,20 & $u-r$ & 187,00 & 0,24 & 739,00 & 0,03 & 322,00 \\
\hline & 0,30 & 0,09 & 474,00 & 0,28 & 786,00 & 0,17 & 626,00 \\
\hline & 0,40 & 0,09 & 481,00 & 0,19 & 657,00 & 0,23 & 724,00 \\
\hline & 0,60 & 0,02 & 298,00 & 0,02 & 294,00 & 0,03 & 329,00 \\
\hline & 1,00 & 0,07 & 427,00 & 0,14 & 580,00 & 0,10 & 490,00 \\
\hline \multirow{6}{*}{$U E$} & 0,10 & 0,01 & 284,00 & 0,13 & 557,00 & 0,09 & 471,00 \\
\hline & 0,20 & 0,02 & 314,00 & 0,08 & 461,00 & 0,07 & 432,00 \\
\hline & 0,30 & 0,08 & 449,00 & 0,22 & 711,00 & 0,19 & 662,00 \\
\hline & 0,40 & 0,08 & 459,00 & 0,19 & 667,00 & 0,17 & 621,00 \\
\hline & 0,60 & 0,11 & 506,00 & 0,20 & 675,00 & 0,18 & 645,00 \\
\hline & 1,00 & 0,08 & 458,00 & 0,14 & 577,00 & 0,20 & 675,00 \\
\hline
\end{tabular}

*A sigla "u-r" indica "under range", isto é, a umidade foi detectada como abaixo da faixa de leitura do equipamento.

Devido aos processos naturais de pedogênese, que conferem aos solos uma conformação predominantemente estratificada, a correlação foi realizada por zonas, considerando os 
valores de 0,0 a $1,0 \mathrm{~m}$ entre os três pontos de monitoramento ( $U A, U C$ e $U E$ ). Os coeficientes de correlação $(r)$ se mantiveram acima de 0,3 em todas as profundidades, exceto para a de $0,2 \mathrm{~m}$, que apresentou coeficiente de correlação negativo (-0.26), porém com reduzida probabilidade de ocorrência em caso de reamostragem $(p=0,48)$ (Figura $5.14)$.

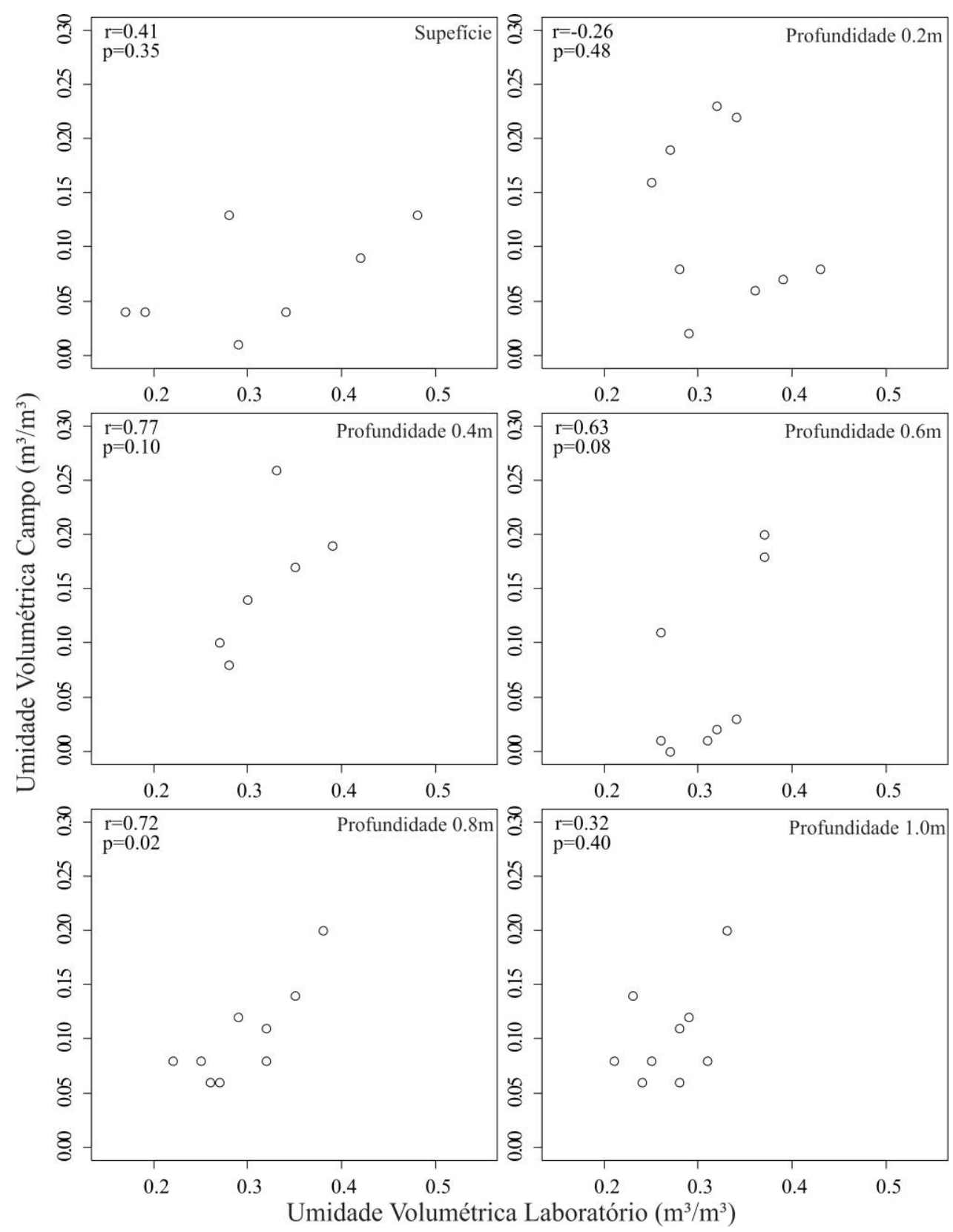

Figura 5.14 - Correlação obtida entre dados de umidade gravimétrica $(\mathrm{g} / \mathrm{g})$ e volumétrica $\left(\mathrm{m}^{3} / \mathrm{m}^{3}\right)$ nos pontos $U A, U C$ e $U E$.

Nesse caso, a amostragem reduzida pode ter interferido na representatividade do comportamento da umidade do solo, bem como a calibração automática para solos 
minerais pode não ter permitido a obtenção de valores de umidade volumétrica que permitissem correlação satisfatória. Nas profundidades de 0,4 e $0,8 \mathrm{~m}$ o coeficiente de correlação apresentou valores satisfatórios $(r>0,7)$, com probabilidade significativa de nova ocorrência desse ajuste em caso de reamostragem $(p<0,05)$ em 0,8 e 0,6 m de profundidade. Em função da ocorrência de coeficientes de correlação abaixo de 0,7 , foi realizada a calibração para as profundidades, conforme procedimento demonstrado no item 4.2.2.2 - (Figura 5.15).

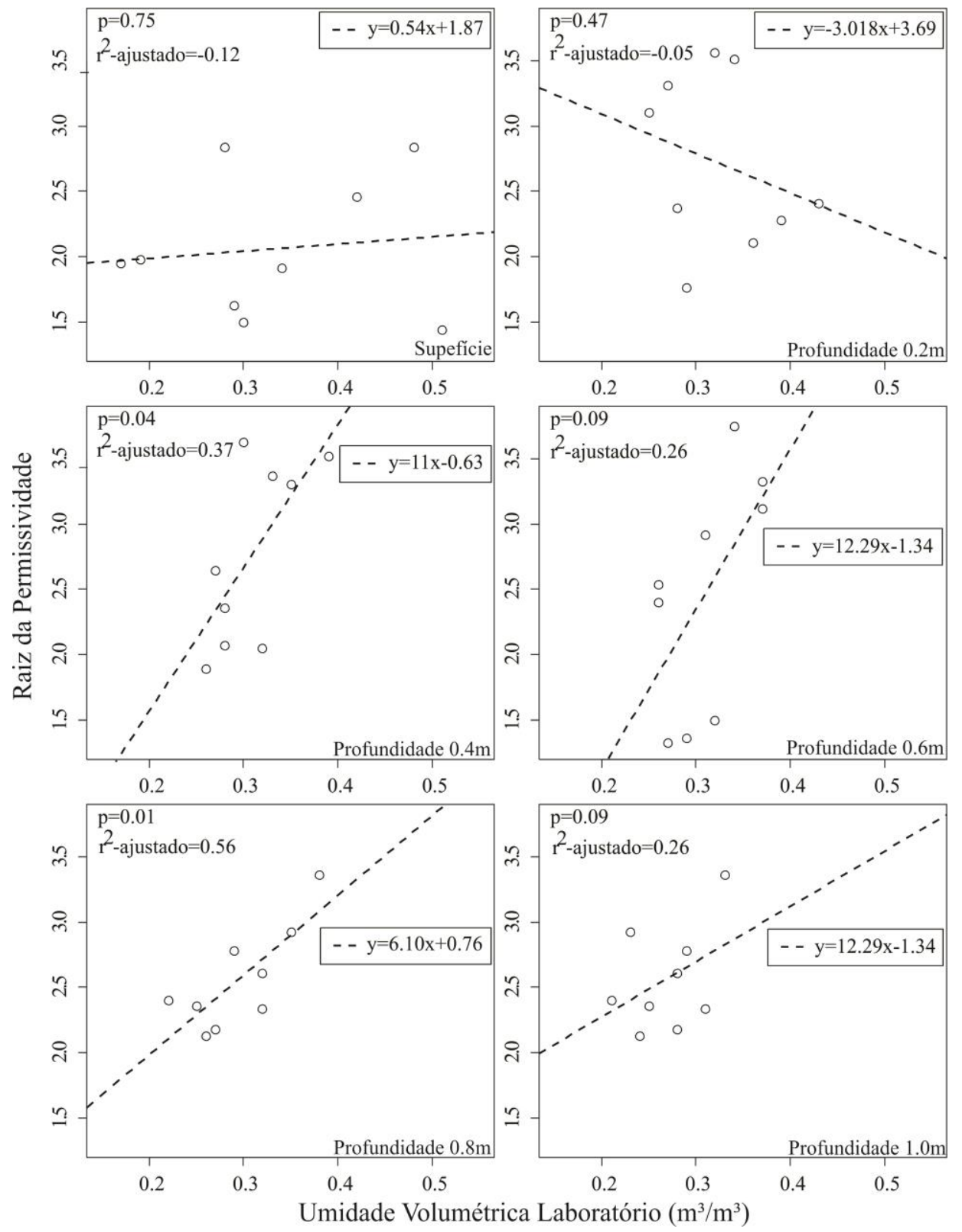

Figura 5.15 - Calibração da sonda $T D R$ por comparação com dados de umidade gravimétrica.

O ajuste linear entre a raiz quadrada da permissividade e os valores de umidade volumétrica fornece os parâmetros $\alpha_{0}$ e $\alpha_{1}$ que possibilitam aquisição dos valores de 
umidade volumétrica por meio da sonda $T D R$ que melhor se aproximam das condições reais. Porém, no processo de calibração o coeficiente de determinação $\left(r^{2}\right)$ ajustado apresentou valores fracos (abaixo de 0,5), sendo o melhor resultado obtido para a profundidade de $0,8 \mathrm{~m}$, com coeficiente de determinação igual a 0,56 e $p$ abaixo de 0,05 . Desse modo, apesar da limitada quantidade de dados ter interferido na possibilidade de inferir padrões acerca da caracterização da umidade do solo por meio da aplicação do método $T D R$, foram identificados ajustes satisfatórios, especialmente abaixo de 0,4 $\mathrm{m}$ de profundidade.

\subsection{3 - Blocos de Resistência Elétrica}

As curvas de calibração fornecidas em conjunto com os blocos de gesso, contidas no Anexo A, foram aplicadas na obtenção de valores de resistência elétrica (Ohm), potencial da água do solo (Bars, posteriormente convertido a mca) e percentual de umidade disponível para as raízes das plantas nas profundidades de 0,5, 1,0 e 1,5 m. Os valores de resistência e umidade calculados a partir das curvas de calibração são apresentados na Tabela 5.3.

Tabela 5.3 - Resistência elétrica dos blocos de gesso $(\Omega)$ e umidade disponível (\%).

\begin{tabular}{|c|c|c|c|c|c|c|c|c|c|}
\hline \multirow{3}{*}{ Local } & \multirow{3}{*}{$\begin{array}{l}\text { Profundidade } \\
\text { (m) }\end{array}$} & \multicolumn{8}{|c|}{ Semanas } \\
\hline & & \multicolumn{2}{|c|}{$15 / 10 / 2015$} & \multicolumn{2}{|c|}{$13 / 11 / 2015$} & \multicolumn{2}{|c|}{$18 / 01 / 2016$} & \multicolumn{2}{|c|}{$04 / 02 / 2016$} \\
\hline & & Ohm & $(\%)$ & Ohm & $(\%)$ & Ohm & $(\%)$ & Ohm & $(\%)$ \\
\hline \multirow{3}{*}{$U A$} & 0,5 & $\mathrm{u}-\mathrm{r}$ & $\mathrm{u}-\mathrm{r}$ & 780,0 & 70,2 & 304,8 & 88,9 & 8259,5 & 29,8 \\
\hline & 1,0 & $\mathrm{u}-\mathrm{r}$ & $\mathrm{u}-\mathrm{r}$ & 2284,5 & 50,6 & 303,2 & 89,0 & 306,5 & 88,8 \\
\hline & 1,5 & $\mathrm{u}-\mathrm{r}$ & $\mathrm{u}-\mathrm{r}$ & u-r & $\mathrm{u}-\mathrm{r}$ & 304,8 & 88,9 & 299,9 & 89,2 \\
\hline \multirow{3}{*}{$U B$} & 0,5 & $\mathrm{u}-\mathrm{r}$ & $\mathrm{u}-\mathrm{r}$ & 5846,0 & 35,1 & 304,8 & 88,9 & $\mathrm{u}-\mathrm{r}$ & $\mathrm{u}-\mathrm{r}$ \\
\hline & 1,0 & 40187,8 & 8,1 & $\mathrm{u}-\mathrm{r}$ & $\mathrm{u}-\mathrm{r}$ & 272,1 & 91,2 & 345,1 & 86,3 \\
\hline & 1,5 & 30678,6 & 11,5 & $\mathrm{u}-\mathrm{r}$ & $\mathrm{u}-\mathrm{r}$ & 330,5 & 87,2 & 615,1 & 74,8 \\
\hline \multirow{3}{*}{$U C$} & 0,5 & $\mathrm{u}-\mathrm{r}$ & $\mathrm{u}-\mathrm{r}$ & 447,3 & 81,1 & 309,8 & 88,5 & 309,8 & 88,5 \\
\hline & 1,0 & $\mathrm{u}-\mathrm{r}$ & $\mathrm{u}-\mathrm{r}$ & $\mathrm{u}-\mathrm{r}$ & $\mathrm{u}-\mathrm{r}$ & 1163,2 & 62,7 & 304,8 & 88,9 \\
\hline & 1,5 & 32909,6 & 10,7 & $\mathrm{u}-\mathrm{r}$ & $\mathrm{u}-\mathrm{r}$ & 4438,7 & 39,5 & 304,8 & 88,9 \\
\hline \multirow{3}{*}{$U D$} & 0,5 & $\mathrm{u}-\mathrm{r}$ & $\mathrm{u}-\mathrm{r}$ & 528,8 & 77,7 & 306,5 & 88,8 & 314,9 & 88,2 \\
\hline & 1,0 & $\mathrm{u}-\mathrm{r}$ & $\mathrm{u}-\mathrm{r}$ & $\mathrm{u}-\mathrm{r}$ & $\mathrm{u}-\mathrm{r}$ & 309,8 & 88,5 & 615,1 & 74,8 \\
\hline & 1,5 & $\mathrm{u}-\mathrm{r}$ & $\mathrm{u}-\mathrm{r}$ & $\mathrm{u}-\mathrm{r}$ & $\mathrm{u}-\mathrm{r}$ & 395,0 & 83,6 & 309,8 & 88,5 \\
\hline \multirow{3}{*}{$E U$} & 0,5 & 31348,4 & 11,3 & 18869,8 & 18,0 & 320,0 & 87,9 & 320,0 & 87,9 \\
\hline & 1,0 & u-r & $\mathrm{u}-\mathrm{r}$ & u-r & $\mathrm{u}-\mathrm{r}$ & 358,4 & 85,5 & 301,5 & 89,1 \\
\hline & 1,5 & 13721,5 & 22,4 & $\mathrm{u}-\mathrm{r}$ & $\mathrm{u}-\mathrm{r}$ & 6874,1 & 32,6 & 303,2 & 89,0 \\
\hline
\end{tabular}


Por ser um sensor cujo princípio de funcionamento é a condutividade elétrica, quanto maior o teor de umidade do solo, maior será a leitura do equipamento e, consequentemente, os valores de resistência e de potencial de água no solo irão se comportar de modo inverso (Figura 5.16). Desse modo, os menores valores de potencial matricial aferidos podem estar relacionados à maior disponibilidade de água no solo, sendo registrados especialmente em 18/01/2016 e 04/02/2016.

Nos dias restantes, foram observados valores de sucção elevados, indicando redução na umidade do solo nos pontos monitorados, além da ocorrência de leituras abaixo de cinco, consideradas inadequadas conforme Delmhorst Instrument Co. (1999). Como afirma Ferreira (2005), as temperaturas do aparelho e do solo podem influenciar as leituras. Contudo, neste estudo não foram consideradas alternativas de acondicionamento do aparelho nem foram realizadas medições de temperatura do solo. Com isso, as inferências a respeito do potencial da água do solo são limitadas, pela curta série de dados e ausência de controle na influência da temperatura.

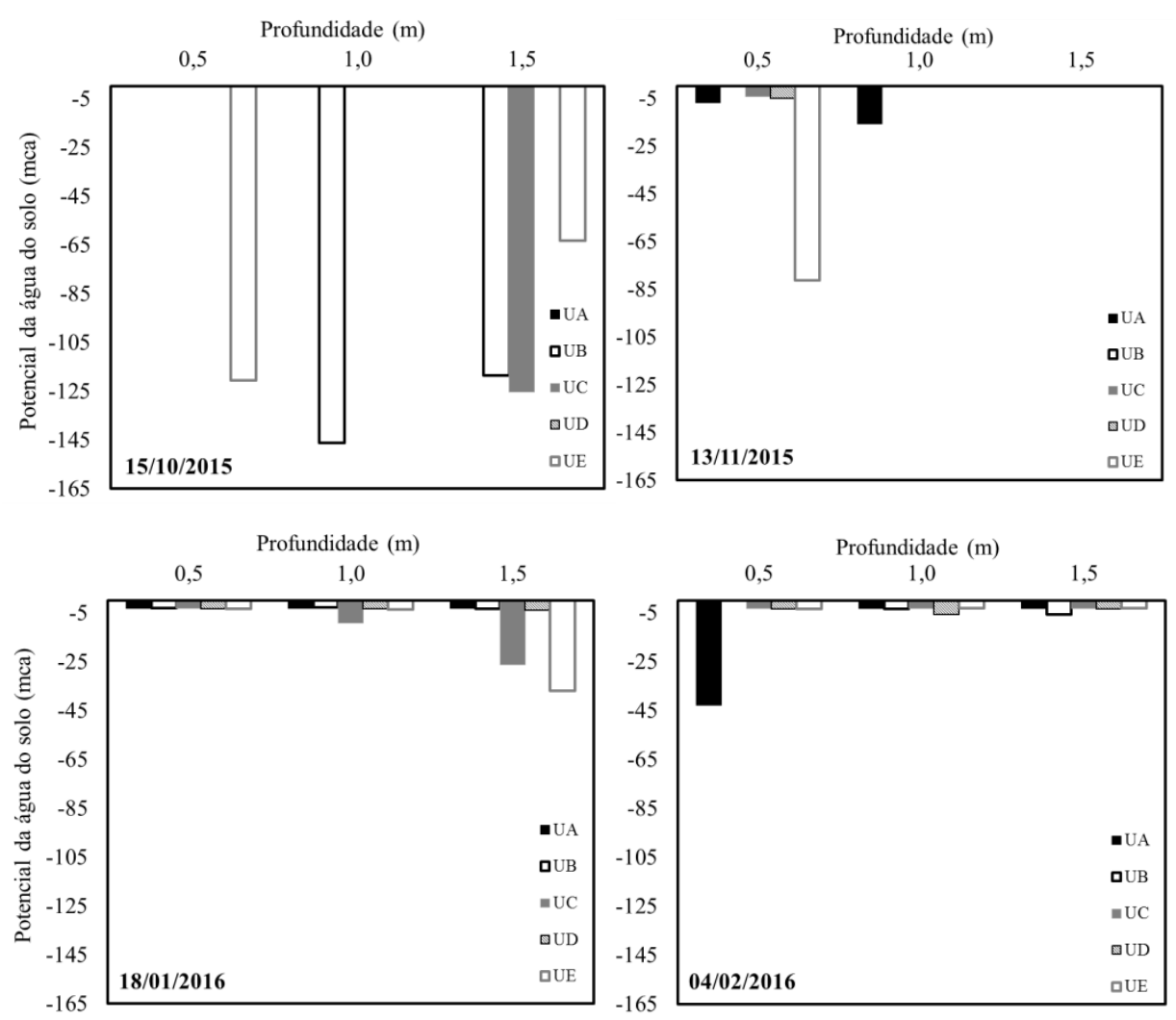

Figura 5.16 - Potencial da água do solo $(m)$ nas profundidades de $0,5,1,0$ e 1,5m. 


\section{3 - MODELAGEM NUMÉRICA DO FLUXO DE ÁGUA SUBTERRÂNEA NA VERTENTE DO CÓRREGO CAPETINGA}

\subsection{1 - Balanço Hídrico e Dados de Entrada do Modelo Numérico}

Considerando as diferenças de fitofisionomia ao longo da vertente, a recarga foi calcula a partir do balanço hídrico tanto para a zona ripária quanto para a região com predomínio de formações savânicas e rupestres. Uma recarga média de $50 \mathrm{~mm} / \mathrm{ano}$ foi estimada para a zona ripária, enquanto que para o restante da vertente atribuiu-se uma recarga de 130 mm/ano (Tabela 5.4). Essa diferenciação decorreu da evapotranspiração real elevada na floresta de galeria, reduzindo assim a parcela de recarga. Os valores de recarga (m/dia) e de carga hidráulica no córrego Capetinga $(\mathrm{m})$ foram utilizados como informações de entrada do modelo.

As informações contidas na Tabela 5.4 dizem respeito à quantificação dos processos de precipitação, escoamento, interceptação, evapotranspiração real e recarga na área da seção bidimensional $\left(830 \mathrm{~m}^{2}\right)$. Por meio do filtro automático de Arnold e Allen (1999), cerca de $300 \mathrm{~mm} / \mathrm{ano}$ foram considerados como contribuição do escoamento subterrâneo da vertente para o córrego Capetinga (Figura 5.17 e Tabela 5.4). Nesse caso, foi adotado um valor de $\beta$ equivalente a 0,994 por permitir um ajuste adequado nos períodos de ascensão e recessão do hidrograma de vazão em comparação a outros valores, num intervalo entre 0,9 e 1,0 . 
Tabela 5.4 - Balanço hídrico para estimativa da recarga na área de estudo.

\begin{tabular}{|c|c|c|c|c|c|c|c|c|c|}
\hline $\begin{array}{c}\text { Ano } \\
\text { Hidrológico }\end{array}$ & $\begin{array}{c}\text { Precipitação } \\
\text { (mm) }\end{array}$ & $\begin{array}{l}\text { Vazão } \\
(\mathbf{m m})\end{array}$ & $\begin{array}{l}\text { Escoamento } \\
\text { de base } \\
(\mathbf{m m})\end{array}$ & $\begin{array}{c}\text { Escoamento } \\
\text { direto } \\
\text { (superficial e } \\
\text { subsuperficial) } \\
\text { (mm) } \\
\end{array}$ & $\begin{array}{c}\text { Interceptação } \\
(\mathbf{m m})\end{array}$ & $\begin{array}{l}\text { Evapotranspiração } \\
\text { real cerrado }(\mathbf{m m})\end{array}$ & $\begin{array}{c}\text { Evapotranspiração } \\
\text { real zona ripária } \\
(\mathrm{mm})\end{array}$ & $\begin{array}{l}\text { Recarga } \\
\text { cerrado } \\
(\mathbf{m m})\end{array}$ & $\begin{array}{c}\text { Recarga } \\
\text { zona } \\
\text { ripária } \\
\text { (mm) }\end{array}$ \\
\hline $2000-2001$ & 1014,60 & 533,31 & 324,52 & 208,79 & 237,11 & 710,88 & 799,74 & $-142,19$ & $-231,05$ \\
\hline 2001-2002 & 1000,90 & 512,71 & 298,00 & 214,71 & 233,91 & 677,73 & 762,44 & $-125,44$ & $-210,16$ \\
\hline $2002-2003$ & 946,80 & 469,26 & 252,70 & 216,56 & 221,27 & 722,75 & 813,09 & $-213,77$ & $-304,11$ \\
\hline $2003-2004$ & 1370,20 & 334,21 & 189,86 & 144,35 & 320,22 & 663,18 & 746,08 & 242,46 & 159,56 \\
\hline 2004-2005 & 1837,50 & 557,93 & 280,75 & 277,18 & 429,42 & 632,21 & 711,24 & 498,68 & 419,65 \\
\hline $2005-2006$ & 1522,52 & 488,90 & 249,57 & 239,33 & 355,81 & 762,28 & 857,57 & 165,10 & 69,81 \\
\hline $2006-2007$ & 2249,42 & 671,95 & 301,94 & 370,01 & 525,69 & 576,86 & 648,96 & 776,87 & 704,76 \\
\hline $2007-2008$ & 1151,30 & 369,38 & 237,50 & 131,87 & 269,06 & 726,18 & 816,95 & 24,19 & $-66,58$ \\
\hline $2008-2009$ & 1621,97 & 494,88 & 259,58 & 235,30 & 379,05 & 731,42 & 822,85 & 276,20 & 184,77 \\
\hline $2010-2011$ & 1261,34 & 400,67 & 224,44 & 176,22 & 294,78 & 640,18 & 720,20 & 150,17 & 70,15 \\
\hline $2011-2012$ & 804,30 & 401,94 & 199,33 & 202,62 & 187,96 & 747,78 & 841,25 & $-334,06$ & $-427,53$ \\
\hline $2012-2013$ & 1237,40 & 378,22 & 178,01 & 200,21 & 289,18 & 779,04 & 876,42 & $-31,03$ & $-128,41$ \\
\hline $2013-2014$ & 1267,00 & 359,32 & 180,30 & 179,02 & 296,10 & 762,10 & 857,37 & 29,78 & $-65,49$ \\
\hline $2014-2015$ & 1592,80 & 323,35 & 143,51 & 179,83 & 372,24 & 720,95 & 811,07 & 319,78 & 229,66 \\
\hline $2015-2016$ & 1295,40 & 227,78 & 92,84 & 134,93 & 302,73 & 664,04 & 747,04 & 193,69 & 110,69 \\
\hline Média & 1356,10 & 438,58 & 229,47 & 209,11 & 316,92 & 696,15 & 783,17 & 133,92 & 46,90 \\
\hline
\end{tabular}




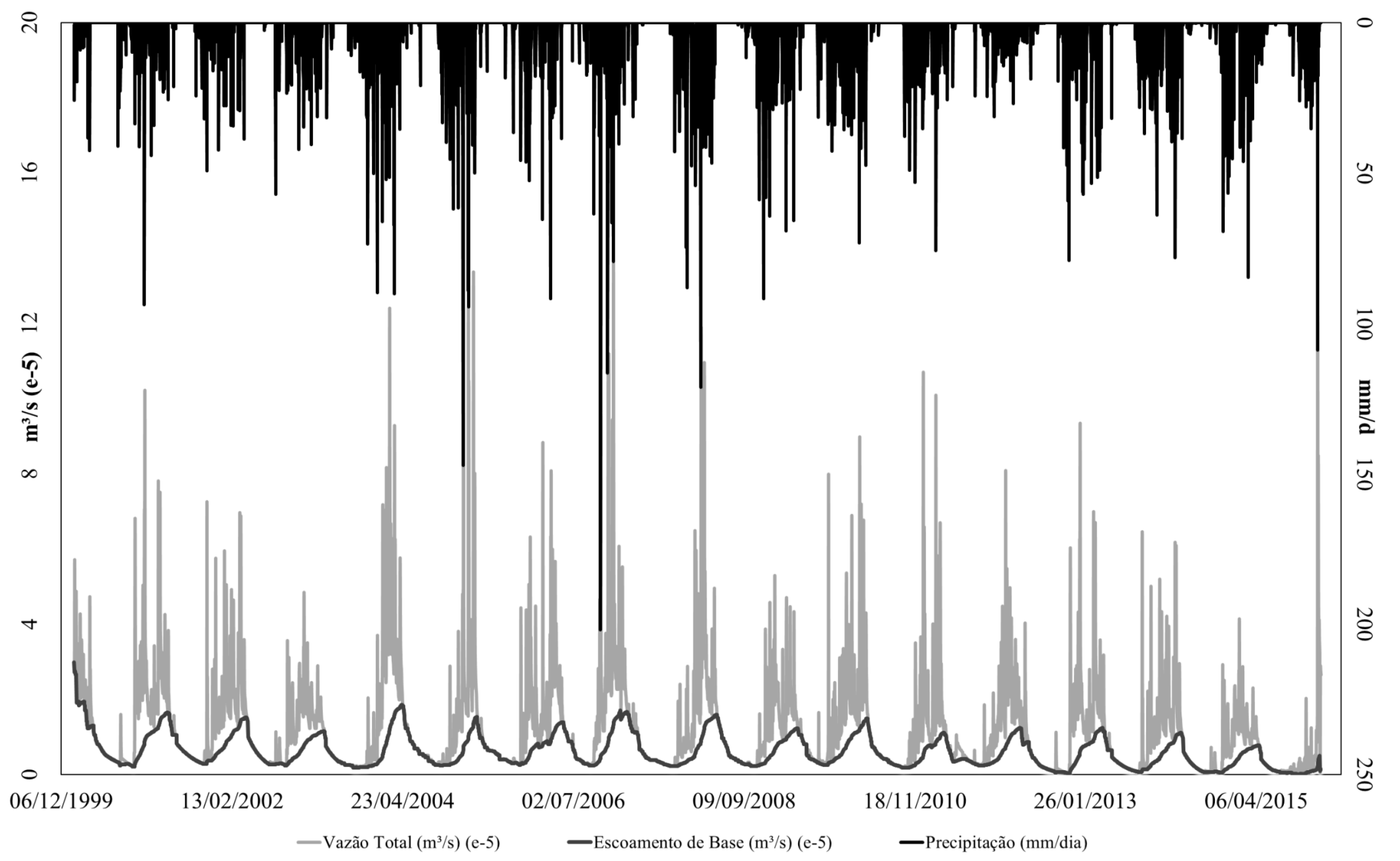

Figura 5.17 - Determinação do escoamento de base da vertente do córrego Capetinga, no período de 05 de fevereiro de 2000 a 04 de fevereiro de 2016 , com filtro automático proposto por Arnold e Allen (1999), sendo o parâmetro de ajuste $\beta=0,994$. 


\subsection{2 - Modelo Numérico Estacionário: Condições Iniciais de Carga Hidráulica}

O modelo numérico calculado em regime estacionário permitiu obter as condições iniciais de carga hidráulica na vertente em estudo, uma vez que não havia monitoramento em campo dessa variável. Com isso, utilizando os dados hidrológicos apresentados no item anterior, foram realizadas simulações considerando $o$ comportamento médio anual da recarga na superfície do domínio, bem como da carga hidráulica junto ao córrego Capetinga. Em todo o domínio foi adotada uma carga hidráulica equivalente a $25 \mathrm{~m}$, com base nos dados de levantamento geofísico, tendo como referencial o fundo do aquífero. A distribuição da carga hidráulica na vertente do córrego Capetinga é apresentada na Figura 5.22.

A linha branca ao longo do domínio representa a região de pressão nula, isto é, a superfície do lençol freático. Esse resultado foi obtido com condutividade hidráulica equivalente a $0,04 \mathrm{~m} / \mathrm{d}$. Testes realizados com valores de condutividade acima de 0,04 $\mathrm{m} /$ dia não apresentaram convergência, considerando erro médio quadrático igual a $10^{-3}$ m. Valores abaixo do adotado ocasionaram elevação extrema do nível freático, que refletiram em saturação do perfil de solo nas simulações em regime transiente. A resposta das vertentes à precipitação é não linear e as condições iniciais, particularmente na zona não saturada, são parâmetros importantes para análise do escoamento em regime transiente (Beven, 1977).

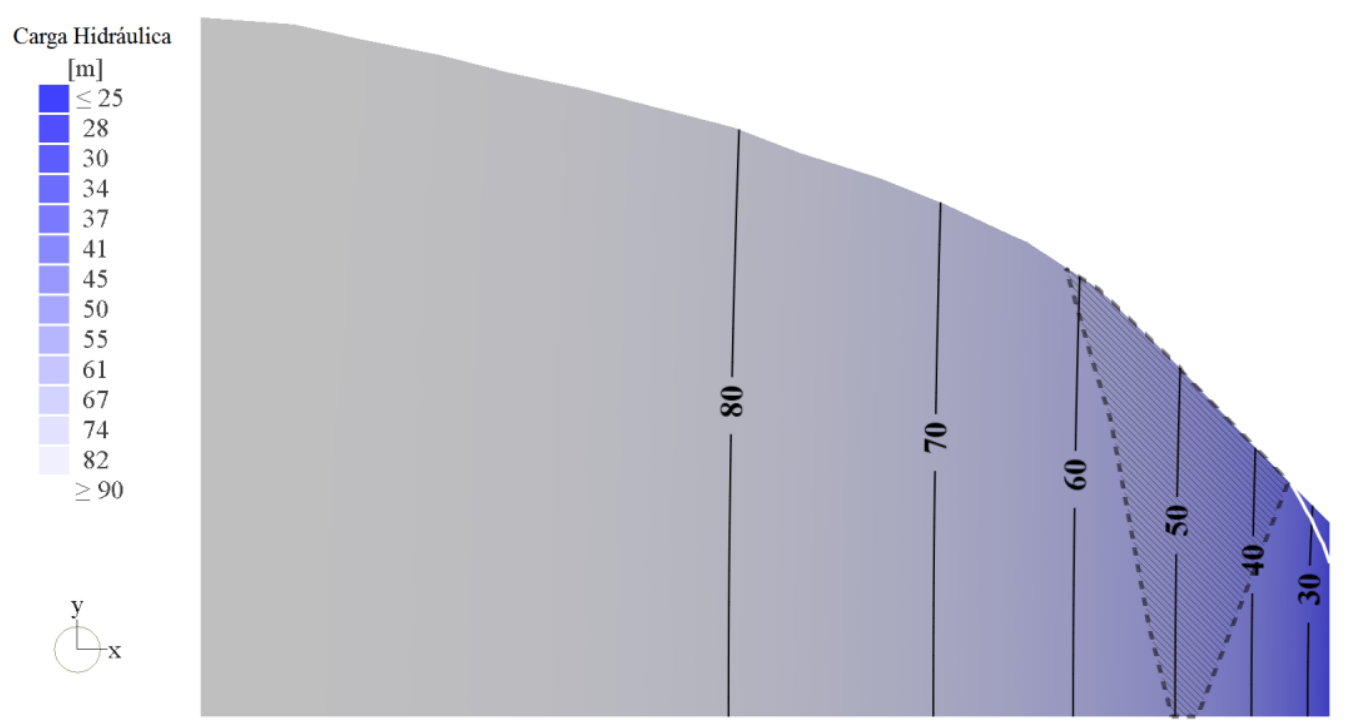

Figura 5.18 - Condições iniciais de carga hidráulica para a vertente do córrego Capetinga. A região em destaque refere-se à área da seção geoelétrica $F$. 


\subsection{3 - Modelo Numérico Transiente}

Adotando as condições iniciais simuladas em regime estacionário e considerando a variação dos dados de recarga e carga hidráulica, foi obtido o primeiro resultado em regime transiente, apresentado na Figura 5.19, que diz respeito à distribuição da carga hidráulica após 12.783 dias de simulação, com a identificação do nível freático acompanhando a conformação do terreno ao longo da vertente. $\mathrm{Na}$ zona ripária, as águas subterrâneas aparentam maior proximidade com a superfície do solo (cerca de 5 $\mathrm{m}$ de profundidade), enquanto que em direção ao divisor topográfico a profundidade do nível da água em relação à superfície é mais acentuada (aproximadamente $10 \mathrm{~m}$ ).

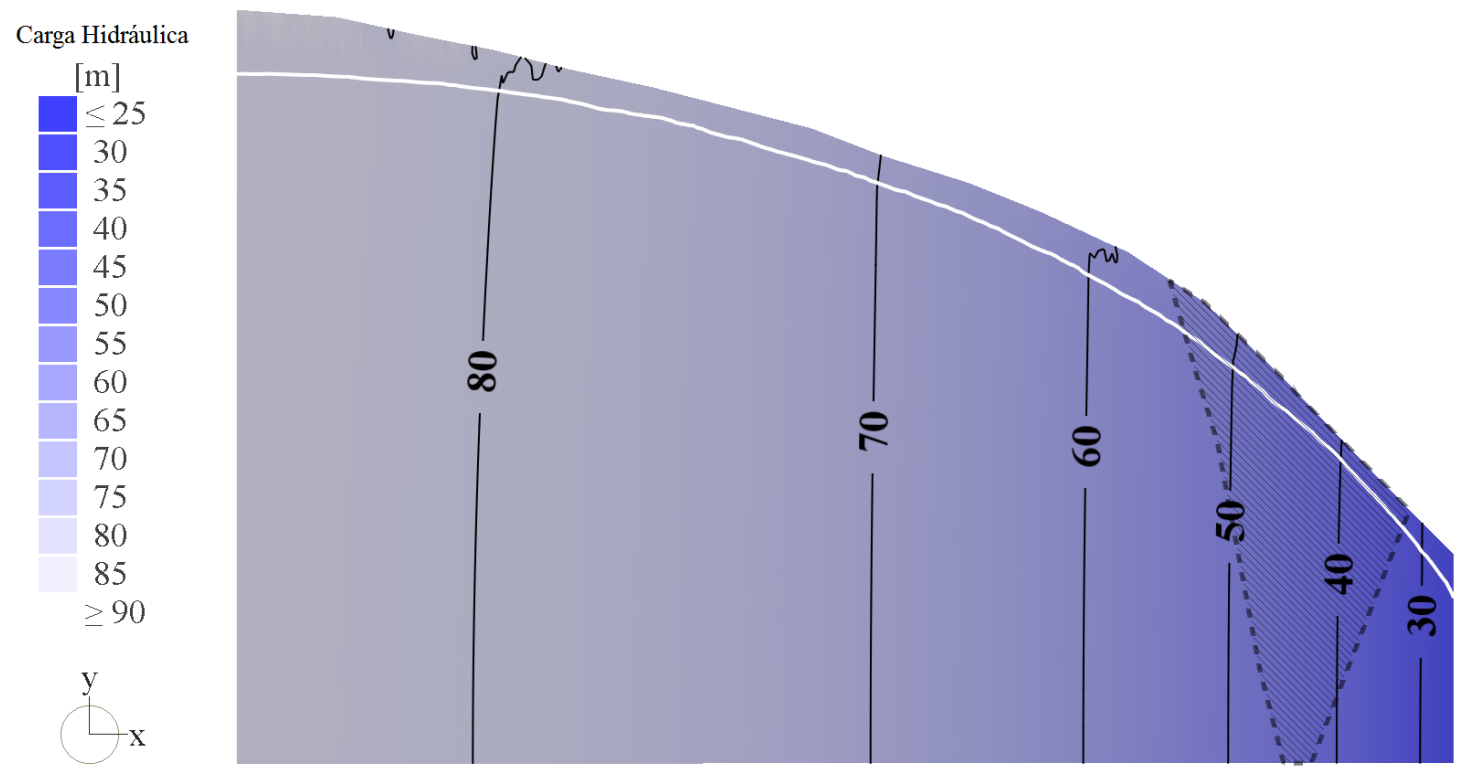

Figura 5.19 - Simulação em regime transiente ao longo de 12.783 dias. A região em destaque refere-se à área da seção geoelétrica $F$.

Os valores de carga hidráulica apresentados na Figura 5.19 foram adotados como condição inicial para o período de interesse do estudo (fevereiro de 2015 a fevereiro de 2016). Somando-se a essa informação a série histórica de dados de carga hidráulica no córrego Capetinga, representando uma superfície de saturação variável com carga hidráulica conhecida, e os valores de recarga na superfície do domínio, num período de 365 dias (fevereiro de 2015 e 2016), realizou-se a segunda etapa da simulação em regime transiente. 
Como resultado, foram obtidos modelos bidimensionais com variação do nível da água subterrânea na vertente do córrego Capetinga, sendo selecionados aqueles referentes aos dias 19 de agosto de 2015 e 04 de fevereiro de 2016, que coincidiam com o início e o término dos experimentos em campo na FAL (Figura 5.21).

Considerando a variação do lençol freático na região em destaque, referente à seção $F$ de levantamento geofísico, pode-se observar um aumento do nível da água subterrânea entre os meses de agosto de 2015 e fevereiro de 2016 (Figura 5.22). Por meio da comparação dos resultados da simulação matemática com aqueles obtidos por imageamento elétrico do solo foi possível identificar um comportamento diferenciado do lençol freático. A anomalia identificada no levantamento geofísico, considerada como indicativa do nível freático, teve sua área reduzida entre agosto de 2015 e fevereiro de 2016, enquanto que, com a simulação, pode-se observar uma pequena elevação do nível freático.

Contudo, deve-se considerar que as seções geoelétricas são resultado de uma ferramenta qualitativa de identificação do comportamento heterogêneo das anomalias relacionadas à presença de água ao longo da vertente. Além disso, os levantamentos ressaltam um comportamento instantâneo do comportamento da água no solo. Na modelagem, a variação do nível freático diferencia-se em função da maneira como o programa considera o comportamento da água no solo. Nesse caso, supõem-se que camadas homogêneas de solo lateralmente respondam de forma homogênea às variáveis que regem os processos de armazenamento e transporte de água.

Vale ressaltar que a determinação do nível da água no modelo se dá pela região de pressão igual à zero, enquanto que as anomalias identificadas no método geofísico têm seu início na zona de saturação que engloba parte da franja de capilaridade. Com isso, a variação entre ambos os métodos, considerando o mesmo intervalo de tempo, pode ter sido resultante desse aspecto. Para o dia 19 de agosto de 2015, essa inferência pode ter sido válida, sendo possível observar sobre-elevação do nível associado à formação saturada no imageamento elétrico do solo. 


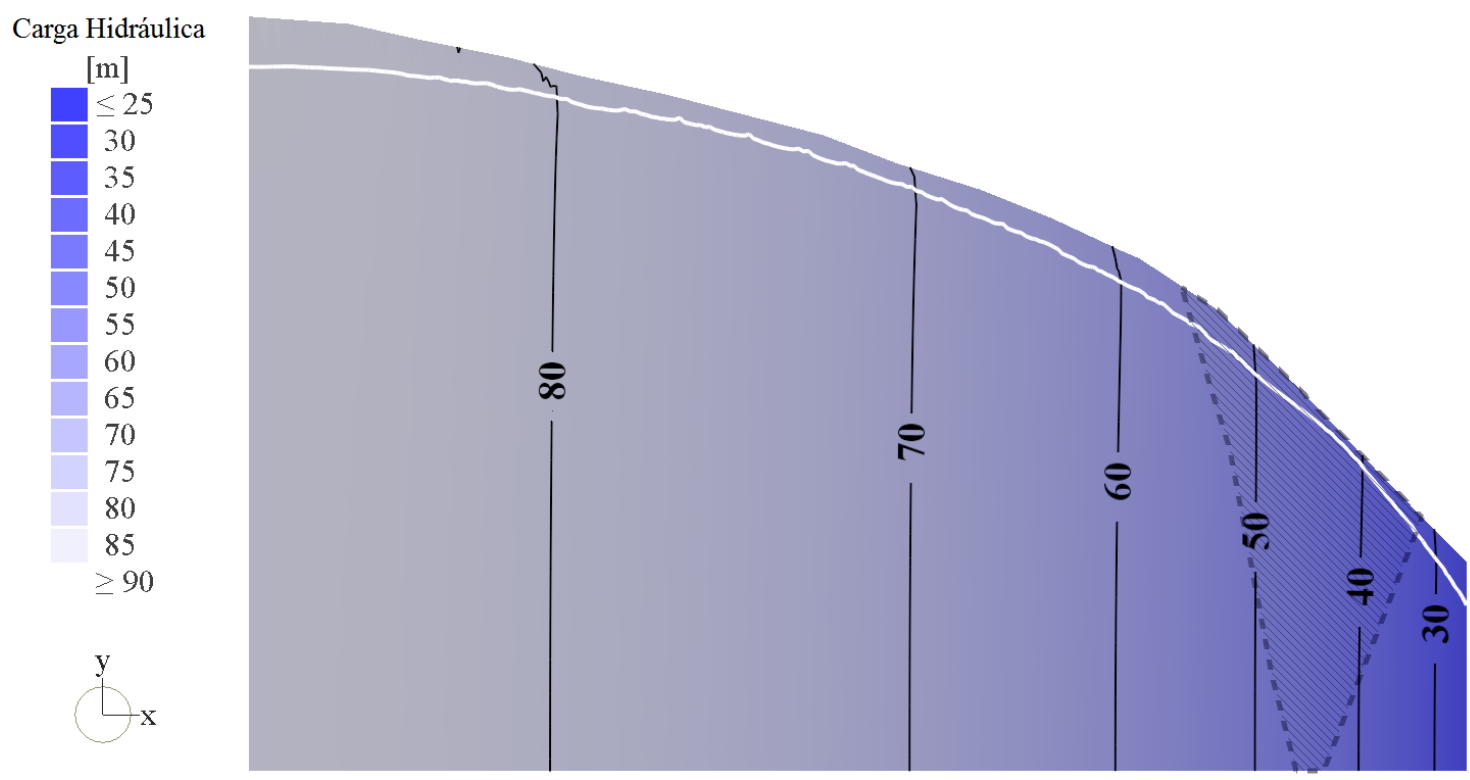

Figura 5.20 - Distribuição da carga hidráulica em 19 de agosto de 2015. A região em destaque refere-se à área da seção geoelétrica $F$.

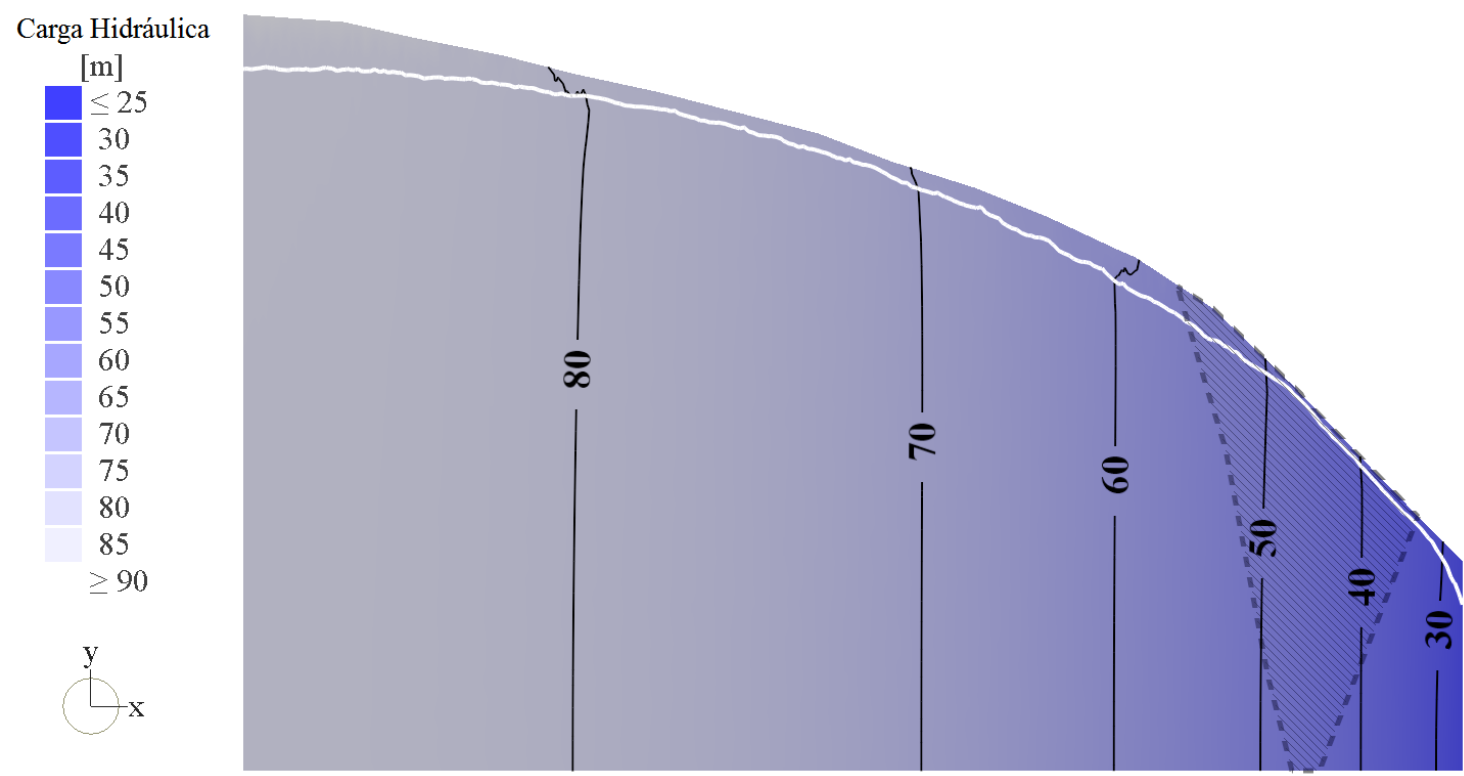

Figura 5.21 - Distribuição da carga hidráulica em 04 de fevereiro de 2016. A região em destaque refere-se à área da seção geoelétrica $F$. 


\section{Imageamento Elétrico}

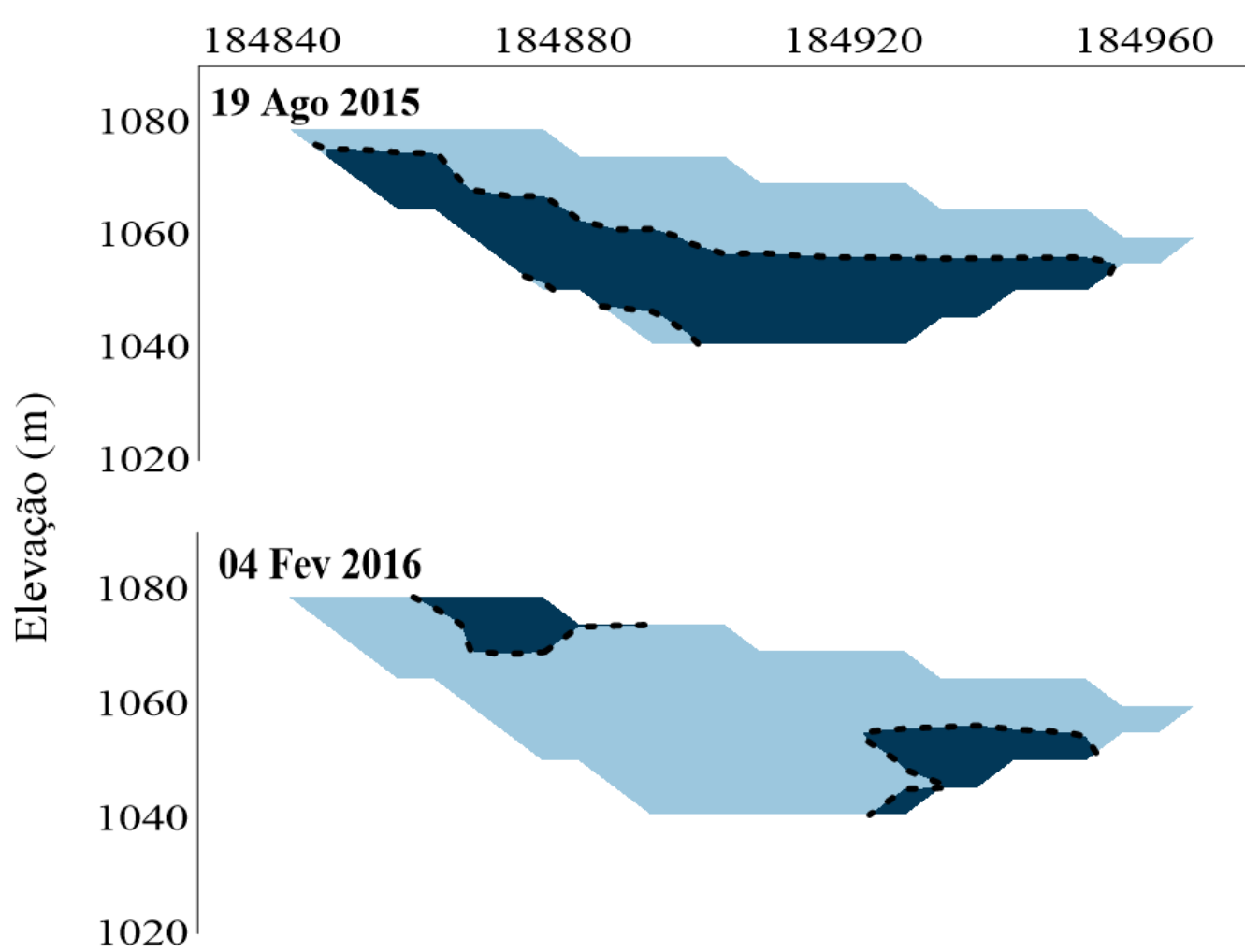

\section{Modelagem Numérica}

$\begin{array}{llll}184840 & 184880 & 184920 & 184960\end{array}$

19 Ago 2015

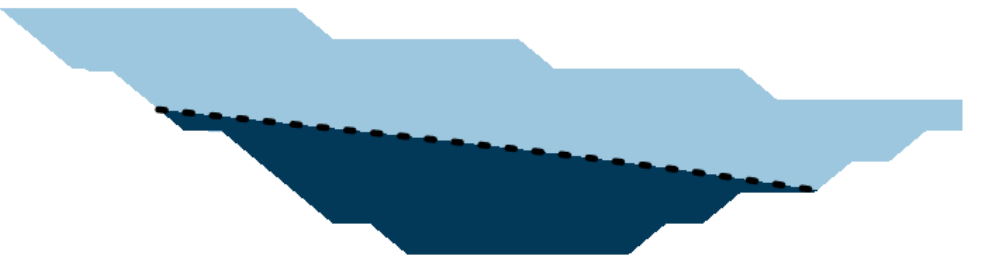

04 Fev 2016

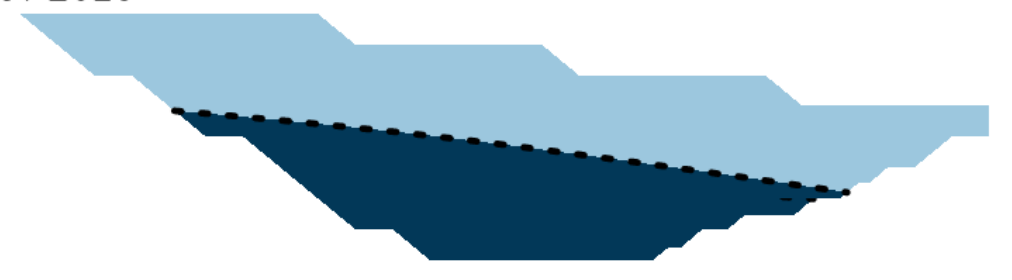

Figura 5.22 - Comparação entre os resultados do levantamento geofísico e da modelagem numérica. 
O escoamento de base estimado a partir da simulação hidrológica totalizou $98 \mathrm{~mm} / \mathrm{ano}$ para o ano hidrológico de 2015, equiparando-se ao valor estimado por meio do filtro automático de Arnold e Allen (1999), equivalente a 92 mm/ano. Considerando a média do escoamento de base acumulado de cada ano, ao longo dos 15 anos simulados, o resultado obtido com o pacote computacional FEFLOW apresentou a mesma ordem de grandeza daquele oriundo da aplicação do filtro matemático (Tabela 5.5).

Tabela 5.5 - Comparação entre os resultados do escoamento de base.

\begin{tabular}{ccc} 
Ano & $\begin{array}{c}\text { FEFLOW } \\
\text { (mm/ano) }\end{array}$ & $\begin{array}{c}\text { Arnold e } \\
\text { Allen (1999) } \\
\text { (mm/ano) }\end{array}$ \\
\hline 2000 & 155,00 & 320,00 \\
2001 & 80,00 & 300,00 \\
2002 & 70,00 & 250,00 \\
2003 & 75,00 & 190,00 \\
2004 & 95,00 & 280,00 \\
2005 & 220,00 & 250,00 \\
2006 & 310,00 & 300,00 \\
2007 & 250,00 & 240,00 \\
2008 & 300,00 & 260,00 \\
2009 & 285,00 & 260,00 \\
2010 & 224,00 & 224,00 \\
2011 & 125,00 & 200,00 \\
2012 & 60,00 & 179,00 \\
2013 & 80,00 & 180,00 \\
2014 & 90,00 & 144,00 \\
2015 & 98,00 & 92,00 \\
\hline Média & 160,00 & 230,00 \\
\hline
\end{tabular}

A comparação entre os valores médios anuais de escoamento de base sugere resultados equiparáveis nos anos de 2005 e 2011 e a partir de 2014 (Figura 5.23). Nos demais períodos o escoamento determinado segundo metodologia proposta por Arnold e Allen (1999) é superestimado em comparação aos resultados gerados pelo modelo. Desse modo, entre 2005 e 2011 é possível verificar respostas condizentes entre o modelo, o filtro automático e os eventos de precipitação. A partir de 2012 a discrepância entre os hidrogramas de escoamento de base para ambos os métodos é novamente acentuada, refletindo, no caso da simulação, o baixo índice de precipitação nesse período, bem como entre os anos de 2000 e 2005. 
A partir de 2014, o ajuste dos valores de escoamento de base tende a se aproximar, especialmente em condições de precipitação elevada. Com isso, a diferença identificada entre os valores de escoamento de base simulados pelo FEFLOW e aqueles estimados por meio do filtro automático demonstra relação com a variação da precipitação ao longo do período estudado (Figura 5.23). Os resultados sugerem comportamento semelhante para os valores de escoamento de base na vertente por meio das duas metodologias adotadas em períodos com ocorrência de precipitação elevada, em contraponto à reduzida capacidade de resposta do modelo nos períodos caracterizados pela redução na de precipitação. 


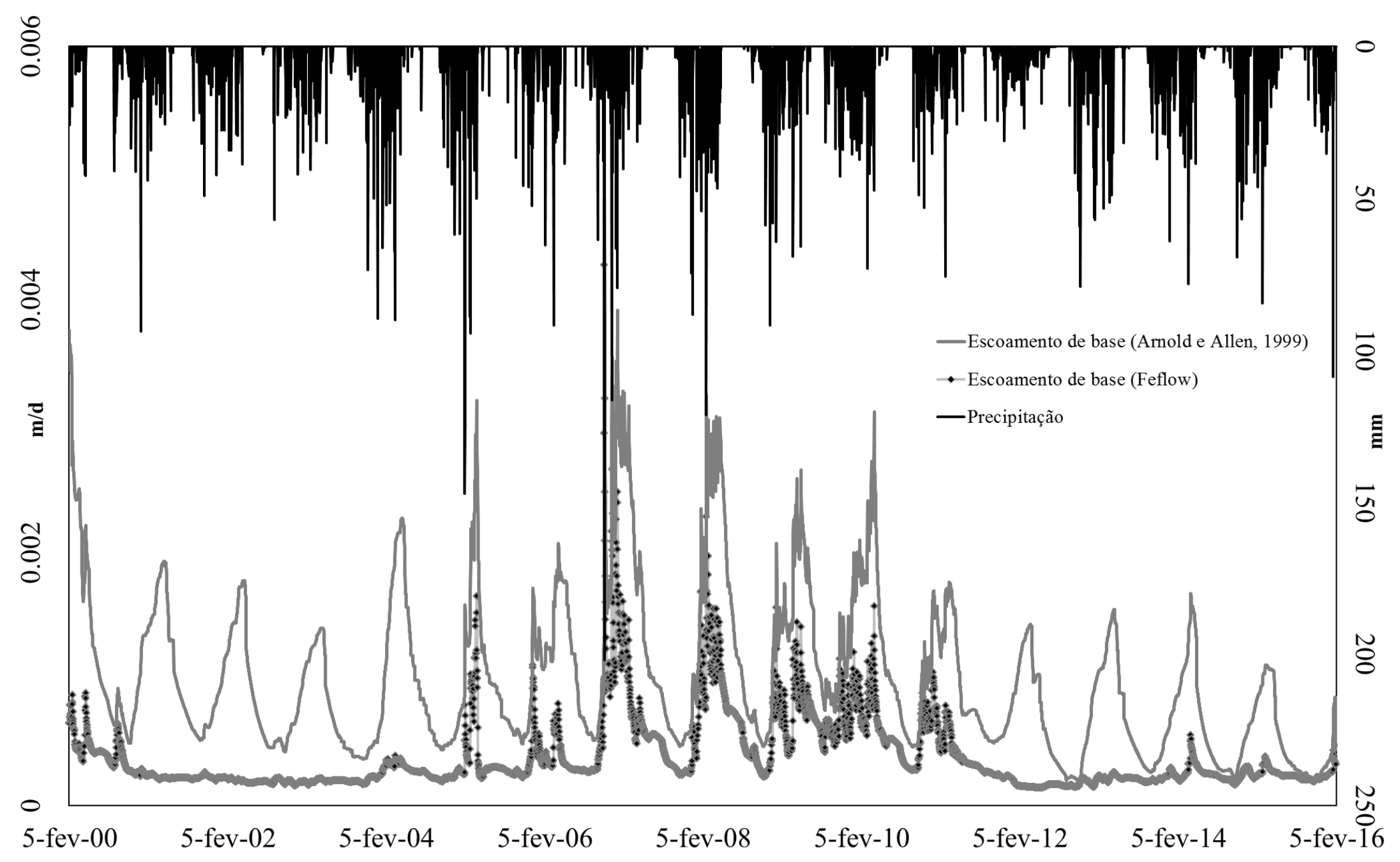

Figura 5.23 - Comparação entre os valores de escoamento de base obtidos a partir da simulação matemática e do filtro automático desenvolvido por Arnold e Allen (1999). 


\section{6 - CONCLUSÃO E CONSIDERAÇÕES FINAIS}

O estudo experimental e a modelagem matemática realizados na vertente do córrego Capetinga possibilitou a caracterização do comportamento da água no solo, com base no parâmetro resistividade elétrica e na identificação da carga hidráulica na área em estudo. Considerando-se os objetivos propostos, foram obtidos resultados satisfatórios quanto às variações temporal e espacial da resistividade, como indicativo da umidade do solo, e ao monitoramento do nível freático, com base nos levantamentos geofísicos e na simulação do fluxo da água na zona saturada. A abordagem adotada neste estudo permitiu identificar condições hidrogeológicos que favorecem a ampliação do entendimento dos processos hidrológicos na escala de vertente, ressaltando a adequação das ferramentas adotadas.

A metodologia geofísica limitou-se à caracterização qualitativa do comportamento da água num perfil de solo com aproximadamente $30 \mathrm{~m}$ de profundidade. Apesar disso, o padrão de distribuição da resistividade elétrica ao longo das profundidades investigadas, especialmente nas linhas dispostas na zona ripária $(C, D$ e $E)$, forneceu informações da estratigrafia do solo, permitindo o delineamento da zona saturada nas regiões com resistividade abaixo de $3.000 \Omega . m$. Esse valor foi característico a $15 \mathrm{~m}$ de profundidade na porção da vertente próxima ao córrego Capetinga, estando associado à redução na amplitude de distribuição dos dados de resistividade elétrica em comparação ao solo superficial. Os levantamentos geofísicos realizados entre agosto de 2015 e fevereiro de 2016 reforçaram então a premissa de que à medida que o solo tende à saturação, reduz-se a faixa de variação temporal dos valores de resistividade em conjunto com a ocorrência de anomalias de baixa resistividade.

A diferenciação das camadas do solo a partir do método elétrico de corrente contínua deveu-se então à redução gradual dos valores de resistividade, na zona considerada saturada, e da amplitude de variação dos mesmos. Tratando-se de registros instantâneos, os resultados do imageamento elétrico possibilitaram retratar a conformação do solo, considerando a influência da heterogeneidade do meio. Foi possível então representar a estratigrafia geoelétrica da vertente ao longo do período de estudo e associar essa informação ao processo de modelagem. 
Além disso, a variação temporal dos valores de resistividade pode ser considerada um indicativo do comportamento sazonal da água no solo, com eventual redução da umidade e da posição do lençol freático em decorrência dos eventos de estiagem. Entretanto, a caracterização geoelétrica requer mecanismos que possibilitem sua validação, com o monitoramento direto da água nas zonas de umidade e de saturação, bem como com a determinação de características físicas que possam influenciar no potencial elétrico natural e na passagem da corrente elétrica no solo. Neste estudo, a medição da umidade não possibilitou comparação com dados geofísicos em função da discrepância entre as profundidades investigadas por ambos os métodos. Além disso, a caracterização física do solo, importante para ampliação das inferências a partir dos dados de resistividade elétrica, não pode ser realizada.

Os dados de umidade gravimétrica, considerados padrão em decorrência da determinação direta, possibilitaram inferências quanto ao comportamento da água num perfil de solo com $1 \mathrm{~m}$ de profundidade. Apesar de não terem sido correlacionados à resistividade elétrica, foi realizada a comparação desses com os dados obtidos de modo automático (sonda $T D R$ ). O método gravimétrico faz-se necessário então para a aquisição de dados que possibilitem a calibração e validação dos métodos indiretos aplicados para mesma finalidade, atribuindo maior confiabilidade aos resultados gerados. Contudo, sua aplicação é dispendiosa, sendo importante a automatização no processo de aquisição de dados, favorecendo a ampliação das escalas de monitoramento temporal e espacial.

A utilização do equipamento TDR e dos blocos de gesso se deu com esse intuito. Porém, a curta série temporal de dados para ambos os casos reduziu a possibilidade de análise e discussão dos mesmos. Tais resultados foram apresentados apenas para comparação com aqueles obtidos pelo método gravimétrico, numa tentativa de automatização do processo de monitoramento da umidade do solo. Apesar das limitações, o trabalho experimental de monitoramento da umidade do solo consistiu numa etapa inicial de aquisição de dados que, ao serem ampliados, irão subsidiar a compreensão dos processos hidrológicos na zona não saturada, com dados primários importantes para o estudo de processos hidrológicos em escala de vertente.

Quanto à modelagem numérica, a aplicação do método de elementos finitos demonstrou resultados satisfatórios para representação do fluxo de água na zona saturada. 
Considerando a condutividade hidráulica de $0,04 \mathrm{~m} /$ dia num perfil bidimensional vertical de solo obteve-se convergência numérica para simulação dos valores de carga hidráulica. De modo geral, o escoamento de base estimado a partir do FEFLOW foi condizente com os valores determinados por meio do filtro matemático proposto por Arnold e Allen (1999). Contudo, a calibração da recarga, bem como da condutividade hidráulica, pode favorecer um ajuste mais adequado dos valores de escoamento de base calculados, especialmente na fase inicial da simulação em regime transiente. Além disso, a abordagem de outras estratégias de discretização temporal e aperfeiçoamento da discretização espacial podem favorecer a adequação dos resultados.

Sugere-se, desse modo, em função dos resultados identificados, a continuidade dos trabalhos no intuito de ampliar a caracterização dos processos hidrológicos na vertente do córrego Capetinga. É recomendado o aprofundamento da análise correlata entre a resistividade elétrica e a umidade do solo, além da incorporação de outras variáveis igualmente interdependentes, tais como textura e matéria orgânica. Quanto ao processo de modelagem, a aquisição de dados altimétricos com resolução adequada à escala de vertente poderá reduzir as incertezas associadas aos dados de entrada utilizados na simulação do fluxo subterrâneo.

Além disso, faz-se necessária a perfuração de novos poços de observação do nível freático, para a validação dos resultados obtidos a partir das ferramentas geofísica e de modelagem numérica. Com isso, a ampliação na escala temporal dos dados ao longo da vertente e o aperfeiçoamento do arranjo experimental podem ampliar o entendimento dos processos hidrológicos na vertente, com destaque para a relação geofísica - modelagem e os reflexos nos estudos hidrológicos em escala de bacia hidrográfica. 


\section{REFERÊNCIAS BIBLIOGRÁFICAS}

Aksoy, H.; Kurt, I.; Eris, E. (2009). Filtered smoothed minima baseflow separation method. Journal of Hydrology, v.372, p.94-101.

Akca, I.; Gunther, T.; Muller-Petke, M.; Basokur, A.T.; Yaramanci, U. (2014). Joint parameter estimation from magnetic resonance and vertical electric soundings using a multi-objective genetic algorithm. Geophysical Prospecting, v. 62, p. 364-376.

Agência Nacional de Águas - ANA (Org.). (2010). Relatório de diagnóstico socioambiental da bacia do Ribeirão Pipiripau. ANA/The Nature Conservancy/Emater-DF/GDF. 59 p.

Al-Othman, A. (2011). Enhancing groundwater recharge in arid region- a case study from Central Saudi Arabia. Scientific Research and Essays, v. 6, n. 13, p. 27572762.

Alo-Aho, P.; Rossi, P.M.; Klove, B. (2015). Estimation of temporal and spatial variations in groundwater recharge in unconfined sand aquifers using Scots pine inventories. Hydrol. Earth Syst. Sci., v. 19, p. 1961-1976.

Amorim-Junior, V.; Lima, O.A.L. (2007). Avaliação hidrogeológica do aquífero Urucuia na bacia do rio das Fêmeas - BA usando resistividade e polarização elétrica induzida. Revista Brasileira de Geofísica, v. 25, n. 2, p. 117-129.

Andersen, T.R.; Poulsen, S.E.; Christensen, S.; Jorgensen, F. (2013). A synthetic study of geophysics-based modelling of groundwater flow in catchments with a buried valley. Hydrogeology Journal, v. 21, p. 491 - 503.

Anderson, M.G.; Burt, T.P. (1990). Process Studies in Hillslope Hydrology: An Overview. In: Anderson, M.G.; Burt, T.P. Process Studies in Hillslope Hydrology. England: John Wiley e Sons. 539 p.

Anderson, M.P.; Woessner, W.W. (2002). Applied groundwater modeling: Simulation of flow and advective transport. USA: Elsevier, 388 p.

Andrade, C.L.T.; Ferreira-Coelho, E.; Couto, L.; Silva, E.L. (1998). Parâmetros de soloágua para a engenharia de irrigação e ambiental. In: 27, Congresso Brasileiro de Engenharia Agrícola, Anais... Poços de Caldas: UFLA/SBEA, p. 1-45.

Arnold, J.G.; Allen, P.M. (1999). Automated methods for estimating baseflow and ground water recharge from streamflow records. Journal of the American Water Resources Association, v. 35, n. 2.

Asawa, G.L. (2008). Irrigation and Water Resources Engineering. New Delhi: New Age International Limited Publishers. 623 p.

Asry, Z.; Samsudin, A.R.; Yaacob, W.Z.; Yaakub, J. (2012). Groundwater Exploration Using 2-D Geoelectrical Resistivity Imaging Technique at Sungai. Udang, Melaka. Journal of Earth Science and Engineering, v. 2, p. 624-630.

Attanásio, C.M.; Gandolfi, S.; Zakia, M.J.B.; Veniziani, J.C.Y.J.; Lima, W.P. (2012). A importância das áreas ripárias para a sustentabilidade hidrológica do uso da terra em microbacias hidrográficas. Bragantia, Campinas, v. 71, n. 4, p. 493-501.

Awan, U.S.K.; Tischbein, B.; Martius, C. (2015). Simulating groundwater dynamics using feflow-3d groundwater model under complex irrigation and drainage network of dryland ecosystems of central Asia. Irrigation and Drainage, v. 64, p. 283-296.

Bachmair, S.; Wiler, M. (2014). Interactions and connectivity between runoff generation processes of different spatial scales. Hydrol. Process. v. 28, p. 19161930. 
Bahrami, S.; Ardejani, F.D.; Aslani, S.; Baafi, E. (2014). Numerical modelling of the groundwater inflow to an advancing open pit mine: Kolahdarvazeh pit, Central Iran. Environ Monit Assess, v. 186, p. 8573-8585.

Barker, R.D. (1989). Depth of investigation of collinear symmetrical four-electrode arrays. Geophysics, v. 54, n. 8, p. 1031-1037.

Bauer, D.F. (1972). Constructing confidence sets using rank statistics. Journal of the American Statistical Association, v. 67, p. 687-690.

Bazin, S.; Pfaffhuber, A.A. (2013). Mapping of quick clay by electrical resistivity tomography under structural constraint. Journal of Applied Geophysics, v. 98, p. 280-287.

Bear, J.; Cheng, A.H.D. (2010). Modeling groundwater flow and contaminant transport. New York: Springer. 834 p.

Behroozmand, A.A.; Keating, K.; Auken, E. (2015). A Review of the Principles and Applications of the NMR Technique for Near-Surface Characterization. Surv Geophys, v. 36, p. 27-85.

Bellmunt, F.; Marcuello, A.; Ledo, J.; Queralt, P.; Falgàs, E.; Benjumea, B.; Velasco, V.; Vásquez-Suné, E. (2012). Time-lapse cross-hole electrical resistivity tomography monitoring effects of an urban tunnel. Journal of Applied Geophysics, v. 87, p. 60-70.

Bernardo, S. (1995). Manual de irrigação. Viçosa: UFV, Imprensa Universitária. 657p.

Besson, A.; Cousin, I.; Bourennane, H.; Nicoullaud, B.; Pasquier, C.; Richard, G.; Dorigny, A.; King, D. (2010). The spatial and temporal organization of soil water at the field scale as described by electrical resistivity measurements. European Journal of Soil Science, February, v. 61, p. 120-132.

Beven, K. (1977). Hillslope Hydrographs by the finite element method. Earth surface processes, v. 2, p. 13-28.

Bharti, A.K.; Pal, S.K.; Priyan, P.; Kumar, S.; Srivastava, S.; Yadav, P.K. (2016). Subsurface cavity detection over Patherdih colliery, Jharia Coalfield, India using electrical resistivity tomography. Environ Earth Sci, v. 75, n. 443, 17 p.

Birkel, C.; Soulsby, C.; Tetzlaff, D. (2015). Conceptual modelling to assess how the interplay of hydrological connectivity, catchment storage and tracer dynamics controls nonstationary water age estimates. Hydrol. Process., v. 29, n. 13, p. 2956-2969.

Birnbaum, Z.W.; Tingey, F.H. (1951). One-Sided Confidence Contours for Probability Distribution Functions. Ann. Math Statist., v. 22, n. 4, p. 592-596.

Blumstock, M.; Tetzlaff, D.; Malcolm, I.A.; Neutzmann, G.; Soulsby, C. (2015). Baseflow dynamics: Multi-tracer surveys to assess variable groundwater contributions to montane streams under low flows. Journal of Hydrology, v. 527, p. 1021-1033.

Boano, F.; Harvey, J.W.; Marion, A.; Packman, A.I.; Revelli, R.; Ridolfi, L.; Worman, A. (2014). Hyporheicflow and transport processes: Mechanisms, models, and biogeochemical implications. Rev. Geophys., v. 52, p. 603-679.

Bouyoucos, G. J.; Mick, A. H. (1940). An electrical resistance method for the continuous measurement of soil moisture under field conditions. Michigan Agr. Expt. Sta. Tech. Bull, v. 172, 38 p.

Brady, N. C.; Weil, R.R. (2013). Elementos da Natureza e Propriedades dos Solos. Porto Alegre: Bookman. 686 p.

Braga, A. C. O. (2007). Métodos Geofísicos Aplicados: Módulo Hidrogeologia. Rio Claro: Universidade Estadual Paulista. 79 p. 
Brievré, G.; Jongmans, D.; Winiarski, T.; Zumbo, V. (2012). Application of geophysical measurements for assessing the role of fissures in water infiltration within a clay landslide (Trieves area, French Alps). Hydrol. Process, v. 26, p. 2128-2142.

Brillante, L.; Bois, B.; Mathieu, O.; Bichet, V.; Michot, D.; Lèvêque, J. (2014). Monitoring soil volume wetness in heterogeneous soils by electrical resistivity. A field-based pedotransfer function. Journal of Hydrology, v. 516, p. 56-66.

Brillante, L.; Mathieu, O.; Bois, B.; Leeuwen, C.; Lévêque, J. (2015). The use of soil electrical resistivity to monitor plant and soil water relationships in vineyards. Soil, v. 1, p. 273-286.

Bronstert, A.; Glusing, B.; Plate, E. (1998). Physically-based hydrological modelling on the hillslope and micro-catchment scale: examples of capabilities and limitations. Hydrology, Water Resources and Ecology in Headwaters, n. 248, p. 207-215.

Brutsaert, W. (2005). Hydrology: An introduction. New York: Cambrige University Press. 617 p.

Buckingham, E. (1907). Studies on the movement of soil moisture. Bulletin, 38, USDA, Bureau of Soils, Washington, D.C. 61 p.

Buettner, M.; Ramirez, A.; Daily, W. (1996). Electrical resistance tomography for imaging concrete structures. Structural Materials Technology an NDT Conference, p. 20-23.

Bugan, R.D.H.; Jovanovic, N.Z.; Clercq, W.P. (2012). The water balance of a seasonal stream in the semi-arid Western Cape (South Africa). Water, v. 38, n. 2. p. 201212.

Burt, T.P.; Pinay, G.; Matheson, F.E.; Haycock, N.E.; Butturini, A. Clement, J.C.; Danielescu, S.; Dowrick, D.J.; Hefting, M.M.; Hillbricht-Ilkowska, A.; Maitre, V. (2002). Water table fluctuations in the riparian zone: comparative results from a pan-European experiment. Journal of Hydrology, v. 265, p. 129-148.

Cabral, J. (1997). Movimento das Águas Subterrâneas. In: Feitosa, F.A.C.; ManoelFilho, J. Hidrogeologia: Conceitos e Aplicações. Fortaleza: CPRM, LABHID UFPE. $412 \mathrm{p}$.

Cabral, J.; Demétrio, J.G.A. (1997). Aplicação de modelos em hidrogeologia. In: Feitosa, F.A.C.; Manoel-Filho, J. Hidrogeologia: Conceitos e Aplicações. Fortaleza: CPRM, LABHID - UFPE. 412 p.

Caicedo, N.L. (2004). Água Subterrânea. p. 289-334. In: Tucci, C.E.M. Hidrologia: Ciência e Aplicação. Porto Alegre: UFRGS/ABRH. 943 p.

Calamita, G. Brocca, L.; Perrone, A.; Piscitelli, S.; Lapenna, V.; Melone, F.; Maramoarco, T. (2012). Electrical resistivity and TDR methods for soil moisture estimation in central Italy test-sites. Journal of Hydrology, v. 454-455, p. 101112.

Campos, J.E.G.; Freitas-Silva, F.H. (1998). Hidrogeologia do Distrito Federal. In: Inventário Hidrogeológico e dos Recursos Hídricos Superficiais do Distrito Federal. Brasília: IEMA/SEMATEC/UnB, p. 1-84, (vol. IV Relatório Técnico).

Carducci, C.E.; Oliveira, G.C.; Severiano, E.C.; Zeviani, W.M. (2011). Modelagem da curva de retenção de água de latossolos utilizando a equação duplo van Genuchten. R. Bras. Ci. Solo, v. 35, p. 77-86.

Carpenter, E.W. (1955). Some notes concerning the Wenner configuration. Geophysical Prospecting, v. 3, p. 338-402. 
Cartwright, I.; Gilfedder, B; Hofmann, H. (2014). Contrasts between estimates of baseflow help discern multiple sources of water contributing to rivers. Hydrol. Earth Syst. Sci., v. 18, p. 15-30.

Castelloé, J.F.; Peterson, T.J.; Halbert, K.; Western, A.W.; Mcdonnell, J.J. (2015). Groundwater surface mapping informs sources of catchment baseflow. Hydrol. Earth Syst. SCI, v. 19, p. 1599-1613.

Cederstrom, D.J. (1964). Água subterrânea: uma introdução. Rio de Janeiro: Centro de Publicações Técnicas da Aliança. 280 p.

Chapra, S.C.; Canale, R.P. (2010). Numerical Methods for Engineers. New York: Mc Graw Hill. 968 p.

Chukwuma E.C.; Orakwe, L.C.; Anizoba, D.C.; Amaefule, D.O.; Odoh, C.C.; Nzediegwu, C. (2015). Geo-electric Groundwater Vulnerability Assessment of Overburden Aquifers at Awka in Anambra State, South-Eastern Nigeria. European J. Biot. Bioscience, v. 3, n.1, p. 29-34.

Cleary, R. (1989). Águas subterrâneas. In: Ramos, F.; Occhipinti, A.G.; Villa-Nova, N.A.; Reichardt, K.; Magalhães, P.C.; Cleary, R.W. Engenharia Hidrológica. Rio de Janeiro: ABRH/UFRJ. 404 p.

Clough, R.W. (1960). The finite element method in plane stress analysis, ASCE Struct. Div Proc. $2^{\text {nd }}$ Conf. Electronic Computation, p. 345-379.

Companhia de Planejamento do Distrito Federal - CODEPLAN (1984). Atlas do Distrito Federal. Brasília: Secretaria do Governo/Secretaria da Educação e Cultura/CODEPLAN, v. 1.78 p.

Conceição, M. A. F. (2001). Determinação da evapotranspiração de referência com base na evaporação do Tanque Classe A na região nordeste de São Paulo. Jales: Embrapa Uva e Vinho, n. 37. 4 p.

Conselho Nacional de Recursos Hídricos - CNRH. (2001). Resolução $n^{o}$ 15, de 11 de janeiro de 2001. Estabelece diretrizes para inserção das águas subterrâneas no instrumento Planos de Recursos Hídricos. Brasília: Diário Oficial da União. Disponível em: http://www.cnrh.gov.br/index.php?option=com_content\&view=article\&id=14>.

Costa, F.M.; Bacellar, L.A.P. (2010). Caracterização Hidrogeológica de Aquíferos a Partir do Fluxo de Base. Revista Brasileira de Recursos Hídricos, v. 15, n. 3, p. 173-183.

Courant, R. (1943). Variation methods for the solution of problems of equilibrium and vibration. Bull. Amer. Math. Soc., v. 49, p. 1-43.

Crosbie, R.S.; Taylor, A.R.; Davis, A.C.; Lamontagne, S.; Munday, T. (2014). Evaluation of infiltration from losing-disconnected rivers using a geophysical characterisation of the riverbed and a simplified infiltration model. Journal of Hydrology, v. 508, p. 102-113.

Darcy, H. (1856). Les fontaines publiques de la ville de Dijon. Paris [s.n.].

Delmhorst Instrument Co. (1999). Model KS-D1: Owner's manual. Towaco: Delmhorst Instrument Co. $16 \mathrm{p}$.

Delta-T Devices Ltd. (2008). User manual for the profile probe type PR2. UK: Delta-T Devices Ltd. 43 p.

Detty, J.M.; Mcguire, K.J. (2010). Topographic controls on shallow groundwater dynamics: implications of hydrologic connectivity between hillslopes and riparian zones in a till mantled catchment. Hydrological Processes, v. 24, p. 2222-2236.

Diersch, H.J. (1998). Finite element modelling of recirculating density driven saltwater intrusion processes in groundwater. Adv. Water Resources, v. 11, p. 25-43. 
Diersch, H.J. (2014). FEFLOW: Finite Element Modeling of Flow, Mass and Heat Transport in Porous and Fractured Media. Springer. 1018 p.

Donagema, G.K.; Campos, D.V.B.; Calderano, S.B.; Teixeira, W.G.; Viana, J.H.M. (Org.) (2011). Manual de Métodos de Análise de Solos. Rio de Janeiro: Embrapa Solos. 230 p.

Donohue, S.; McCarthy, V.; Rafferty, P.; Orr, A.; Flynn, R. (2015). Geophysical and hydrogeological characterisation of the impacts of on-site wastewater treatment discharge to groundwater in a poorly productive bedrock aquifer. Science of the Total Environment, n. 523, p. 109-119.

Doulatyari, B.; Basso, S.; Schirmer, M.; Botter, G. (2014). River flow regimes and vegetation dynamics along a river transect. Advances in Water Resources, v. 73, p. 30-43.

Eckhardt, K. (2005). How to construct recursive digital filters for baseflow separation. Hydrol. Process. v. 19, p. 507-515.

Empresa Brasileira de Pesquisa Agropecuária - EMBRAPA (1978). Levantamento de reconhecimento dos solos do Distrito Federal. Rio de Janeiro: EMBRAPASNLCS. $455 \mathrm{p}$.

Escosteguy, P.A.V.; Galliassi, K.; Ceretta, C.A. (2007). Determinação de matéria orgânica do solo pela perda de massa por ignição, em amostras do Rio Grande do Sul. R. Bras. Ci. Solo, v. 31, p. 247-255.

Eunice, V.B.; Luiz, J.G.; Leal, L.R.B.; Fenzl, N.; Morales, G.P. (2011). Diagnóstico sobre contaminação das águas subterrâneas na área do parque estadual do Utinga, Belém - PA, pelos métodos elétrico e eletromagnético. Revista Brasileira de Geofísica, Brasil, v. 29, n. 4, p. 753-770.

Feitosa, E.C. (1997). Pesquisa de Água Subterrânea. In: Feitosa, F.A.C.; Manoel-Filho, J. Hidrogeologia: Conceitos e Aplicações. Fortaleza: CPRM, LABHID - UFPE. $412 \mathrm{p}$.

Ferreira, P.A. (2005). Quantificação e análise do uso da água em práticas de agricultura irrigada na bacia do Descoberto - DF. Distrito Federal: Departamento de Engenharia Civil e Ambiental. Universidade de Brasília, Dissertação de Mestrado. 173 p.

Fetter C. W. (1994). Applied Hydrogeology. Englewood Cliffs: Prentice-Hall. 691 p.

Fleckenstein, J.H.; Krause, S.; Hannah, D.M.; Boano, F. (2010). Groundwater-surface water interactions: New methods and models to improve understanding of processes and dynamics. Advances in Water Resources, v. 33, p. 1291-1295.

Franke, O.R.; Reilly, T.E.; Bennet, G.D. (1987). Definition of Boundary and Initial Conditions in the Analysis of Satured Ground Water Flow Systems - An Introduction. Techniques of Water-Resources Investigations of the U. S. Geological Survey. Applications of Hydraulics. Reston: USGS, Chapter B5. 22 p.

Freeze, R.A.; Cherry, J.A. (1979). Groundwater. USA: Prentice-Hall. 604 p.

Freitas-Silva F.H.; Campos J.E.G. (1998). Geologia do Distrito Federal. In: IEMA/SEMATEC/UnB. Inventário Hidrogeológico e dos Recursos Hídricos Superficiais do Distrito Federal. Brasília: IEMA/ SEMATEC/UnB, v. 1, Parte I. $86 \mathrm{p}$.

Galerkin, B,G. (1915). Series solution of some problems of elastic equilibrium of rods and plates (in Russian). Vestn Inzh. Tech., v. 19, p. 897-908.

Gao, H. (2011). Groundwater Modeling for Flow Systems with Complex Geological and Hydrogeological Conditions. Procedia Earth and Planetary Science, n. 3, p. 23-28. 
Gardner, W.R.; Widtsoe, J.A. (1921). The movement of soil moisture. Soil Science, v. 11, p. 214-232.

Golden Software, Inc., (2002). SURFER: User's Guide. Contouring and 3D Surface Mapping for Scientists and Engineers, Golden Software, Inc., Golden, Colorado, $640 \mathrm{p}$.

Greentec Tecnologia Ambiental (Org.). (2013). Zoneamento Econômico Ecológico do Distrito Federal. 2010. Disponível em: < http://www.zee-df.com.br/ >. Acesso em: 20 de nov.

Gregory, S.V.; Ashkenas, L. (1990) Riparian Management Guide. USDA: Forest Service Pacific Northwest Region. $120 \mathrm{p}$

Griffiths, D.H.; Barker, R.D. (1993). Two-dimensional resistivity imaging and modelling in areas of complex geology. Journal of Applied Geophysics, v. 29, p. 211-226.

Guerra, A.F.; Rodrigues, G.C.; Nazareno, R.B. (2002). Uso do Tanque Classe A para irrigação do feijão pérola no Cerrado. Planaltina: Embrapa Cerrados, v. 84., 4 p.

Hanspal, N.S.; Nassehi, V., Kulkarni, A. (2013). Three-dimensional finite element modelling of coupled free/porous flows: applications to industrial and environmental flows. Int. J. Numer. Meth. Fluid, v. 71, p. 1382-1421.

Harvey, J.W.; Wagner, B.J.; Thorp, J.H. (2000). Quantifying hydrologic interactions between streams and their subsurface hyporheic zone. p. 1-41. In: Jones, B; Mulholland, P.J. (Eds.). Streams and Groundwaters, California: Elsevier.

Haught, D.R.W.; van Meerveld, H.J. (2011). Spatial variation in transient water table responses: differences between an upper and lower hillslope zone. Hydrol. Process., v. 25, p. 3866-3877.

Hirata, R. (2008). Recursos hídricos. In: Teixeira, W.; Fairchild, T. R.; Toledo, M.C.; Taioli, F. (Org.) Decifrando a Terra. São Paulo: Companhia Editora Nacional, $623 \mathrm{p}$.

Hill, A.R. (2000). Stream chemistry and riparian zones. In: Jones, J.; Mulholland, P. (Eds.). Streams and Ground Waters, California: Elsevier, pp. 83-110.

Hillel, D. (1998). Environmental Soil Physics. San Diego: Academic Press, 757p.

Horton, R.E. (1933). The role of infiltration in the hydrologic cycle. Am. Geophys. Union Trans, v. 14, p. 446-460.

Instituto Brasileiro de Geografia e Estatística - IBGE (2007). Manual técnico de pedologia. Rio de Janeiro: IBGE. 316 p. Disponível em: < http://biblioteca.ibge.gov.br/visualizacao/livros/liv37318.pdf>. Acesso em: 20 de mar. 2015.

Instituto Brasileiro de Geografia e Estatística - IBGE (2011). Pesquisa Nacional de Saneamento Básico. Rio de Janeiro: IBGE. 268 p. Disponível em: <http://www.ibge.gov.br/home/estatistica/populacao/atlas_saneamento/default_z ip.shtm >. Acesso em: 02 de jun. 2015.

Instituto Brasileiro de Geografia e Estatística - IBGE (2013). Manual técnico de uso da terra. Rio de Janeiro: IBGE. $171 \mathrm{p}$.

Instituto Nacional de Meteorologia - INMET (2016). BDMEP - Banco de Dados Meteorológicos para Ensino e Pesquisa. Disponível em: < http://www.inmet.gov.br/portal/index.php?r=bdmep/bdmep>. Acesso em: 23 de mar. 2016.

Ireson, A.M.; Kamp, G.; Nachshon, U. Wheater, H.S. (2013). Hydrogeological processes in seasonally frozen northern latitudes: understanding, gaps and challenges. Hydrogeology Journal, Berlin, v. 21, p. 53-66. 
Jencso, K.G.; McGlynn, B.L.; Gooseff, M.N.; Bencala, K.E.; Wondzell, S.M. (2010). Hillslope hydrologic connectivity controls riparian groundwater turnover: Implications of catchment structure for riparian buffering and stream water sources. Water Resources Research, v. 46, 18 p.

Jiang, R.; Hatano, R.; Hill, R.; Kuramochi, K.; Jiang, T.; Zhao, Y. (2015). Water connectivity in hillslope of upland-riparian zone and the implication for stream nitrate-N export during rain events in an agricultural and forested watershed. Environ Earth Sci., v. 74, p. 4535-4547.

Johnson, A.I. (1992). Methods of Measuring Soil Moisture in the Field. USA: USGS. $29 \mathrm{p}$.

Jones, J.B.; Mulholland, P.J. (Eds.). (2000). Streams and ground waters. California: Elsevier. 447 p.

Kaiser, D.R.; Reinert, D.J.; Reichert, J.M.; Minella, J.P.G. (2010). Dielectric constant obtained from TDR and volumetric moisture of soils in southern Brazil. R. Bras. Ci. Solo, v. 34, p. 649-658.

Karmann, I. (2008). Ciclo da água, água subterrânea e sua ação geológica. In: Teixeira, W.; Fairchild, T. R.; Toledo, M.C.; Taioli, F. (Org.) Decifrando a Terra. São Paulo: Companhia Editora Nacional. 623 p.

Keller, G.V.; Frischknecht, F.C. (1977). Electrical methods in geophysical Prospecting. UK: Pergamon Press.

Kelson, V. (2012). Predicting Collector Well Yields with Modflow. Ground Water, v. 50, n. 6, p. 918-926.

Knight, R.; Pyrak-Nolte, L.J.; Slater, L.; Atekwana, E.; Endres, A.; Geller, J.; Lesmes, D.; Nakagawa, S.; Revil, A.; Sharma, M.M.; Straley, C. (2010). Geophysics at the interface: response of geophysical properties to solid-fluid, fluid-fluid, and solid-solid interfaces. Rev. Geophys., v. 48, 30 p.

Koefoed O. (1979). Resistivity Sounding Measurements. Amsterdan: Elsevier. 276 p.

Kramer, J.H.; Stephen, J.C.; Everett, L.G. (2000). Vadose Zone Monitoring with the Neutron Moisture Probe. In: Wilson, L.G.; Everett, L.G.; Cullen, S.J. Handbook of Vadose Zone Characterization and Monitoring. EUA: Lewis Publishers. 730 p.

Kresic, N. (2007). Hydrogeology and groundwater modeling. EUA: Taylor e Francis Group. 830 p.

Lamari, C.R. (Coor.). (2000). Os recursos hídricos da Terra. Campinas: Editora Unicamp, $146 \mathrm{p}$.

Levy, J.; Xu, Y. (2012). Review: Groundwater management and groundwater/surfacewater interaction in the context of South African water policy. Hydrogeology Journal, v. 20, p. 205-226.

Lima, E. (2001). Recursos hídricos no Brasil e no mundo. Planaltina: Embrapa Cerrados. $44 \mathrm{p}$

Lima, J.E.F.W.; Silva, C.L.; Oliveira, C.A.S. (2001). Comparação da evapotranspiração real simulada e observada em uma bacia hidrográfica em condições naturais de cerrado. Revista Brasileira de Engenharia Agrícola e Ambiental, v. 5, n. 1, p. 33-41.

Lima, W.P. (2008). Hidrologia florestal aplicada ao manejo de bacias hidrográficas. 2 ed. Piracicaba: USP. 243 p.

Lima, J.E.F.W. (2010). Modelagem numérica do fluxo da água no solo e do escoamento de base em uma bacia experimental em área agrícola no Cerrado (Distrito Federal). Brasília: Faculdade de Tecnologia, Universidade de Brasília, Tese de Doutorado. $312 \mathrm{p}$. 
Loáiciga, H.A.; Pingel, T.J.; Garcia, E.S. (2012). Sea Water Intrusion by Sea-Level Rise: Scenarios for the 21st Century. Ground Water, v. 50, n. 1, p. 37-47.

Loke, M.H. (2000). Topographic modelling in electrical imaging inversion. In: $62^{\text {nd }}$, EAGE Conference and Technical Exhibition. Glasgow, Scotland.

Lopes, J.W.B.; Pinheiro, E.A.R. (2014). Análise temporal da conectividade e da capacidade de transporte potencial de sedimentos em meso-bacia semiárida, CE, Brasil. Revista AgroAmbiente On-line, v. 7, n. 2, p. 136-144.

Lousada, E.O.; Campos, J.E.G. (2005). Proposta de modelos hidrogeológicos conceituais aplicados aos aqüíferos da região do Distrito Federal. Revista Brasileira de Geociências, Brasil, v. 35, n. 3, p. 407-414.

Lowrance, R., Tedd, R.; Fail Jr, J.; Hendrickson Jr, O.; Leonard, R.; Asmussen, L. (1984). Riparian Filters in Watersheds Agricultural. BioScience, v. 34, n. 6, p. 374-377.

Luo, Y.; Arnold, J.; Allen, P.; Chen, X. (2012). Baseflow simulation using SWAT model in an inland river basin in Tianshan Mountains, Northwest China. Hydrol. Earth Syst. Sci., v. 16, p. 1259-1267.

Macedo, J. (1996). Solos da região do Cerrado. In: Alvarez, V. H.; Fontes, L. E. F.; Fontes, M. P. F.(orgs). O solo nos grandes domínios morfoclimáticos do Brasil e o desenvolvimento sustentado. Viçosa: Universidade Federal de Viçosa. p. 135156.

Maia, J.M.F.; Baptista, G.M.M. (2008). Clima. In: Fonseca, F. O. (Org.). Águas Emendadas. Brasília: Secretaria de Desenvolvimento Urbano e Meio Ambiente. p. 101-110.

McMillan, H.K.; Srinivassan, M.S. (2015). Characteristics and controls of variability in soil moisture and groundwater in a headwater catchment. Hydrol. Earth Syst. Sci., v. 19, p. 1767-1786.

Maksoud, H. (1961). O estado atual dos conhecimentos sobre os recursos de água no Nordeste. Revista Brasileira de Geografia, Brasil, n. 1, p. 3-121.

Manoel-Filho, J.M. (1997a). Água subterrânea: histórico e importância. In: Feitosa, A.C.; Manoel-Filho, J.M (Coor.). Hidrogeologia: conceitos e aplicações. Fortaleza: CPRM, LABHID-UFPE. 412 p.

Manoel-Filho, J.M. (1997b). Ocorrência das águas subterrâneas. In: Feitosa, A.C.; Manoel-Filho, J.M (Coor.). Hidrogeologia: conceitos e aplicações. Fortaleza: CPRM, LABHID-UFPE. 412 p.

Martins, E.S; Reatto, A.; Farias, M.F.R; Silva, A.V.; Bloise, G.L.F.; Cardoso, E.A. (2002). Geologia da margem direita do Córrego Divisa, Bacia do São Bartolomeu -DF, escala 1:10.000. Planaltina: Embrapa Cerrados. 21 p.

Martínez-Carreras, N.; Wetzel, C.E.; Frentress, J.; Ector, L.; McDonnell, J.J.; Hoffmann, L.; Pfister, L. (2015). Hydrological connectivity inferred from diatom transport through the riparian-stream system. Hydrol. Earth Syst. Sci., v. 19, p. 3133-3151.

Matthews, S. (2010). Effect of drying temperature on fuel moisture content measurements. International Journal of Wildland Fire, v. 19, p. 800-802.

Mazac, O.; Kelly, W.E.; Landa, I. (1987). Surface geoelectrics for groundwater pollution and protection studies. J. Hydrol., v. 93, p. 277-294.

McMillan, H.K.; Srinivassan, M.S. (2015). Characteristics and controls of variability in soil moisture and groundwater in a headwater catchment. Hydrol. Earth Syst. Sci., v. 19, p. 1767-1786. 
Menziani, M.; Rivasi, M.R.; Pugnaghi, S.; Santangelo, R.; Vicenzi, S. (1996). Soil volumetric water contente measurements using TDR technique, Annali di Geofisica, v. 40, n. 1, p. 91-96.

Michot, D.; Benderitter, Y.; Doringny, A.; Nicoullaud, B.; King, D.; Tabbagh, A. (2003). Spatial and temporal monitoring of soil water content with an irrigated corn crop cover using surface electrical resistivity tomography. Water Resources Research, v. 39, n. 5, 20 p.

Mierzwa, J. C.; Hespanhol, I. (2005). Água na indústria: uso racional e reuso. São Paulo: Oficina de textos. 143p.

Miller, G.T. (2008). Ciência ambiental. São Paulo: Cenagage Learning, 11 ed., 592 p.

Monte-Mor, R.C.A.; Palmier, L.R.; Pinto, E.J.A.; Lima, J.E.S. (2012). Estabilidade Temporal da Distribuição Espacial da Umidade do Solo em uma Bacia Intermitente no Semiárido de Minas Gerais. Revista Brasileira de Recursos Hídricos, v. 17, n.3, p. 101-113.

Moraes, L. L.; Campos, J. E. G. (2008). Hidrogeologia. In: Fonseca, F. O. (Org.). Águas Emendadas. Brasília: Secretaria de Desenvolvimento Urbano e Meio Ambiente. p. 122-131.

Moreira, C.A.; Cavalheiro, M.L.D.; Pereira, A.M.; Caron, F. (2012). Relações entre condutividade hidráulica, transmissividade, condutância longitudinal e sólidos totais dissolvidos para o aquífero livre de Caçapava do Sul (RS), Brasil. Eng. Sanit. Ambient. v. 17, n. 2, p. 193-202.

Mousinho, D.S. (2012). Simulação numérica do fluxo hídrico subterrâneo na bacia hidrográfica do rio Pitimbu - RN. Rio Grande do Norte: Centro de Tecnologia. Universidade Federal do Rio Grande do Norte, Dissertação de Mestrado. 100 p.

Mualem, Y. (1976). A new model for predicting the hydraulic conductivity of unsaturated porous media. Water Resources Research, v. 12, p. 513-522.

Musgrave, H.; Binley, A. (2011). Revealing the temporal dynamics of subsurface temperature in a wetland using time-lapse geophysics. Journal of Hydrology, v. 396, p. 258-266.

Naiman, R.J.; Décamps, H. (1997). The ecology of interfaces: riparian zones. Annu. Rev. Ecol. Syst, n. 28, p. 621-658.

Naiman, R.J.; Décamps, H.; McClain, M.E (2005). Riparian: Ecology, Conservation, and Management of Streamside Communities. UK: Elsevier. 446 p.

Nascimento, C.T.C.; Varella, R.F.; Pires, A.C.B.; Santos, R.V. (2001). Valores de Resistividade Elétrica em um Latossolo do Distrito Federal. In: Congresso Internacional da Sociedade Brasileira de Geofísica, 7. Anais... Bahia: Sociedade Brasileira de Geofísica.

Nascimento, C.T.C.; Pires, A.C.B.; Moraes, R.A.V. (2004). Reconhecimento de solos por meio de resistividade elétrica e radiação gama. Revista Brasileira de Geociências, Brasil, v. 34, n. 3, p. 383-392.

Neves, A.V.B.; Luiz, J.G. (2015). Estimativa da velocidade de fluxo subterrâneo por imageamento elétrico. Águas Subterrâneas, v. 29, n. 1, p. 104-115.

Nusret, D.; Dug, S. (2012). Applying the inverse distance weighting and kriging methods of the spatial interpolation on the mapping the annual precipitation in Bosnia and Herzegovina. In: International Congress on Environmental Modeling and Software, Anais... Germany, 7 p.

Nyquist, J.E.; Freyer, P.A.; Toran, L. (2008). Stream bottom resistivity tomography to map ground-water discharge. Ground Water, v. 46, n 4, p 561-569.

Olasehinde, P.L.; Amandi, A.N.; Idris-Nda, A.; Katu, M.J.; Unuevho, C.L.; Jimoh, M.O. (2015). Aquifers characterization in Agaie, North-Central Nigeria using 
electrical resistivity method and borehole lithologs. American Journal of Environmental Protection, v. 3, n. 3, p. 60-66.

Osman, K.T. (2013). Soils: principles, properties and management. London: Springer. $295 \mathrm{p}$.

Orellana, E. (1972). Prospeccion Geoelectrica en Corriente Continua. Madrid, Paraninfo. $523 \mathrm{p}$.

Plattner, A.; Maurer, H.R.; Vorloeper, J.; Dahmen, W. (2010). Three-dimensional geoelectric modelling with optimal work/accuracy rate using an adaptive wavelet algorithm. Geophys. J. Int., v. 182, p. 741-752.

Porciúncula, R.J.; Lima, O. A.L. (2012). Geoelectric evaluation of subsurface contamination at a gas and service station, Alagoinhas, BA, Brazil. Revista Brasileira de Geofísica, v. 30, n. 2, p. 201-212.

Poulsen, J.R.; Sebok, E.; Duque, C.; Tetzlaff, D.; Engesgaard, P.K. (2015). Detecting groundwater discharge dynamics from point-to-catchment scale in a lowland stream: combining hydraulic and tracer methods. Hydrol. Earth Syst. Sci., v. 19, p. 1871-1886.

Rabelo-Coelho, V.H.; Almeida, C.N.; Silans, A.,.B.P. (2012). Análise da Flutuação do Nível D'água para Estimativa da Recarga Subterrânea da Bacia Representativa do Rio Gramame no Nordeste Brasileiro. Revista Brasileira de Recursos Hídricos, v. 17, n.2, p. 241-252.

Reatto, A.; Martins, E.S.; Farias, M.F.R.; Silva, A.V.; Carvalho, O.A.J. (2004). Mapa pedológico digital - SIG atualizado do DF escala 1:100.000 e uma síntese do texto explicativo. Planaltina: Embrapa Cerrados. 31 p.

Rebouças, C.A. (2006b). Águas Subterrâneas. In: Rebouças, A.C.; Braga, B.; Tundisi, J.G (Org.). Águas Doces no Brasil: Capital Ecológico, Uso e Conservação. 3 ed. São Paulo: Escrituras. p. 111-144.

Ren, Z.; Tang, J. (2014). A goal-oriented adaptive finite-element approach for multielectrode resistivity system. Geophys. J. Int., v. 199, p. 136-145.

Reeves, T.L.; Smith, M.A. (1992). Time domain reflectometry for measuring soil water content in range surveys. J. Range Manage., v. 45, p. 412-414.

Reynolds, J.M. (1997). An introduction to applied and environmental geophysics. New York: John Wiley \& Sons. 799 p.

Richards, L.A. (1931). Capillary conduction of liquids trough porous media. Physics, v. 1, p. 318-33.

Ritz, W. (1908). Über eine neue Methode zur Lösung gewisser Variationsprobleme der mathematischen Physik. Journal für die Reine und Angewandte Mathematik, v. 135, p. 1-61.

Rodhe, A.; Sibert, J. (2011). Groundwater dynamics in a till hillslope: flow directions, gradients and delay. Hydrol. Process., v. 25, p. 1899-1909.

Rodriguez, L.B.; Cello, A.P.; Vionnet, C.A.; Goodrich, D. (2008). Fully conservative coupling of HEC-RAS with MODFLOW to simulate stream-aquifer interactions in a drainage basin. Journal of Hydrology, v. 353, p. 129- 142.

Rushton, K.R. (2003). Groundwater Hydrology: Conceptual and Computational Models. UK: Wiley. 433 p.

Santos, H.G.; Jacomine, P.K.T.; Anjos, L.H.C.; Oliveira, V.A.; Lumbreras, J.F.; Rizzato, M.C.; Almeida, J.A.; Cunha, T.J.F.; Oliveira, J.B. (2013). Sistema Brasileiro de Classificação de Solos. Brasília: EMBRAPA. 353 p.

Sarkar, R.; Dutta, S. (2015). Parametric study of a physically-based, plotscale hillslope hydrological model through virtual experiments. Hydrological Sciences Journal, v. 60, n. 3 . 
Schunk, C. Ruth, B.; Leuchner, M.; Wastl, C.; Menzel, A. (2016). Comparison of different methods for the in situ measurement of forest litter moisture content. Nat. Hazards Earth Syst. Sci., v. 16, p. 403-415.

Secretaria de Estado de Gestão do Territorio e Habitação - SEDHAB. (2009). Ortofotocartas SICAD $n^{\circ}$ 184, 185, 200 e 201. 200. Disponível em: < http://www.sedhab.df.gov.br/mapas_sicad/index_sirgas.htm>. Acesso em: 09 mar. 2015.

Selby, M.J. (2005). Hillslope Materials and Processes. UK: Oxford University Press. $480 \mathrm{p}$.

Sheriff, R.E. (2002). Encyclopedic Dictionary of Applied Geophysics: Society of Exploration Geophysicist. Geophysical References Series, Fourth Edition. 429 p.

Silva, L.C. (2003). Análise estatística das características de vazão do córrego Capetinga. Revista Brasileira de Engenharia Agrícola e Ambiental, v.7, n.2, p.311-317.

Silva, R.W.C.; Malagutti-Filho, W. (2010). Emprego do imageamento elétrico no estudo da contaminação por cemitérios. Geociências, v. 29, n. 3, p. 343-354.

Singha, K.; Day-Lewis, F.D.; Johnson, T.; Slater, L.D. (2015). Advances in interpretation of subsurface processes with time-lapse electrical imaging. Hydrol. Process., v. 29, p. 1549-1576.

Solberg, I.L.; Hansen, L.; Ronning, J.S.; Haugen, E.D.; Dalsegg, E.; Tonnesen, J.F. (2012). Combined geophysical and geotechnical approach to ground investigations and hazard zonation of a quick clay area, mid Norway. Bull Eng Geol Environ, v. 71, p. 119-133.

Souza, M.T.; Campos, J.E.G. (2001). O papel dos regolitos nos processos de recarga de aquíferos do Distrito Federal. Revista Escola de Minas, v. 54, n. 3, 11 p.

Steinich, B.; Marin, L.E. (1996). Hydrogeological investigations in northwestern Yucatan, Mexico, using resistivity surveys. Ground Water, v. 34, n. 4, p. 640646.

Távora, B.E. (2016). Zona ripária de Cerrado: Processos hidrológicos e influência na qualidade da água. Brasília: Faculdade de Tecnologia, Universidade de Brasília, Tese de Doutorado em elaboração.

Teixeira, W.; Fairchild, T. R.; Toledo, M.C.; Taioli, F. (Org.). (2008). Decifrando a Terra. São Paulo: Companhia Editora Nacional, 623 p.

Telford, W. M.; Geldart, L. P.; Sheriff, R.E. (1990). Applied Geophysics. Cambridge University Press, Cambridge. $771 \mathrm{p}$.

Thornthwaite, C.W. (1948). An Approach toward a Rational Classification of Climate. Geographical Review, v. 38, n. 1, p. 5594.

Topp, G.C.; Davis, J.L.; Annan, A.P. (1980). Electromagnetic Determination of soil water Content: measurements in coaxial transmission lines. Water Resources Research, v. 16, n. 3, p. 574-582.

Tucci, C.E.M. (1998). Modelos Hidrológicos. Porto Alegre: Ed. Universidade/UFRGS/ABRH. 669 p.

Universidade de Brasília - UnB. (2009). Histórico da Fazenda Água Limpa. Disponível em:

http://www.fal.unb.br/index.php?option=com_content\&view=article\&id=51:hist orico\&catid=35:fazenda-agua-limpa\&Itemid=61>. Acesso em: 28 mai. 2015 .

van Genuchten, M.T. (1980). A closed form equation for predicting the hydraulic conductivity of unsaturated soils. Soil Sci. Soc. Am. J., v. 44, p. 892-898.

Vidon, P.G.F.; Hill, A.R. (2004). Landscape controls on the hydrology of stream riparian zones. Journal of Hydrology, v. 292, p. 210-228. 
von Freyberg, J.V.; Radny, D.; Gall, H.E.; Schirmer, M. (2014). Implications of hydrologic connectivity between hillslopes and riparian zones on streamflow composition. Journal of Contaminant Hydrology, v. 169, p. 62-74.

von Freyberg, J.; Suresh, P.; Rao, C.; Radny, D.; Schirmer, M. (2015). The impact of hillslope groundwater dynamics and landscape functioning in event-flow generation: a field study in the Rietholzbach catchment, Switzerland. Hydrogeology Journal, v. 23, n. 5, 14 p.

Wang, H.F.; Anderson, M.P. (1982). Introduction of ground-water modeling: finite difference and finite element methods. San Francisco: W.H. Freeman and Company, $237 \mathrm{p}$.

Ward, A.S.; Gooseff, M.N.; Fitzgerald, M.; Voltz, T.J; Singha, K. (2014). Spatially distributed characterization of hyporheic solute transport during baseflow recession in a headwater mountain stream using electrical geophysical imaging. Journal of Hydrology, v. 517, p. 362-377.

Wennigar, J.; Uhlenbrook, S.; Lorentz, S.; Christian, L. (2008). Identification of runoff generation processes using combined hydrometric, tracer and geophysical methods in a headwater catchment in South Africa. Hydrological Sciences Journal des Sciences Hydrologiques, n. 53, p. 65-80.

White, I.; Zegelin, S.J. (2000). Electric and Dielectric Methods for Monitoring SoilWater Content. In: Wilson, L.G.; Everett, L.G.; Cullen, S.J. Handbook of Vadose Zone Characterization e Monitoring. EUA: Lewis Publishers. 730 p.

Wienhofer, J.; Germer, K.; Lindenmaier, F.; Farber, A.; Zehe, E. (2009). Applied tracers for the observation of subsurface stormflow at the hillslope scale. Hydrol. Earth Syst. Sci., v. 13, p. 1145-1161.

Wilson, L.G.; Everett, L.G.; Cullen, S.J. (2000). Handbook of Vadose Zone Characterization e Monitoring. EUA: Lewis Publishers. 730 p.

Wrobel, L.C. (1989). Introdução aos métodos numéricos. In: Wrobel, L.C.; Eiger, S.; Rosman, P.C.; Tucci, C.E.; Cirillo, J.A.; Cabral, J.P. Métodos numéricos em recursos hídricos. Rio de Janeiro: ABRH. 380 p.

Wunderlich, T.; Wilken, D.; Andersen, J.; Rabbel, W.; Zori, D.; Kalmring, S.; Byock, J. (2015). On the Ability of Geophysical Methods to Image Medieval Turf Buildings in Iceland. Archaeol. Prospect, 16 p.

Yeboah-Forson, A.; Whitman, D. (2014). Electrical Resistivity Characterization of Anisotropy in the Biscayne Aquifer. Groundwater, v. 52, n. 5, p. 728-736.

Yeh, T.C.J.; Guzman-Guzman, A. Tensiometry. In: Wilson, L.G.; Everett, L.G.; Cullen, S.J. (2000). Handbook of Vadose Zone Characterization e Monitoring. EUA: Lewis Publishers. 730 p.

Zarroca, M; Linares, R.; Rodellas, V.; Garcia-Orellana, J.; Roqué, C.; Bach, J.; Masqué, P. (2014). Delineating coastal groundwater discharge processes in a wetland area by means of electrical resistivity imaging, 224Ra and $222 \mathrm{Rn}$. Hydrological Processes, v. 28, p. $2382-2395$.

Zheng, C. (2011). Reflections: 2002-2010. Ground Water, v. 49, n. 2, p. 129-132.

Zoby, J.L.G.; Duarte, U. (2001). Caracterização hidrogeológica da bacia do Ribeirão Sobradinho - Brasília (DF). Revista do Instituto de Geociências, USP, v. 1, p. 79-99. 
APÊNDICE 


\section{APÊNDICE A - ANÁLISE DESCRITIVA DOS VALORES DE RESISTIVIDADE CALCULADOS A PARTIR DO PROCESSO DE INVERSÃO}

As tabelas a seguir apresentam mediana, máximo e mínimo (entre parênteses) dos valores de resistividade $(\Omega, \mathrm{m})$ das seções geoelétricas $A, B, C, D, E$ e $F$. Ao longo das linhas da tabela estão contidos os valores de resistividade de cada profundidade em cada semana, sendo que na última coluna, denominada Semanas, é possível verificar os valores de mediana/máximo-mínimo das nove semanas para cada profundidade. A visualização das colunas fornece uma análise descritiva das diferentes profundidades numa mesma semana. A linha intitulada Seção descreve todas as profundidades em cada semana. A última linha de cada grupo (Total) considera os valores de resistividade da seção completa, nas nove semanas de levantamento geofísico. 


\begin{tabular}{|c|c|c|c|c|c|c|c|c|c|c|c|}
\hline \multirow{2}{*}{ Seção } & \multirow{2}{*}{$\begin{array}{c}\text { Profundidade } \\
\text { (m) }\end{array}$} & \multicolumn{10}{|c|}{ Semana } \\
\hline & & $1(n=76)$ & $2(n=76)$ & $3(n=76)$ & $4(n=76)$ & $5(n=76)$ & $6(n=76)$ & $7(n=76)$ & $8(n=76)$ & $9(n=76)$ & Semanas* \\
\hline \multirow{8}{*}{$A$} & $5(n=17)$ & $\begin{array}{c}3677(4123 \\
-2944)\end{array}$ & $\begin{array}{c}3182(4321 \\
-2334)\end{array}$ & $\begin{array}{c}3789(5137 \\
-2898)\end{array}$ & $\begin{array}{l}4533(5650 \\
-3779)\end{array}$ & $\begin{array}{c}3727(4656 \\
-3412)\end{array}$ & $\begin{array}{l}5424(7728 \\
-4411)\end{array}$ & $\begin{array}{l}4143(5001 \\
-3134)\end{array}$ & $\begin{array}{l}4744(5578 \\
-3733)\end{array}$ & $\begin{array}{c}3699(4747 \\
-2985)\end{array}$ & $\begin{array}{c}4094(7728 \\
-2334)\end{array}$ \\
\hline & $10(n=17)$ & $\begin{array}{c}3677(4204 \\
-3053)\end{array}$ & $\begin{array}{c}3180(4351 \\
-2417)\end{array}$ & $\begin{array}{c}3766(4814 \\
-2947)\end{array}$ & $\begin{array}{l}4448(5315 \\
-3525)\end{array}$ & $\begin{array}{c}3605(4542 \\
-3393)\end{array}$ & $\begin{array}{c}5425(6184 \\
-4418)\end{array}$ & $\begin{array}{l}4085(6540 \\
-3096)\end{array}$ & $\begin{array}{l}4322(5276 \\
-3755)\end{array}$ & $\begin{array}{c}3687(4742 \\
-3024)\end{array}$ & $\begin{array}{c}3881(6540 \\
-2417)\end{array}$ \\
\hline & $15(n=15)$ & $\begin{array}{c}3379(4456 \\
-3167)\end{array}$ & $\begin{array}{c}3184(4431 \\
-2636)\end{array}$ & $\begin{array}{c}3448(4463 \\
-2954)\end{array}$ & $\begin{array}{c}3444(3768 \\
-3366)\end{array}$ & $\begin{array}{c}3473(3842 \\
-3392)\end{array}$ & $\begin{array}{c}3663(5443 \\
-2993)\end{array}$ & $\begin{array}{c}3068(4628 \\
-2822)\end{array}$ & $\begin{array}{c}4089(4765 \\
-2988)\end{array}$ & $\begin{array}{c}3628(4692 \\
-3295)\end{array}$ & $\begin{array}{c}3480(5443 \\
-2636)\end{array}$ \\
\hline & $21(n=13)$ & $\begin{array}{l}3322(4520 \\
-3245)\end{array}$ & $\begin{array}{l}3195(4631 \\
-2710)\end{array}$ & $\begin{array}{l}2971(4615 \\
-2873)\end{array}$ & $\begin{array}{c}3385(3764 \\
-2605)\end{array}$ & $\begin{array}{c}3492(3749 \\
-3214)\end{array}$ & $\begin{array}{c}2707(5427 \\
-2199)\end{array}$ & $\begin{array}{l}2955(4728 \\
-2203)\end{array}$ & $\begin{array}{c}3783(4652 \\
-2950)\end{array}$ & $\begin{array}{c}3404(8254 \\
-3229)\end{array}$ & $\begin{array}{c}3367(8254 \\
-2199)\end{array}$ \\
\hline & $28(n=9)$ & $\begin{array}{l}3324(4496 \\
-3236)\end{array}$ & $\begin{array}{l}4149(5340 \\
-3216)\end{array}$ & $\begin{array}{c}2899(5362 \\
-2852)\end{array}$ & $\begin{array}{c}3562(3869 \\
-2396)\end{array}$ & $\begin{array}{c}3869(4139 \\
-3155)\end{array}$ & $\begin{array}{l}2802(4831 \\
-2531)\end{array}$ & $\begin{array}{l}2930(5205 \\
-2128)\end{array}$ & $\begin{array}{c}3490(4374 \\
-3373)\end{array}$ & $\begin{array}{c}3675(8037 \\
-3334)\end{array}$ & $\begin{array}{c}3490(8037 \\
-2128)\end{array}$ \\
\hline & $35(n=5)$ & $\begin{array}{l}4346(4488 \\
-3271)\end{array}$ & $\begin{array}{c}5632(5686 \\
-4171)\end{array}$ & $\begin{array}{c}5589(5807 \\
-3395)\end{array}$ & $\begin{array}{c}4415(4427 \\
-3428)\end{array}$ & $\begin{array}{c}4683(4698 \\
-3497)\end{array}$ & $\begin{array}{c}4193(4427 \\
-3029)\end{array}$ & $\begin{array}{c}5119(5321 \\
-2737)\end{array}$ & $\begin{array}{l}4290(4385 \\
-3520)\end{array}$ & $\begin{array}{c}4944(7539 \\
-4344)\end{array}$ & $\begin{array}{c}4415(7539 \\
-2737)\end{array}$ \\
\hline & $\operatorname{Seção~}(n=76)$ & $\begin{array}{c}3625(4520 \\
-2944)\end{array}$ & $\begin{array}{c}3235(5686 \\
-2334)\end{array}$ & $\begin{array}{c}3469(5807 \\
-2852)\end{array}$ & $\begin{array}{c}3766(5650 \\
-2396)\end{array}$ & $\begin{array}{c}3602(4698 \\
-3155)\end{array}$ & $\begin{array}{l}4595(7728 \\
-2199)\end{array}$ & $\begin{array}{c}3595(6540 \\
-2128)\end{array}$ & $\begin{array}{c}4248(5578 \\
-2950)\end{array}$ & $\begin{array}{c}3673(8254 \\
-2985)\end{array}$ & \\
\hline & Total $(n=684)$ & & & & & 3728 & $4-2128)$ & & & & \\
\hline
\end{tabular}

*Para cada seção geoelétrica foram levantados 76 valores de resistividade $(n=76)$, considerando todas as profundidades de monitoramento, a cada semana. Com isso, foi obtido um conjunto amostral de 684 medições ao longo de nove semanas, exceto para as seções B e D (n=608), que não foram monitoradas na terceira semana. 


\begin{tabular}{|c|c|c|c|c|c|c|c|c|c|c|c|}
\hline \multirow{2}{*}{ Seção } & \multirow{2}{*}{$\begin{array}{c}\text { Profundidade } \\
(\mathbf{m})\end{array}$} & \multicolumn{10}{|c|}{ Semana } \\
\hline & & $1(n=76)$ & $2(n=76)$ & $3(n=76)$ & $4(n=76)$ & $5(n=76)$ & $6(n=76)$ & $7(n=76)$ & $8(n=76)$ & $9(n=76)$ & Semanas* \\
\hline \multirow{8}{*}{$B$} & $5(n=17)$ & $\begin{array}{l}4956(7205 \\
-3748)\end{array}$ & $\begin{array}{l}4302(5213 \\
-2180)\end{array}$ & - & $\begin{array}{c}4246(6961 \\
-3880)\end{array}$ & $\begin{array}{l}4355(5761 \\
-3162)\end{array}$ & $\begin{array}{c}6667(7470 \\
-4150)\end{array}$ & $\begin{array}{l}4596(5841 \\
-3162)\end{array}$ & $\begin{array}{c}3844(5899 \\
-2190)\end{array}$ & $\begin{array}{l}4358(5505 \\
-2560)\end{array}$ & $\begin{array}{c}4246(7470 \\
-2180)\end{array}$ \\
\hline & $10(n=17)$ & $\begin{array}{c}4840(6990 \\
-3662)\end{array}$ & $\begin{array}{c}4164(5086 \\
-2211)\end{array}$ & - & $\begin{array}{c}3976(6803 \\
-3722)\end{array}$ & $\begin{array}{c}4332(5683 \\
-3174)\end{array}$ & $\begin{array}{c}5791(6816 \\
-4114)\end{array}$ & $\begin{array}{c}4520(5757 \\
-3198)\end{array}$ & $\begin{array}{c}3844(5897 \\
-2246)\end{array}$ & $\begin{array}{l}4392(5502 \\
-2566)\end{array}$ & $\begin{array}{l}4121(6990 \\
-2211)\end{array}$ \\
\hline & $15(n=15)$ & $\begin{array}{c}4670(5443 \\
-3464)\end{array}$ & $\begin{array}{c}3695(4472 \\
-3141)\end{array}$ & - & $\begin{array}{c}3753(4775 \\
-2754)\end{array}$ & $\begin{array}{l}3771(5155 \\
-3217)\end{array}$ & $\begin{array}{l}3255(5948 \\
-3052)\end{array}$ & $\begin{array}{l}3495(4796 \\
-3273)\end{array}$ & $\begin{array}{c}3925(5872 \\
-2296)\end{array}$ & $\begin{array}{l}4316(5527 \\
-2625)\end{array}$ & $\begin{array}{c}3650(5948 \\
-2296)\end{array}$ \\
\hline & $21(n=13)$ & $\begin{array}{l}4270(5202 \\
-3018)\end{array}$ & $\begin{array}{l}3526(4266 \\
-3252)\end{array}$ & - & $\begin{array}{c}3380(3946 \\
-2694)\end{array}$ & $\begin{array}{c}3300(4720 \\
-3136)\end{array}$ & $\begin{array}{c}2859(4861 \\
-2698)\end{array}$ & $\begin{array}{l}3318(4541 \\
-3072)\end{array}$ & $\begin{array}{c}4325(7196 \\
-2935)\end{array}$ & $\begin{array}{c}3776(8279 \\
-3202)\end{array}$ & $\begin{array}{c}3382(8279 \\
-2694)\end{array}$ \\
\hline & $28(n=9)$ & $\begin{array}{c}2443(3229 \\
-2190)\end{array}$ & $\begin{array}{c}3196(3726 \\
-3112)\end{array}$ & - & $\begin{array}{c}3414(3569 \\
-2825)\end{array}$ & $\begin{array}{c}2996(3282 \\
-2898)\end{array}$ & $\begin{array}{c}2978(3006 \\
-2950)\end{array}$ & $\begin{array}{c}3304(3522 \\
-3039)\end{array}$ & $\begin{array}{c}3662(8132 \\
-3270)\end{array}$ & $\begin{array}{l}3516(6560 \\
-3159)\end{array}$ & $\begin{array}{c}3159(8132 \\
-2190)\end{array}$ \\
\hline & $35(n=5)$ & $\begin{array}{c}2295(2363 \\
-2057)\end{array}$ & $\begin{array}{c}2945(3757 \\
-2937)\end{array}$ & - & $\begin{array}{c}3436(3458 \\
-3229)\end{array}$ & $\begin{array}{c}2832(3342 \\
-2799)\end{array}$ & $\begin{array}{c}3018(3160 \\
-2998)\end{array}$ & $\begin{array}{c}3063(3366 \\
-3047)\end{array}$ & $\begin{array}{c}3635(8131 \\
-3235)\end{array}$ & $\begin{array}{c}3262(3836 \\
-3056)\end{array}$ & $\begin{array}{c}3053(8131 \\
-2057)\end{array}$ \\
\hline & $\operatorname{Seção~}(n=76)$ & $\begin{array}{l}4340(7205 \\
-2057)\end{array}$ & $\begin{array}{l}3505(5213 \\
-2180)\end{array}$ & - & $\begin{array}{c}3883(6961 \\
-2694)\end{array}$ & $\begin{array}{c}3438(5761 \\
-2799)\end{array}$ & $\begin{array}{c}4120(7470 \\
-2698)\end{array}$ & $\begin{array}{l}3444(5841 \\
-3039)\end{array}$ & $\begin{array}{c}3948(8132 \\
-2190)\end{array}$ & $\begin{array}{c}3836(8279 \\
-2560)\end{array}$ & \\
\hline & Total $(n=608)$ & \multicolumn{10}{|c|}{$3588(8279-2057)$} \\
\hline
\end{tabular}

*Para cada seção geoelétrica foram levantados 76 valores de resistividade $(n=76)$, considerando todas as profundidades de monitoramento, a cada semana. Com isso, foi obtido um conjunto amostral de 684 medições ao longo de nove semanas, exceto para as seções B e D (n=608), que não foram monitoradas na terceira semana. 


\begin{tabular}{|c|c|c|c|c|c|c|c|c|c|c|c|}
\hline \multirow{2}{*}{ Seção } & \multirow{2}{*}{$\begin{array}{c}\text { Profundidade } \\
\text { (m) }\end{array}$} & \multicolumn{5}{|c|}{ Semana } & \multicolumn{5}{|c|}{ Semana } \\
\hline & & $1(n=76)$ & $2(n=76)$ & $3(n=76)$ & $4(n=76)$ & $5(n=76)$ & $6(n=76)$ & $7(n=76)$ & $8(n=76)$ & $9(n=76)$ & Semanas* \\
\hline \multirow{8}{*}{$C$} & $5(n=17)$ & $\begin{array}{c}3859(7202 \\
-3395)\end{array}$ & $\begin{array}{l}4878(8008 \\
-3736)\end{array}$ & $\begin{array}{c}5236(8198 \\
-4088)\end{array}$ & $\begin{array}{c}5768(8429 \\
-4640)\end{array}$ & $\begin{array}{c}5623(8912 \\
-3592)\end{array}$ & $\begin{array}{c}6245(9031 \\
-4869)\end{array}$ & $\begin{array}{c}5711(9031 \\
-5062)\end{array}$ & $\begin{array}{l}4802(7635 \\
-3648)\end{array}$ & $\begin{array}{l}4494(6158 \\
-3570)\end{array}$ & $\begin{array}{c}5329(9031 \\
-3395)\end{array}$ \\
\hline & $10(n=17)$ & $\begin{array}{c}3874(7202 \\
-3395)\end{array}$ & $\begin{array}{c}4607(8008 \\
-3736)\end{array}$ & $\begin{array}{l}5223(8198 \\
-4088)\end{array}$ & $\begin{array}{c}5193(8429 \\
-4640)\end{array}$ & $\begin{array}{c}5473(8912 \\
-3592)\end{array}$ & $\begin{array}{l}5745(9031 \\
-4869)\end{array}$ & $\begin{array}{c}5374(9031 \\
-5062)\end{array}$ & $\begin{array}{l}4797(7635 \\
-3648)\end{array}$ & $\begin{array}{l}4488(6158 \\
-3570)\end{array}$ & $\begin{array}{c}4113(7920 \\
-3490)\end{array}$ \\
\hline & $15(n=15)$ & $\begin{array}{l}3805(7202 \\
-3395)\end{array}$ & $\begin{array}{l}4004(8008 \\
-3736)\end{array}$ & $\begin{array}{l}3823(8198 \\
-4088)\end{array}$ & $\begin{array}{c}4376(8429 \\
-4640)\end{array}$ & $\begin{array}{c}3817(8912 \\
-3592)\end{array}$ & $\begin{array}{l}4044(9031 \\
-4869)\end{array}$ & $\begin{array}{c}3909(9031 \\
-5062)\end{array}$ & $\begin{array}{l}4425(7635 \\
-3648)\end{array}$ & $\begin{array}{l}4576(6158 \\
-3570)\end{array}$ & $\begin{array}{l}4124(6118 \\
-3178)\end{array}$ \\
\hline & $21(n=13)$ & $\begin{array}{c}3698(7202 \\
-3395)\end{array}$ & $\begin{array}{l}3548(8008 \\
-3736)\end{array}$ & $\begin{array}{c}3476(8198 \\
-4088)\end{array}$ & $\begin{array}{c}4126(8429 \\
-4640)\end{array}$ & $\begin{array}{c}3164(8912 \\
-3592)\end{array}$ & $\begin{array}{c}3066(9031 \\
-4869)\end{array}$ & $\begin{array}{c}3167(9031 \\
-5062)\end{array}$ & $\begin{array}{c}4137(7635 \\
-3648)\end{array}$ & $\begin{array}{l}4386(6158 \\
-3570)\end{array}$ & $\begin{array}{c}3630(5441 \\
-2272)\end{array}$ \\
\hline & $28(n=9)$ & $\begin{array}{c}3389(7164 \\
-3395)\end{array}$ & $\begin{array}{c}2378(6654 \\
-3736)\end{array}$ & $\begin{array}{c}2384(7445 \\
-4088)\end{array}$ & $\begin{array}{c}2776(7315 \\
-4640)\end{array}$ & $\begin{array}{c}2360(7620 \\
-3592)\end{array}$ & $\begin{array}{l}2511(8100 \\
-4869)\end{array}$ & $\begin{array}{l}2324(7686 \\
-5062)\end{array}$ & $\begin{array}{c}2908(6507 \\
-3648)\end{array}$ & $\begin{array}{l}4058(6144 \\
-3570)\end{array}$ & $\begin{array}{l}2509(4871 \\
-2103)\end{array}$ \\
\hline & $35(n=5)$ & $\begin{array}{l}2891(7164 \\
-3395)\end{array}$ & $\begin{array}{c}2177(6654 \\
-3736)\end{array}$ & $\begin{array}{l}2169(7445 \\
-4088)\end{array}$ & $\begin{array}{l}2490(7315 \\
-4640)\end{array}$ & $\begin{array}{c}1978(7620 \\
-3592)\end{array}$ & $\begin{array}{l}2189(8100 \\
-4869)\end{array}$ & $\begin{array}{c}2263(7686 \\
-5062)\end{array}$ & $\begin{array}{c}2688(6507 \\
-3648)\end{array}$ & $\begin{array}{c}3130(6144 \\
-3570)\end{array}$ & $\begin{array}{c}2381(4019 \\
-1969)\end{array}$ \\
\hline & $\operatorname{Seção~}(n=76)$ & $\begin{array}{c}3782(7164 \\
-3395)\end{array}$ & $\begin{array}{l}4155(6654 \\
-3736)\end{array}$ & $\begin{array}{l}4164(7445 \\
-4088)\end{array}$ & $\begin{array}{c}5037(7315 \\
-4640)\end{array}$ & $\begin{array}{c}4535(7620 \\
-3592)\end{array}$ & $\begin{array}{l}4818(8100 \\
-4869)\end{array}$ & $\begin{array}{l}4998(7686 \\
-5091)\end{array}$ & $\begin{array}{l}4513(6507 \\
-3648)\end{array}$ & $\begin{array}{l}4445(6144 \\
-3570)\end{array}$ & \\
\hline & Total $(n=684)$ & & & & & $4404(903$ & 1 - 1969) & & & & \\
\hline
\end{tabular}

*Para cada seção geoelétrica foram levantados 76 valores de resistividade $(n=76)$, considerando todas as profundidades de monitoramento, a cada semana. Com isso, foi obtido um conjunto amostral de 684 medições ao longo de nove semanas, exceto para as seções B e D ( $n=608)$, que não foram monitoradas na terceira semana. 


\begin{tabular}{|c|c|c|c|c|c|c|c|c|c|c|c|}
\hline \multirow{2}{*}{ Seção } & \multirow{2}{*}{$\begin{array}{c}\text { Profundidade } \\
(\mathbf{m})\end{array}$} & \multicolumn{10}{|c|}{ Semana } \\
\hline & & $1(n=76)$ & $2(n=76)$ & $3(n=76)$ & $4(n=76)$ & $5(n=76)$ & $6(n=76)$ & $7(n=76)$ & $8(n=76)$ & $9(n=76)$ & Semanas* \\
\hline \multirow{8}{*}{$D$} & $5(n=17)$ & $\begin{array}{l}4524(6177 \\
-3554)\end{array}$ & $\begin{array}{c}4479(5187 \\
-3543)\end{array}$ & - & $\begin{array}{c}4749(6296 \\
-3719)\end{array}$ & $\begin{array}{c}4773(6760 \\
-3026)\end{array}$ & $\begin{array}{c}4948(7187 \\
-3660)\end{array}$ & $\begin{array}{l}4994(6545 \\
-3189)\end{array}$ & $\begin{array}{l}4528(6412 \\
-3203)\end{array}$ & $\begin{array}{c}3681(4266 \\
-3063)\end{array}$ & $\begin{array}{c}4403(7187 \\
-3026)\end{array}$ \\
\hline & $10(n=17)$ & $\begin{array}{c}4482(6177 \\
-3554)\end{array}$ & $\begin{array}{c}4252(5187 \\
-3543)\end{array}$ & - & $\begin{array}{c}4220(6296 \\
-3719)\end{array}$ & $\begin{array}{l}4402(6760 \\
-3026)\end{array}$ & $\begin{array}{c}4578(7187 \\
-3660)\end{array}$ & $\begin{array}{c}4378(6545 \\
-3189)\end{array}$ & $\begin{array}{c}4220(6412 \\
-3203)\end{array}$ & $\begin{array}{c}3669(4266 \\
-3063)\end{array}$ & $\begin{array}{l}4198(6501 \\
-3122)\end{array}$ \\
\hline & $15(n=15)$ & $\begin{array}{c}2935(6177 \\
-3554)\end{array}$ & $\begin{array}{c}2965(5187 \\
-3543)\end{array}$ & - & $\begin{array}{c}3699(6296 \\
-3719)\end{array}$ & $\begin{array}{c}3119(6760 \\
-3026)\end{array}$ & $\begin{array}{c}3486(7187 \\
-3660)\end{array}$ & $\begin{array}{l}3332(6545 \\
-3189)\end{array}$ & $\begin{array}{c}3400(6412 \\
-3203)\end{array}$ & $\begin{array}{l}3571(4266 \\
-3063)\end{array}$ & $\begin{array}{c}3287(4248 \\
-2559)\end{array}$ \\
\hline & $21(n=13)$ & $\begin{array}{c}2158(6177 \\
-3554)\end{array}$ & $\begin{array}{c}2183(5187 \\
-3543)\end{array}$ & - & $\begin{array}{l}2531(6296 \\
-3719)\end{array}$ & $\begin{array}{c}2233(6760 \\
-3026)\end{array}$ & $\begin{array}{c}2471(7187 \\
-3660)\end{array}$ & $\begin{array}{c}2388(6545 \\
-3189)\end{array}$ & $\begin{array}{c}2662(6412 \\
-3203)\end{array}$ & $\begin{array}{c}2407(4266 \\
-3063)\end{array}$ & $\begin{array}{c}2299(3683 \\
-2028)\end{array}$ \\
\hline & $28(n=9)$ & $\begin{array}{c}1841(6177 \\
-3554)\end{array}$ & $\begin{array}{c}2106(5187 \\
-3543)\end{array}$ & - & $\begin{array}{c}2213(6296 \\
-3841)\end{array}$ & $\begin{array}{c}1958(6760 \\
-3463)\end{array}$ & $\begin{array}{c}1681(7187 \\
-4048)\end{array}$ & $\begin{array}{l}1944(6545 \\
-3539)\end{array}$ & $\begin{array}{c}2235(6412 \\
-3262)\end{array}$ & $\begin{array}{c}2395(4266 \\
-3063)\end{array}$ & $\begin{array}{c}2026(2803 \\
-1614)\end{array}$ \\
\hline & $35(n=5)$ & $\begin{array}{c}1820(5570 \\
-3554)\end{array}$ & $\begin{array}{c}2144(5187 \\
-3543)\end{array}$ & - & $\begin{array}{c}2196(5909 \\
-3841)\end{array}$ & $\begin{array}{c}1941(6760 \\
-3463)\end{array}$ & $\begin{array}{c}1593(7187 \\
-4048)\end{array}$ & $\begin{array}{c}1908(6545 \\
-3539)\end{array}$ & $\begin{array}{c}2255(6412 \\
-3262)\end{array}$ & $\begin{array}{c}2433(4266 \\
-3063)\end{array}$ & $\begin{array}{c}2004(2737 \\
-1586)\end{array}$ \\
\hline & $\operatorname{Seção~}(n=76)$ & $\begin{array}{c}3269(5570 \\
-3554)\end{array}$ & $\begin{array}{c}3409(5187 \\
-3445)\end{array}$ & - & $\begin{array}{c}3805(5909 \\
-3761)\end{array}$ & $\begin{array}{c}3343(6760 \\
-3463)\end{array}$ & $\begin{array}{c}3622(7187 \\
-4048)\end{array}$ & $\begin{array}{l}3423(6545 \\
-3539)\end{array}$ & $\begin{array}{c}3296(6412 \\
-3262)\end{array}$ & $\begin{array}{c}3551(4266 \\
-3063)\end{array}$ & \\
\hline & Total $(n=608)$ & \multicolumn{10}{|c|}{$3266(7187-1586)$} \\
\hline
\end{tabular}

*Para cada seção geoelétrica foram levantados 76 valores de resistividade $(n=76)$, considerando todas as profundidades de monitoramento, a cada semana. Com isso, foi obtido um conjunto amostral de 684 medições ao longo de nove semanas, exceto para as seções B e D ( $n=608)$, que não foram monitoradas na terceira semana. 


\begin{tabular}{|c|c|c|c|c|c|c|c|c|c|c|c|}
\hline \multirow{2}{*}{ Seção } & \multirow{2}{*}{$\begin{array}{c}\text { Profundidade } \\
(\mathbf{m})\end{array}$} & \multicolumn{10}{|c|}{ Semana } \\
\hline & & $1(n=76)$ & $2(n=76)$ & $3(n=76)$ & $4(n=76)$ & $5(n=76)$ & $6(n=76)$ & $7(n=76)$ & $8(n=76)$ & $9(n=76)$ & Semanas* \\
\hline \multirow{8}{*}{$E$} & $5(n=17)$ & $\begin{array}{l}4495(5520 \\
-3578)\end{array}$ & $\begin{array}{l}4372(5814 \\
-3211)\end{array}$ & $\begin{array}{c}5030(6791 \\
-3902)\end{array}$ & $\begin{array}{l}5800(7546 \\
-4011)\end{array}$ & $\begin{array}{c}4934(5975 \\
-3713)\end{array}$ & $\begin{array}{c}5742(6697 \\
-4329)\end{array}$ & $\begin{array}{l}5513(6423 \\
-4122)\end{array}$ & $\begin{array}{c}5380(6732 \\
-3889)\end{array}$ & $\begin{array}{l}3878(5038 \\
-3221)\end{array}$ & $\begin{array}{c}4988(7546 \\
-3211)\end{array}$ \\
\hline & $10(n=17)$ & $\begin{array}{l}4452(5154 \\
-3577)\end{array}$ & $\begin{array}{c}3949(5804 \\
-3214)\end{array}$ & $\begin{array}{c}4550(5695 \\
-3924)\end{array}$ & $\begin{array}{l}5556(6408 \\
-4006)\end{array}$ & $\begin{array}{c}4667(5697 \\
-3709)\end{array}$ & $\begin{array}{c}5324(6284 \\
-4303)\end{array}$ & $\begin{array}{c}5329(5810 \\
-4111)\end{array}$ & $\begin{array}{c}5247(6109 \\
-3877)\end{array}$ & $\begin{array}{c}3896(4984 \\
-3212)\end{array}$ & $\begin{array}{c}4666(6408 \\
-3212)\end{array}$ \\
\hline & $15(n=15)$ & $\begin{array}{c}3436(4257 \\
-3349)\end{array}$ & $\begin{array}{c}3394(3505 \\
-2967)\end{array}$ & $\begin{array}{c}3417(3775 \\
-3247)\end{array}$ & $\begin{array}{c}3983(4274 \\
-3840)\end{array}$ & $\begin{array}{c}3998(4356 \\
-3272)\end{array}$ & $\begin{array}{c}3722(4442 \\
-3269)\end{array}$ & $\begin{array}{l}3251(3856 \\
-3164)\end{array}$ & $\begin{array}{l}3521(4510 \\
-3306)\end{array}$ & $\begin{array}{l}3781(4407 \\
-3202)\end{array}$ & $\begin{array}{c}3595(4510 \\
-2967)\end{array}$ \\
\hline & $21(n=13)$ & $\begin{array}{c}2784(3125 \\
-2723)\end{array}$ & $\begin{array}{c}2719(3113 \\
-2400)\end{array}$ & $\begin{array}{c}2567(3251 \\
-2519)\end{array}$ & $\begin{array}{c}2924(3417 \\
-2511)\end{array}$ & $\begin{array}{c}2877(3542 \\
-2573)\end{array}$ & $\begin{array}{c}2850(3400 \\
-2481)\end{array}$ & $\begin{array}{c}2408(3387 \\
-2322)\end{array}$ & $\begin{array}{c}2607(3208 \\
-2482)\end{array}$ & $\begin{array}{c}2569(2925 \\
-2402)\end{array}$ & $\begin{array}{c}2735(3542 \\
-2322)\end{array}$ \\
\hline & $28(n=9)$ & $\begin{array}{c}2107(2129 \\
-2070)\end{array}$ & $\begin{array}{l}2076(2083 \\
-2025)\end{array}$ & $\begin{array}{c}2022(2177 \\
-1974)\end{array}$ & $\begin{array}{c}2233(2260 \\
-1799)\end{array}$ & $\begin{array}{c}1994(2034 \\
-1984)\end{array}$ & $\begin{array}{l}2065(2460 \\
-2018)\end{array}$ & $\begin{array}{l}2191(2362 \\
-2137)\end{array}$ & $\begin{array}{c}2239(2309 \\
-2218)\end{array}$ & $\begin{array}{l}2522(2579 \\
-2349)\end{array}$ & $\begin{array}{c}2129(2579 \\
-1799)\end{array}$ \\
\hline & $35(n=5)$ & $\begin{array}{c}2104(2161 \\
-2087)\end{array}$ & $\begin{array}{l}2075(2088 \\
-2064)\end{array}$ & $\begin{array}{c}1971(2175 \\
-1951)\end{array}$ & $\begin{array}{l}2218(2231 \\
-2069)\end{array}$ & $\begin{array}{c}1948(1959 \\
-1928)\end{array}$ & $\begin{array}{c}2013(2243 \\
-1984)\end{array}$ & $\begin{array}{c}2156(2346 \\
-2142)\end{array}$ & $\begin{array}{c}2228(2323 \\
-2218)\end{array}$ & $\begin{array}{l}2504(2518 \\
-2454)\end{array}$ & $\begin{array}{c}2140(2518 \\
-1928)\end{array}$ \\
\hline & $\operatorname{Seção~}(n=76)$ & $\begin{array}{l}3577(5520 \\
-2070)\end{array}$ & $\begin{array}{c}3396(5814 \\
-2025)\end{array}$ & $\begin{array}{c}3642(6791 \\
-1951)\end{array}$ & $\begin{array}{c}4007(7546 \\
-1799)\end{array}$ & $\begin{array}{c}4045(5975 \\
-1928)\end{array}$ & $\begin{array}{c}4035(6697 \\
-1984)\end{array}$ & $\begin{array}{c}3487(6423 \\
-2137)\end{array}$ & $\begin{array}{c}3638(6732 \\
-2218)\end{array}$ & $\begin{array}{l}3701(5038 \\
-2349)\end{array}$ & \\
\hline & Total $(n=684)$ & & & & & $3677(75$ & $6-1799)$ & & & & \\
\hline
\end{tabular}

*Para cada seção geoelétrica foram levantados 76 valores de resistividade $(n=76)$, considerando todas as profundidades de monitoramento, a cada semana. Com isso, foi obtido um conjunto amostral de 684 medições ao longo de nove semanas, exceto para as seções B e D ( $n=608)$, que não foram monitoradas na terceira semana. 


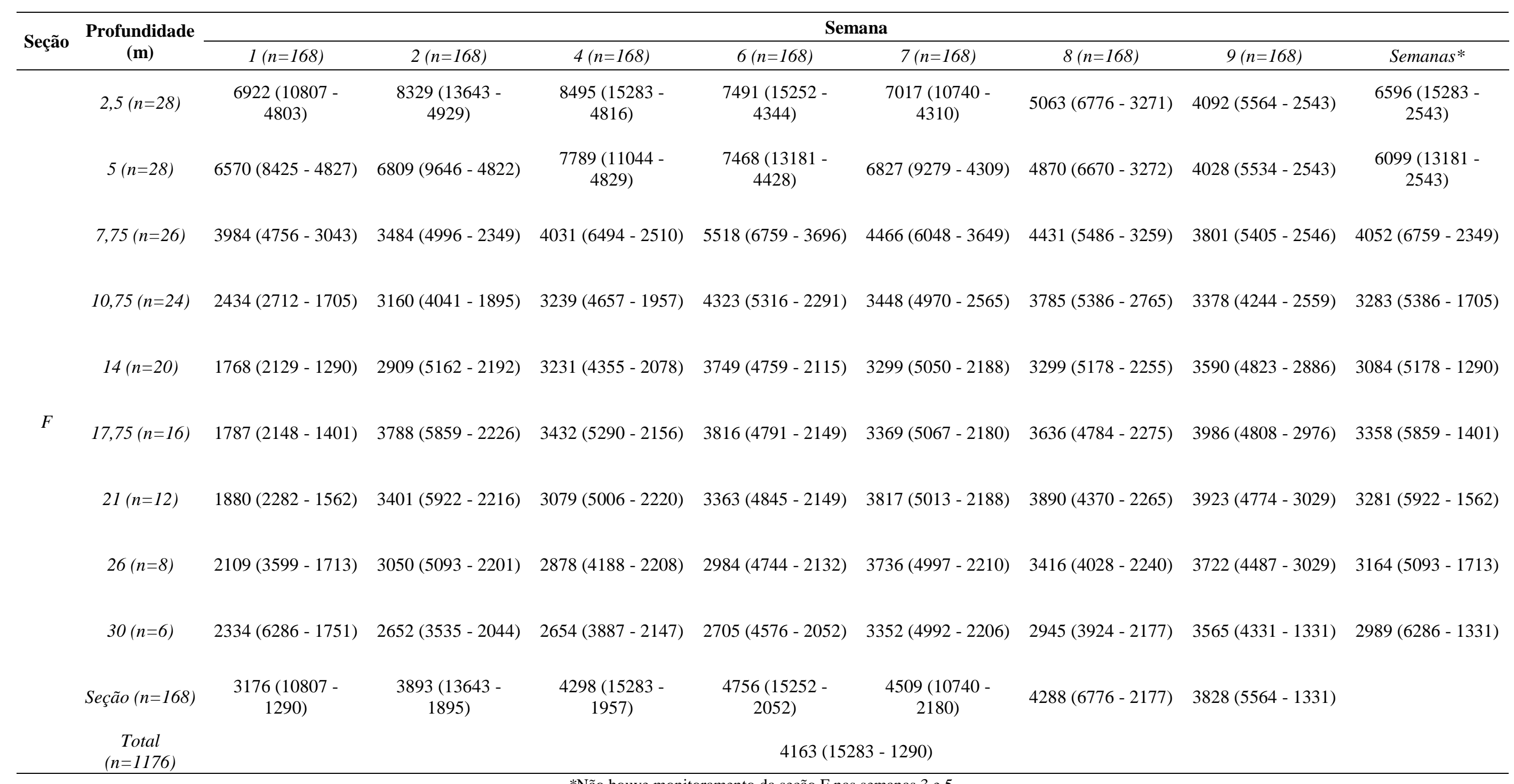


ANEXO 


\section{ANEXO A - CURVA DE CALIBRAÇÃO DOS BLOCOS DE GESSO}

As figuras a seguir se referem às curvas para calibração dos blocos de gesso fornecidas por Delmhorst Instrument Co. (1999) para a obtenção do potencial de água no solo e da resistência elétrica a partir da leitura dos blocos, no primeiro caso, e da umidade disponível no solo, para o segundo. Os rótulos dos dados fora dos parênteses referem-se ao potencial da água do solo (em Bars) associado à respectiva leitura do bloco de gesso, entre parênteses. A segunda figura consiste na curva para obtenção do percentual de umidade disponível no solo. A relação estabelecida no gráfico indica a variação da leitura do equipamento em função do teor de água no solo disponível para as raízes.

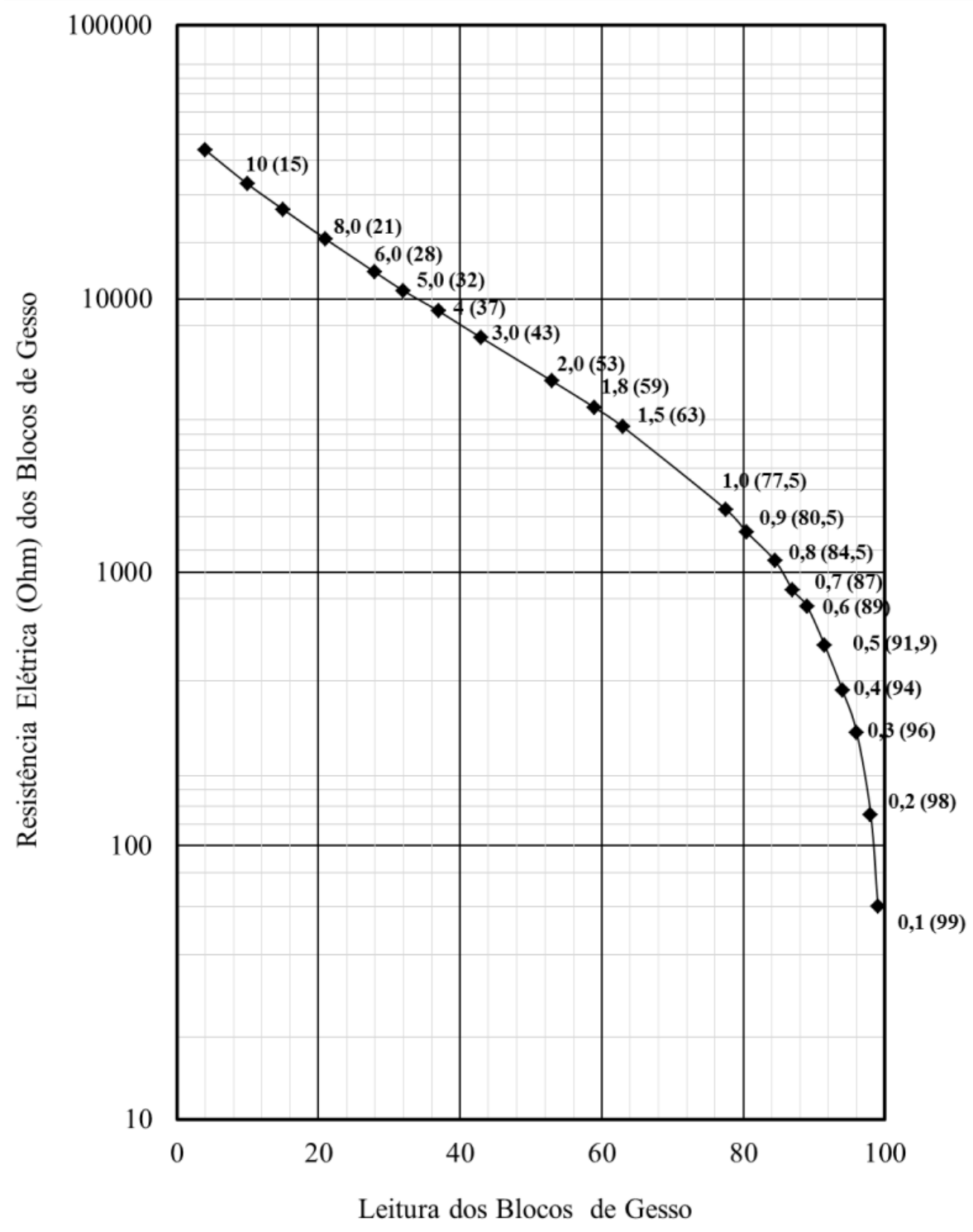




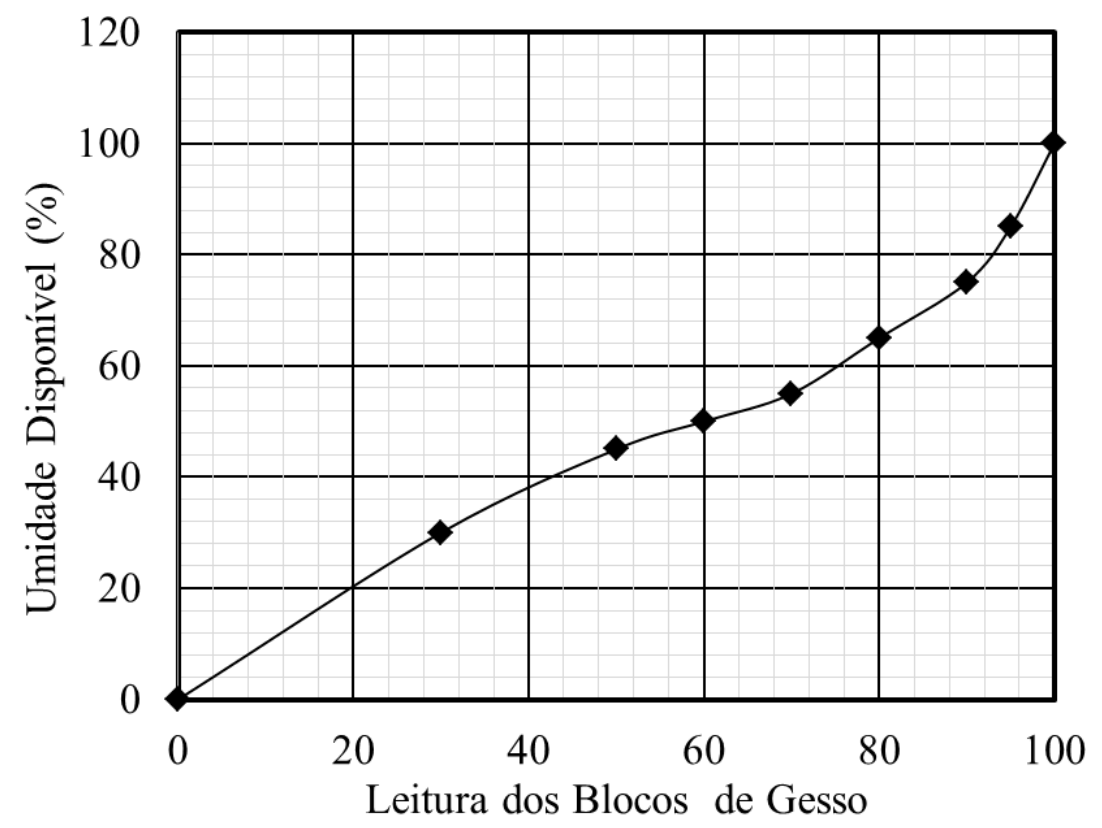

